\title{
New and extended parameterization of the thermodynamic model AIOMFAC: calculation of activity coefficients for organic-inorganic mixtures containing carboxyl, hydroxyl, carbonyl, ether, ester, alkenyl, alkyl, and aromatic functional groups
}

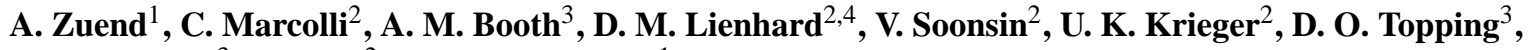 \\ G. McFiggans ${ }^{3}$, T. Peter ${ }^{2}$, and J. H. Seinfeld ${ }^{1}$ \\ ${ }^{1}$ Department of Chemical Engineering, California Institute of Technology, Pasadena, California, USA \\ ${ }^{2}$ Institute for Atmospheric and Climate Science, ETH Zurich, Zurich, Switzerland \\ ${ }^{3}$ School of Earth, Environmental and Atmospheric Science, University of Manchester, Manchester, UK \\ ${ }^{4}$ School of Chemistry, University of Bristol, Bristol, UK
}

Received: 26 April 2011 - Published in Atmos. Chem. Phys. Discuss.: 20 May 2011

Revised: 25 August 2011 - Accepted: 1 September 2011 - Published: 7 September 2011

\begin{abstract}
We present a new and considerably extended parameterization of the thermodynamic activity coefficient model AIOMFAC (Aerosol Inorganic-Organic Mixtures Functional groups Activity Coefficients) at room temperature. AIOMFAC combines a Pitzer-like electrolyte solution model with a UNIFAC-based group-contribution approach and explicitly accounts for interactions between organic functional groups and inorganic ions. Such interactions constitute the salt-effect, may cause liquid-liquid phase separation, and affect the gas-particle partitioning of aerosols. The previous AIOMFAC version was parameterized for alkyl and hydroxyl functional groups of alcohols and polyols. With the goal to describe a wide variety of organic compounds found in atmospheric aerosols, we extend here the parameterization of AIOMFAC to include the functional groups carboxyl, hydroxyl, ketone, aldehyde, ether, ester, alkenyl, alkyl, aromatic carbon-alcohol, and aromatic hydrocarbon. Thermodynamic equilibrium data of organic-inorganic systems from the literature are critically assessed and complemented with new measurements to establish a comprehensive database. The database is used to determine simultaneously the AIOMFAC parameters describing interactions of organic functional groups with the ions $\mathrm{H}^{+}, \mathrm{Li}^{+}, \mathrm{Na}^{+}, \mathrm{K}^{+}, \mathrm{NH}_{4}^{+}$, $\mathrm{Mg}^{2+}, \mathrm{Ca}^{2+}, \mathrm{Cl}^{-}, \mathrm{Br}^{-}, \mathrm{NO}_{3}^{-}, \mathrm{HSO}_{4}^{-}$, and $\mathrm{SO}_{4}^{2-}$. Detailed descriptions of different types of thermodynamic data, such
\end{abstract}

as vapor-liquid, solid-liquid, and liquid-liquid equilibria, and their use for the model parameterization are provided. Issues regarding deficiencies of the database, types and uncertainties of experimental data, and limitations of the model, are discussed. The challenging parameter optimization problem is solved with a novel combination of powerful global minimization algorithms. A number of exemplary calculations for systems containing atmospherically relevant aerosol components are shown. Amongst others, we discuss aqueous mixtures of ammonium sulfate with dicarboxylic acids and with levoglucosan. Overall, the new parameterization of AIOMFAC agrees well with a large number of experimental datasets. However, due to various reasons, for certain mixtures important deviations can occur. The new parameterization makes AIOMFAC a versatile thermodynamic tool. It enables the calculation of activity coefficients of thousands of different organic compounds in organic-inorganic mixtures of numerous components. Models based on AIOMFAC can be used to compute deliquescence relative humidities, liquid-liquid phase separations, and gas-particle partitioning of multicomponent mixtures of relevance for atmospheric chemistry or in other scientific fields.

Correspondence to: A. Zuend

(zuend@caltech.edu)

Published by Copernicus Publications on behalf of the European Geosciences Union. 


\section{Introduction}

Thermodynamic models are key tools to gain insight into the non-ideal behavior of organic-inorganic mixtures. Atmospheric aerosols present prominent examples for organicinorganic mixtures of remarkable complexity, containing a multitude of different organic compounds, inorganic salts and acids, and water (e.g., Rogge et al., 1993; Saxena and Hildemann, 1996; Murphy and Thomson, 1997; Middlebrook et al., 1998; Decesari et al., 2000; Lee et al., 2002; Griffin et al., 2002; Maria et al., 2004; Kanakidou et al., 2005; Murphy et al., 2006; Decesari et al., 2006; Zhang et al., 2007; Russell et al., 2009). Gas-particle partitioning of water and semivolatile organic and inorganic compounds is determined by thermodynamic equilibrium between the gaseous and condensed phases (Pankow, 1994, 2003; Hallquist et al., 2009; Zuend et al., 2010) and by the kinetics of exchange processes such as gas phase diffusion (Marcolli et al., 2004b). The non-ideality of mixtures in aerosol particles influences the gas-particle partitioning and affects the physical state of the condensed phase, potentially leading to liquid-liquid phase separation (Pankow, 2003; Erdakos and Pankow, 2004; Marcolli and Krieger, 2006; Chang and Pankow, 2006; Ciobanu et al., 2009; Zuend et al., 2010; Kwamena et al., 2010; Smith et al., 2011; Bertram et al., 2011), the formation of crystalline solid phases (Nenes et al., 1998; Clegg et al., 1998a; Colberg et al., 2004; Zaveri et al., 2005; Fountoukis and Nenes, 2007), or the transition to an amorphous solid state (Zobrist et al., 2008, 2011; Murray, 2008; Mikhailov et al., 2009; Virtanen et al., 2010).

Inorganic salts and acids (electrolytes) that for the most part dissociate into ions (charged molecules or atoms) in liquid solutions play an important role in aqueous organicinorganic systems. Interactions between ions and neutral organic molecules may have a crucial impact on the dissolution behavior and phase state of a system, commonly known as the salt-effect: Increasing the concentration of a strong electrolyte in a mixture may lead to "salting-out" of relatively nonpolar organics, i.e., the dissolved ions drive the organic compounds out of the mixed phase - either to the gas phase or into a different, organic-rich liquid phase, initiating or modifying a liquid-liquid phase separation and a new equilibrium state. This well-known property of electrolytes is used in chemical and biochemical process engineering to separate aqueous organic mixtures (liquid-liquid extraction, two-phase partitioning) and to shift azeotropes in distillation processes, with large-scale applications in the petrochemical industry, in seawater desalination plants, and water purification systems. With respect to tropospheric aerosols, recent modeling studies (Zuend et al., 2010) and experiments (Smith et al., 2011; Bertram et al., 2011) on the phase state of idealized laboratory organic-inorganic aerosol mixtures suggest that ambient aerosols likely exhibit liquid-liquid phase separation at relative humidities $(\mathrm{RH}) \lesssim 85 \%$.
Activity coefficients of the different components represent the degree of thermodynamic non-ideality in a specific multicomponent mixture, caused by the combined effects of all molecular interactions. For atmospheric purposes the vapor pressures of water and semivolatile organic and inorganic compounds are required in gas-particle partitioning calculations, which depend on the saturation vapor pressures of the pure compounds and their activity coefficients in the liquid aerosol mixture. For example, in case of water, the equilibrium water vapor pressure over a liquid mixture, $p_{\mathrm{w}}$, is related to the water activity on the mole fraction basis (denoted by superscript $(x)), a_{\mathrm{w}}^{(x)}$, by $p_{\mathrm{w}}=p_{\mathrm{w}}^{\circ} a_{\mathrm{w}}^{(x)}$, where $p_{\mathrm{w}}^{\circ}$ is the saturation vapor pressure over pure liquid water (a function of temperature only). Activity and activity coefficient, $\gamma_{s}^{(x)}$, of a compound $s$ are related by $a_{s}^{(x)}=\gamma_{s}^{(x)} x_{s}$, where $x_{s}$ is the mole fraction of $s$ in the liquid mixture. These basic thermodynamic relationships, corresponding chemical potentials and standard states, are described in detail by Zuend et al. (2010). In case of atmospheric water at gas-particle equilibrium, relative humidity and aerosol water activity are related by $\mathrm{RH}=a_{\mathrm{w}}^{(x)}=\gamma_{\mathrm{w}}^{(x)} x_{\mathrm{w}}$ (strictly valid only for droplet sizes where the Kelvin effect due to the curvature of the surface can be neglected, i.e., for droplet diameters $>100 \mathrm{~nm}$ ). At the core of thermodynamic equilibrium calculations are therefore models to calculate activity coefficients.

In the past, the development of activity coefficient models mainly evolved in two categories: (1) models for (organicfree) aqueous electrolyte solutions or for (electrolyte-free) aqueous organic mixtures, and (2) models for mixed organicinorganic systems. In category (1), a number of successful models for calculating thermodynamic aerosol properties of aqueous electrolyte mixtures have been developed based on Pitzer's extension of the Debye-Hückel theory and the Pitzer-Simonson-Clegg approach (e.g., Clegg and Pitzer, 1992; Clegg et al., 1992; Carslaw et al., 1995; Clegg et al., 1998a,b; Topping et al., 2005a; Amundson et al., 2006; Zuend et al., 2008) or the Kusik-Meissner relationship and Bromley's formula (Nenes et al., 1998; Fountoukis and Nenes, 2007). Aerosol models for mixtures of organics and water are most often based on the UNIQUAC (UNIversal QUAsi Chemical) model (Abrams and Prausnitz, 1975) or its group-contribution version UNIFAC (UNIquac Functional group Activity Coefficients) (Fredenslund et al., 1975; Hansen et al., 1991). Models for organic-inorganic mixtures are generally composed of an aqueous electrolyte term, an (aqueous) organic term, and an organic-ion mixing term (Tong et al., 2008). In category (2), models for organicinorganic mixtures can be further categorized into (i) socalled decoupled models, where an explicit organic-ion mixing term is not considered, and (ii) fully coupled models, as described in detail by Tong et al. (2008). Decoupled organicinorganic models are based on combinations of existing approaches for the electrolyte part and the organic part, and a mixing rule such as the Zdanovskii-Stokes-Robinson (ZSR) 
scheme (Zdanovskii, 1936, 1948; Clegg et al., 2003; Clegg and Seinfeld, 2004) is used to calculate the water content of mixtures. Examples of such decoupled models are the approach by Clegg et al. (2001) and the aerosol diameter dependent equilibrium model (ADDEM) of Topping et al. (2005b). Hybrid approaches to combine two specific models, of which one describes the inorganic part and the other the organic part, have been discussed by Clegg and Seinfeld (2006a). Many coupled organic-inorganic models for aerosols are based on an extended UNIFAC approach (e.g. Ming and Russell, 2002; Raatikainen and Laaksonen, 2005; Chang and Pankow, 2006; Erdakos et al., 2006; Zuend et al., 2008), differing mainly in the degree of detail regarding the description of aqueous electrolyte solutions and the coupling via an organic-inorganic interaction part, as discussed by Zuend et al. (2008).

Tong et al. (2008) compared four different organicinorganic models, two of which are fully coupled, to test whether the inclusion of explicit ion-organic interaction terms improves the performance over that of decoupled models. They tested this question by comparison of model predictions with experimental water activity data of dicarboxylic acids mixed with $\mathrm{NaCl}$ or $\left(\mathrm{NH}_{4}\right)_{2} \mathrm{SO}_{4}$. Tong et al. found for the systems studied, that the decoupled models performed as well as the coupled models and in some cases even better. However, water activity predictions show only the abilities of thermodynamic models to calculate particle water content, but not the ability to correctly calculate the activity coefficients of all components. In fact, for systems of more than two components, a thermodynamic model might accurately predict water activities, while failing to accurately predict activities of the other components. As we point out in this study, a rigorous thermodynamic calculation of the activity coefficients of all species in a system is essential to accurately compute vapor-liquid, liquid-liquid, and solidliquid equilibria, and, hence, the gas-particle partitioning and phase states. The AIOMFAC model, described in the following sections, is a fully coupled model that allows consistent calculations of activity coefficients and phase states. This is essential for a proper description of mixed tropospheric aerosols, which are expected to exhibit liquid-liquid phase separation at $\mathrm{RH} \lesssim 85 \%$ (Zuend et al., 2010; Smith et al., 2011).

\section{AIOMFAC model}

The thermodynamic model AIOMFAC (Aerosol InorganicOrganic Mixtures Functional groups Activity Coefficients) is a group-contribution model designed for the calculation of activity coefficients in aqueous organic-inorganic systems (Zuend et al., 2008). The group-contribution concept treats organic molecules as structures composed of different functional groups. This approach allows the representation of thousands of different organic compounds using a relatively small and manageable number of functional groups. Especially regarding the organic aerosol fraction, a compoundspecific approach may not be feasible except in the case of well-defined laboratory systems. Field studies reporting important individual organic compounds, compound classes, and/or distributions of functional groups found in ambient aerosols, identified alkyl, carboxyl, hydroxyl, ketone, aldehyde, amines, organosulfates, ether, alkenyl, and aromatic groups (Decesari et al., 2000; Maria et al., 2003; Decesari et al., 2006; Russell et al., 2009; Gilardoni et al., 2009; Liu et al., 2009; Takahama et al., 2011). Hence, many organic aerosol components can be characterized by means of about 10 different kinds of organic functional groups.

AIOMFAC is based on the group-contribution model LIFAC (Yan et al., 1999) - yet modified in many respects to better represent relevant species, reference states, and the relative humidity range of the atmosphere. This is described in our previous work (Zuend et al., 2008), where we we have considered cations $\mathrm{H}^{+}, \mathrm{Li}^{+}, \mathrm{Na}^{+}, \mathrm{K}^{+}, \mathrm{NH}_{4}^{+}, \mathrm{Mg}^{2+}$, and $\mathrm{Ca}^{2+}$, anions $\mathrm{Cl}^{-}, \mathrm{Br}^{-}, \mathrm{NO}_{3}^{-}, \mathrm{HSO}_{4}^{-}$, and $\mathrm{SO}_{4}^{2-}$ and a wide range of alcohols/polyols composed of the alkyl $\left(\mathrm{CH}_{\mathrm{n}}, \mathrm{n}=\right.$ $0,1,2,3)$ and hydroxyl $(\mathrm{OH})$ functional groups for a first parameterization of organic-inorganic interactions.

In this study, we revise and extend the AIOMFAC model parameterization for the full range of atmospheric compositions covering activity coefficient calculations of mixtures containing carboxyl, hydroxyl, ketone, aldehyde, ether, ester, alkenyl, alkyl, aromatic carbon, and aromatic carbonalcohol functional groups, plus water and the inorganic ions as given above. We discuss how the availability, reliability, and abundance or in some cases lack of experimental data, define the main limitations for the current parameterization of the different binary functional group $\leftrightarrow$ ion interactions (the double arrow $\leftrightarrow$ is used to mark interactions). The semi-empirical middle-range parameterization of explicit organic $\leftrightarrow$ inorganic interactions in organic + water + salt solutions enables accurate and thermodynamically consistent computations of activity coefficients for all mixture species, required for the prediction of vapor-liquid equilibria (VLE), solid-liquid equilibria (SLE), liquid-liquid equilibria (LLE), and the computation of gas/particle partitioning of multicomponent systems (Zuend et al., 2010). It should be noted that, similar to the previous version, the model so far is constrained to room temperature ( $298 \mathrm{~K} \pm 5 \mathrm{~K})$. Generalizations of the model applicable to other temperatures are presently underway.

\section{Methods}

\subsection{Activity coefficients in AIOMFAC}

Molecular interactions in liquid mixtures containing ions and neutral species are represented by AIOMFAC using thermodynamic expressions for long-range (LR), middle-range 
(MR), and short-range (SR) contributions (Zuend et al., 2008). These three interaction ranges contribute to the Gibbs excess energy $G^{\mathrm{ex}}\left(p, T, n_{j}\right)$ of a thermodynamic system, constituting the system's deviation from an ideal mixture:

$G^{\mathrm{ex}}\left(p, T, n_{j}\right)=G_{\mathrm{LR}}^{\mathrm{ex}}+G_{\mathrm{MR}}^{\mathrm{ex}}+G_{\mathrm{SR}}^{\mathrm{ex}}$.

Here, $p$ is the total pressure, $T$ the absolute temperature, and $n_{j}(j=1, \ldots, k)$ the molar amounts of the $k$ components in a system. Mole fraction based activity coefficients $\gamma_{j}^{(x)}$ of the different components are derived from expressions for the different parts of $G^{\mathrm{ex}}$ using the relation

$\ln \gamma_{j}^{(x)}=\left[\frac{\partial G^{\mathrm{ex}} /(R T)}{\partial n_{j}}\right]_{p, T, n_{j^{\prime} \neq j}}$,

where $R$ is the universal gas constant. Accordingly, the activity coefficients are calculated from the three model parts:

$\ln \gamma_{j}^{(x)}=\ln \gamma_{j}^{(x), \mathrm{LR}}+\ln \gamma_{j}^{(x), \mathrm{MR}}+\ln \gamma_{j}^{(x), \mathrm{SR}}$.

The long-range part, an extended Debye-Hückel expression, and the semi-empirical middle-range part form together a Pitzer-like group-contribution model, enabling accurate descriptions of electrolyte solutions, from dilute to highly concentrated conditions into regions supersaturated with respect to crystalline phases.

Short-range interactions are calculated with a slightly modified UNIFAC model (Fredenslund et al., 1975) using the revised parameter set of Hansen et al. (1991) (standard UNIFAC) for most of the functional group interactions. Modifications of the UNIFAC model part within AIOMFAC include further the introduction of inorganic ions, to account for their effects on the entropy and enthalpy of mixing apart from their charge-related interactions (Li et al., 1994; Yan et al., 1999; Zuend et al., 2008). Owing to the importance of hydroxyl and carboxyl functional groups in organic aerosols, we furthermore use the specific UNIFAC parameterizations of Marcolli and Peter (2005) for alcohols/polyols and the parameterization of Peng et al. (2001) for the $\mathrm{COOH}$ group of carboxylic acids, for associated interaction parameters where these improved UNIFAC parameterizations differ from the standard UNIFAC parameterization by Hansen et al. (1991). Revisions and new UNIFAC parameters are compatible with the standard UNIFAC parameter set as long as the same mathematical model expressions are used. The UNIFAC parameters of Marcolli and Peter (2005) and of Peng et al. (2001) differ only in a few main group interaction parameters from standard UNIFAC and their compatibility is guaranteed. The impact on calculated activity coefficients when combining parameters from the different UNIFAC parameterizations within AIOMFAC has been tested and it was found that the model accuracy improves in most cases as compared to using parameters from standard UNIFAC only.

Figure 1 shows examples for the assignment of main groups in AIOMFAC. Note that the functional groups of a chemical species are divided into so-called main groups and subgroups according to UNIFAC convention (Fredenslund et al., 1975; Marcolli and Peter, 2005; Zuend et al., 2008). E.g., the alkyl groups $\mathrm{CH}_{3}, \mathrm{CH}_{2}, \mathrm{CH}$ and $\mathrm{C}$ are different subgroups classified into the main group $\mathrm{CH}_{n}$. The distinction of different alkyl groups by Marcolli and Peter (2005): $\mathrm{CH}_{\mathrm{n}}^{[\mathrm{OH}]}$ with an attached $\mathrm{OH}$ group, $\mathrm{CH}_{\mathrm{n}}^{[\text {alc-tail }]}$ in hydrophobic tails of alcohols, and $\mathrm{CH}_{\mathrm{n}}^{[\mathrm{alc}]}$ elsewhere in alcohols, is implemented in full detail in the UNIFAC part of AIOMFAC, leading to the significant improvement in the description of interactions of alcohol (and polyol) molecules with themselves and water as described by these authors. However, AIOMFAC main group $\leftrightarrow$ ion interactions involving the groups $\mathrm{CH}_{\mathrm{n}}^{[\text {alc-tail] }}$ and $\mathrm{CH}_{\mathrm{n}}^{[\text {alc] }}$ are described with the same parameters as $\mathrm{CH}_{\mathrm{n}}$ (standard UNIFAC) $\leftrightarrow$ ion interactions, as the current database and associated uncertainties do not suggest that a further distinction leads to an overall improvement. With the exception of $\mathrm{CH}_{\mathrm{n}}^{[\mathrm{OH}]}$ groups, standard UNIFAC $\mathrm{CH}_{\mathrm{n}}$ groups are used for alkyl groups in molecules which contain hydroxyl groups combined with different other functional groups (i.e., non-pure alcohols, see Fig. 1). As intensive testing shows, the consideration of a specific $\mathrm{CH}_{\mathrm{n}}^{[\mathrm{OH}]}$ group, which accounts for the induced polarity by the neighboring hydroxyl group, leads to a better description of different alcohols, polyols, and sugars within the group-contribution concept. Including the $\mathrm{CH}_{n}^{[\mathrm{OH}]}$ group as a distinct functional group in AIOMFAC is justified, since unlike other polar groups, such as $\mathrm{COOH}$ or $\mathrm{CH}_{\mathrm{n}} \mathrm{CO}$, the $\mathrm{OH}$ group does not comprise the $\mathrm{CH}_{\mathrm{n}}$ group it is bonded to.

Note that organic acids are treated as undissociated species in AIOMFAC. This is a simplification, as organic acids, e.g., dicarboxylic acids, tend to dissociate at least partially in dilute aqueous solutions. This simplification is justified for moderately to highly concentrated solutions of carboxylic acids and when reactions with strong bases are not considered. The reason for this simplification, and with it the omission of carboxylate ions and salts, is the group-contribution representation. In order to explicitly treat the partial dissociation of organic acids within a group-contribution method, one would need to define a dissociation constant of the carboxyl functional group, but different organic acids have quite different dissociation constants (Clegg and Seinfeld, 2006a,b), making it difficult to assign a specific dissociation constant to the $\mathrm{COOH}$ group. Moreover, experimental data to determine interactions between carboxylate anions and inorganic cations are rather incomplete (Clegg and Seinfeld, 2006b). Therefore, we neglect the dissociation of organic acids in aqueous solutions. However, the effects of partially dissociated carboxylic acids on the non-ideal mixing behavior are to some extent implied by means of the ionic strengthdependent $\mathrm{COOH} \leftrightarrow$ ion interaction contributions.

All compound-specific parameters in the LR and SR parts are already set and non-adjustable, as described by Zuend et al. (2008). This includes all interactions among different 


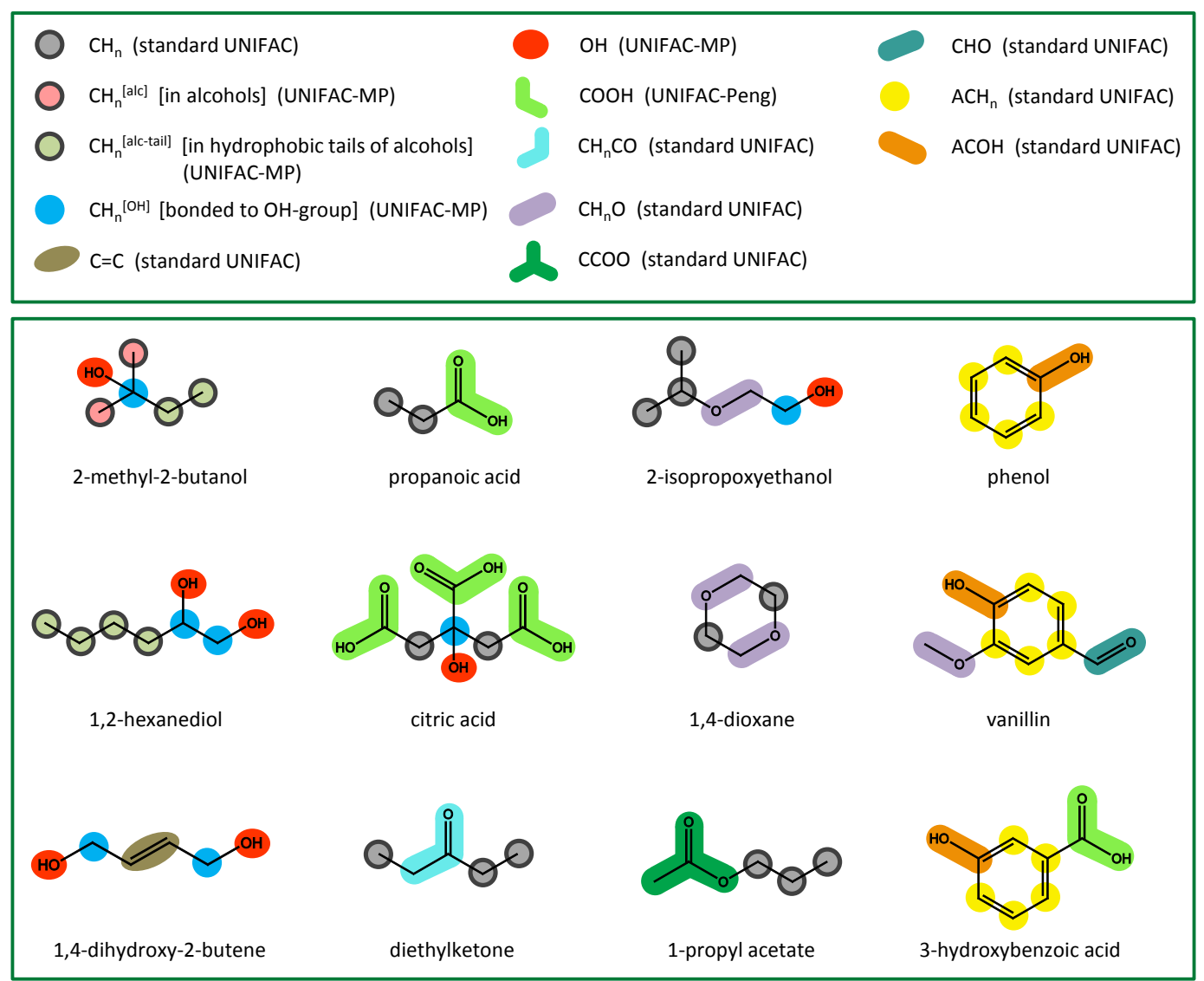

Fig. 1. Upper box: complete list of types of organic functional main groups used in AIOMFAC. AIOMFAC follows the UNIFAC naming convention for functional groups (see also Fig. 8). Besides the functional groups and associated interaction parameters of standard UNIFAC (Hansen et al., 1991), specific groups of Marcolli and Peter (2005) (UNIFAC-MP) and of Peng et al. (2001) (UNIFAC-Peng) are used as indicated. AIOMFAC middle-range main group $\leftrightarrow$ ion interactions involving the specific alkyl groups $\mathrm{CH}_{\mathrm{n}}^{\text {[alc-tail] }}$ [in hydrophobic tails of alcohols] and $\mathrm{CH}_{\mathrm{n}}^{[\mathrm{alc}]}$ [in alcohols, (but not in hydrophobic tail nor bonded to $\mathrm{OH}$ group)] are described with the same parameters as $\mathrm{CH}_{\mathrm{n}}$ (standard UNIFAC) $\leftrightarrow$ ion interactions, denoted by the common outline color. Lower box: examples.

organic compounds and water, which are treated in the modified UNIFAC model that makes up the AIOMFAC SR part. Hence, all adjustable AIOMFAC parameters to optimize the description of organic functional groups $\leftrightarrow$ ion interactions in mixtures are implemented in the MR part. We focus in the following description only on the new and extended parameterization of the organic main group $\leftrightarrow$ ion interactions to additional functional groups in the MR part, while retaining the AIOMFAC MR-part expressions as given by Zuend et al. (2008) and refer to that previous work for a complete and detailed description of the AIOMFAC model expressions.

The expression for $G_{\mathrm{MR}}^{\mathrm{ex}}$ of a mixture containing $n_{k}$ moles of solvent main groups $k$ (main groups of organics and water), with molar masses $M_{k}$, and $n_{i}$ moles of ions $i$ is (Zuend et al., 2008):

$$
\frac{G_{\mathrm{MR}}^{\mathrm{ex}}}{R T}=\frac{1}{\sum_{k} n_{k} M_{k}} \sum_{k} \sum_{i} B_{k, i}(I) n_{k} n_{i}
$$

$$
\begin{aligned}
& +\frac{1}{\sum_{k} n_{k} M_{k}} \sum_{c} \sum_{a} B_{c, a}(I) n_{c} n_{a} \\
& +\frac{1}{\sum_{k} n_{k} M_{k}} \sum_{c} \sum_{a} C_{c, a}(I) n_{c} n_{a} \sum_{i} \frac{n_{i}\left|z_{i}\right|}{\sum_{k} n_{k} M_{k}} \\
& +\frac{1}{\sum_{k} n_{k} M_{k}} \sum_{c} \sum_{c^{\prime} \geq c} R_{c, c^{\prime}} n_{c} n_{c^{\prime}} \\
& +\frac{1}{\left(\sum_{k} n_{k} M_{k}\right)^{2}} \sum_{c} \sum_{c^{\prime} \geq c} \sum_{a} Q_{c, c^{\prime}, a} n_{c} n_{c^{\prime}} n_{a} .
\end{aligned}
$$

Here, $n_{c}$ and $n_{c^{\prime}}$ are moles of cations, $n_{a}$ are moles of anions, and $I$ is the ionic strength on a molal basis: $I=\frac{1}{2} \sum_{i} m_{i} z_{i}^{2}$, with molalities $m_{i}$ and integer number of elementary charges $z_{i}$ of ions $i . B_{k, i}(I)$ and $B_{c, a}(I)$ are ionic strength dependent binary interaction coefficients between solvent main groups and ions, and between cations and anions, respectively. 
$C_{c, a}(I)$ are interaction coefficients between cation $\leftrightarrow$ anion pairs with respect to the total charge concentration. The coefficients $R_{c, c^{\prime}}$ and $Q_{c, c^{\prime}, a}$ describe binary and ternary interactions involving two different cations. These latter two interaction coefficients have been introduced by Zuend et al. (2008) to improve the description of systems containing the ion combinations $\mathrm{NH}_{4}^{+}, \mathrm{H}^{+}$or $\mathrm{NH}_{4}^{+}, \mathrm{H}^{+}, \mathrm{SO}_{4}^{2-}$ (e.g., aqueous sulfuric acid + ammonium sulfate solutions), especially at very high ionic strength. Hence, the last two terms of Eq. (4) vanish in other cases.

The first three interaction coefficients in Eq. (4) are parameterized as functions of ionic strength $I$. In AIOMFAC, we use expressions similar to those used for Pitzer models:

$$
\begin{aligned}
& B_{k, i}(I)=b_{k, i}^{(1)}+b_{k, i}^{(2)} e^{-b_{k, i}^{(3)} \sqrt{I}}, \\
& B_{c, a}(I)=b_{c, a}^{(1)}+b_{c, a}^{(2)} e^{-b_{c, a}^{(3)} \sqrt{I}}, \\
& C_{c, a}(I)=c_{c, a}^{(1)} e^{-c_{c, a}^{(2)} \sqrt{I}},
\end{aligned}
$$

where $b_{k, i}^{(1)}, b_{k, i}^{(2)}, b_{c, a}^{(1)}, b_{c, a}^{(2)}, b_{c, a}^{(3)}, c_{c, a}^{(1)}$, and $c_{c, a}^{(2)}$ are adjustable AIOMFAC parameters. The parameter $b_{c, a}^{(3)}$ has been found to describe most aqueous salt solutions, when assuming a fixed value of $0.8 \mathrm{~kg}^{1 / 2} \mathrm{~mol}^{-1 / 2}$. In cases where this value did not result in a satisfactory data fit, $b_{c, a}^{(3)}$ has been allowed to vary (Zuend et al., 2008). The parameter $b_{k, i}^{(3)}$ is kept constant for all organic-inorganic solutions at a value of $1.2 \mathrm{~kg}^{1 / 2} \mathrm{~mol}^{-1 / 2}$. All interaction coefficients in the MR part are symmetric, i.e. $B_{k, i}(I)=B_{i, k}(I)$. Since water is defined as the reference solvent for inorganic ions, no explicit ion $\leftrightarrow$ water interactions are determined, i.e., $B_{k=\mathrm{H}_{2} \mathrm{O}, i}(I)=$ 0 for all inorganic ions. However, non-ideality effects from cations and anions interacting with water molecules are indirectly accounted for via the cation $\leftrightarrow$ anion interaction coefficients, $B_{c, a}(I), C_{c, a}(I), R_{c, c^{\prime}}$, and $Q_{c, c^{\prime}, a}$, as the corresponding interaction parameters have been determined on the basis of (organic-free) aqueous electrolyte solutions.

In this study, the organic main group $\leftrightarrow$ ion interaction parameters $b_{k, i}^{(1)}$ and $b_{k, i}^{(2)}$ of the $B_{k, i}(I)$ coefficients (Eq. 5) are revised or determined for the first time. In addition, we revise the MR parameters involved in aqueous ammonium sulfate + sulfuric acid mixtures (to correct for an error in the previous parameter estimation, see Sect. 5.1) and we fitted the parameters of Eqs. (6) and (7) for $\mathrm{Mg}^{2+} \leftrightarrow \mathrm{Br}^{-}$, $\mathrm{Ca}^{2+} \leftrightarrow \mathrm{Br}^{-}$, and $\mathrm{Ca}^{2+} \leftrightarrow \mathrm{SO}_{4}^{2-}$ interactions. All other model parameters are kept as given in Zuend et al. (2008).

\subsection{Uncertainty and the determination of model parameters}

The adequate consideration of uncertainties in both experimental data and the model is crucial for the determination of organic main group $\leftrightarrow$ ion interaction parameters. Qualitatively, an organic + water + salt system can be modeled in terms of organic $\leftrightarrow$ organic, organic $\leftrightarrow$ water, or- ganic $\leftrightarrow$ ion, and aqueous cation $\leftrightarrow$ anion interactions (cation $\leftrightarrow$ cation and anion $\leftrightarrow$ anion interactions can usually be neglected, see description of Eq. (4) for exceptions). In the group-contribution framework of AIOMFAC (and UNIFAC), organic $\leftrightarrow$ organic interactions are implemented on the level of interactions between organic functional groups (subgroups/main groups in UNIFAC part), while organic $\leftrightarrow$ ion interactions are described by organic main groups interacting with inorganic ions (no distinction on subgroup level as in LIFAC, Yan et al., 1999; Kiepe et al., 2006). Model uncertainties are associated with each of these types of interactions. Moreover, each measured quantity has its own level of random and systematic errors, which also depend on mixture composition, rendering some data points more reliable than others. This needs to be considered during the parameter determination procedure, e.g., by applying a meaningful weighting procedure to the individual datasets.

In order to parameterize organic $\leftrightarrow$ ion interactions from measurements, the deviations between measured thermodynamic equilibrium quantities and corresponding calculated quantities can be minimized by improving the organic $\leftrightarrow$ ion interaction parameters, provided that the contributions from all other binary interactions are already correctly considered. However, if there are significant uncertainties and corresponding deviations caused by other interaction contributions, the deviations between measured and calculated quantities cannot be attributed entirely to the organic $\leftrightarrow$ ion interaction. Zuend et al. (2008) showed that activity coefficients in aqueous electrolyte solutions are accurately calculated by AIOMFAC, so that it is justified to assume uncertainties from aqueous cation $\leftrightarrow$ anion interactions to be negligible. Inherent to the group-contribution concept, organic $\leftrightarrow$ water and organic $\leftrightarrow$ organic contributions from the UNIFAC model part bear higher uncertainties, as can be seen from comparisons of UNIFAC calculations and measurements for salt-free systems. A reduction of the influence of random and systematic errors can be achieved by basing the parameterization on a wide range of data, including different data types and different organic compounds. Preprocessing of some experimental data types in order to isolate the salt-effect on the organics from other contributions, as described in Sect. 4, helps to avoid that deviations arising from limitations of the UNIFAC part are erroneously compensated by organic-inorganic interactions.

Experimental data are not evenly available over all systems of interest. For example, to determine the model parameters for the $\mathrm{COOH} \leftrightarrow \mathrm{Cl}^{-}$interaction, ternary datasets of the type "carboxylic acid + water + chloride salt", covering a wide range of different cations are ideally needed for optimum separation of organic $\leftrightarrow$ anion interactions. Yet our database contains many more datasets in which the chloride salt is $\mathrm{NaCl}$ as compared to $\mathrm{NH}_{4} \mathrm{Cl}$ (for describing this specific interaction). Hence, the determined $\mathrm{COOH} \leftrightarrow \mathrm{Cl}^{-}$interaction parameters might be biased towards $\mathrm{NaCl}$-systems. Another effect, inherent to the group-contribution concept, 
might interfere: when the ternary systems from the example mentioned above are dominated by propanoic acid $\left(\mathrm{CH}_{3} \mathrm{CH}_{2} \mathrm{COOH}\right)$ as the carboxylic acid, which is composed of two $\mathrm{CH}_{\mathrm{n}}$ main groups in addition to the carboxyl group, the $\mathrm{COOH} \leftrightarrow \mathrm{Cl}^{-}$interaction parameters tend to become biased towards systems with a $\mathrm{CH}_{\mathrm{n}}: \mathrm{COOH}$ ratio of $2: 1$, although the $\mathrm{CH}_{\mathrm{n}} \leftrightarrow \mathrm{Cl}^{-}$interaction contribution should not be reflected by the $\mathrm{COOH} \leftrightarrow \mathrm{Cl}^{-}$interaction parameters. Furthermore, if only a certain type of data is available to determine a specific organic-inorganic interaction, e.g., experimental water activities, it might not be sufficient to constrain model parameters for accurate predictions of activities of all components. In general, such issues emerge from the representation of systems and components in AIOMFAC (or any other group-contribution model) and the amount and distribution of datasets used for the model parameter determination.

Although it cannot be completely avoided that an uneven distribution of datasets biases the model parameterization, a database containing a large variety of different datasets for the description of all the binary organic main group $\leftrightarrow$ ion interactions is the key to reduce parameterization interferences. This emphasizes the necessity and advantage of fitting all binary interaction parameters simultaneously using the entire database, since all systems are coupled by common ions and/or organic main groups. Provided a sufficient amount of experimental data for different systems exists, covering a wide range of concentrations, the diverse effects arising from organic main group $\leftrightarrow$ ion interactions can be disentangled by the parameter optimization procedure.

\subsection{Objective function}

Finding optimal organic $\leftrightarrow$ ion interaction parameters is a challenging multidimensional global optimization problem. In due consideration of the various aspects of model and measurement uncertainties and to enable intercomparability of different quantities, we formulate the following general objective function, subject to minimization:

$F_{\mathrm{obj}}=\sum_{d} \sum_{u} w_{d, u}\left[\frac{Q_{d, u}^{\mathrm{calc}}-Q_{d, u}^{\mathrm{ref}}}{\left|Q_{d, u}^{\mathrm{ref}}\right|+Q_{d, u}^{\mathrm{tol}}}\right]^{2}$.

Here, $d$ is a dataset index, $u$ denotes a point in the dataset, $w_{d, u}$ is the weighting of a data point as calculated from Eq. (9), and the sums cover all data points in all datasets considered. $Q_{d, u}^{\text {ref }}$ is a given reference quantity, i.e., a measured value or a quantity derived from measurements by means of thermodynamic relations. $Q_{d, u}^{\text {calc }}$ is the corresponding quantity calculated with the model at given conditions. $Q_{d, u}^{\text {tol }}$ is a tolerance quantity ( $>0$ ) with the same units as $Q_{d, u}^{\text {ref }}$, representing the measurement uncertainty or model sensitivity as described below. The range of values and units of the actual quantities depend on the data type (data types are discussed in Sect. 4). To simplify the procedure of assigning individual weightings to data points based on the data type and other properties, such as the number of data points in a dataset, $N_{d}$, the following approach is used:

$w_{d, u}= \begin{cases}w_{d}^{\text {init }} & \text { if } N_{d} \leq \eta, \\ w_{d}^{\text {init }} \times \frac{\eta}{N_{d}} & \text { if } N_{d}>\eta,\end{cases}$

where $w_{d}^{\text {init }}$ is an initial weighting assigned to dataset $d$, assuming the number of data points to be $\eta$, regardless of the actual number $\left(N_{d}\right)$. Here we set $\eta=10$, which is a characteristic number of points of the datasets considered. Equation (9) reduces the influence of datasets containing a large number of points, while avoiding an inordinately large weighting of datasets with only very few points. Initial weightings assigned to the datasets for the model fit are given in Table 2. The following rules were applied to assign initial weightings based on data type (see Sect. 4), temperature range and considerations regarding overall model optimization. LLE and SLE data close to $298 \mathrm{~K}$ were assigned a $w_{d}^{\text {init }}$ of 1.0 , mean molal activity coefficients, $\gamma_{ \pm}$, and $a_{w}$ (bulk) data an initial weighting of 2.0, water activity data from electrodynamic balance measurements, $a_{w}(\mathrm{EDB})$, a value of 1.0, and VLE data an initial weighting of 0.5 (or less depending on the temperature range). In addition, datasets showing large scatter or inconsistency with most other comparable data were given lower weightings or were set to zero. Dataset contributions to the objective function value after trial optimization iterations were analyzed and used to identify potential inconsistencies among datasets, possible mistakes in the dataset conversion or the implementation in the model (quality control), and to avoid that a few datasets completely dominate the parameter optimization due to numerical issues or other unjustified reasons.

In case $Q_{d, u}^{\text {ref }}$ in Eq. (8) is an experimentally determined value, such as a ternary mixture composition at salt saturation or the relative humidity in equilibrium with a bulk solution (i.e., the water activity), the corresponding tolerance quantity, $Q_{d, u}^{\text {tol }}$, can be considered a characteristic uncertainty of the measurement. $Q_{d, u}^{\text {tol }}$ would then be a stated measurement error or the standard deviation of several repeated experiments. However, for most of the data considered in the model fit, error bars are not given. Furthermore, we would like to know the sensitivity of activity coefficients with respect to a stated or assumed experimental uncertainty. Common to all measurements is the possibility of a slight error in composition. Therefore, we use the AIOMFAC model to calculate the effect of a tiny change in composition on the activity coefficients of the different mixture components by means of a total molar derivative:

$$
\begin{array}{r}
s_{t}^{\gamma}\left(x^{\star}\right)=d n^{\mathrm{tol}}\left(\left|\frac{\partial \gamma_{t}}{\partial n_{1}}\right|_{T, n_{j} \neq n_{1}}+\left|\frac{\partial \gamma_{t}}{\partial n_{2}}\right|_{T, n_{j} \neq n_{2}}\right. \\
\left.+\ldots+\left|\frac{\partial \gamma_{t}}{\partial n_{k}}\right|_{T, n_{j} \neq n_{k}}\right) .
\end{array}
$$


Here, $s_{t}^{\gamma}\left(x^{\star}\right)$ is the activity coefficient sensitivity of component $t$ at a composition $x^{\star}\left(x_{1}, x_{2}, \ldots, x_{k}\right)$ of a $k$-component system and $d n^{\text {tol }}$ is a molar increment corresponding to a mole fraction tolerance $x^{\text {tol }}$ characteristic for the dataset $\left(d n^{\mathrm{tol}}=x^{\mathrm{tol}} \times 1 \mathrm{~mol}\right)$. In this study, we chose $x^{\mathrm{tol}}=0.01$ for all datasets, which we consider a reasonable error tolerance for the use with a group-contribution model. The partial derivatives of $\gamma_{t}$ are calculated with respect to a molar change of each independent mixture component $\left(n_{1}, \ldots, n_{k}\right)$, while keeping the molar amounts $n_{j}$ of all other components fixed at the values corresponding to $x^{\star}$. Similarly, replacing the activity coefficient by the activity $a_{t}$ of a component in Eq. (10), the activity sensitivity $s_{t}^{a}\left(x^{\star}\right)$ is calculated. The sensitivity $s_{t}^{\gamma}\left(x^{\star}\right)$ provides a measure of the extent to which calculated AIOMFAC activity coefficients are sensitive to an error in a given mixture composition. If the relationship between a mixture composition and associated activity coefficients is experimentally determined to some degree of certainty and found to be sufficiently well represented by AIOMFAC, the calculated activity coefficient sensitivity can also be used to assess the quality of experimental data. Therefore, this concept enables an estimate of compositionrelated uncertainties of measurements and, thus, a way to determine how much one can trust a certain data point relative to other points/measurements. Other sources of error, more related to the accuracy of a specific experimental technique, can be factored in via the initial dataset weighting. For data types in which the $Q_{d, u}^{\text {ref }}$ are activity coefficients or activities, AIOMFAC sensitivities are used to calculate the tolerance quantity of a specific data point required for the objective function computation. For example, if $Q_{d, u}^{\text {ref }}$ and $Q_{d, u}^{\text {calc }}$ are measured and calculated water activities at composition $x^{\star}$, then $Q_{d, u}^{\text {tol }}=s_{\mathrm{w}}^{a}\left(x^{\star}\right)$. In other cases, e.g., when $Q_{d, u}^{\text {ref }}$ and $Q_{d, u}^{\text {calc }}$ are measured and calculated compositions in mole fractions, $Q_{d, u}^{\mathrm{tol}}$ is simply: $Q_{d, u}^{\mathrm{tol}}=x^{\mathrm{tol}}$.

Due to the fact that we use AIOMFAC to compute the sensitivities with a certain test set of interaction parameters at each iteration step ( $F_{\text {obj }}$ evaluation) during the parameter optimization procedure, the sensitivities calculated from Eq. (10) are a result of the AIOMFAC test-parameterization that feeds back on the objective function value. Hence, in principle there are two options to minimize $F_{\text {obj: }}$ : (1) by minimizing the numerator $\left(Q_{d, u}^{\text {calc }}-Q_{d, u}^{\text {ref }}\right)^{2}$ of Eq. (8), which is desired, or (2) by maximizing the denominator (at a suboptimal nominator) via maximizing $Q_{d, u}^{\mathrm{tol}}$, which should be avoided. In practice, feedback loops maximizing $Q_{d, u}^{\text {tol }}$ during parameter optimization do not pose a problem, because $Q_{d, u}^{\mathrm{tol}}$ depends only on the sensitivities for certain data types. Data distributed over a wide concentration range automatically corrects a tendency for option (2). The denominator of Eq. (8) is also designed to restrict the influence of data points with a very low sensitivity by the additional term $Q_{d, u}^{\text {ref }}$. Data with a very low activity coefficient sensitivity are typically rather insensitive to organic main group $\leftrightarrow$ ion interactions, e.g., water activity at high mole fractions of water, and a high weighting of such data would only add more noise instead of signal to the actual parameter optimization problem.

\subsection{Constraints based on functional group polarity series}

The physicochemical meaning of the binary interaction coefficients $B_{k, i}(I)$ provides additional information to constrain the parameters $b_{k, i}^{(1)}$ and $b_{k, i}^{(2)}$ to a meaningful range. The first term on the right-hand side of Eq. (4) (which includes $\left.B_{k, i}(I)\right)$ represents contributions to the Gibbs excess energy attributed to two-body interactions between organic main groups and ions. While the contribution of this term scales with the molalities of involved organic main groups and ions, the interaction coefficients $B_{k, i}(I)$ are functions of ionic strength only. These coefficients represent interaction strengths, specific to each main group-ion pair. However, relative to the same ion $i^{\star}$ at a given ionic strength $I^{\diamond}$, we argue that the different $B_{k, i^{\star}}\left(I^{\diamond}\right)$ values are not independent of each other, but rather that they are related to each other and depend on the polarity of the main groups $k$. Ions have a higher affinity for polar functional groups than for nonpolar groups due to charge $\leftrightarrow$ permanent dipole interactions with polar functional groups. Additionally, the polar carboxyl group partially dissociates in dilute solutions, enabling charge $\leftrightarrow$ charge interactions and certain ions, e.g., $\mathrm{NO}_{3}^{-}$and $\mathrm{SO}_{4}^{2-}$, can also form hydrogen bonds with hydroxyl and carboxyl groups, which can lead to salting-in of organic compounds. On the other hand, much weaker (attractive) interactions between ions and nonpolar main groups are the main cause for the salting-out effect of ions on organics in aqueous solutions. Here, the reference value for $B_{k, i^{\star}}\left(I^{\diamond}\right)$ is the interaction with water, for which we have $B_{\mathrm{H}_{2} \mathrm{O}, i^{\star}}\left(I^{\diamond}\right)=0$ (by definition). Therefore, in the case of nonpolar main groups, the $B_{k, i^{\star}}\left(I^{\diamond}\right)$ values are expected to be positive and greater than the $B_{k, i^{\star}}\left(I^{\diamond}\right)$ of polar main groups, representing the larger difference of nonpolar group $\leftrightarrow$ ion interactions relative to interactions of ions with polar water molecules. We formulate a functional group polarity series for the interaction coefficient $B_{k, i^{\star}}\left(I^{\diamond}\right)$ with the polarity of main groups $k$ in decreasing order:

$$
\begin{aligned}
& \mathrm{COOH}<\mathrm{ACOH} \lesssim\left(\mathrm{OH}+\mathrm{CH}_{\mathrm{n}}^{[\mathrm{OH}]}\right)<\mathrm{CHO} \\
& \lesssim \mathrm{CH}_{\mathrm{n}} \mathrm{O} \lesssim \mathrm{CH}_{\mathrm{n}}^{[\mathrm{OH}]} \lesssim \mathrm{ACH}_{\mathrm{n}} \lesssim \mathrm{CH}_{\mathrm{n}}<\mathrm{C}=\mathrm{C} \\
& \text { and } \\
& \mathrm{CCOO}<\mathrm{CH}_{\mathrm{n}} \mathrm{CO}<\mathrm{C}=\mathrm{C} .
\end{aligned}
$$

The inequality signs are with respect to the values of $B_{k, i^{\star}}\left(I^{\diamond}\right)$. The decrease in polarity of this series is parallel to the decrease in the oxygen-to-carbon ratio $(\mathrm{O}: \mathrm{C})$ of the main groups. Note that the groups $\mathrm{CCOO}, \mathrm{CH}_{n} \mathrm{CO}$, and $\mathrm{C}=\mathrm{C}$ are distinct from the other functional groups in that they consist of two carbon atoms and therefore need to be 
considered in a separate series. However, in terms of their Gibbs energy contributions according to Eq. (4), these functional groups can be thought of as units consisting of two single carbon-containing groups, e.g., $\mathrm{CH}_{\mathrm{n}} \mathrm{CO} \approx \mathrm{CH}_{\mathrm{n}}+\mathrm{CHO}$ or $\mathrm{C}=\mathrm{C} \approx \mathrm{CH}_{\mathrm{n}}+\mathrm{CH}_{\mathrm{n}}$. Hence, the second series of Relation (11) is, within a certain tolerance, related to the first series. Relation (11) allows one to formulate a set of inequality expressions, e.g.: $B_{\mathrm{COOH}, i^{\star}}\left(I^{\diamond}\right)<B_{\mathrm{ACOH}, i^{\star}}\left(I^{\diamond}\right)$, $B_{\mathrm{CH}_{\mathrm{n}} \mathrm{O}, i^{\star}}\left(I^{\diamond}\right)<B_{\mathrm{CH}_{\mathrm{n}}, i^{\star}}\left(I^{\diamond}\right), B_{\mathrm{CH}_{\mathrm{n}} \mathrm{CO}, i^{\star}}\left(I^{\diamond}\right)<B_{\mathrm{C}=\mathrm{C}, i^{\star}}\left(I^{\diamond}\right)$, etc. Such inequality expressions are used as additional constraints during the determination of the model parameters by evaluating $B_{k, i^{\star}}\left(I^{\diamond}\right)$ at $I^{\diamond}=0.001 \mathrm{~mol} \mathrm{~kg}-1,0.1 \mathrm{~mol} \mathrm{~kg}{ }^{-1}$, $10 \mathrm{~mol} \mathrm{~kg}^{-1}$, and $100 \mathrm{~mol} \mathrm{~kg}^{-1}$. These constraints effectively restrict the parameter range for each main group-ion pair. Among the advantages of such an approach are the resulting physically meaningful $B_{k, i}(I)$ interaction contributions and, with regard to predictions (extrapolations) on the basis of the group-contribution concept, a more reliable parameterization of AIOMFAC.

\section{Types and processing of experimental data}

Central for a reliable parameterization of AIOMFAC is a broad distribution of experimental data, comprising mixtures containing the target functional groups and inorganic ions at various concentrations. The theoretical basis common to different experimental techniques and data types is thermodynamic equilibrium. Equilibria between the gas phase and a liquid mixture constitute the basis for vapor-liquid equilibrium (VLE) phase composition measurements, equilibria between coexisting liquid phases provide liquid-liquid equilibrium (LLE) tie-line data, and equilibria between solid and liquid phases (SLE) furnish composition data of saturated solutions. Measurements of the electrical conductivity in electrolyte solutions relative to a standard cell potential, so called electromotive force (EMF) measurements, allow a direct determination of mean molal activity coefficients.

The relatively weak temperature dependence of activity coefficients allows the use of data measured at somewhat higher or lower temperatures than $298 \mathrm{~K}$. In this respect, dataset weightings are also used to account for a temperature effect, assigning higher weightings to datasets closer to $298 \mathrm{~K}$. In the following, the different data types, their processing and use in the model parameterization are described.

\subsection{Vapor-liquid equilibrium data}

VLE data comprise the mole fraction composition of the gas phase $(y)$ and the liquid mixture $(x)$ under isothermal or isobaric conditions $(x-y-T-p$ VLE data). Isobaric measurements are typically conducted at $1 \mathrm{~atm}$ pressure $(101325 \mathrm{~Pa})$, by measuring the boiling point temperature of different mixture compositions. Therefore, such measurements report data at higher temperatures. Almost all VLE data considered are ternary organic + water + salt mixtures, in which the salt is present only in the liquid phase. Treating the gas phase as an ideal gas mixture, activity coefficients of the organic component and water can be obtained from modified Raoult's law:

$\gamma_{j}^{(x)}=\frac{p_{j}}{p_{j}^{\circ} x_{j}}$.

Here, $p_{j}$ is the partial pressure of the semivolatile component $j$, given from $p_{j}=y_{j} p$, where $y_{j}$ is the measured gasphase mole fraction at total system pressure $p . \quad p_{j}^{\circ}(T)$ is the pure liquid compound saturation vapor pressure and $x_{j}$ the liquid-phase mole fraction, defined on the basis of the completely dissociated salt: $x_{j}=n_{j} /\left(\sum_{s} n_{s}+\sum_{i} n_{i}\right)$, where $n_{s}$ are moles of solvent species (organics, water) and $n_{i}$ are moles of the different ions. Saturation vapor pressures of organics and water at different temperatures are calculated using the Antoine equation with coefficients from the LandoltBörnstein database (Dykyj et al., 2000). With the exception of carboxylic acids, the assumption of an ideal gas mixture is well justified for the pressure and temperature range of the data. Tests with gas-phase fugacity corrections show a negligible effect on $\gamma_{j}^{(x)}$ - partly since the ratio $p_{j} / p_{j}^{\circ}$ moderates real-gas behavior. Gas-phase association of carboxylic acids, such as formic, acetic, and propanoic acids, is accounted for by the relations of Chueh (1974) with dimerization equilibrium coefficients from Tsonopoulos and Prausnitz (1970). The availability of VLE measurements for saltfree organic + water systems at similar conditions allows a further processing of activity coefficients with the goal to isolate the salt-effect on the organics from other contributions. Isolating the salt-effect enables achieving qualitative agreement of model and experimental data in terms of salting-in or salting-out effects of a certain electrolyte on an organic compound. This is useful since at lower salt concentrations uncertainties in the UNIFAC part of AIOMFAC might lead to a qualitatively wrong parameter fitting, i.e., forcing the model towards predicting a salting-in effect when salting-out is actually observed. The idea of isolating the salt-effect is to calculate the deviation $\Delta^{\mathrm{sc}, \mathrm{sf}} \gamma_{j}^{(x)}\left(x_{j}^{\prime}\right)$ of a component's activity coefficient in the salt-containing (sc) from the corresponding salt-free (sf) system, calculated at the same liquid mixture mole fraction $x_{j}^{\prime}$ (superscript / denotes here the calculation of mole fractions on a salt-free basis, i.e., even when a salt is present in the mixture) and temperature range:

$\Delta^{\mathrm{sc}, \mathrm{sf}} \gamma_{j}^{(x)}\left(x_{j}^{\prime}\right)=\gamma_{j}^{(x), \mathrm{sc}}\left(x_{j}^{\prime}\right)-\gamma_{j}^{(x), \mathrm{sf}}\left(x_{j}^{\prime}\right)$.

To compute activity coefficients in salt-free systems at exactly the same $x_{j}^{\prime}$ as given from the salt-containing VLE data, we use a molar Gibbs excess energy parameterization, fitted to VLE data of salt-free systems, preferentially measured by the same groups/experimental setups that also report datasets of salt-containing mixtures. Following McGlashan (1963), we formulate a 4th-order molar Gibbs excess energy series 

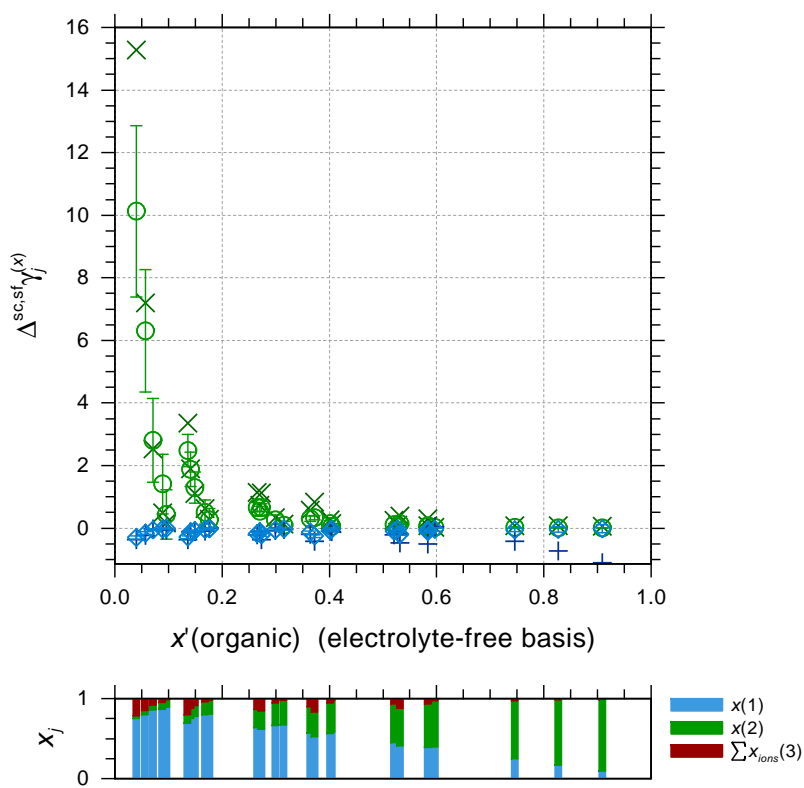

Fig. 2. Activity coefficient deviations $\Delta^{\mathrm{sc}, \mathrm{sf}} \gamma_{j}^{(x)}$ of saltfree vs. salt-containing mixtures in the water (1)+2-propanol (2) $+\mathrm{LiCl}(3)$ system derived from isobaric VLE data at $354-358 \mathrm{~K}$. Experimental data $(\times,+)$ by Lin et al. (1993) and calculated values $(\bigcirc, \diamond)$ are shown in blue for water and in green for 2-propanol. The error bars represent the model sensitivity to a composition variation by $x^{\text {tol }}=0.01$. The mixture compositions with respect to completely dissociated $\mathrm{LiCl}$ are shown in the bar graphs.

parameterization satisfying the Gibbs-Duhem-Margules relation for binary systems (McGlashan, 1963; Soonsin et al., 2010):

$$
\begin{aligned}
\frac{g^{\mathrm{ex}}}{R T} & =x_{2}\left(1-x_{2}\right)+\left[\sum_{i=1}^{k} c_{i}\left(1-2 x_{2}\right)^{i-1}\right], \\
\frac{d\left[g^{\mathrm{ex}} /(R T)\right]}{d x_{2}} & =\left(1-2 x_{2}\right)+\left[\sum_{i=1}^{k} c_{i}\left(1-2 x_{2}\right)^{i-1}\right] \\
+x_{2}\left(1-x_{2}\right)\left[-2 \sum_{i=2}^{k}(i-1) c_{i}\left(1-2 x_{2}\right)^{i-2}\right], & \\
\ln \gamma_{2}^{(x)} & =\frac{g^{\mathrm{ex}}}{R T}+\left(1-x_{2}\right) \frac{d\left[g^{\mathrm{ex}} /(R T)\right]}{d x_{2}}, \\
\ln \gamma_{1}^{(x)} & =\frac{g^{\mathrm{ex}}}{R T}-x_{2} \frac{d\left[g^{\mathrm{ex}} /(R T)\right]}{d x_{2}},
\end{aligned}
$$

where $g^{\text {ex }}$ is the molar Gibbs excess energy of a binary solution (components 1 and 2) and $c_{i}(i=1, \ldots, k)$ are fitted, system-specific coefficients up to order $k=4$, given in Table 1. Equations (16) and (17) provide then the $\gamma_{j}^{(x), \text { sf }}$ required in Eq. (13). The data processing with Eq. (13) leads in most cases to a clear qualitative and quantitative distinction between the salt-effect on water (predominately salting-in) and on organic compounds (predominately salting-out).
For complete $(x-y-T-p)$ VLE datasets, Eq. (13) is used to define the reference quantity, $Q_{d, u}^{\text {ref }}=\Delta^{\mathrm{sc}, \mathrm{sf}} \gamma_{j}^{(x)} . Q_{d, u}^{\text {calc }}$ is calculated accordingly by the model. $Q_{d, u}^{\text {tol }}$ is defined using the model sensitivity of the activity coefficient deviation as $Q_{d, u}^{\text {tol }}=s_{t}^{\gamma}\left(\Delta^{\mathrm{sc}, \mathrm{sf}} \gamma_{j}^{(x)}\right)+1$, where the term $+1\left(=\gamma_{j}^{(x), \text { ideal }}\right)$ attenuates effects from noisy data on the special salt-effect isolation treatment (when introduced in the denominator of Eq. 8). An example of the use of VLE data processed this way is shown in Fig. 2 for the ternary system water +2 propanol $+\mathrm{LiCl}$. This system is representative for the behavior of many ternary VLE systems in that it shows a strong salting-out effect on the organic, i.e., large positive deviations from the electrolyte-free baseline (where $\Delta^{\mathrm{sc}, \mathrm{sf}} \gamma_{\mathrm{org}}^{(x)}=$ 0 ), at compositions where the organic component makes up only a small fraction of the solution and the electrolyte concentration is relatively high. This enhanced salting-out effect can be intuitively explained by the microscopic view that at such conditions, moderating organic $\leftrightarrow$ organic interactions are largely diminished, whereas organic $\leftrightarrow$ ion interactions are more frequent, due to the higher probabilities of an organic molecule to directly interact with an ion (or with a water molecule), than with another organic molecule. The salt-effect isolation treatment removes the effects of organic $\leftrightarrow$ water interactions on the activity coefficients of both water and the organic compound. Hence, deviations from the electrolyte-free baseline in Fig. 2 (and similar figures) represent the direct and indirect effects of dissolved ions on activity coefficients of the organic compound and water. Organic $\leftrightarrow$ ion interactions directly affect the activity coefficients of the organic compound, while water $\leftrightarrow$ ion interactions indirectly affect organic activity coefficients according to the Gibbs-Duhem relation. Typical for electrolytecontaining mixtures when dilute with respect to the organic fraction, is an increased model sensitivity to small variations in composition, which explains and justifies an increase in the deviations between calculated and measured activity coefficients of the organic compound.

Some VLE datasets are incomplete in the sense that they provide only, e.g., $x-y-T$ data, where total pressure information is missing. In our database, the data type $\operatorname{VLE}(x-$ $y-T)$ coincides with ternary mixtures containing monocarboxylic acids, such as propanoic acid, which associate in the gas phase to form significant amounts of dimers. Therefore, individual activity coefficients of water and the organic compound cannot be derived from the experimental data in the way it is achieved for complete $\operatorname{VLE}(x-y-p-T)$ data and no isolation of the salt-effect is attempted. However, the measured mole fraction of water in the gas phase, $y_{1}=\frac{p_{1}}{p_{1}+p_{2 m}+2 p_{2 d}}$ (Chueh, 1974), can be compared to the AIOMFAC ${ }^{2}$ calculation of $y_{1}$ when the gas-phase association equilibrium is considered. In the expression for $y_{1}, p_{1}$ is the partial pressure of water, while $p_{2 m}$ and $p_{2 d}$ are the partial pressures of carboxylic acid (component 2) monomer and dimer, respectively. The partial pressures of monomer 
Table 1. Coefficients for the Gibbs-Duhem-Margules parameterization fitted to salt-free binary VLE data.

\begin{tabular}{|c|c|c|c|c|c|c|c|}
\hline \multirow[t]{2}{*}{ Binary system components } & \multirow[t]{2}{*}{$p(\mathrm{kPa})^{\mathrm{a}}$} & \multirow[t]{2}{*}{$T(\mathrm{~K})^{\mathrm{a}}$} & \multicolumn{4}{|c|}{ Coefficients of 4-parameter fit (-) } & \multirow[t]{2}{*}{ Exp. data } \\
\hline & & & $c_{1}$ & $c_{2}$ & $c_{3}$ & $c_{4}$ & \\
\hline water $(1)+$ formic $\operatorname{acid}(2)$ & 101.3 & $375-381$ & $-3.02194 \times 10^{-1}$ & $7.34748 \times 10^{-2}$ & $1.57832 \times 10^{-1}$ & $-6.52176 \times 10^{-2}$ & $\mathrm{~b}$ \\
\hline water(1) + $\operatorname{acetic} \operatorname{acid}(2)$ & 98.8 & $373-386$ & $6.05562 \times 10^{-1}$ & $1.58468 \times 10^{-1}$ & $1.66632 \times 10^{-1}$ & $1.12213 \times 10^{-1}$ & $\mathrm{c}$ \\
\hline water $(1)+\operatorname{acetone}(2)$ & $101.3,80.0$ & $323-368$ & 1.79411 & $2.77094 \times 10^{-1}$ & $1.89513 \times 10^{-1}$ & $-1.14564 \times 10^{-1}$ & d \\
\hline water(1) + tetrahydrofuran $(2)$ & 101.3 & $336-338$ & 2.27524 & $2.76082 \times 10^{-1}$ & $4.88769 \times 10^{-1}$ & $4.38607 \times 10^{-1}$ & $\mathrm{e}$ \\
\hline water(1) + ethyl acetate(2) & 101.3 & $343-346$ & 2.36413 & $2.31960 \times 10^{-1}$ & $5.23751 \times 10^{-1}$ & $3.72833 \times 10^{-1}$ & $\mathrm{f}$ \\
\hline ethyl acetate $(1)+$ ethanol(2) & 101.3 & $345-349$ & $8.74984 \times 10^{-1}$ & $1.64586 \times 10^{-2}$ & $-9.86961 \times 10^{-2}$ & $-5.90410 \times 10^{-2}$ & $\mathrm{~g}$ \\
\hline water(1) + 1-propanol(2) & 101.3 & $360-371$ & 1.63307 & $5.52340 \times 10^{-1}$ & $3.59556 \times 10^{-1}$ & $3.80381 \times 10^{-1}$ & $\mathrm{~h}$ \\
\hline water(1) + 2-propanol(2) & $101.3,44-82$ & $353-372,384$ & 1.52632 & $5.00563 \times 10^{-1}$ & $2.84293 \times 10^{-1}$ & $1.84488 \times 10^{-1}$ & i \\
\hline water(1) + ethanol $(2)$ & 101.3 & 351-372 & 1.20197 & $2.96224 \times 10^{-1}$ & $1.49670 \times 10^{-1}$ & $4.79250 \times 10^{-2}$ & $\mathrm{j}$ \\
\hline water(1) + ethanol(2) & $12-30$ & $307-323$ & 1.18990 & $3.15496 \times 10^{-1}$ & $-2.48741 \times 10^{-2}$ & $-1.21881 \times 10^{-1}$ & $\mathrm{k}$ \\
\hline
\end{tabular}

a Pressure and temperature ranges are stated with respect to the experimental data used for the fit.

Experimental data references: ${ }^{b}$ Yun et al. (1998), ${ }^{\mathrm{c}}$ Narayana et al. (1985), ${ }^{\mathrm{d}}$ Brunjes and Bogart (1943); Al-Sahhaf and Jabbar (1993), ${ }^{\mathrm{e}}$ Sada et al. (1975b), ${ }^{\mathrm{f}}$ Rajendran et al. (1991), ${ }^{g}$ Topphoff et al. (2001), ${ }^{h}$ Vercher et al. (1999); Morrison et al. (1990); Gmehling et al. (1981); Lin et al. (1993), ${ }^{i}$ Kato et al. (1971); Sada et al. (1975b); Morrison et al. (1990); Lin et al. (1993); Gmehling et al. (1981); Gironi and Lamberti (1995); Rajendran et al. (1991), j Gmehling et al. (1981); Kurihara et al. (1993); Johnson and Furter (1957); Kirschbaum and Gerstner (1939), ${ }^{\mathrm{k}}$ Kirschbaum and Gerstner (1939); Gmehling et al. (1981).

and dimer are related by: $p_{2 d}=\left(p_{2 m}\right)^{2} K_{2}(T)$, where $K_{2}$ is the temperature dependent association equilibrium constant as given, e.g., by Tsonopoulos and Prausnitz (1970). The expression to calculate $y_{1}$ with AIOMFAC is then:

$$
y_{1}=\frac{\gamma_{1}^{(x)} x_{1} p_{1}^{\circ}}{\gamma_{1}^{(x)} x_{1} p_{1}^{\circ}+\gamma_{2}^{(x)} x_{2} p_{2 m}^{\circ}+2 K_{2}\left(\gamma_{2}^{(x)} x_{2} p_{2 m}^{\circ}\right)^{2}} .
$$

Here, $p_{2 m}^{\circ}$ is the saturation vapor pressure of the monomer of component 2 at $T$, calculated by solving the quadratic equation: $K_{2}\left(p_{2 m}^{\circ}\right)^{2}+p_{2 m}^{\circ}-p_{2}^{\circ}=0$, where $p_{2}^{\circ}$ is the total saturation vapor pressure of component 2 at $T$, obtained from the Antoine Equation with coefficients from the LandoltBörnstein database (Dykyj et al., 2000). Hence the unknowns in Eq. (18) are the activity coefficients, which are calculated with AIOMFAC. The tolerance quantity of data type $\operatorname{VLE}(x-$ $y-T)$ is set to $Q_{d, u}^{\text {tol }}=x^{\text {tol }}$.

\subsection{Water activity data}

A special case of VLE data are water activities $a_{\mathrm{w}}$ of bulk solutions or from aqueous droplets. The latter are typically investigated in an electrodynamic balance (EDB), with a hygroscopicity tandem differential mobility analyzer (HTDMA), or by micro-Raman spectroscopy. In bulk experiments, the (water) vapor pressure or relative humidity ( $\mathrm{RH})$ of the gas phase in equilibrium with a solution of a given composition is measured. Solution concentrations up to saturation can be reached. In EDB, HTDMA or micro-Raman measurements, droplets are equilibrated in an atmosphere of known RH. The radius or volume change of the droplets reflects the water uptake or release as a function of $\mathrm{RH}$ and can be related to absolute water content when the dry mass is known or when bulk reference water activities at high RH are available. EDB and HTDMA measurements are usually less accurate than bulk measurements because of uncertainties in both, ambient RH and water content. However, they can access the supersaturated concentration range because small droplets with little contact to surfaces can reach high supersaturations. Accurate water activity measurements of bulk solutions and droplets require the vapor pressure of the organic component to be low with respect to the water vapor pressure. Water activity measurements have the advantage of providing data at room (or even lower) temperatures and are a useful data source to constrain organic $\leftrightarrow$ ion interactions, although water activities are only indirectly affected by such interactions (Gibbs-Duhem relation). In case of $a_{\mathrm{w}}$ data, $Q_{d, u}^{\mathrm{ref}}$ and $Q_{d, u}^{\mathrm{calc}}$ are the measured and calculated $a_{\mathrm{w}}^{(x)}$ values at given mixture compositions and $Q_{d, u}^{\mathrm{tol}}$ are the calculated water activity sensitivities (Eq. 10). Figure 3 shows measured and calculated water activities in the system water + malonic acid $+\left(\mathrm{NH}_{4}\right)_{2} \mathrm{SO}_{4}$ at $298 \mathrm{~K}$. The deviations of water activities in the ternary mixtures as compared to $a_{\mathrm{w}}$ of the salt-free water + malonic acid system represent the effects of water $\leftrightarrow$ ion and malonic acid $\leftrightarrow$ ion interactions (here the ions are $\mathrm{NH}_{4}^{+}$and $\mathrm{SO}_{4}^{2-}$ ). In this example, measured water activities are relatively well represented by the AIOMFAC calculations, with slightly higher deviations at lower water contents. The many data points in this dataset, with compositions covering a variety of malonic acid:ammonium sulfate ratios, are one way to facilitate that the model parameter optimization is not biased towards a specific organic:inorganic mixing ratio.

\subsection{Liquid-liquid equilibrium data}

The type of LLE data that is useful for the AIOMFAC parameterization are so-called tie-line measurements, where the compositions of two coexisting liquid phases at a 

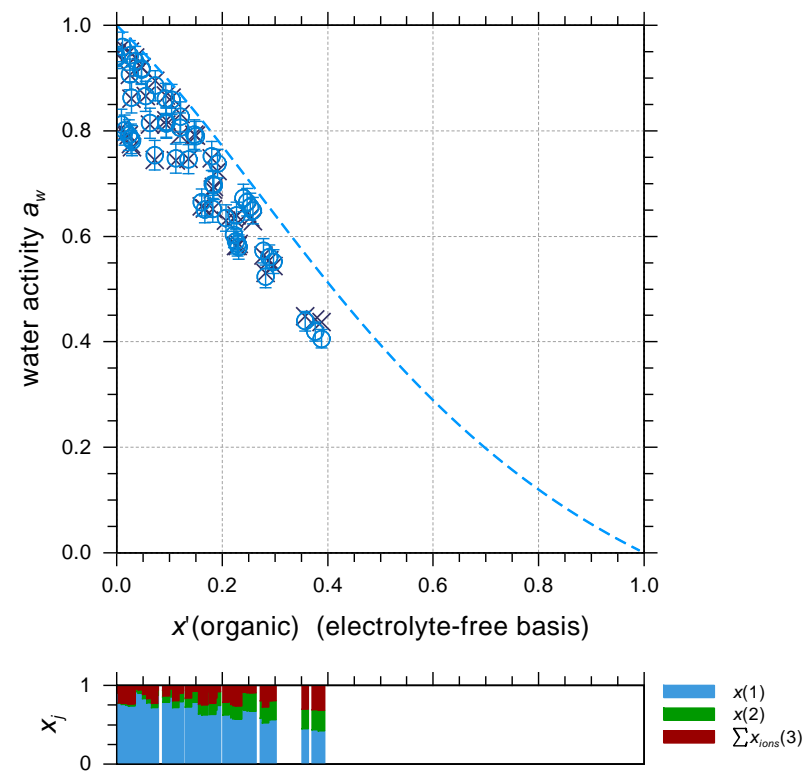

Fig. 3. Water activities in the ternary system water $(1)+$ malonic acid $(2)+\left(\mathrm{NH}_{4}\right)_{2} \mathrm{SO}_{4}(3)$ at $298 \mathrm{~K}$. Experimental bulk $a_{\mathrm{W}}$ data $(\times)$ by Salcedo (2006) and corresponding calculated values $(O)$ at various mixture compositions, as shown in the bar graphs. The error bars represent the model $a_{\mathrm{W}}$-sensitivity to a composition variation by $x^{\text {tol }}=0.01$. The dashed curve shows the calculated water activity of the salt-free solvent mixture.

certain temperature are determined. One way to compare AIOMFAC predictions with experimental data, is to perform a liquid-liquid phase separation computation, for which an initial mixture composition of the experimental tie-line is needed as input. To do this, we use the computation method for liquid-liquid phase separation described by Zuend et al. (2010), using AIOMFAC for the Gibbs energy calculation. An initial mixture composition, with mole fractions $x_{j}^{\text {init }}$, on an unstable/metastable point on a tie-line is generated by

$x_{j}^{\text {init }}=\frac{1}{2}\left(x_{j}^{\alpha}+x_{j}^{\beta}\right)$,

where $x_{j}^{\alpha}$ and $x_{j}^{\beta}$ are the experimentally determined compositions of the two liquid phases, $\alpha$ and $\beta$, at equilibrium. This way, measured and calculated phase compositions can be directly compared. However, this approach unfortunately involves high computational costs that cannot be avoided when a reliable detection of the LLE composition is essential. Such computational demands are acceptable when only a few LLE data points are used with a small number of fit parameters. In this study, where thousands of LLE data points are used and $\sim 250$ parameters need to be determined simultaneously, taking up to a million objective function evaluations including billions of AIOMFAC calls - the described LLE prediction approach is simply unfeasible. Thus, a different, computationally more efficient use of LLE data is mandatory.
To overcome this technical barrier, we make use of the thermodynamic phase equilibrium conditions. Based on the reference state definitions of AIOMFAC, activities of the different independent components have to be equal in coexisting phases, i.e., $a_{s}^{(x), \alpha}=a_{s}^{(x), \beta}$ in case of solvent components and $\operatorname{IAP}_{\mathrm{MX}}^{\alpha}=\operatorname{IAP}_{\mathrm{MX}}^{\beta}$ in case of electrolytes, where

$\operatorname{IAP}_{\mathrm{MX}}=\left(a_{\mathrm{M}}^{(m)}\right)^{v^{+}} \times\left(a_{\mathrm{X}}^{(m)}\right)^{v^{-}}$

is the molal ion activity product of electrolyte unit " $\mathrm{M}_{v^{+}} \mathrm{X}_{v^{-}}$" with $v^{+}$cations $\mathrm{M}$ and $v^{-}$anions $\mathrm{X}$ (Zuend et al., 2010). This isoactivity condition enables a direct calculation and comparison of activities in coexisting phases at the experimental LLE compositions. Typical for organic + water + salt LLE is that only a very small amount of electrolyte is dissolved in the organic-rich phase and only a small part of the organic fraction is present in the aqueouselectrolyte phase. This makes the sensitivity to small errors in phase composition very high, because tiny amounts of electrolyte need to be detected accurately in a predominantly aqueous-organic phase. Moreover, the activity sensitivities of electrolytes and organics in their respective concentrationpoor phases are very high. Therefore, a good choice for $Q_{d, u}^{\mathrm{ref}}$ and especially the consideration of the sensitivities by $Q_{d, u}^{\text {tol }}$ is of crucial importance. The objective function terms of LLE data are therefore defined in a dataset- and componentspecific manner. For each component in a dataset $d$, the phase in which the activity sensitivity $s_{j}^{a}$ is smaller on average, is defined as the reference phase, which is typically the phase where $j$ is enriched. At a data point $u, Q_{d, u}^{\text {ref }}$ of a component $j$ is then set to the calculated activity value (IAP in case of electrolytes) of $j$ in the reference phase. The tolerance quantity is defined as the sum of the activity sensitivities from both phases: $Q_{d, u}^{\text {tol }}=s_{j}^{a, \alpha}+s_{j}^{a, \beta}$. Note that according to the error propagation rule the expression $Q_{d, u}^{\text {tol }}=\sqrt{\left(s_{j}^{a, \alpha}\right)^{2}+\left(s_{j}^{a, \beta}\right)^{2}}$ should be used (as pointed out by a reviewer). However, since in most cases here the activity sensitivity in one phase is much larger than in the other phase, using the sum of sensitivities introduces little error. Hence, we use a relative activity deviation in the expression of the objective function (Eq. 8) for LLE data. This "rel. activity deviation" is defined as $\frac{a_{j}^{\beta}-a_{j}^{\alpha}}{a_{j}^{\alpha}+s_{j}^{a, \alpha}+s_{j}^{a, \beta}}$ for the case where phase $\alpha$ is the reference phase of component $j$ (otherwise all superscripts $\alpha$ have to be interchanged to $\beta$ and vice versa). Figure 4 shows such LLE rel. activity deviations for tie-line data of the quaternary system water $+4-$ methyl-2-pentanone + acetic acid $+\mathrm{NaCl}$ at $308 \mathrm{~K}$. In these kind of LLE data representations, a value of $\mid$ rel. activity deviation $\mid<0.2$ can be considered relatively "good". Figure 4 reveals that components which predominately partition to one of the liquid phases, i.e., electrolytes and hydrophobic organics, typically show higher sensitivity to small composition changes than components more abundant in both phases, 

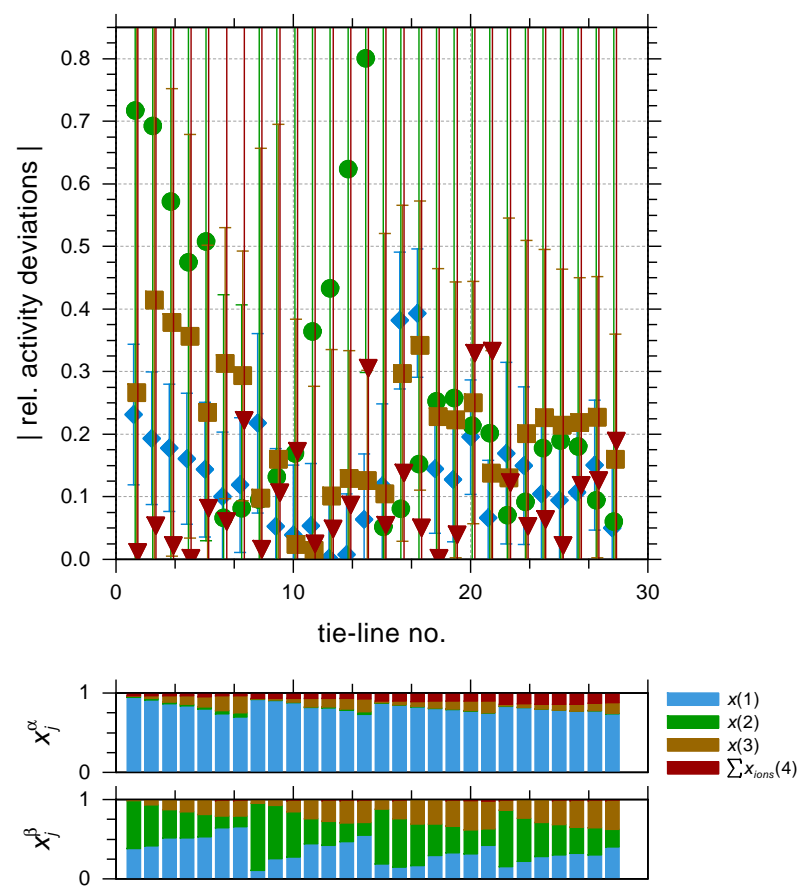

Fig. 4. Calculated relative activity deviations in the quaternary LLE system water (1)+4-methyl-2-pentanone (2) + acetic acid (3) $+\mathrm{NaCl}$ (4) at $308 \mathrm{~K}$. Compositions of the two phases $\alpha$ and $\beta$ are given in the bar graphs at each tie-line, measured by Govindarajan and Sabarathinam (1995). Relative activity deviations and corresponding model sensitivities (error bars) are shown for water $(\diamond)$, 4-methyl-2-pentanone $(\bullet)$, acetic acid $(\square)$, and rel. IAP deviations for $\mathrm{NaCl}(\boldsymbol{\nabla})$. For clarity, symbols of the different components at a tie-line are shifted slightly in $\mathrm{x}$-axis direction.

as e.g., water. The reasons for this behavior are analogous to the ones discussed above in case of VLE data.

The described isoactivity condition method is computationally efficient and enables an alternative way to use LLE data for the model parameter determination. For plots and evaluation of calculated and experimental ternary LLE data, we use the LLE phase separation computation approach as well, enabling a direct comparison of predicted and experimentally determined phase compositions. An example of this is shown in Fig. 5 for the ternary system water + tertbutanol $+\mathrm{NaCl}$ at $298 \mathrm{~K}$. Panel (a) of Fig. 5 shows the miscibility gap mapped on a coordinate system that depicts the water contents of the two phases as a function of the waterfree "dry" composition. Panel (b) shows the same system on a coordinate system that emphasizes the very different contents of tert-butanol and $\mathrm{NaCl}$ in the two phases. The phase separation computation using AIOMFAC predicts a slightly wider miscibility gap, but is in general agreement with the measurements. Neither the binary water + tert-butanol system nor the binary water $+\mathrm{NaCl}$ system exhibit a liquidliquid phase separation at any mixing ratio at $298 \mathrm{~K}$. Hence, the phase separation in the ternary system can only be caused by interactions attributed to the salting-out effect of ions on organics. The salting-out effect is mainly considered by means of the parameters representing the middle-range interactions between involved ions and organic main groups. For example, setting for testing purposes all middle-range organic $\leftrightarrow$ ion parameters to zero, i.e., equal to the value of water $\leftrightarrow$ ion interactions, results in a predicted single-phase solution. Thus, a good fit of AIOMFAC organic $\leftrightarrow$ ion MRparameters is essential for accurate representations of liquidliquid equilibria.

\subsection{Solid-liquid equilibrium data}

Solid-liquid equilibria constitute mixture composition data, at which liquid mixtures are in equilibrium with a solid phase. In the case of binary systems at isothermal conditions, there is only one specific SLE-composition point, e.g., the saturated solution of a salt in water at $298 \mathrm{~K}$ (at a saltspecific equilibrium deliquescence relative humidity). For ternary systems at constant temperature, SLE data define a solubility limit curve of points at different mixture compositions. In case of ternary aqueous organic-inorganic systems, the salt, water or the organic compound can form crystalline solids, depending on the mixture composition and temperature. Solid-liquid equilibria can become complicated when hydrates or mixed crystals form. Thermodynamic equilibrium conditions require all solution components, present in the solid phase, to hold a specific liquid phase activity, or activity product (in case of salts, hydrates and mixed crystals) at different solution compositions in equilibrium with the same solid phase. For example, a ternary system of 2ethoxyethanol + water $+\mathrm{KCl}$ in SLE with solid $\mathrm{KCl}$, shown in Fig. 6, requires a constant molal ion activity product $\mathrm{IAP}_{\mathrm{KCl}}=K_{\mathrm{sp}}(T)$ at different compositions. A reference value for the solubility product $K_{\mathrm{sp}}(T)$ can be calculated with AIOMFAC from the solubility limit in the corresponding binary aqueous system (in this example, water $+\mathrm{KCl}$ ). Hence, the following information is needed for the use of SLE data: mixture compositions at solubility limit, temperature, and composition of the solid phase.

In order to compare measured with calculated isothermal SLE data, AIOMFAC is used to calculate mixture compositions that fulfill the solubility limit equilibrium conditions. For the following description of our method, let us assume for that a salt MX forms the solid phase. First, the solubility product $K_{\mathrm{sp}}(T)$ at the solubility limit of MX is calculated from binary aqueous composition data. Second, at a given ternary composition the salt-free mole fraction composition, $x_{j, j \neq \mathrm{MX}}^{\prime}$, is kept constant, while the molar content of MX with respect to $1 \mathrm{~mol}$ total solution is varied (thus changing the mole fractions of all components), until the composition is found, at which the condition $\operatorname{IAP}_{\mathrm{KCl}}=K_{\mathrm{sp}}(T)$ is fulfilled. This is numerically solved by using a root bracketing algorithm (starting at the experimental composition), followed by a few bisection steps, and a modification of 

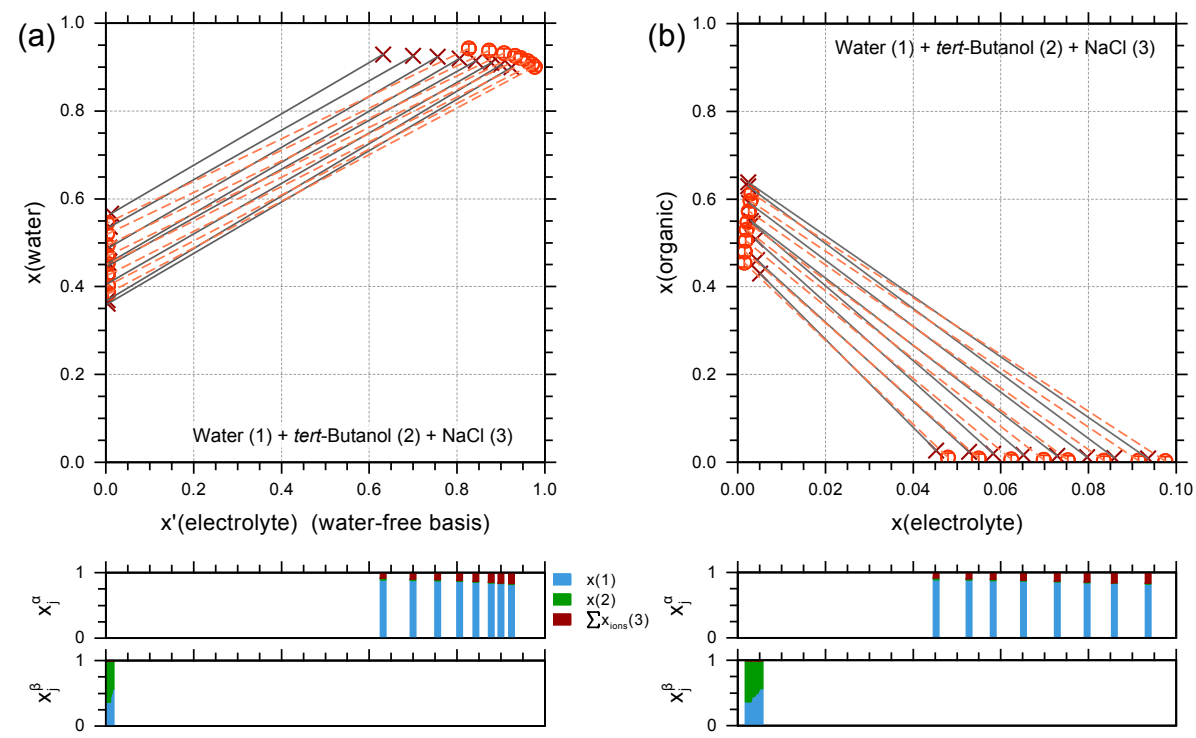

Fig. 5. Experimental and computed LLE phase compositions of the ternary system water (1) + tert-butanol (2) + $\mathrm{NaCl}(3)$ at $298 \mathrm{~K}$. Measured tie-line data $(X)$ by Gomis et al. (1996) and computed compositions $(O)$ using AIOMFAC with the phase separation prediction module (Zuend et al., 2010). (a) Phase diagram where the abscissa represents the water-free "dry" molar mixture composition, $x^{\prime}(\mathrm{NaCl})$. The solid gray and dashed red lines indicate coexisting phase compositions of the measured and calculated compositions, respectively (non-standard tielines in this coordinate system). (b) Phase diagram of the same system, plotted on mole fraction axis, $x(\mathrm{NaCl}) \mathrm{vs} . x($ tert-butanol). In this coordinate system, tie-lines maintain their standard meaning, i.e., initial (unstable) and stable end points are collinear. In (b), experimental and calculated tie-lines intersect at the initial compositions, $x_{j}^{\text {init }}$, used for the phase separation computations.

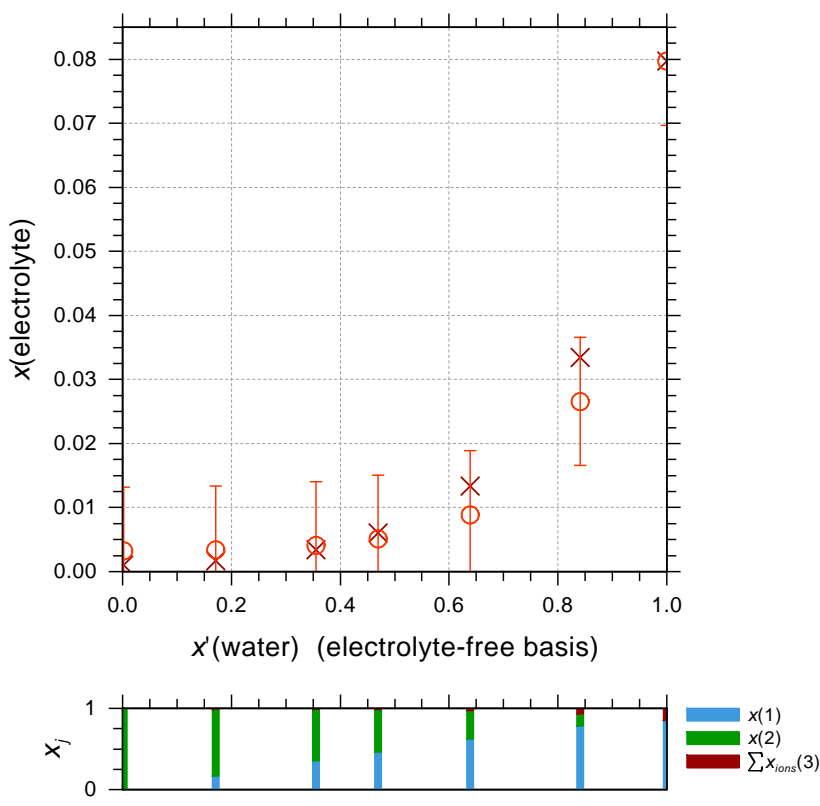

Fig. 6. Experimental and calculated SLE compositions of the system water (1) +2-ethoxyethanol (2) $+\mathrm{KCl}(3)$ at $298 \mathrm{~K}$, saturated with KCl. SLE composition measurements $(X)$ by Chiavone-Filho and Rasmussen (1993) and calculated solubility limits $(\bigcirc)$ using the $\mathrm{IAP}_{\mathrm{KCl}}$ of the saturated binary water $+\mathrm{KCl}$ solution as reference. Error bars represent $x^{\text {tol }}=0.01$.

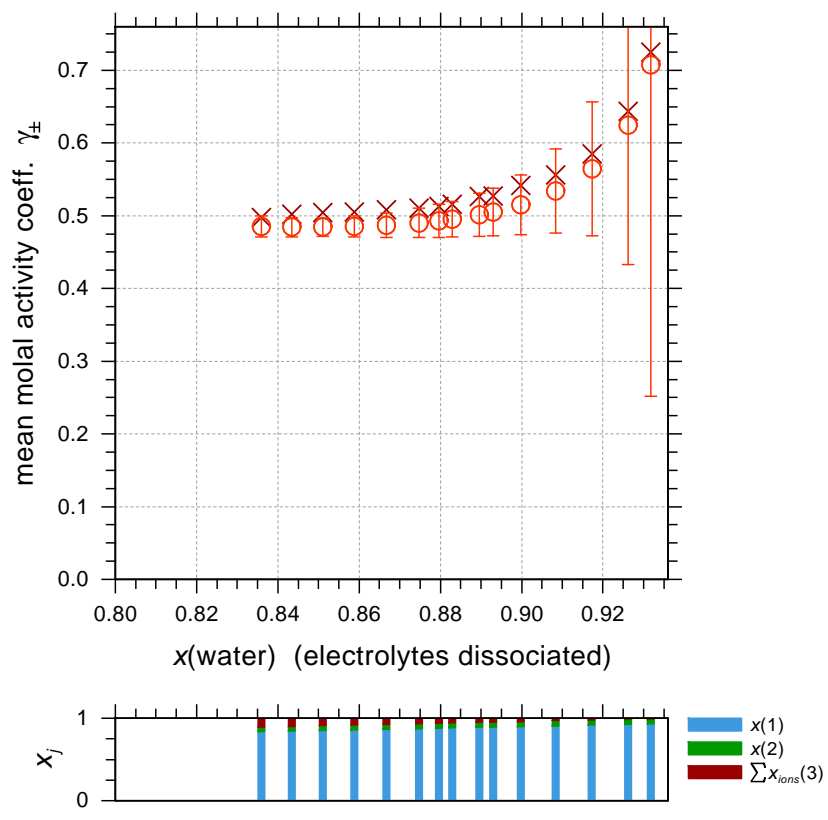

Fig. 7. Mean molal activity coefficients $\gamma_{ \pm}$of $\mathrm{KCl}$ in the system water (1) + ethanol (2) $+\mathrm{KCl}(3)$ at $298 \mathrm{~K}$. Experimental values $(\times)$ derived from EMF measurements by Lopes et al. (1999), calculated $\gamma_{ \pm}$values $(O)$ and corresponding activity coefficient sensitivities (error bars) are with regard to the mixed solvent reference state definition. 


\begin{tabular}{|c|c|c|c|c|c|c|c|c|c|c|c|c|c|}
\hline group name & $\begin{array}{l}\text { ions } \rightarrow \\
\text { main groups } \downarrow\end{array}$ & $\mathrm{H}^{+}$ & $\mathrm{Li}^{+}$ & $\mathrm{Na}^{+}$ & $\mathrm{K}^{+}$ & $\mathrm{NH}_{4}^{+}$ & $\mathrm{Mg}^{2+}$ & $\mathrm{Ca}^{2+}$ & $\mathrm{Cl}^{-}$ & $\mathrm{Br}$ & $\mathrm{NO}_{3}^{-}$ & $\mathrm{HSO}_{4}^{-}$ & $\mathrm{SO}_{4}{ }^{2-}$ \\
\hline alkyl & $\mathrm{CH}_{\mathrm{n}}$ & 19 & 31 & 184 & 68 & 90 & 16 & 35 & 256 & 35 & 43 & 5 & 104 \\
\hline $\begin{array}{l}\text { alkyl bonded to } \\
\text { hydroxyl group }\end{array}$ & $\mathrm{CH}_{\mathrm{n}}{ }^{[\mathrm{OH}]}$ & 10 & 19 & 91 & 40 & 43 & 13 & 20 & 140 & 21 & 23 & 1 & 51 \\
\hline hydroxyl & $\mathrm{OH}$ & 10 & 19 & 91 & 40 & 43 & 13 & 20 & 140 & 21 & 23 & 1 & 51 \\
\hline carboxyl & $\mathrm{COOH}$ & 4 & 9 & 47 & 33 & 48 & 6 & 6 & 66 & 9 & 18 & 4 & 56 \\
\hline ketone & $\mathrm{CH}_{\mathrm{n}} \mathrm{CO}$ & 4 & 2 & 40 & 9 & 3 & 2 & 2 & 37 & 4 & 7 & & 14 \\
\hline aldehyde & $\mathrm{CHO}$ & & 1 & 4 & 1 & 1 & 1 & 1 & 4 & 1 & 2 & & 2 \\
\hline ether & $\mathrm{CH}_{n} \mathrm{O}$ & 2 & 7 & 24 & 14 & 4 & 1 & 5 & 45 & 5 & 2 & 1 & 4 \\
\hline ester & Ccoo & & 4 & 14 & 2 & & & 5 & 19 & 4 & 1 & & 1 \\
\hline alkenyl & $C=C$ & 1 & 1 & 4 & 1 & 7 & 1 & 1 & 6 & 1 & 4 & 1 & 4 \\
\hline $\begin{array}{l}\text { aromatic } \\
\text { hydrocarbon }\end{array}$ & $\mathrm{ACH}_{\mathrm{n}}$ & 7 & 8 & 19 & 26 & 4 & 5 & 2 & 40 & 8 & 6 & 1 & 16 \\
\hline $\begin{array}{l}\text { aromatic carbon- } \\
\text { alcohol }\end{array}$ & $\mathrm{ACOH}$ & 3 & 7 & 14 & 24 & 1 & 5 & 1 & 32 & 6 & 4 & & 13 \\
\hline
\end{tabular}

Fig. 8. Distribution of datasets for the determination of organic main group $\leftrightarrow$ ion interaction parameters. The number of different datasets associated with each interaction pair is shown. Percentile-wise coloring based on the number of datasets suggests the degree of confidence (based only on statistical considerations) in the determined interaction parameters: blue (low confidence) to red (high confidence). Main group $\mathrm{CH}_{\mathrm{n}}$ represents here also the specific alkyl main groups $\mathrm{CH}_{\mathrm{n}}^{[\mathrm{alc}]}$ and $\mathrm{CH}_{\mathrm{n}}^{[\mathrm{alc}-\text { tail] }}$, as they share the same main group $\leftrightarrow$ ion interaction parameters.

Powell's hybrid method (Moré et al., 1980, 1984) to find the root of $\mathrm{IAP}_{\mathrm{KCl}}-K_{\mathrm{sp}}(T)=0$ efficiently. If the solid phase is an organic, an analogous procedure is used, by keeping the organic-free mole fraction composition constant and varying the organic amount. Therefore, in case of SLE data, $Q_{d, u}^{\text {ref }}$ is the experimentally determined composition in mole fractions, $Q_{d, u}^{\text {calc }}$ the corresponding mole fractions calculated with AIOMFAC as described above, and $Q_{d, u}^{\mathrm{tol}}=x^{\mathrm{tol}}(=0.01)$.

Some datasets state the solubility limit of an organic compound in aqueous electrolyte solutions that are in equilibrium with an organic-rich liquid phase (e.g., Segatin and Klofutar, 2000). If the condition is true, that virtually no electrolyte is present in the organic-rich liquid phase, such ternary LLEsolubility data can be used analogously to SLE solubility data. This condition is fulfilled only in the case of rather hydrophobic organic compounds, which also exhibit limited solubility in pure water.

\subsection{Electromotive force data}

In EMF measurements, the electric potential difference between two different electrodes in an electrolyte solution (galvanic cell) is recorded as a function of pressure, temperature, and solution composition. Using the modified Nernst equation and a system-specific activity coefficient model, such as a Pitzer model, mean molal activity coefficients $\gamma_{ \pm}$can be calculated from the EMF data at different electrolyte molalities (e.g., Robinson and Stokes, 2002; Roy et al., 1972a; Esteso et al., 1989). Mean molal activity coefficients from
EMF data are derived with the reference state of an infinitely dilute electrolyte solution in the corresponding solvent mixture, while the reference state of electrolytes in AIOMFAC is the infinitely dilute solution in pure water. Hence, to correctly use such EMF $\gamma_{ \pm}$data, we run AIOMFAC in a mode that also refers to the aqueous-organic solvent mixture as reference state. Figure 7 shows such $\gamma_{ \pm}$data and associated model sensitivities for the system water + ethanol $+\mathrm{KCl}$. In case of EMF data, $Q_{d, u}^{\text {ref }}$ and $Q_{d, u}^{\text {calc }}$ are measured and calculated $\gamma_{ \pm}$on molal solvent mixture reference state basis and $Q_{d, u}^{\text {tol }}$ is the corresponding $\gamma_{ \pm}$sensitivity, $s^{\gamma_{ \pm}}$.

\subsection{Database overview}

The nature of the group-contribution concept requires the use of several organic compounds, representing combinations of functional groups in different ratios, to unambiguously attribute interaction contributions to each main group $\leftrightarrow$ ion pair, as discussed in Sect. 3.2. We therefore carried out an extensive literature search to establish the AIOMFAC parameterization database, covering experimental datasets published in the time period from 1896 to 2010 . This included the laborious task of converting many different kinds of concentration scales that have been used by the authors to report their measurements into a consistent set of input data for AIOMFAC. We furthermore conducted selected water activity and solubility measurements to complement the literature data. Tables reporting our own measurements and a 
brief discussion of the experimental methods are presented in Appendix A2.

An overview of the database is given in Table 2, listing for all datasets the corresponding system components and main groups, data type, temperature range of the measurements, number of data points, the assigned initial weighting used in the model fit, and the data source. Overall, the database contains more than 450 different datasets totaling $\sim 10000$ data points, covering 12 different inorganic ions and more than 90 different organic compounds composed of 11 different organic main groups. Table 3 presents selected properties of the organic compounds and their structural representation in terms of UNIFAC/AIOMFAC subgroups.

Figure 8 summarizes the database in terms of number of datasets per main group $\leftrightarrow$ ion interaction pair. The number of different datasets per interaction pair serves as a qualitative estimate of the degree of confidence that can be expected for a certain interaction parameter, shown by the coloring in Fig. 8. Of course, factors like the composition range, experimental and model uncertainties, and counterions and main groups present in a mixture also influence how well a certain main group $\leftrightarrow$ ion interaction pair is constrained by the available data. In a best case scenario, a single dataset covering a wide composition range can be sufficient to constrain a certain main group $\leftrightarrow$ ion interaction parameter, if all other main groups and the counterion present in the mixture are well constrained by other data. Compared to that, in other cases, several similar datasets, covering only a limited composition range, might not reach the same degree of confidence associated with determined interaction parameters, albeit the higher number of datasets.

Apparent gaps and deficiencies in the database concerning the coverage of main group $\leftrightarrow$ ion interaction pairs are due to the lack of experimental data for systems including those interactions. Especially for some of the interactions involving inorganic acids and bromides, this lack of data is explained by the difficulty of conducting experiments with systems in which components may chemically react, e.g., hydration reaction of aldehydes or oxidation of aldehydes in $\mathrm{Br}^{-}$containing solutions.

A relatively high number of datasets contain $\mathrm{Na}^{+}$and/or $\mathrm{Cl}^{-}$ions, and $\mathrm{NaCl}$ is one of the most abundant salts throughout the database. This reflects the importance of $\mathrm{NaCl}$ and other chlorides in chemical process engineering and industrial applications of VLE and LLE for mixture separation purposes, for which many experimental studies have been conducted. From a practical viewpoint regarding new measurements supporting the AIOMFAC parameterization, $\mathrm{NaCl}$ can be considered a reference electrolyte and further measurements can be linked to the well-established main group $\leftrightarrow \mathrm{Na}^{+} / \mathrm{Cl}^{-}$interaction contributions by using different counterions combined with $\mathrm{Na}^{+}$or $\mathrm{Cl}^{-}$in otherwise identical systems. This way, the AIOMFAC model can be extended in the future without the necessity for a simultaneous fit of all interaction parameters.

\section{Results and Discussion}

\subsection{New and revised aqueous electrolyte systems}

\subsection{1 $\mathrm{CaBr}_{2}, \mathrm{MgBr}_{2}$, and $\mathrm{CaSO}_{4}$}

Zuend et al. (2008) did not determine all bromide interaction parameters in the original AIOMFAC model. Here we consider the binary bromide systems water $+\mathrm{CaBr}_{2}$ and water $+\mathrm{MgBr}_{2}$ and the sulfate system water $+\mathrm{CaSO}_{4}$. In order to complete the parameter matrix in this respect, we determined the cation $\leftrightarrow$ anion interaction parameters $b_{c, a}^{(1)}, b_{c, a}^{(2)}$, $b_{c, a}^{(3)}, c_{c, a}^{(1)}$, and $c_{c, a}^{(2)}$ for these systems using the experimental datasets listed in Table 4. Resulting middle-range interaction parameters are given in Table 5. The addition of these binary interaction coefficients enables the use of $\mathrm{CaBr}_{2}$ - and $\mathrm{MgBr}_{2}$-containing organic-inorganic mixture data for the fit of main group $\leftrightarrow$ ion interactions. Figure 9 shows the calculated water activity and molal mean activity coefficients of the bromide systems in comparison with the experimental data used in the AIOMFAC fit. As for most binary aqueous electrolyte systems, the agreement between AIOMFAC and the measurements is excellent and the extrapolation to high ionic strength (low water content/RH), where experimental data are lacking, appears to behave in a physically reasonable manner.

\subsubsection{Revised implementation of $\mathrm{NH}_{4}^{+}\left|\mathrm{H}^{+}\right| \mathrm{HSO}_{4}^{-} \mid$ $\mathrm{SO}_{4}^{2-}$ interactions}

Due to an erroneous implementation of the $R_{c, c^{\prime}}$ term of Eq. (4) in the previous AIOMFAC source code, the reported values of $R_{\mathrm{NH}_{4}^{+}, \mathrm{H}^{+}}$in Zuend et al. (2008) led to larger deviations at high concentrations in the water + sulfuric acid +ammonium sulfate system. Although this does not directly affect the binary water + sulfuric acid system, we revised related interaction parameters involved in the water + sulfuric acid + ammonium bisulfate system to ensure accurate model calculations for different molar mixing ratios of $\left(\mathrm{NH}_{4}\right)_{2} \mathrm{SO}_{4}: \mathrm{H}_{2} \mathrm{SO}_{4}$. The redetermined parameters are given in Tables 5 and 6 . The experimental datasets used in the revision of these parameters are listed in Table 4. The new AIOMFAC parameterization and measurements for this system with different $\left(\mathrm{NH}_{4}\right)_{2} \mathrm{SO}_{4}: \mathrm{H}_{2} \mathrm{SO}_{4}$ mixing ratios $(3: 1$, $2: 1,1: 1,1: 2$, and $0: 1$ ) are shown in Fig. 10.

\subsection{Extended set of main group $\leftrightarrow$ ion interaction parameters}

The $\sim 250$ middle-range main group $\leftrightarrow$ ion interaction parameters $b_{k, i}^{(1)}$ and $b_{k, i}^{(2)}$ (Eq. 5) have been determined by a simultaneous AIOMFAC fit to the whole database using the global optimization methods described in Appendix A1. Table 7 reports the parameters organized in the form of an interaction matrix as done in Fig. 8. While Table 7 provides the numerical values for each main group $\leftrightarrow$ ion interaction 
Table 2. Components, main groups, temperature range, number of data points $\left(N_{d}\right)$, initial weighting ( $\left.w_{d}^{\text {init }}\right)$ and references of "water + organic + inorganic salt/acid" datasets used for the middle-range parameterization of organic main group $\leftrightarrow$ ion interactions .

\begin{tabular}{|c|c|c|c|c|c|c|c|}
\hline Organic compounds ${ }^{a}$ & Org. main groups ${ }^{b}$ & Inorg. salts/acids & $T(\mathrm{~K})$ & Data type ${ }^{\mathrm{c}}$ & $N_{d}$ & $w_{d}^{\text {init }}$ & Reference \\
\hline \multicolumn{8}{|c|}{ - water + alcohol/polyol/sugar + salt/acid systems -} \\
\hline ethanol & $\mathrm{CH}_{\mathrm{n}}, \mathrm{CH}_{\mathrm{n}}^{[\mathrm{OH}]}, \mathrm{OH}$ & $\left(\mathrm{NH}_{4}\right)_{2} \mathrm{SO}_{4}$ & 298 & LLE & 6 & 0.30 & Wang et al. (2010) \\
\hline 2-propanol & $\mathrm{CH}_{\mathrm{n}}, \mathrm{CH}_{\mathrm{n}}^{[\mathrm{OH}]}, \mathrm{OH}$ & $\left(\mathrm{NH}_{4}\right)_{2} \mathrm{SO}_{4}$ & 298 & LLE & 4 & 1.00 & Sun et al. (2009) \\
\hline tert-butanol & $\mathrm{CH}_{\mathrm{n}}, \mathrm{CH}_{\mathrm{n}}^{[\mathrm{OH}]}, \mathrm{OH}$ & $\left(\mathrm{NH}_{4}\right)_{2} \mathrm{SO}_{4}$ & 298 & LLE & 1 & 1.00 & Kiss and Borbas (2003) \\
\hline glycerol & $\mathrm{CH}_{\mathrm{n}}^{[\mathrm{OH}]}, \mathrm{OH}$ & $\left(\mathrm{NH}_{4}\right)_{2} \mathrm{SO}_{4}$ & 298 & $a_{\mathrm{w}}($ bulk $)$ & 10 & 2.00 & Marcolli and Krieger (2006) \\
\hline 1,2,4-butanetriol & $\mathrm{CH}_{\mathrm{n}}, \mathrm{CH}_{\mathrm{n}}^{[\mathrm{OH}]}, \mathrm{OH}$ & $\left(\mathrm{NH}_{4}\right)_{2} \mathrm{SO}_{4}$ & 298 & $a_{\mathrm{w}}($ bulk $)$ & 9 & 2.00 & Zuend et al. (2008) \\
\hline 1,2-butanediol & $\mathrm{CH}_{\mathrm{n}}, \mathrm{CH}_{\mathrm{n}}^{[\mathrm{OH}]}, \mathrm{OH}$ & $\left(\mathrm{NH}_{4}\right)_{2} \mathrm{SO}_{4}$ & 298 & $a_{\mathrm{w}}($ bulk) & 8 & 2.00 & Zuend et al. (2008) \\
\hline 1,4-butanediol & $\mathrm{CH}_{\mathrm{n}}, \mathrm{CH}_{\mathrm{n}}^{[\mathrm{OH}]}, \mathrm{OH}$ & $\left(\mathrm{NH}_{4}\right)_{2} \mathrm{SO}_{4}$ & 298 & $a_{\mathrm{w}}($ bulk $)$ & 12 & 2.00 & Marcolli and Krieger (2006) \\
\hline 2,4-pentanediol & $\mathrm{CH}_{\mathrm{n}}, \mathrm{CH}_{\mathrm{n}}^{[\mathrm{OH}]}, \mathrm{OH}$ & $\left(\mathrm{NH}_{4}\right)_{2} \mathrm{SO}_{4}$ & 298 & $a_{\mathrm{w}}($ bulk $)$ & 10 & 2.00 & Zuend et al. (2008) \\
\hline 1,2-hexanediol & $\mathrm{CH}_{\mathrm{n}}, \mathrm{CH}_{\mathrm{n}}^{[\mathrm{OH}]}, \mathrm{OH}$ & $\left(\mathrm{NH}_{4}\right)_{2} \mathrm{SO}_{4}$ & 298 & $a_{\mathrm{w}}($ bulk $)$ & 12 & 2.00 & Marcolli and Krieger (2006) \\
\hline 2,5-hexanediol & $\mathrm{CH}_{\mathrm{n}}, \mathrm{CH}_{\mathrm{n}}^{[\mathrm{OH}]}, \mathrm{OH}$ & $\left(\mathrm{NH}_{4}\right)_{2} \mathrm{SO}_{4}$ & 298 & $a_{\mathrm{w}}($ bulk $)$ & 8 & 2.00 & Zuend et al. (2008) \\
\hline 1,7-heptanediol & $\mathrm{CH}_{\mathrm{n}}, \mathrm{CH}_{\mathrm{n}}^{[\mathrm{OH}]}, \mathrm{OH}$ & $\left(\mathrm{NH}_{4}\right)_{2} \mathrm{SO}_{4}$ & 298 & $a_{\mathrm{w}}($ bulk $)$ & 9 & 2.00 & Zuend et al. (2008) \\
\hline glycerol & $\mathrm{CH}_{\mathrm{n}}^{[\mathrm{OH}]}, \mathrm{OH}$ & $\left(\mathrm{NH}_{4}\right)_{2} \mathrm{SO}_{4}$ & 298 & SLE & 9 & 1.00 & Marcolli and Krieger (2006) \\
\hline 1,4-butanediol & $\mathrm{CH}_{\mathrm{n}}, \mathrm{CH}_{\mathrm{n}}^{[\mathrm{OH}]}, \mathrm{OH}$ & $\left(\mathrm{NH}_{4}\right)_{2} \mathrm{SO}_{4}$ & 298 & SLE & 6 & 1.00 & Marcolli and Krieger (2006) \\
\hline 1,2-hexanediol & $\mathrm{CH}_{\mathrm{n}}, \mathrm{CH}_{\mathrm{n}}^{[\mathrm{OH}]}, \mathrm{OH}$ & $\left(\mathrm{NH}_{4}\right)_{2} \mathrm{SO}_{4}$ & 298 & SLE & 2 & 1.00 & Marcolli and Krieger (2006) \\
\hline levoglucosan & $\mathrm{CH}_{\mathrm{n}}, \mathrm{CH}_{\mathrm{n}}^{[\mathrm{OH}]}, \mathrm{OH}, \mathrm{CH}_{\mathrm{n}} \mathrm{O}$ & $\left(\mathrm{NH}_{4}\right)_{2} \mathrm{SO}_{4}$ & 291 & $a_{\mathrm{w}}(\mathrm{EDB})$ & 89 & 1.00 & Lienhard et al. (2011) \\
\hline 1-propanol & $\mathrm{CH}_{\mathrm{n}}, \mathrm{CH}_{\mathrm{n}}^{[\mathrm{OH}]}, \mathrm{OH}$ & $\mathrm{Ca}\left(\mathrm{NO}_{3}\right)_{2}$ & $362-372$ & VLE & 15 & 0.05 & Miro and Gonzalez (1958) \\
\hline 2-propanol & $\mathrm{CH}_{\mathrm{n}}, \mathrm{CH}_{\mathrm{n}}^{[\mathrm{OH}]}, \mathrm{OH}$ & $\mathrm{Ca}\left(\mathrm{NO}_{3}\right)_{2}$ & $355-361$ & VLE & 23 & 0.05 & Miro and Gonzalez (1958) \\
\hline ethanol & $\mathrm{CH}_{\mathrm{n}}, \mathrm{CH}_{\mathrm{n}}^{[\mathrm{OH}]}, \mathrm{OH}$ & $\mathrm{Ca}\left(\mathrm{NO}_{3}\right)_{2}$ & $335-356$ & VLE & 42 & 0.50 & Polka and Gmehling (1994) \\
\hline 2-propanol & $\mathrm{CH}_{\mathrm{n}}, \mathrm{CH}_{\mathrm{n}}^{[\mathrm{OH}]}, \mathrm{OH}$ & $\mathrm{Ca}\left(\mathrm{NO}_{3}\right)_{2}$ & $335-354$ & VLE & 41 & 0.50 & Polka and Gmehling (1994) \\
\hline ethanol & $\mathrm{CH}_{\mathrm{n}}, \mathrm{CH}_{\mathrm{n}}^{[\mathrm{OH}]}, \mathrm{OH}$ & $\mathrm{CaCl}_{2}$ & $307-321$ & VLE & 13 & 0.50 & Meyer et al. (1991) \\
\hline 2-propanol & $\mathrm{CH}_{\mathrm{n}}, \mathrm{CH}_{\mathrm{n}}^{[\mathrm{OH}]}, \mathrm{OH}$ & $\mathrm{CaCl}_{2}$ & $354-356$ & VLE & 12 & 0.50 & Kato et al. (1971) \\
\hline 2-propanol & $\mathrm{CH}_{\mathrm{n}}, \mathrm{CH}_{\mathrm{n}}^{[\mathrm{OH}]}, \mathrm{OH}$ & $\mathrm{CaCl}_{2}$ & $356-368$ & VLE & 42 & 0.00 & Rajendran et al. (1991) \\
\hline 2-propanol & $\mathrm{CH}_{\mathrm{n}}, \mathrm{CH}_{\mathrm{n}}^{[\mathrm{OH}]}, \mathrm{OH}$ & $\mathrm{CaCl}_{2}$ & 348 & VLE & 18 & 0.50 & Sada et al. (1975a) \\
\hline 1-propanol (water-free) & $\mathrm{CH}_{\mathrm{n}}, \mathrm{CH}_{\mathrm{n}}^{[\mathrm{OH}]}, \mathrm{OH}$ & $\mathrm{CaCl}_{2}$ & $361-372$ & VLE(org) & 40 & 0.01 & $\mathrm{Fu}(2005)$ \\
\hline 2-propanol (water-free) & $\mathrm{CH}_{\mathrm{n}}, \mathrm{CH}_{\mathrm{n}}^{[\mathrm{OH}]}, \mathrm{OH}$ & $\mathrm{CaCl}_{2}$ & $347-357$ & VLE(org) & 40 & 0.01 & $\mathrm{Fu}(2005)$ \\
\hline 1-butanol (water-free) & $\mathrm{CH}_{\mathrm{n}}, \mathrm{CH}_{\mathrm{n}}^{[\mathrm{OH}]}, \mathrm{OH}$ & $\mathrm{CaCl}_{2}$ & 374-392 & VLE(org) & 40 & 0.01 & $\mathrm{Fu}(2005)$ \\
\hline isobutanol (water-free) & $\mathrm{CH}_{\mathrm{n}}, \mathrm{CH}_{\mathrm{n}}^{[\mathrm{OH}]}, \mathrm{OH}$ & $\mathrm{CaCl}_{2}$ & $374-392$ & VLE(org) & 30 & 0.01 & $\mathrm{Fu}(2005)$ \\
\hline ethanol, 3-methyl-1-butanol & $\mathrm{CH}_{\mathrm{n}}, \mathrm{CH}_{\mathrm{n}}^{[\mathrm{OH}]}, \mathrm{OH}$ & $\mathrm{CaCl}_{2}$ & 298 & LLE & 6 & 1.00 & Aznar et al. (2000) \\
\hline ethanol, 1-butanol & $\mathrm{CH}_{\mathrm{n}}, \mathrm{CH}_{\mathrm{n}}^{[\mathrm{OH}]}, \mathrm{OH}$ & $\mathrm{CaCl}_{2}$ & 298 & LLE & 6 & 1.00 & Aznar et al. (2000) \\
\hline D-mannopyranose & $\mathrm{CH}_{\mathrm{n}}^{[\mathrm{OH}]}, \mathrm{OH}, \mathrm{CH}_{\mathrm{n}} \mathrm{O}$ & $\mathrm{CaCl}_{2}$ & 298 & $\gamma_{ \pm}$ & 40 & 2.00 & Yang et al. (2004) \\
\hline D-ribofuranose & $\mathrm{CH}_{\mathrm{n}}^{[\mathrm{OH}]}, \mathrm{OH}, \mathrm{CH}_{\mathrm{n}} \mathrm{O}$ & $\mathrm{CaCl}_{2}$ & 298 & $\gamma_{ \pm}$ & 40 & 2.00 & Yang et al. (2004) \\
\hline 2-propanol (water-free) & $\mathrm{CH}_{\mathrm{n}}, \mathrm{CH}_{\mathrm{n}}^{[\mathrm{OH}]}, \mathrm{OH}$ & $\mathrm{HCl}$ & 298 & $\gamma_{ \pm}$ & 5 & 2.00 & Roy et al. (1972b) \\
\hline 1-propanol (water-free) & $\mathrm{CH}_{\mathrm{n}}, \mathrm{CH}_{\mathrm{n}}^{[\mathrm{OH}]}, \mathrm{OH}$ & $\mathrm{HCl}$ & 298 & $\gamma_{ \pm}$ & 7 & 2.00 & Roy et al. (1971d) \\
\hline 2-propanol & $\mathrm{CH}_{\mathrm{n}}, \mathrm{CH}_{\mathrm{n}}^{[\mathrm{OH}]}, \mathrm{OH}$ & $\mathrm{HCl}$ & 298 & $\gamma_{ \pm}$ & 8 & 2.00 & Roy et al. (1971a) \\
\hline glycerol & $\mathrm{CH}_{\mathrm{n}}^{[\mathrm{OH}]}, \mathrm{OH}$ & $\mathrm{HCl}$ & 298 & $\gamma_{ \pm}$ & 11 & 2.00 & Roy et al. (1971b) \\
\hline glycerol & $\mathrm{CH}_{\mathrm{n}}^{[\mathrm{OH}]}, \mathrm{OH}$ & $\mathrm{HCl}$ & 298 & $\gamma_{ \pm}$ & 22 & 2.00 & Knight et al. (1953) \\
\hline 1-butanol & $\mathrm{CH}_{\mathrm{n}}, \mathrm{CH}_{\mathrm{n}}^{[\mathrm{OH}]}, \mathrm{OH}$ & $\mathrm{HCl}$ & 298 & $\gamma_{ \pm}$ & 7 & 2.00 & Roy et al. (1972a) \\
\hline tert-butanol & $\mathrm{CH}_{\mathrm{n}}, \mathrm{CH}_{\mathrm{n}}^{[\mathrm{OH}]}, \mathrm{OH}$ & $\mathrm{HCl}$ & 298 & $\gamma_{ \pm}$ & 23 & 2.00 & Roy et al. (1971c) \\
\hline ethanol & $\mathrm{CH}_{\mathrm{n}}, \mathrm{CH}_{\mathrm{n}}^{[\mathrm{OH}]}, \mathrm{OH}$ & $\mathrm{HCl}$ & 298 & $\gamma_{ \pm}$ & 119 & 2.00 & $\begin{array}{l}\text { Deyhimi and Karimzadeh } \\
\text { (2009) }\end{array}$ \\
\hline 2-propanol & $\mathrm{CH}_{\mathrm{n}}, \mathrm{CH}_{\mathrm{n}}^{[\mathrm{OH}]}, \mathrm{OH}$ & $\mathrm{HCl}$ & 298 & $\gamma_{ \pm}$ & 104 & 2.00 & $\begin{array}{l}\text { Deyhimi and Karimzadeh } \\
\text { (2010) }\end{array}$ \\
\hline ethanol & $\mathrm{CH}_{\mathrm{n}}, \mathrm{CH}_{\mathrm{n}}^{[\mathrm{OH}]}, \mathrm{OH}$ & $\mathrm{K}_{2} \mathrm{SO}_{4}$ & 298 & SLE & 12 & 1.00 & Fox and Gauge (1910) \\
\hline 1-propanol & $\mathrm{CH}_{\mathrm{n}}, \mathrm{CH}_{\mathrm{n}}^{[\mathrm{OH}]}, \mathrm{OH}$ & $\mathrm{K}_{2} \mathrm{SO}_{4}$ & 298 & SLE & 16 & 1.00 & Taboada et al. (2002) \\
\hline 2-propanol & $\mathrm{CH}_{\mathrm{n}}, \mathrm{CH}_{\mathrm{n}}^{[\mathrm{OH}]}, \mathrm{OH}$ & $\mathrm{K}_{2} \mathrm{SO}_{4}$ & 303 & SLE & 13 & 1.00 & Mydlarz et al. (1989) \\
\hline 2-propanol & $\mathrm{CH}_{\mathrm{n}}, \mathrm{CH}_{\mathrm{n}}^{[\mathrm{OH}]}, \mathrm{OH}$ & $\mathrm{K}_{2} \mathrm{SO}_{4}$ & 293 & SLE & 11 & 0.80 & Mydlarz et al. (1989) \\
\hline ethanol, 1-pentanol & $\mathrm{CH}_{\mathrm{n}}, \mathrm{CH}_{\mathrm{n}}^{[\mathrm{OH}]}, \mathrm{OH}$ & $\mathrm{K}_{2} \mathrm{SO}_{4}$ & 298 & LLE & 10 & 1.00 & Aznar et al. (2000) \\
\hline 1-butanol & $\mathrm{CH}_{\mathrm{n}}, \mathrm{CH}_{\mathrm{n}}^{[\mathrm{OH}]}, \mathrm{OH}$ & $\mathrm{KBr}$ & 298 & LLE & 10 & 1.00 & Li et al. (1995) \\
\hline 1-propanol & $\mathrm{CH}_{\mathrm{n}}, \mathrm{CH}_{\mathrm{n}}^{[\mathrm{OH}]}, \mathrm{OH}$ & $\mathrm{KBr}$ & $359-362$ & VLE & 30 & 0.05 & Morrison et al. (1990) \\
\hline ethanol & $\mathrm{CH}_{\mathrm{n}}, \mathrm{CH}_{\mathrm{n}}^{[\mathrm{OH}]}, \mathrm{OH}$ & $\mathrm{KBr}$ & $354-357$ & VLE & 36 & 0.50 & Burns and Furter (1975) \\
\hline ethanol & $\mathrm{CH}_{\mathrm{n}}, \mathrm{CH}_{\mathrm{n}}^{[\mathrm{OH}]}, \mathrm{OH}$ & $\mathrm{KBr}$ & 303 & SLE & 11 & 0.10 & Taylor (1897) \\
\hline 1-butanol & $\mathrm{CH}_{\mathrm{n}}, \mathrm{CH}_{\mathrm{n}}^{[\mathrm{OH}]}, \mathrm{OH}$ & $\mathrm{KBr}$ & 298 & LLE & 11 & 1.00 & $\begin{array}{l}\text { Al-Sahhaf and Kapetanovic } \\
\text { (1997) }\end{array}$ \\
\hline tert-butanol, 1-butanol & $\mathrm{CH}_{\mathrm{n}}, \mathrm{CH}_{\mathrm{n}}^{[\mathrm{OH}]}, \mathrm{OH}$ & $\mathrm{KBr}$ & 293 & LLE & 14 & 1.00 & Pereira and Aznar (2006) \\
\hline tert-butanol, 1-butanol & $\mathrm{CH}_{\mathrm{n}}, \mathrm{CH}_{\mathrm{n}}^{[\mathrm{OH}]}, \mathrm{OH}$ & $\mathrm{KBr}$ & 313 & LLE & 5 & 1.00 & Pereira and Aznar (2006) \\
\hline
\end{tabular}


Table 2. Continued.

\begin{tabular}{|c|c|c|c|c|c|c|c|}
\hline Organic compounds ${ }^{\text {a }}$ & Org. main groups ${ }^{b}$ & Inorg. salts/acids & $T(\mathrm{~K})$ & Data type ${ }^{c}$ & $N_{d}$ & $w_{d}^{\text {init }}$ & Reference \\
\hline ethanol, 1-pentanol & $\mathrm{CH}_{\mathrm{n}}, \mathrm{OH}$ & $\mathrm{KBr}$ & 298 & LLE & 20 & 1.00 & Aznar et al. (2000) \\
\hline ethanol & $\mathrm{CH}_{\mathrm{n}}, \mathrm{CH}_{\mathrm{n}}^{[\mathrm{OH}]}, \mathrm{OH}$ & $\mathrm{KCl}$ & $350-369$ & VLE & 11 & 0.50 & Johnson and Furter (1965) \\
\hline 1-propanol & $\mathrm{CH}_{\mathrm{n}}, \mathrm{CH}_{\mathrm{n}}^{[\mathrm{OH}]}, \mathrm{OH}$ & $\mathrm{KCl}$ & $361-372$ & VLE & 8 & 0.50 & Johnson and Furter (1965) \\
\hline 1-propanol & $\mathrm{CH}_{\mathrm{n}}, \mathrm{CH}_{\mathrm{n}}^{[\mathrm{OH}]}, \mathrm{OH}$ & $\mathrm{KCl}$ & $360-363$ & VLE & 32 & 0.50 & Lin et al. (1993) \\
\hline 1-butanol & $\mathrm{CH}_{\mathrm{n}}, \mathrm{CH}_{\mathrm{n}}^{[\mathrm{OH}]}, \mathrm{OH}$ & $\mathrm{KCl}$ & 298 & LLE & 8 & 1.00 & Li et al. (1995) \\
\hline 1-propanol & $\mathrm{CH}_{\mathrm{n}}, \mathrm{CH}_{\mathrm{n}}^{[\mathrm{OH}]}, \mathrm{OH}$ & $\mathrm{KCl}$ & 298 & LLE & 9 & 1.00 & Chou et al. (1998) \\
\hline 1-propanol & $\mathrm{CH}_{\mathrm{n}}, \mathrm{CH}_{\mathrm{n}}^{[\mathrm{OH}]}, \mathrm{OH}$ & $\mathrm{KCl}$ & 298 & LLE & 4 & 1.00 & Gomis et al. (1996) \\
\hline 1-butanol & $\mathrm{CH}_{\mathrm{n}}, \mathrm{CH}_{\mathrm{n}}^{[\mathrm{OH}]}, \mathrm{OH}$ & $\mathrm{KCl}$ & 298 & LLE & 9 & 1.00 & Gomis et al. (1996) \\
\hline 2-butanol & $\mathrm{CH}_{\mathrm{n}}, \mathrm{CH}_{\mathrm{n}}^{[\mathrm{OH}]}, \mathrm{OH}$ & $\mathrm{KCl}$ & 298 & LLE & 9 & 1.00 & Gomis et al. (1996) \\
\hline isobutanol & $\mathrm{CH}_{\mathrm{n}}, \mathrm{CH}_{\mathrm{n}}^{[\mathrm{OH}]}, \mathrm{OH}$ & $\mathrm{KCl}$ & 298 & LLE & 9 & 1.00 & Gomis et al. (1996) \\
\hline ethanol & $\mathrm{CH}_{\mathrm{n}}, \mathrm{CH}_{\mathrm{n}}^{[\mathrm{OH}]}, \mathrm{OH}$ & $\mathrm{KCl}$ & 298 & $\gamma_{ \pm}$ & 60 & 2.00 & Lopes et al. (1999) \\
\hline ethanol, 1-pentanol & $\mathrm{CH}_{\mathrm{n}}, \mathrm{CH}_{\mathrm{n}}^{[\mathrm{OH}]}, \mathrm{OH}$ & $\mathrm{KCl}$ & 298 & LLE & 19 & 1.00 & Aznar et al. (2000) \\
\hline 1,2-ethanediol & $\mathrm{CH}_{\mathrm{n}}, \mathrm{CH}_{\mathrm{n}}^{[\mathrm{OH}]}, \mathrm{OH}$ & $\mathrm{KCl}$ & 298 & $\gamma_{ \pm}$ & 96 & 2.00 & Ma et al. (2010) \\
\hline ethanol & $\mathrm{CH}_{\mathrm{n}}, \mathrm{CH}_{\mathrm{n}}^{[\mathrm{OH}]}, \mathrm{OH}$ & $\mathrm{KNO}_{3}$ & $351-369$ & VLE & 8 & 0.50 & $\begin{array}{l}\text { Rieder and Thompson } \\
(1950)\end{array}$ \\
\hline ethanol & $\mathrm{CH}_{\mathrm{n}}, \mathrm{CH}_{\mathrm{n}}^{[\mathrm{OH}]}, \mathrm{OH}$ & $\mathrm{KNO}_{3}$ & $351-364$ & VLE & 49 & 0.50 & Vercher et al. (1996) \\
\hline ethanol & $\mathrm{CH}_{\mathrm{n}}, \mathrm{CH}_{\mathrm{n}}^{[\mathrm{OH}]}, \mathrm{OH}$ & $\mathrm{KNO}_{3}$ & 303 & SLE & 10 & 1.00 & Bathrick (1896) \\
\hline 1-propanol & $\mathrm{CH}_{\mathrm{n}}, \mathrm{CH}_{\mathrm{n}}^{[\mathrm{OH}]}, \mathrm{OH}$ & $\mathrm{Li}_{2} \mathrm{SO}_{4}$ & 298 & LLE & 5 & 1.00 & Taboada (2003) \\
\hline ethanol & $\mathrm{CH}_{\mathrm{n}}, \mathrm{CH}_{\mathrm{n}}^{[\mathrm{OH}]}, \mathrm{OH}$ & $\mathrm{LiBr}$ & 333 & VLE & 19 & 0.05 & Rudakoff et al. (1972) \\
\hline 2-propanol & $\mathrm{CH}_{\mathrm{n}}, \mathrm{CH}_{\mathrm{n}}^{[\mathrm{OH}]}, \mathrm{OH}$ & $\mathrm{LiBr}$ & 348 & VLE & 18 & 0.50 & Sada et al. (1975a) \\
\hline 2-propanol & $\mathrm{CH}_{\mathrm{n}}, \mathrm{CH}_{\mathrm{n}}^{[\mathrm{OH}]}, \mathrm{OH}$ & $\mathrm{LiBr}$ & $353-357$ & VLE & 28 & 0.50 & Lin et al. (1993) \\
\hline ethanol & $\mathrm{CH}_{\mathrm{n}}, \mathrm{CH}_{\mathrm{n}}^{[\mathrm{OH}]}, \mathrm{OH}$ & $\mathrm{LiCl}$ & 298 & $\gamma_{ \pm}$ & 42 & 2.00 & Hu et al. (2008) \\
\hline ethanol & $\mathrm{CH}_{\mathrm{n}}, \mathrm{CH}_{\mathrm{n}}^{[\mathrm{OH}]}, \mathrm{OH}$ & $\mathrm{LiCl}$ & 298 & $\gamma_{ \pm}$ & 64 & 2.00 & Hernandez-Luis et al. (2008) \\
\hline 2-propanol & $\mathrm{CH}_{\mathrm{n}}, \mathrm{CH}_{\mathrm{n}}^{[\mathrm{OH}]}, \mathrm{OH}$ & $\mathrm{LiCl}$ & 348 & VLE & 26 & 0.50 & Sada et al. (1975a) \\
\hline 2-propanol & $\mathrm{CH}_{\mathrm{n}}, \mathrm{CH}_{\mathrm{n}}^{[\mathrm{OH}]}, \mathrm{OH}$ & $\mathrm{LiCl}$ & $353-357$ & VLE & 28 & 0.50 & Lin et al. (1993) \\
\hline 1-butanol & $\mathrm{CH}_{\mathrm{n}}, \mathrm{CH}_{\mathrm{n}}^{[\mathrm{OH}]}, \mathrm{OH}$ & $\mathrm{LiCl}$ & 298 & LLE & 17 & 0.10 & $\begin{array}{l}\text { Al-Sahhaf and Kapetanovic } \\
\text { (1997) }\end{array}$ \\
\hline tert-butanol & $\mathrm{CH}_{\mathrm{n}}, \mathrm{CH}_{\mathrm{n}}^{[\mathrm{OH}]}, \mathrm{OH}$ & $\mathrm{LiCl}$ & 298 & LLE & 10 & 0.10 & Gomis et al. (2008) \\
\hline 1-pentanol & $\mathrm{CH}_{\mathrm{n}}, \mathrm{CH}_{\mathrm{n}}^{[\mathrm{OH}]}, \mathrm{OH}$ & $\mathrm{LiCl}$ & 298 & LLE & 9 & 0.10 & Gomis et al. (2004) \\
\hline 2-pentanol & $\mathrm{CH}_{\mathrm{n}}, \mathrm{CH}_{\mathrm{n}}^{[\mathrm{OH}]}, \mathrm{OH}$ & $\mathrm{LiCl}$ & 298 & LLE & 9 & 0.10 & Gomis et al. (2004) \\
\hline 3-pentanol & $\mathrm{CH}_{\mathrm{n}}, \mathrm{CH}_{\mathrm{n}}^{[\mathrm{OH}]}, \mathrm{OH}$ & $\mathrm{LiCl}$ & 298 & LLE & 9 & 0.10 & Gomis et al. (2004) \\
\hline 2-methyl-1-butanol & $\mathrm{CH}_{\mathrm{n}}, \mathrm{CH}_{\mathrm{n}}^{[\mathrm{OH}]}, \mathrm{OH}$ & $\mathrm{LiCl}$ & 298 & LLE & 9 & 0.10 & Gomis et al. (2004) \\
\hline 2-methyl-2-butanol & $\mathrm{CH}_{\mathrm{n}}, \mathrm{CH}_{\mathrm{n}}^{[\mathrm{OH}]}, \mathrm{OH}$ & $\mathrm{LiCl}$ & 298 & LLE & 9 & 0.10 & Gomis et al. (2004) \\
\hline ethanol, (water-free) & $\mathrm{CH}_{\mathrm{n}}, \mathrm{CH}_{\mathrm{n}}^{[\mathrm{OH}]}, \mathrm{OH}$ & $\mathrm{LiNO}_{3}$ & 298 & VLE(org) & 10 & 0.50 & Verevkin et al. (2006) \\
\hline 1-propanol, (water-free) & $\mathrm{CH}_{\mathrm{n}}, \mathrm{CH}_{\mathrm{n}}^{[\mathrm{OH}]}, \mathrm{OH}$ & $\mathrm{LiNO}_{3}$ & $370-374$ & VLE(org) & 17 & 0.50 & Vercher et al. (2002) \\
\hline 1-propanol & $\mathrm{CH}_{\mathrm{n}}, \mathrm{CH}_{\mathrm{n}}^{[\mathrm{OH}]}, \mathrm{OH}$ & $\mathrm{LiNO}_{3}$ & $361-374$ & VLE & 103 & 0.50 & Vercher et al. (2002) \\
\hline 2-propanol & $\mathrm{CH}_{\mathrm{n}}, \mathrm{CH}_{\mathrm{n}}^{[\mathrm{OH}]}, \mathrm{OH}$ & $\mathrm{MgBr}_{2}$ & $353-359$ & VLE & 33 & 0.50 & Gironi and Lamberti (1995) \\
\hline 1,3-nonanediol & $\mathrm{CH}_{\mathrm{n}}, \mathrm{OH}$ & $\mathrm{MgCl}_{2}$ & 298 & LLE & 1 & 1.00 & Putnin' et al. (1974) \\
\hline 2-propanol & $\mathrm{CH}_{\mathrm{n}}, \mathrm{CH}_{\mathrm{n}}^{[\mathrm{OH}]}, \mathrm{OH}$ & $\mathrm{MgCl}_{2}$ & 313 & SLE & 5 & 0.50 & Balaban and Kuranov (1999) \\
\hline 2-propanol & $\mathrm{CH}_{\mathrm{n}}, \mathrm{CH}_{\mathrm{n}}^{[\mathrm{OH}]}, \mathrm{OH}$ & $\mathrm{MgCl}_{2}$ & 313 & SLE & 9 & 0.01 & Balaban and Kuranov (1999) \\
\hline 2-propanol & $\mathrm{CH}_{\mathrm{n}}, \mathrm{CH}_{\mathrm{n}}^{[\mathrm{OH}]}, \mathrm{OH}$ & $\mathrm{MgCl}_{2}$ & 313 & SLE & 7 & 0.01 & Balaban and Kuranov (1999) \\
\hline 2-propanol & $\mathrm{CH}_{\mathrm{n}}, \mathrm{CH}_{\mathrm{n}}^{[\mathrm{OH}]}, \mathrm{OH}$ & $\mathrm{MgCl}_{2}$ & $353-370$ & VLE & 72 & 0.50 & Gironi and Lamberti (1995) \\
\hline tert-butanol, 1-butanol & $\mathrm{CH}_{\mathrm{n}}, \mathrm{CH}_{\mathrm{n}}^{[\mathrm{OH}]}, \mathrm{OH}$ & $\mathrm{MgCl}_{2}$ & 293 & LLE & 14 & 1.00 & Pereira and Aznar (2006) \\
\hline tert-butanol, 1-butanol & $\mathrm{CH}_{\mathrm{n}}, \mathrm{CH}_{\mathrm{n}}^{[\mathrm{OH}]}, \mathrm{OH}$ & $\mathrm{MgCl}_{2}$ & 313 & LLE & 14 & 0.80 & Pereira and Aznar (2006) \\
\hline 2-propanol & $\mathrm{CH}_{\mathrm{n}}, \mathrm{CH}_{\mathrm{n}}^{[\mathrm{OH}]}, \mathrm{OH}$ & $\mathrm{MgCl}_{2}, \mathrm{CaCl}_{2}$ & 313 & VLE & 38 & 0.50 & Balaban and Kuranov (2002) \\
\hline ethanol & $\mathrm{CH}_{\mathrm{n}}, \mathrm{CH}_{\mathrm{n}}^{[\mathrm{OH}]}, \mathrm{OH}$ & $\mathrm{MgSO}_{4}$ & 298 & SLE & 11 & 0.50 & $\begin{array}{l}\text { Zafarani-Moattar and } \\
\text { Salabat (1997) }\end{array}$ \\
\hline 1-propanol & $\mathrm{CH}_{\mathrm{n}}, \mathrm{CH}_{\mathrm{n}}^{[\mathrm{OH}]}, \mathrm{OH}$ & $\mathrm{MgSO}_{4}$ & 298 & LLE & 6 & 1.00 & $\begin{array}{l}\text { Zafarani-Moattar and } \\
\text { Salabat (1997) }\end{array}$ \\
\hline 2-propanol & $\mathrm{CH}_{\mathrm{n}}, \mathrm{CH}_{\mathrm{n}}^{[\mathrm{OH}]}, \mathrm{OH}$ & $\mathrm{MgSO}_{4}$ & 298 & LLE & 5 & 0.50 & $\begin{array}{l}\text { Zafarani-Moattar and } \\
\text { Salabat (1997) }\end{array}$ \\
\hline tert-butanol & $\mathrm{CH}_{\mathrm{n}}, \mathrm{CH}_{\mathrm{n}}^{[\mathrm{OH}]}, \mathrm{OH}$ & $\mathrm{MgSO}_{4}$ & 298 & LLE & 6 & 1.00 & $\begin{array}{l}\text { Zafarani-Moattar and } \\
\text { Salabat (1997) }\end{array}$ \\
\hline ethanol & $\mathrm{CH}_{\mathrm{n}}, \mathrm{CH}_{\mathrm{n}}^{[\mathrm{OH}]}, \mathrm{OH}$ & $\mathrm{Na}_{2} \mathrm{SO}_{4}$ & 298 & LLE & 3 & 1.00 & Greve and Kula (1991) \\
\hline 1,2-ethanediol & $\mathrm{CH}_{\mathrm{n}}, \mathrm{CH}_{\mathrm{n}}^{[\mathrm{OH}]}, \mathrm{OH}$ & $\mathrm{Na}_{2} \mathrm{SO}_{4}$ & 308 & SLE & 13 & 0.80 & Vener and Thompson (1949) \\
\hline 1-propanol & $\mathrm{CH}_{\mathrm{n}}, \mathrm{CH}_{\mathrm{n}}^{[\mathrm{OH}]}, \mathrm{OH}$ & $\mathrm{Na}_{2} \mathrm{SO}_{4}$ & 293 & SLE & 5 & 1.00 & Brenner et al. (1992) \\
\hline 2-propanol & $\mathrm{CH}_{\mathrm{n}}, \mathrm{CH}_{\mathrm{n}}^{[\mathrm{OH}]}, \mathrm{OH}$ & $\mathrm{Na}_{2} \mathrm{SO}_{4}$ & 293 & SLE & 10 & 1.00 & Brenner et al. (1992) \\
\hline tert-butanol & $\mathrm{CH}_{\mathrm{n}}, \mathrm{CH}_{\mathrm{n}}^{[\mathrm{OH}]}, \mathrm{OH}$ & $\mathrm{Na}_{2} \mathrm{SO}_{4}$ & 293 & SLE & 5 & 1.00 & Brenner et al. (1992) \\
\hline 1-propanol & $\mathrm{CH}_{\mathrm{n}}, \mathrm{CH}_{\mathrm{n}}^{[\mathrm{OH}]}, \mathrm{OH}$ & $\mathrm{Na}_{2} \mathrm{SO}_{4}$ & $297-353$ & LLE & 12 & 1.00 & Brenner et al. (1992) \\
\hline 2-propanol & $\mathrm{CH}_{\mathrm{n}}, \mathrm{CH}_{\mathrm{n}}^{[\mathrm{OH}]}, \mathrm{OH}$ & $\mathrm{Na}_{2} \mathrm{SO}_{4}$ & $302-353$ & LLE & 8 & 1.00 & Brenner et al. (1992) \\
\hline
\end{tabular}


Table 2. Continued.

\begin{tabular}{|c|c|c|c|c|c|c|c|}
\hline Organic compounds a & Org. main groups ${ }^{b}$ & Inorg. salts/acids & $T(\mathrm{~K})$ & Data type ${ }^{c}$ & $N_{d}$ & $w_{d}^{\text {init }}$ & Reference \\
\hline 2-propanol & $\mathrm{CH}_{\mathrm{n}}, \mathrm{CH}_{\mathrm{n}}^{[\mathrm{OH}]}, \mathrm{OH}$ & $\mathrm{Na}_{2} \mathrm{SO}_{4}$ & 308 & LLE & 8 & 1.00 & Lynn et al. (1996) \\
\hline tert-butanol & $\mathrm{CH}_{\mathrm{n}}, \mathrm{CH}_{\mathrm{n}}^{[\mathrm{OH}]}, \mathrm{OH}$ & $\mathrm{Na}_{2} \mathrm{SO}_{4}$ & 308 & LLE & 12 & 1.00 & Lynn et al. (1996) \\
\hline tert-butanol & $\mathrm{CH}_{\mathrm{n}}, \mathrm{CH}_{\mathrm{n}}^{[\mathrm{OH}]}, \mathrm{OH}$ & $\mathrm{Na}_{2} \mathrm{SO}_{4}$ & $296-353$ & LLE & 13 & 0.10 & Brenner et al. (1992) \\
\hline 2-propanol & $\mathrm{CH}_{\mathrm{n}}, \mathrm{CH}_{\mathrm{n}}^{[\mathrm{OH}]}, \mathrm{OH}$ & $\mathrm{Na}_{2} \mathrm{SO}_{4}$ & 298 & SLE & 11 & 1.00 & Brenner et al. (1992) \\
\hline ethanol & $\mathrm{CH}_{\mathrm{n}}, \mathrm{CH}_{\mathrm{n}}^{[\mathrm{OH}]}, \mathrm{OH}$ & $\mathrm{Na}_{2} \mathrm{SO}_{4}$ & 313 & VLE(org) & 6 & 0.10 & Falabella et al. (2006) \\
\hline 1-propanol & $\mathrm{CH}_{\mathrm{n}}, \mathrm{CH}_{\mathrm{n}}^{[\mathrm{OH}]}, \mathrm{OH}$ & $\mathrm{Na}_{2} \mathrm{SO}_{4}$ & 313 & VLE(org) & 5 & 0.10 & Falabella et al. (2006) \\
\hline 1-butanol & $\mathrm{CH}_{\mathrm{n}}, \mathrm{CH}_{\mathrm{n}}^{[\mathrm{OH}]}, \mathrm{OH}$ & $\mathrm{Na}_{2} \mathrm{SO}_{4}$ & 313 & VLE(org) & 6 & 0.10 & Falabella et al. (2006) \\
\hline 1-pentanol & $\mathrm{CH}_{\mathrm{n}}, \mathrm{CH}_{\mathrm{n}}^{[\mathrm{OH}]}, \mathrm{OH}$ & $\mathrm{Na}_{2} \mathrm{SO}_{4}$ & 313 & VLE(org) & 6 & 0.10 & Falabella et al. (2006) \\
\hline 1-hexanol & $\mathrm{CH}_{\mathrm{n}}, \mathrm{CH}_{\mathrm{n}}^{[\mathrm{OH}]}, \mathrm{OH}$ & $\mathrm{Na}_{2} \mathrm{SO}_{4}$ & 313 & VLE(org) & 6 & 0.10 & Falabella et al. (2006) \\
\hline 1-propanol & $\mathrm{CH}_{\mathrm{n}}, \mathrm{CH}_{\mathrm{n}}^{[\mathrm{OH}]}, \mathrm{OH}$ & $\mathrm{NaBr}$ & $360-364$ & VLE & 26 & 0.50 & Morrison et al. (1990) \\
\hline 2-propanol & $\mathrm{CH}_{\mathrm{n}}, \mathrm{CH}_{\mathrm{n}}^{[\mathrm{OH}]}, \mathrm{OH}$ & $\mathrm{NaBr}$ & $353-358$ & VLE & 55 & 0.50 & Morrison et al. (1990) \\
\hline 1-propanol & $\mathrm{CH}_{\mathrm{n}}, \mathrm{CH}_{\mathrm{n}}^{[\mathrm{OH}]}, \mathrm{OH}$ & $\mathrm{NaBr}$ & 298 & LLE & 11 & 0.50 & Chou et al. (1998) \\
\hline 1-butanol & $\mathrm{CH}_{\mathrm{n}}, \mathrm{CH}_{\mathrm{n}}^{[\mathrm{OH}]}, \mathrm{OH}$ & $\mathrm{NaBr}$ & 298 & LLE & 18 & 1.00 & $\begin{array}{l}\text { Al-Sahhaf and Kapetanovic } \\
\text { (1997) }\end{array}$ \\
\hline D-mannopyranose & $\mathrm{CH}_{\mathrm{n}}^{[\mathrm{OH}]}, \mathrm{OH}, \mathrm{CH}_{\mathrm{n}} \mathrm{O}$ & $\mathrm{NaBr}$ & 298 & $\gamma_{ \pm}$ & 32 & 2.00 & Yang et al. (2004) \\
\hline D-ribofuranose & $\mathrm{CH}_{\mathrm{n}}^{[\mathrm{OH}]}, \mathrm{OH}, \mathrm{CH}_{\mathrm{n}} \mathrm{O}$ & $\mathrm{NaBr}$ & 298 & $\gamma_{ \pm}$ & 32 & 2.00 & Yang et al. (2004) \\
\hline ethanol & $\mathrm{CH}_{\mathrm{n}}, \mathrm{CH}_{\mathrm{n}}^{[\mathrm{OH}]}, \mathrm{OH}$ & $\mathrm{NaCl}$ & 298 & $\gamma_{ \pm}$ & 28 & 2.00 & Esteso et al. (1989) \\
\hline ethanol & $\mathrm{CH}_{\mathrm{n}}, \mathrm{CH}_{\mathrm{n}}^{[\mathrm{OH}]}, \mathrm{OH}$ & $\mathrm{NaCl}$ & 298 & $\gamma_{ \pm}$ & 25 & 2.00 & Esteso et al. (1989) \\
\hline ethanol & $\mathrm{CH}_{\mathrm{n}}, \mathrm{CH}_{\mathrm{n}}^{[\mathrm{OH}]}, \mathrm{OH}$ & $\mathrm{NaCl}$ & 298 & $\gamma_{ \pm}$ & 24 & 2.00 & Esteso et al. (1989) \\
\hline ethanol & $\mathrm{CH}_{\mathrm{n}}, \mathrm{CH}_{\mathrm{n}}^{[\mathrm{OH}]}, \mathrm{OH}$ & $\mathrm{NaCl}$ & 298 & $\gamma_{ \pm}$ & 17 & 1.00 & Esteso et al. (1989) \\
\hline ethanol & $\mathrm{CH}_{\mathrm{n}}, \mathrm{CH}_{\mathrm{n}}^{[\mathrm{OH}]}, \mathrm{OH}$ & $\mathrm{NaCl}$ & 298 & $\gamma_{ \pm}$ & 15 & 0.50 & Esteso et al. (1989) \\
\hline ethanol & $\mathrm{CH}_{\mathrm{n}}, \mathrm{CH}_{\mathrm{n}}^{[\mathrm{OH}]}, \mathrm{OH}$ & $\mathrm{NaCl}$ & 298 & $\gamma_{ \pm}$ & 14 & 0.50 & Esteso et al. (1989) \\
\hline ethanol & $\mathrm{CH}_{\mathrm{n}}, \mathrm{CH}_{\mathrm{n}}^{[\mathrm{OH}]}, \mathrm{OH}$ & $\mathrm{NaCl}$ & 298 & SLE & 7 & 1.00 & Pinho and Macedo (1996) \\
\hline ethanol & $\mathrm{CH}_{\mathrm{n}}, \mathrm{CH}_{\mathrm{n}}^{[\mathrm{OH}]}, \mathrm{OH}$ & $\mathrm{NaCl}$ & $306-313$ & VLE & 16 & 0.50 & Meyer et al. (1991) \\
\hline ethanol & $\mathrm{CH}_{\mathrm{n}}, \mathrm{CH}_{\mathrm{n}}^{[\mathrm{OH}]}, \mathrm{OH}$ & $\mathrm{NaCl}$ & $350-361$ & VLE & 13 & 0.50 & Johnson and Furter (1965) \\
\hline ethanol & $\mathrm{CH}_{\mathrm{n}}, \mathrm{CH}_{\mathrm{n}}^{[\mathrm{OH}]}, \mathrm{OH}$ & $\mathrm{NaCl}$ & $316-332$ & VLE & 14 & 0.50 & Meyer et al. (1991) \\
\hline 1-propanol & $\mathrm{CH}_{\mathrm{n}}, \mathrm{CH}_{\mathrm{n}}^{[\mathrm{OH}]}, \mathrm{OH}$ & $\mathrm{NaCl}$ & $359-363$ & VLE & 36 & 0.50 & Morrison et al. (1990) \\
\hline 1-propanol & $\mathrm{CH}_{\mathrm{n}}, \mathrm{CH}_{\mathrm{n}}^{[\mathrm{OH}]}, \mathrm{OH}$ & $\mathrm{NaCl}$ & $362-375$ & VLE & 10 & 0.50 & Johnson and Furter (1965) \\
\hline 1-propanol & $\mathrm{CH}_{\mathrm{n}}, \mathrm{CH}_{\mathrm{n}}^{[\mathrm{OH}]}, \mathrm{OH}$ & $\mathrm{NaCl}$ & $360-365$ & VLE & 27 & 0.50 & Lin et al. (1993) \\
\hline 2-propanol & $\mathrm{CH}_{\mathrm{n}}, \mathrm{CH}_{\mathrm{n}}^{[\mathrm{OH}]}, \mathrm{OH}$ & $\mathrm{NaCl}$ & $353-362$ & VLE & 56 & 0.00 & Rajendran et al. (1991) \\
\hline glycerol & $\mathrm{CH}_{\mathrm{n}}^{[\mathrm{OH}]}, \mathrm{OH}$ & $\mathrm{NaCl}$ & 298 & $a_{\mathrm{w}}($ bulk $)$ & 10 & 2.00 & Marcolli and Krieger (2006) \\
\hline 1,4-butanediol & $\mathrm{CH}_{\mathrm{n}}, \mathrm{CH}_{\mathrm{n}}^{[\mathrm{OH}]}, \mathrm{OH}$ & $\mathrm{NaCl}$ & 298 & $a_{\mathrm{W}}($ bulk $)$ & 10 & 2.00 & Marcolli and Krieger (2006) \\
\hline ethanol & $\mathrm{CH}_{\mathrm{n}}, \mathrm{CH}_{\mathrm{n}}^{[\mathrm{OH}]}, \mathrm{OH}$ & $\mathrm{NaCl}$ & 298 & $\gamma_{ \pm}$ & 48 & 2.00 & Lopes et al. (2001) \\
\hline 1-propanol & $\mathrm{CH}_{\mathrm{n}}, \mathrm{CH}_{\mathrm{n}}^{[\mathrm{OH}]}, \mathrm{OH}$ & $\mathrm{NaCl}$ & 298 & LLE & 11 & 1.00 & De Santis et al. (1976) \\
\hline 2-propanol & $\mathrm{CH}_{\mathrm{n}}, \mathrm{CH}_{\mathrm{n}}^{[\mathrm{OH}]}, \mathrm{OH}$ & $\mathrm{NaCl}$ & 298 & LLE & 8 & 1.00 & De Santis et al. (1976) \\
\hline 1-butanol & $\mathrm{CH}_{\mathrm{n}}, \mathrm{CH}_{\mathrm{n}}^{[\mathrm{OH}]}, \mathrm{OH}$ & $\mathrm{NaCl}$ & 298 & LLE & 20 & 1.00 & De Santis et al. (1976) \\
\hline isobutanol & $\mathrm{CH}_{\mathrm{n}}, \mathrm{CH}_{\mathrm{n}}^{[\mathrm{OH}]}, \mathrm{OH}$ & $\mathrm{NaCl}$ & 298 & LLE & 20 & 1.00 & De Santis et al. (1976) \\
\hline 2-butanol & $\mathrm{CH}_{\mathrm{n}}, \mathrm{CH}_{\mathrm{n}}^{[\mathrm{OH}]}, \mathrm{OH}$ & $\mathrm{NaCl}$ & 298 & LLE & 20 & 1.00 & De Santis et al. (1976) \\
\hline tert-butanol & $\mathrm{CH}_{\mathrm{n}}, \mathrm{CH}_{\mathrm{n}}^{[\mathrm{OH}]}, \mathrm{OH}$ & $\mathrm{NaCl}$ & 298 & LLE & 14 & 1.00 & De Santis et al. (1976) \\
\hline 1-propanol & $\mathrm{CH}_{\mathrm{n}}, \mathrm{CH}_{\mathrm{n}}^{[\mathrm{OH}]}, \mathrm{OH}$ & $\mathrm{NaCl}$ & 298 & LLE & 8 & 1.00 & Chou et al. (1998) \\
\hline 1-propanol & $\mathrm{CH}_{\mathrm{n}}, \mathrm{CH}_{\mathrm{n}}^{[\mathrm{OH}]}, \mathrm{OH}$ & $\mathrm{NaCl}$ & 298 & LLE & 5 & 1.00 & Gomis et al. (1994) \\
\hline 2-propanol & $\mathrm{CH}_{\mathrm{n}}, \mathrm{CH}_{\mathrm{n}}^{[\mathrm{OH}]}, \mathrm{OH}$ & $\mathrm{NaCl}$ & 298 & LLE & 5 & 1.00 & Gomis et al. (1994) \\
\hline 1-butanol & $\mathrm{CH}_{\mathrm{n}}, \mathrm{CH}_{\mathrm{n}}^{[\mathrm{OH}]}, \mathrm{OH}$ & $\mathrm{NaCl}$ & 298 & LLE & 10 & 1.00 & Li et al. (1995) \\
\hline 2-butanol & $\mathrm{CH}_{\mathrm{n}}, \mathrm{CH}_{\mathrm{n}}^{[\mathrm{OH}]}, \mathrm{OH}$ & $\mathrm{NaCl}$ & 298 & LLE & 9 & 1.00 & Gomis et al. (1996) \\
\hline isobutanol & $\mathrm{CH}_{\mathrm{n}}, \mathrm{CH}_{\mathrm{n}}^{[\mathrm{OH}]}, \mathrm{OH}$ & $\mathrm{NaCl}$ & 298 & LLE & 9 & 1.00 & Gomis et al. (1996) \\
\hline tert-butanol & $\mathrm{CH}_{\mathrm{n}}, \mathrm{CH}_{\mathrm{n}}^{[\mathrm{OH}]}, \mathrm{OH}$ & $\mathrm{NaCl}$ & 298 & LLE & 8 & 1.00 & Gomis et al. (1996) \\
\hline 1-butanol & $\mathrm{CH}_{\mathrm{n}}, \mathrm{CH}_{\mathrm{n}}^{[\mathrm{OH}]}, \mathrm{OH}$ & $\mathrm{NaCl}$ & 313 & LLE & 19 & 0.50 & De Santis et al. (1976) \\
\hline 1,2-hexanediol & $\mathrm{CH}_{\mathrm{n}}, \mathrm{CH}_{\mathrm{n}}^{[\mathrm{OH}]}, \mathrm{OH}$ & $\mathrm{NaCl}$ & 298 & $a_{\mathrm{w}}($ bulk $)$ & 17 & 2.00 & Marcolli and Krieger (2006) \\
\hline glycerol & $\mathrm{CH}_{\mathrm{n}}, \mathrm{CH}_{\mathrm{n}}^{[\mathrm{OH}]}, \mathrm{OH}$ & $\mathrm{NaCl}$ & 298 & SLE & 9 & 1.00 & Marcolli and Krieger (2006) \\
\hline 1,4-butanediol & $\mathrm{CH}_{\mathrm{n}}, \mathrm{CH}_{\mathrm{n}}^{[\mathrm{OH}]}, \mathrm{OH}$ & $\mathrm{NaCl}$ & 298 & SLE & 9 & 1.00 & Marcolli and Krieger (2006) \\
\hline 1,2-hexanediol & $\mathrm{CH}_{\mathrm{n}}, \mathrm{CH}_{\mathrm{n}}^{[\mathrm{OH}]}, \mathrm{OH}$ & $\mathrm{NaCl}$ & 298 & SLE & 8 & 1.00 & Marcolli and Krieger (2006) \\
\hline 1,4-dihydroxy-2-butene & $\mathrm{CH}_{\mathrm{n}}, \mathrm{CH}_{\mathrm{n}}^{[\mathrm{OH}]}, \mathrm{OH}, \mathrm{C}=\mathrm{C}$ & $\mathrm{NaCl}$ & 298 & SLE & 6 & 1.00 & Raridon and Kraus (1971) \\
\hline ethanol, 3-methyl-1-butanol & $\mathrm{CH}_{\mathrm{n}}, \mathrm{CH}_{\mathrm{n}}^{[\mathrm{OH}]}, \mathrm{OH}$ & $\mathrm{NaCl}$ & 298 & LLE & 9 & 1.00 & Aznar et al. (2000) \\
\hline ethanol, 1-butanol & $\mathrm{CH}_{\mathrm{n}}, \mathrm{CH}_{\mathrm{n}}^{[\mathrm{OH}]}, \mathrm{OH}$ & $\mathrm{NaCl}$ & 298 & LLE & 9 & 1.00 & Aznar et al. (2000) \\
\hline D-fructopyranose & $\mathrm{CH}_{\mathrm{n}}^{[\mathrm{OH}]}, \mathrm{OH}, \mathrm{CH}_{\mathrm{n}} \mathrm{O}$ & $\mathrm{NaCl}$ & 298 & $\gamma_{ \pm}$ & 56 & 2.00 & Hernandez-Luis et al. (2004) \\
\hline D-mannopyranose & $\mathrm{CH}_{\mathrm{n}}^{[\mathrm{OH}]}, \mathrm{OH}, \mathrm{CH}_{\mathrm{n}} \mathrm{O}$ & $\mathrm{NaCl}$ & 298 & $\gamma_{ \pm}$ & 32 & 2.00 & Yang et al. (2004) \\
\hline D-ribofuranose & $\mathrm{CH}_{\mathrm{n}}^{[\mathrm{OH}]}, \mathrm{OH}, \mathrm{CH}_{\mathrm{n}} \mathrm{O}$ & $\mathrm{NaCl}$ & 298 & $\gamma_{ \pm}$ & 32 & 2.00 & Yang et al. (2004) \\
\hline ethanol & $\mathrm{CH}_{\mathrm{n}}, \mathrm{CH}_{\mathrm{n}}^{[\mathrm{OH}]}, \mathrm{OH}$ & $\mathrm{NaCl}, \mathrm{KCl}$ & 298 & $\gamma_{ \pm}$ & 31 & 2.00 & Farelo et al. (2002) \\
\hline
\end{tabular}


Table 2. Continued.

\begin{tabular}{|c|c|c|c|c|c|c|c|}
\hline Organic compounds ${ }^{\text {a }}$ & Org. main groups $b$ & Inorg. salts/acids & $T(\mathrm{~K})$ & Data type $^{\mathrm{c}}$ & $N_{d}$ & $w_{d}^{\text {init }}$ & Reference \\
\hline ethanol & $\mathrm{CH}_{\mathrm{n}}, \mathrm{CH}_{\mathrm{n}}^{[\mathrm{OH}]}, \mathrm{OH}$ & $\mathrm{NaNO}_{3}$ & $351-373$ & VLE & 122 & 0.50 & Pena et al. (1996) \\
\hline ethanol & $\mathrm{CH}_{\mathrm{n}}, \mathrm{CH}_{\mathrm{n}}^{[\mathrm{OH}]}, \mathrm{OH}$ & $\mathrm{NaNO}_{3}$ & 303 & SLE & 10 & 0.50 & Taylor (1897) \\
\hline ethanol & $\mathrm{CH}_{\mathrm{n}}, \mathrm{CH}_{\mathrm{n}}^{[\mathrm{OH}]}, \mathrm{OH}$ & $\mathrm{NH}_{4} \mathrm{Br}$ & $355-358$ & VLE & 39 & 0.50 & Burns and Furter (1975) \\
\hline ethanol & $\mathrm{CH}_{\mathrm{n}}, \mathrm{CH}_{\mathrm{n}}^{[\mathrm{OH}]}, \mathrm{OH}$ & $\mathrm{NH}_{4} \mathrm{Cl}$ & 298 & $\gamma_{ \pm}$ & 18 & 2.00 & Deyhimi et al. (2005) \\
\hline ethanol & $\mathrm{CH}_{\mathrm{n}}, \mathrm{CH}_{\mathrm{n}}^{[\mathrm{OH}]}, \mathrm{OH}$ & $\mathrm{NH}_{4} \mathrm{Cl}$ & 298 & $\gamma_{ \pm}$ & 18 & 2.00 & Deyhimi et al. (2005) \\
\hline ethanol & $\mathrm{CH}_{\mathrm{n}}, \mathrm{CH}_{\mathrm{n}}^{[\mathrm{OH}]}, \mathrm{OH}$ & $\mathrm{NH}_{4} \mathrm{Cl}$ & 298 & $\gamma_{ \pm}$ & 18 & 2.00 & Deyhimi et al. (2005) \\
\hline ethanol & $\mathrm{CH}_{\mathrm{n}}, \mathrm{CH}_{\mathrm{n}}^{[\mathrm{OH}]}, \mathrm{OH}$ & $\mathrm{NH}_{4} \mathrm{Cl}$ & 298 & $\gamma_{ \pm}$ & 18 & 2.00 & Deyhimi et al. (2005) \\
\hline ethanol & $\mathrm{CH}_{\mathrm{n}}, \mathrm{CH}_{\mathrm{n}}^{[\mathrm{OH}]}, \mathrm{OH}$ & $\mathrm{NH}_{4} \mathrm{Cl}$ & 298 & $\gamma_{ \pm}$ & 18 & 2.00 & Deyhimi et al. (2005) \\
\hline ethanol & $\mathrm{CH}_{\mathrm{n}}, \mathrm{CH}_{\mathrm{n}}^{[\mathrm{OH}]}, \mathrm{OH}$ & $\mathrm{NH}_{4} \mathrm{Cl}$ & 303 & SLE & 10 & 1.00 & Bathrick (1896) \\
\hline ethanol & $\mathrm{CH}_{\mathrm{n}}, \mathrm{CH}_{\mathrm{n}}^{[\mathrm{OH}]}, \mathrm{OH}$ & $\mathrm{NH}_{4} \mathrm{Cl}$ & $350-366$ & VLE & 32 & 0.50 & Johnson and Furter (1965) \\
\hline 1-propanol & $\mathrm{CH}_{\mathrm{n}}, \mathrm{CH}_{\mathrm{n}}^{[\mathrm{OH}]}, \mathrm{OH}$ & $\mathrm{NH}_{4} \mathrm{Cl}$ & $362-383$ & VLE & 9 & 0.50 & Johnson and Furter (1965) \\
\hline 2-propanol & $\mathrm{CH}_{\mathrm{n}}, \mathrm{CH}_{\mathrm{n}}^{[\mathrm{OH}]}, \mathrm{OH}$ & $\mathrm{NH}_{4} \mathrm{Cl}$ & 298 & $\gamma_{ \pm}$ & 46 & 2.00 & $\begin{array}{l}\text { Deyhimi and } \\
\text { Ghalami-Choobar (2006) }\end{array}$ \\
\hline levoglucosan & $\mathrm{CH}_{\mathrm{n}}, \mathrm{CH}_{\mathrm{n}}^{[\mathrm{OH}]}, \mathrm{OH}, \mathrm{CH}_{\mathrm{n}} \mathrm{O}$ & $\mathrm{NH}_{4} \mathrm{HSO}_{4}$ & 291 & $a_{\mathrm{W}}(\mathrm{EDB})$ & 69 & 1.00 & Lienhard et al. (2011) \\
\hline glycerol & $\mathrm{CH}_{\mathrm{n}}^{[\mathrm{OH}]}, \mathrm{OH}$ & $\mathrm{NH}_{4} \mathrm{NO}_{3}$ & 298 & $a_{\mathrm{W}}($ bulk $)$ & 9 & 2.00 & Marcolli and Krieger (2006) \\
\hline 1,4-butanediol & $\mathrm{CH}_{\mathrm{n}}, \mathrm{CH}_{\mathrm{n}}^{[\mathrm{OH}]}, \mathrm{OH}$ & $\mathrm{NH}_{4} \mathrm{NO}_{3}$ & 298 & $a_{\mathrm{W}}($ bulk $)$ & 12 & 2.00 & Marcolli and Krieger (2006) \\
\hline 1,2-hexanediol & $\mathrm{CH}_{\mathrm{n}}, \mathrm{CH}_{\mathrm{n}}^{[\mathrm{OH}]}, \mathrm{OH}$ & $\mathrm{NH}_{4} \mathrm{NO}_{3}$ & 298 & $a_{\mathrm{W}}($ bulk $)$ & 16 & 2.00 & Marcolli and Krieger (2006) \\
\hline glycerol & $\mathrm{CH}_{\mathrm{n}}^{[\mathrm{OH}]}, \mathrm{OH}$ & $\mathrm{NH}_{4} \mathrm{NO}_{3}$ & 298 & SLE & 8 & 1.00 & Marcolli and Krieger (2006) \\
\hline 1,4-butanediol & $\mathrm{CH}_{\mathrm{n}}, \mathrm{CH}_{\mathrm{n}}^{[\mathrm{OH}]}, \mathrm{OH}$ & $\mathrm{NH}_{4} \mathrm{NO}_{3}$ & 298 & SLE & 11 & 1.00 & Marcolli and Krieger (2006) \\
\hline 1,2-hexanediol & $\mathrm{CH}_{\mathrm{n}}, \mathrm{CH}_{\mathrm{n}}^{[\mathrm{OH}]}, \mathrm{OH}$ & $\mathrm{NH}_{4} \mathrm{NO}_{3}$ & 298 & SLE & 8 & 1.00 & Marcolli and Krieger (2006) \\
\hline levoglucosan & $\mathrm{CH}_{\mathrm{n}}, \mathrm{CH}_{\mathrm{n}}^{[\mathrm{OH}]}, \mathrm{OH}, \mathrm{CH}_{\mathrm{n}} \mathrm{O}$ & $\mathrm{NH}_{4} \mathrm{NO}_{3}$ & 291 & $a_{\mathrm{W}}(\mathrm{EDB})$ & 73 & 1.00 & Lienhard et al. (2011) \\
\hline \multicolumn{8}{|c|}{ - water + carboxylic acid + salt/acid systems -} \\
\hline malonic acid & $\mathrm{CH}_{\mathrm{n}}, \mathrm{COOH}$ & $\left(\mathrm{NH}_{4}\right)_{2} \mathrm{SO}_{4}$ & 298 & $a_{\mathrm{W}}(\mathrm{EDB})$ & 18 & 1.00 & Ling and Chan (2008) \\
\hline glutaric acid & $\mathrm{CH}_{\mathrm{n}}, \mathrm{COOH}$ & $\left(\mathrm{NH}_{4}\right)_{2} \mathrm{SO}_{4}$ & 298 & $a_{\mathrm{W}}(\mathrm{EDB})$ & 21 & 1.00 & Ling and Chan (2008) \\
\hline succinic acid & $\mathrm{CH}_{\mathrm{n}}, \mathrm{COOH}$ & $\left(\mathrm{NH}_{4}\right)_{2} \mathrm{SO}_{4}$ & 298 & $a_{\mathrm{W}}(\mathrm{EDB})$ & 17 & 1.00 & Ling and Chan (2008) \\
\hline succinic acid & $\mathrm{CH}_{\mathrm{n}}, \mathrm{COOH}$ & $\left(\mathrm{NH}_{4}\right)_{2} \mathrm{SO}_{4}$ & 295 & $a_{\mathrm{W}}($ bulk $)$ & 5 & 2.00 & Choi and Chan (2002) \\
\hline malonic acid & $\mathrm{CH}_{\mathrm{n}}, \mathrm{COOH}$ & $\left(\mathrm{NH}_{4}\right)_{2} \mathrm{SO}_{4}$ & 295 & $a_{\mathrm{W}}($ bulk $)$ & 5 & 2.00 & Choi and Chan (2002) \\
\hline glutaric acid & $\mathrm{CH}_{\mathrm{n}}, \mathrm{COOH}$ & $\left(\mathrm{NH}_{4}\right)_{2} \mathrm{SO}_{4}$ & 295 & $a_{\mathrm{W}}($ bulk $)$ & 10 & 2.00 & Choi and Chan (2002) \\
\hline citric acid & $\mathrm{CH}_{\mathrm{n}}, \mathrm{CH}_{\mathrm{n}}^{[\mathrm{OH}]}, \mathrm{COOH}, \mathrm{OH}$ & $\left(\mathrm{NH}_{4}\right)_{2} \mathrm{SO}_{4}$ & 295 & $a_{\mathrm{W}}($ bulk $)$ & 8 & 2.00 & Choi and Chan (2002) \\
\hline citric acid & $\mathrm{CH}_{\mathrm{n}}, \mathrm{CH}_{\mathrm{n}}^{[\mathrm{OH}]}, \mathrm{COOH}, \mathrm{OH}$ & $\left(\mathrm{NH}_{4}\right)_{2} \mathrm{SO}_{4}$ & 295 & $a_{\mathrm{W}}(\mathrm{SEDB})$ & 54 & 0.10 & Choi and Chan (2002) \\
\hline malonic acid & $\mathrm{CH}_{\mathrm{n}}, \mathrm{COOH}$ & $\left(\mathrm{NH}_{4}\right)_{2} \mathrm{SO}_{4}$ & 298 & $a_{\mathrm{W}}(\mathrm{bulk})$ & 52 & 2.00 & Salcedo (2006) \\
\hline malonic acid & $\mathrm{CH}_{\mathrm{n}}, \mathrm{COOH}$ & $\left(\mathrm{NH}_{4}\right)_{2} \mathrm{SO}_{4}$ & 298 & SLE & 4 & 1.00 & Salcedo (2006) \\
\hline malonic acid & $\mathrm{CH}_{\mathrm{n}}, \mathrm{COOH}$ & $\left(\mathrm{NH}_{4}\right)_{2} \mathrm{SO}_{4}$ & 298 & SLE & 6 & 1.00 & Salcedo (2006) \\
\hline malonic acid & $\mathrm{CH}_{\mathrm{n}}, \mathrm{COOH}$ & $\left(\mathrm{NH}_{4}\right)_{2} \mathrm{SO}_{4}$ & 297 & $a_{\mathrm{W}}($ micro-Raman $)$ & 61 & 0.20 & Yeung and Chan (2010) \\
\hline glutaric acid & $\mathrm{CH}_{\mathrm{n}}, \mathrm{COOH}$ & $\left(\mathrm{NH}_{4}\right)_{2} \mathrm{SO}_{4}$ & 297 & $a_{\mathrm{W}}($ micro-Raman $)$ & 71 & 0.20 & Yeung and Chan (2010) \\
\hline malonic acid & $\mathrm{CH}_{\mathrm{n}}, \mathrm{COOH}$ & $\left(\mathrm{NH}_{4}\right)_{2} \mathrm{SO}_{4}$ & 298 & $a_{\mathrm{W}}($ bulk $)$ & 1 & 2.00 & Wise et al. (2003) \\
\hline glutaric acid & $\mathrm{CH}_{\mathrm{n}}, \mathrm{COOH}$ & $\left(\mathrm{NH}_{4}\right)_{2} \mathrm{SO}_{4}$ & 298 & $a_{\mathrm{W}}($ bulk $)$ & 1 & 2.00 & Wise et al. (2003) \\
\hline succinic acid & $\mathrm{CH}_{\mathrm{n}}, \mathrm{COOH}$ & $\left(\mathrm{NH}_{4}\right)_{2} \mathrm{SO}_{4}$ & 298 & $a_{\mathrm{W}}($ bulk $)$ & 1 & 2.00 & Wise et al. (2003) \\
\hline oxalic acid & $\mathrm{CH}_{\mathrm{n}}, \mathrm{COOH}$ & $\left(\mathrm{NH}_{4}\right)_{2} \mathrm{SO}_{4}$ & 298 & $a_{\mathrm{W}}($ bulk $)$ & 1 & 2.00 & Wise et al. (2003) \\
\hline maleic acid & $\mathrm{C}=\mathrm{C}, \mathrm{COOH}$ & $\left(\mathrm{NH}_{4}\right)_{2} \mathrm{SO}_{4}$ & 298 & $a_{\mathrm{W}}($ bulk $)$ & 1 & 2.00 & Wise et al. (2003) \\
\hline malic acid & $\mathrm{CH}_{\mathrm{n}}, \mathrm{CH}_{\mathrm{n}}^{[\mathrm{OH}]}, \mathrm{COOH}, \mathrm{OH}$ & $\left(\mathrm{NH}_{4}\right)_{2} \mathrm{SO}_{4}$ & 298 & $a_{\mathrm{W}}($ bulk $)$ & 1 & 1.00 & Wise et al. (2003) \\
\hline $\begin{array}{l}\text { M5: malic acid, malonic acid, } \\
\text { maleic acid, glutaric acid, } \\
\text { methylsuccinic acid }\end{array}$ & $\begin{array}{l}\mathrm{CH}_{\mathrm{n}}, \mathrm{CH}_{\mathrm{n}}^{[\mathrm{OH}]}, \mathrm{COOH}, \mathrm{OH}, \\
\mathrm{C}=\mathrm{C}\end{array}$ & $\left(\mathrm{NH}_{4}\right)_{2} \mathrm{SO}_{4}$ & 298 & $a_{\mathrm{W}}($ bulk $)$ & 25 & 2.00 & Marcolli et al. (2004a) \\
\hline $\begin{array}{l}\text { M5: malic acid, malonic acid, } \\
\text { maleic acid, glutaric acid, } \\
\text { methylsuccinic acid }\end{array}$ & $\begin{array}{l}\mathrm{CH}_{\mathrm{n}}, \mathrm{CH}_{\mathrm{n}}^{[\mathrm{OH}]}, \mathrm{COOH}, \mathrm{OH}, \\
\mathrm{C}=\mathrm{C}\end{array}$ & $\left(\mathrm{NH}_{4}\right)_{2} \mathrm{SO}_{4}$ & 298 & SLE & 8 & 1.00 & Marcolli et al. (2004a) \\
\hline oxalic acid & $\mathrm{CH}_{\mathrm{n}}, \mathrm{COOH}$ & $\left(\mathrm{NH}_{4}\right)_{2} \mathrm{SO}_{4}$ & 293 & $a_{\mathrm{W}}($ bulk $)$ & 7 & 2.00 & this study \\
\hline malonic acid & $\mathrm{CH}_{\mathrm{n}}, \mathrm{COOH}$ & $\left(\mathrm{NH}_{4}\right)_{2} \mathrm{SO}_{4}$ & 293 & $a_{\mathrm{W}}($ bulk $)$ & 16 & 2.00 & this study \\
\hline glutaric acid & $\mathrm{CH}_{\mathrm{n}}, \mathrm{COOH}$ & $\left(\mathrm{NH}_{4}\right)_{2} \mathrm{SO}_{4}$ & 293 & $a_{\mathrm{W}}($ bulk $)$ & 9 & 2.00 & this study \\
\hline succinic acid & $\mathrm{CH}_{\mathrm{n}}, \mathrm{COOH}$ & $\left(\mathrm{NH}_{4}\right)_{2} \mathrm{SO}_{4}$ & 293 & $a_{\mathrm{W}}($ bulk $)$ & 9 & 2.00 & this study \\
\hline adipic acid & $\mathrm{CH}_{\mathrm{n}}, \mathrm{COOH}$ & $\left(\mathrm{NH}_{4}\right)_{2} \mathrm{SO}_{4}$ & 293 & $a_{\mathrm{W}}($ bulk $)$ & 3 & 2.00 & this study \\
\hline glutaric acid & $\mathrm{CH}_{\mathrm{n}}, \mathrm{COOH}$ & $\left(\mathrm{NH}_{4}\right)_{2} \mathrm{SO}_{4}$ & 291 & $a_{\mathrm{W}}(\mathrm{EDB})$ & 38 & 1.00 & Zardini et al. (2008) \\
\hline citric acid & $\mathrm{CH}_{\mathrm{n}}, \mathrm{CH}_{\mathrm{n}}^{[\mathrm{OH}]}, \mathrm{COOH}, \mathrm{OH}$ & $\left(\mathrm{NH}_{4}\right)_{2} \mathrm{SO}_{4}$ & 291 & $a_{\mathrm{W}}(\mathrm{EDB})$ & 62 & 1.00 & Zardini et al. (2008) \\
\hline citric acid & $\mathrm{CH}_{\mathrm{n}}, \mathrm{CH}_{\mathrm{n}}^{[\mathrm{OH}]}, \mathrm{COOH}, \mathrm{OH}$ & $\left(\mathrm{NH}_{4}\right)_{2} \mathrm{SO}_{4}$ & 291 & $a_{\mathrm{W}}(\mathrm{EDB})$ & 57 & 1.00 & Zardini et al. (2008) \\
\hline citric acid & $\mathrm{CH}_{\mathrm{n}}, \mathrm{CH}_{\mathrm{n}}^{[\mathrm{OH}]}, \mathrm{COOH}, \mathrm{OH}$ & $\left(\mathrm{NH}_{4}\right)_{2} \mathrm{SO}_{4}$ & 291 & $a_{\mathrm{W}}(\mathrm{EDB})$ & 45 & 1.00 & Zardini et al. (2008) \\
\hline $\begin{array}{l}\text { 2-methylglutaric acid, } \\
\text { 3-methylglutaric acid, } \\
\text { 2,2-dimethylsuccinic acid }\end{array}$ & $\mathrm{CH}_{\mathrm{n}}, \mathrm{COOH}$ & $\left(\mathrm{NH}_{4}\right)_{2} \mathrm{SO}_{4}$ & 291 & $a_{\mathrm{W}}(\mathrm{EDB})$ & 88 & 1.00 & this study \\
\hline maleic acid & $\mathrm{C}=\mathrm{C}, \mathrm{COOH}$ & $\mathrm{Ca}\left(\mathrm{NO}_{3}\right)_{2}$ & 293 & $a_{\mathrm{W}}($ bulk $)$ & 13 & 2.00 & this study \\
\hline propanoic acid, 1-butanol & $\mathrm{CH}_{\mathrm{n}}, \mathrm{CH}_{\mathrm{n}}^{[\mathrm{OH}]}, \mathrm{COOH}, \mathrm{OH}$ & $\mathrm{CaCl}_{2}$ & 303 & LLE & 26 & 1.00 & Zurita et al. (1998) \\
\hline propanoic acid & $\mathrm{CH}_{\mathrm{n}}, \mathrm{COOH}$ & $\mathrm{CaCl}_{2}$ & 333 & $\operatorname{VLE}(x-y-T)$ & 5 & 0.50 & Banat et al. (2002) \\
\hline
\end{tabular}


Table 2. Continued.

\begin{tabular}{|c|c|c|c|c|c|c|c|}
\hline Organic compounds ${ }^{a}$ & Org. main groups ${ }^{b}$ & Inorg. salts/acids & $T(\mathrm{~K})$ & Data type $^{\mathrm{c}}$ & $N_{d}$ & $w_{d}^{\text {init }}$ & Reference \\
\hline propanoic acid & $\mathrm{CH}_{\mathrm{n}}, \mathrm{COOH}$ & $\mathrm{CaCl}_{2}$ & 333 & $\operatorname{VLE}(x-y-T)$ & 20 & 0.50 & Banat et al. (2003a) \\
\hline propanoic acid & $\mathrm{CH}_{\mathrm{n}}, \mathrm{COOH}$ & $\mathrm{CaCl}_{2}$ & 313 & $\operatorname{VLE}(x-y-T)$ & 5 & 0.50 & Banat et al. (2003b) \\
\hline propanoic acid & $\mathrm{CH}_{\mathrm{n}}, \mathrm{COOH}$ & $\mathrm{CaCl}_{2}$ & 323 & $\operatorname{VLE}(x-y-T)$ & 15 & 0.50 & Banat et al. (2003b) \\
\hline acetic acid & $\mathrm{CH}_{\mathrm{n}}, \mathrm{COOH}$ & $\mathrm{K}_{2} \mathrm{SO}_{4}$ & $373-375$ & VLE & 26 & 0.50 & Narayana et al. (1985) \\
\hline propanoic acid & $\mathrm{CH}_{\mathrm{n}}, \mathrm{COOH}$ & $\mathrm{KBr}$ & 333 & $\operatorname{VLE}(x-y-T)$ & 5 & 0.50 & Banat et al. (2003a) \\
\hline acetic acid & $\mathrm{CH}_{\mathrm{n}}, \mathrm{COOH}$ & $\mathrm{KCl}$ & $374-386$ & VLE & 21 & 0.50 & Narayana et al. (1985) \\
\hline acetic acid & $\mathrm{CH}_{\mathrm{n}}, \mathrm{COOH}$ & $\mathrm{KCl}$ & 303 & SLE & 9 & 0.50 & Narayana et al. (1985) \\
\hline propanoic acid & $\mathrm{CH}_{\mathrm{n}}, \mathrm{COOH}$ & $\mathrm{KCl}$ & 333 & $\operatorname{VLE}(x-y-T)$ & 5 & 0.50 & Banat et al. (2003a) \\
\hline acetic acid, 1-butanol & $\mathrm{CH}_{\mathrm{n}}, \mathrm{CH}_{\mathrm{n}}^{[\mathrm{OH}]}, \mathrm{COOH}, \mathrm{OH}$ & $\mathrm{KCl}$ & 298 & LLE & 38 & 1.00 & Tan and Aravinth (1999) \\
\hline propanoic acid & $\mathrm{CH}_{\mathrm{n}}, \mathrm{COOH}$ & $\mathrm{KNO}_{3}$ & 333 & $\operatorname{VLE}(x-y-T)$ & 5 & 0.50 & Banat et al. (2003a) \\
\hline acetic acid & $\mathrm{CH}_{\mathrm{n}}, \mathrm{COOH}$ & $\mathrm{KNO}_{3}$ & 298 & SLE & 1 & 0.01 & Davidson and Geer (1933) \\
\hline 2-methylpropanoic acid & $\mathrm{CH}_{\mathrm{n}}, \mathrm{COOH}$ & $\mathrm{LiCl}$ & 303 & LLE & 4 & 1.00 & $\begin{array}{l}\text { Sergeeva and } \\
\text { Matyushinskaya (1969) }\end{array}$ \\
\hline malonic acid & $\mathrm{CH}_{\mathrm{n}}, \mathrm{COOH}$ & $\mathrm{LiNO}_{3}$ & 303 & $a_{\mathrm{W}}($ bulk $)$ & 12 & 2.00 & this study \\
\hline malonic acid & $\mathrm{CH}_{\mathrm{n}}, \mathrm{COOH}$ & $\mathrm{LiNO}_{3}$ & 293 & $a_{\mathrm{W}}($ bulk $)$ & 12 & 2.00 & this study \\
\hline maleic acid & $\mathrm{C}=\mathrm{C}, \mathrm{COOH}$ & $\mathrm{Mg}\left(\mathrm{NO}_{3}\right)_{2}$ & 293 & $a_{\mathrm{W}}($ bulk $)$ & 7 & 2.00 & this study \\
\hline formic acid & $\mathrm{COOH}$ & $\mathrm{MgCl}_{2}$ & $377-400$ & VLE & 40 & 0.50 & Yun et al. (1998) \\
\hline citric acid & $\mathrm{CH}_{\mathrm{n}}, \mathrm{CH}_{\mathrm{n}}^{[\mathrm{OH}]}, \mathrm{COOH}, \mathrm{OH}$ & $\mathrm{Na}_{2} \mathrm{SO}_{4}$ & 298 & $a_{\mathrm{w}}($ bulk $)$ & 33 & 2.00 & Schunk and Maurer (2004) \\
\hline acetic acid & $\mathrm{CH}_{\mathrm{n}}, \mathrm{COOH}$ & $\mathrm{Na}_{2} \mathrm{SO}_{4}$ & $374-388$ & VLE & 23 & 0.50 & Narayana et al. (1985) \\
\hline malonic acid & $\mathrm{CH}_{\mathrm{n}}, \mathrm{COOH}$ & $\mathrm{Na}_{2} \mathrm{SO}_{4}$ & 303 & $a_{\mathrm{W}}($ bulk $)$ & 8 & 2.00 & this study \\
\hline malonic acid & $\mathrm{CH}_{\mathrm{n}}, \mathrm{COOH}$ & $\mathrm{Na}_{2} \mathrm{SO}_{4}$ & 293 & $a_{\mathrm{W}}($ bulk $)$ & 8 & 2.00 & this study \\
\hline glutaric acid & $\mathrm{CH}_{\mathrm{n}}, \mathrm{COOH}$ & $\mathrm{NaCl}$ & 295 & $a_{\mathrm{W}}(\mathrm{SEDB})$ & 19 & 1.00 & Choi and Chan (2002) \\
\hline malonic acid & $\mathrm{CH}_{\mathrm{n}}, \mathrm{COOH}$ & $\mathrm{NaCl}$ & 295 & $a_{\mathrm{W}}($ bulk $)$ & 6 & 2.00 & Choi and Chan (2002) \\
\hline malonic acid & $\mathrm{CH}_{\mathrm{n}}, \mathrm{COOH}$ & $\mathrm{NaCl}$ & 295 & $a_{\mathrm{W}}(\mathrm{SEDB})$ & 38 & 1.00 & Choi and Chan (2002) \\
\hline succinic acid & $\mathrm{CH}_{\mathrm{n}}, \mathrm{COOH}$ & $\mathrm{NaCl}$ & 295 & $a_{\mathrm{W}}(\mathrm{bulk})$ & 6 & 2.00 & Choi and Chan (2002) \\
\hline succinic acid & $\mathrm{CH}_{\mathrm{n}}, \mathrm{COOH}$ & $\mathrm{NaCl}$ & 295 & $a_{\mathrm{W}}(\mathrm{SEDB})$ & 22 & 1.00 & Choi and Chan (2002) \\
\hline citric acid & $\mathrm{CH}_{\mathrm{n}}, \mathrm{CH}_{\mathrm{n}}^{[\mathrm{OH}]}, \mathrm{COOH}, \mathrm{OH}$ & $\mathrm{NaCl}$ & 295 & $a_{\mathrm{W}}($ bulk $)$ & 7 & 2.00 & Choi and Chan (2002) \\
\hline citric acid & $\mathrm{CH}_{\mathrm{n}}, \mathrm{CH}_{\mathrm{n}}^{[\mathrm{OH}]}, \mathrm{COOH}, \mathrm{OH}$ & $\mathrm{NaCl}$ & 295 & $a_{\mathrm{w}}(\mathrm{SEDB})$ & 37 & 1.00 & Choi and Chan (2002) \\
\hline $\begin{array}{l}\text { M5: malic acid, malonic acid, } \\
\text { maleic acid, glutaric acid, } \\
\text { methylsuccinic acid }\end{array}$ & $\begin{array}{l}\mathrm{CH}_{\mathrm{n}}, \mathrm{CH}_{\mathrm{n}}^{[\mathrm{OH}]}, \mathrm{COOH}, \mathrm{OH}, \\
\mathrm{C}=\mathrm{C}\end{array}$ & $\mathrm{NaCl}$ & 298 & $a_{\mathrm{W}}($ bulk $)$ & 10 & 2.00 & Marcolli et al. (2004a) \\
\hline $\begin{array}{l}\text { M5: malic acid, malonic acid, } \\
\text { maleic acid, glutaric acid, } \\
\text { methylsuccinic acid }\end{array}$ & $\begin{array}{l}\mathrm{CH}_{\mathrm{n}}, \mathrm{CH}_{\mathrm{n}}^{[\mathrm{OH}]}, \mathrm{COOH}, \mathrm{OH}, \\
\mathrm{C}=\mathrm{C}\end{array}$ & $\mathrm{NaCl}$ & 298 & SLE & 10 & 1.00 & Marcolli et al. (2004a) \\
\hline citric acid & $\mathrm{CH}_{\mathrm{n}}, \mathrm{CH}_{\mathrm{n}}^{[\mathrm{OH}]}, \mathrm{COOH}, \mathrm{OH}$ & $\mathrm{NaCl}$ & 298 & $a_{\mathrm{W}}($ bulk $)$ & 37 & 2.00 & Schunk and Maurer (2004) \\
\hline citric acid, 2-butanol & $\mathrm{CH}_{\mathrm{n}}, \mathrm{CH}_{\mathrm{n}}^{[\mathrm{OH}]}, \mathrm{COOH}, \mathrm{OH}$ & $\mathrm{NaCl}$ & 298 & LLE & 15 & 1.00 & Lintomen et al. (2000) \\
\hline propanoic acid, 1-butanol & $\mathrm{CH}_{\mathrm{n}}, \mathrm{CH}_{\mathrm{n}}^{[\mathrm{OH}]}, \mathrm{COOH}, \mathrm{OH}$ & $\mathrm{NaCl}$ & 303 & LLE & 19 & 1.00 & Solimo et al. (1997) \\
\hline propanoic acid & $\mathrm{CH}_{\mathrm{n}}, \mathrm{COOH}$ & $\mathrm{NaCl}$ & 333 & $\operatorname{VLE}(x-y-T)$ & 23 & 0.50 & Banat et al. (2002) \\
\hline propanoic acid & $\mathrm{CH}_{\mathrm{n}}, \mathrm{COOH}$ & $\mathrm{NaCl}$ & 313 & $\operatorname{VLE}(x-y-T)$ & 5 & 0.50 & Banat et al. (2003b) \\
\hline propanoic acid & $\mathrm{CH}_{\mathrm{n}}, \mathrm{COOH}$ & $\mathrm{NaCl}$ & 323 & $\operatorname{VLE}(x-y-T)$ & 15 & 0.50 & Banat et al. (2003b) \\
\hline malonic acid & $\mathrm{CH}_{\mathrm{n}}, \mathrm{COOH}$ & $\mathrm{NaCl}$ & 303 & $a_{\mathrm{W}}($ bulk $)$ & 8 & 2.00 & this study \\
\hline malonic acid & $\mathrm{CH}_{\mathrm{n}}, \mathrm{COOH}$ & $\mathrm{NaCl}$ & 293 & $a_{\mathrm{W}}($ bulk $)$ & 8 & 2.00 & this study \\
\hline glutaric acid & $\mathrm{CH}_{\mathrm{n}}, \mathrm{COOH}$ & $\mathrm{NaCl}$ & 295 & $a_{\mathrm{W}}(\mathrm{EDB})$ & 42 & 1.00 & Pope et al. (2010) \\
\hline malonic acid & $\mathrm{CH}_{\mathrm{n}}, \mathrm{COOH}$ & $\mathrm{NaCl}$ & 295 & $a_{\mathrm{W}}(\mathrm{EDB})$ & 29 & 1.00 & Pope et al. (2010) \\
\hline acetic acid, 1-butanol & $\mathrm{CH}_{\mathrm{n}}, \mathrm{CH}_{\mathrm{n}}^{[\mathrm{OH}]}, \mathrm{COOH}, \mathrm{OH}$ & $\mathrm{NaCl}$ & 298 & LLE & 41 & 1.00 & Tan and Aravinth (1999) \\
\hline citric acid & $\mathrm{CH}_{\mathrm{n}}, \mathrm{CH}_{\mathrm{n}}^{[\mathrm{OH}]}, \mathrm{COOH}, \mathrm{OH}$ & $\mathrm{NaNO}_{3}$ & 298 & $a_{\mathrm{W}}($ bulk $)$ & 35 & 2.00 & Schunk and Maurer (2004) \\
\hline acetic acid & $\mathrm{CH}_{\mathrm{n}}, \mathrm{COOH}$ & $\mathrm{NaNO}_{3}$ & 298 & SLE & 1 & 0.01 & Davidson and Geer (1933) \\
\hline malonic acid & $\mathrm{CH}_{\mathrm{n}}, \mathrm{COOH}$ & $\mathrm{NH}_{4} \mathrm{Br}$ & 303 & $a_{\mathrm{w}}($ bulk $)$ & 9 & 2.00 & this study \\
\hline malonic acid & $\mathrm{CH}_{\mathrm{n}}, \mathrm{COOH}$ & $\mathrm{NH}_{4} \mathrm{Br}$ & 293 & $a_{\mathrm{W}}($ bulk $)$ & 9 & 2.00 & this study \\
\hline maleic acid & $\mathrm{C}=\mathrm{C}, \mathrm{COOH}$ & $\mathrm{NH}_{4} \mathrm{Br}$ & 293 & $a_{\mathrm{W}}($ bulk $)$ & 7 & 2.00 & this study \\
\hline propanoic acid & $\mathrm{CH}_{\mathrm{n}}, \mathrm{COOH}$ & $\mathrm{NH}_{4} \mathrm{Cl}$ & 333 & $\operatorname{VLE}(x-y-T)$ & 5 & 0.50 & Banat et al. (2002) \\
\hline propanoic acid & $\mathrm{CH}_{\mathrm{n}}, \mathrm{COOH}$ & $\mathrm{NH}_{4} \mathrm{Cl}$ & 313 & $\operatorname{VLE}(x-y-T)$ & 5 & 0.50 & Banat et al. (2003b) \\
\hline propanoic acid & $\mathrm{CH}_{\mathrm{n}}, \mathrm{COOH}$ & $\mathrm{NH}_{4} \mathrm{Cl}$ & 323 & $\operatorname{VLE}(x-y-T)$ & 5 & 0.50 & Banat et al. (2003b) \\
\hline methacrylic acid & $\mathrm{CH}_{\mathrm{n}}, \mathrm{C}=\mathrm{C} \mathrm{COOH}$ & $\mathrm{NH}_{4} \mathrm{HSO}_{4}$ & 298 & LLE & 4 & 0.01 & Obmelyukhina et al. (1979) \\
\hline malonic acid & $\mathrm{CH}_{\mathrm{n}}, \mathrm{COOH}$ & $\mathrm{NH}_{4} \mathrm{HSO}_{4}$ & 298 & $a_{\mathrm{W}}($ bulk $)$ & 66 & 2.00 & Salcedo (2006) \\
\hline malonic acid & $\mathrm{CH}_{\mathrm{n}}, \mathrm{COOH}$ & $\mathrm{NH}_{4} \mathrm{HSO}_{4}$ & 298 & SLE & 8 & 1.00 & Salcedo (2006) \\
\hline malonic acid & $\mathrm{CH}_{\mathrm{n}}, \mathrm{COOH}$ & $\mathrm{NH}_{4} \mathrm{HSO}_{4}$ & 289 & SLE & 5 & 1.00 & Salcedo (2006) \\
\hline $\begin{array}{l}\text { M5: malic acid, malonic acid, } \\
\text { maleic acid, glutaric acid, } \\
\text { methylsuccinic acid }\end{array}$ & $\begin{array}{l}\mathrm{CH}_{\mathrm{n}}, \mathrm{CH}_{\mathrm{n}}^{[\mathrm{OH}]}, \mathrm{COOH}, \mathrm{OH}, \\
\mathrm{C}=\mathrm{C}\end{array}$ & $\mathrm{NH}_{4} \mathrm{NO}_{3}$ & 298 & $a_{\mathrm{W}}(\mathrm{bulk})$ & 6 & 2.00 & Marcolli et al. (2004a) \\
\hline $\begin{array}{l}\text { M5: malic acid, malonic acid, } \\
\text { maleic acid, glutaric acid, } \\
\text { methylsuccinic acid }\end{array}$ & $\begin{array}{l}\mathrm{CH}_{\mathrm{n}}, \mathrm{CH}_{\mathrm{n}}^{[\mathrm{OH}]}, \mathrm{COOH}, \mathrm{OH}, \\
\mathrm{C}=\mathrm{C}\end{array}$ & $\mathrm{NH}_{4} \mathrm{NO}_{3}$ & 298 & SLE & 6 & 1.00 & Marcolli et al. (2004a) \\
\hline malonic acid & $\mathrm{CH}_{\mathrm{n}}, \mathrm{COOH}$ & $\mathrm{NH}_{4} \mathrm{NO}_{3}$ & 293 & $a_{\mathrm{W}}($ bulk $)$ & 16 & 2.00 & this study \\
\hline
\end{tabular}


Table 2. Continued.

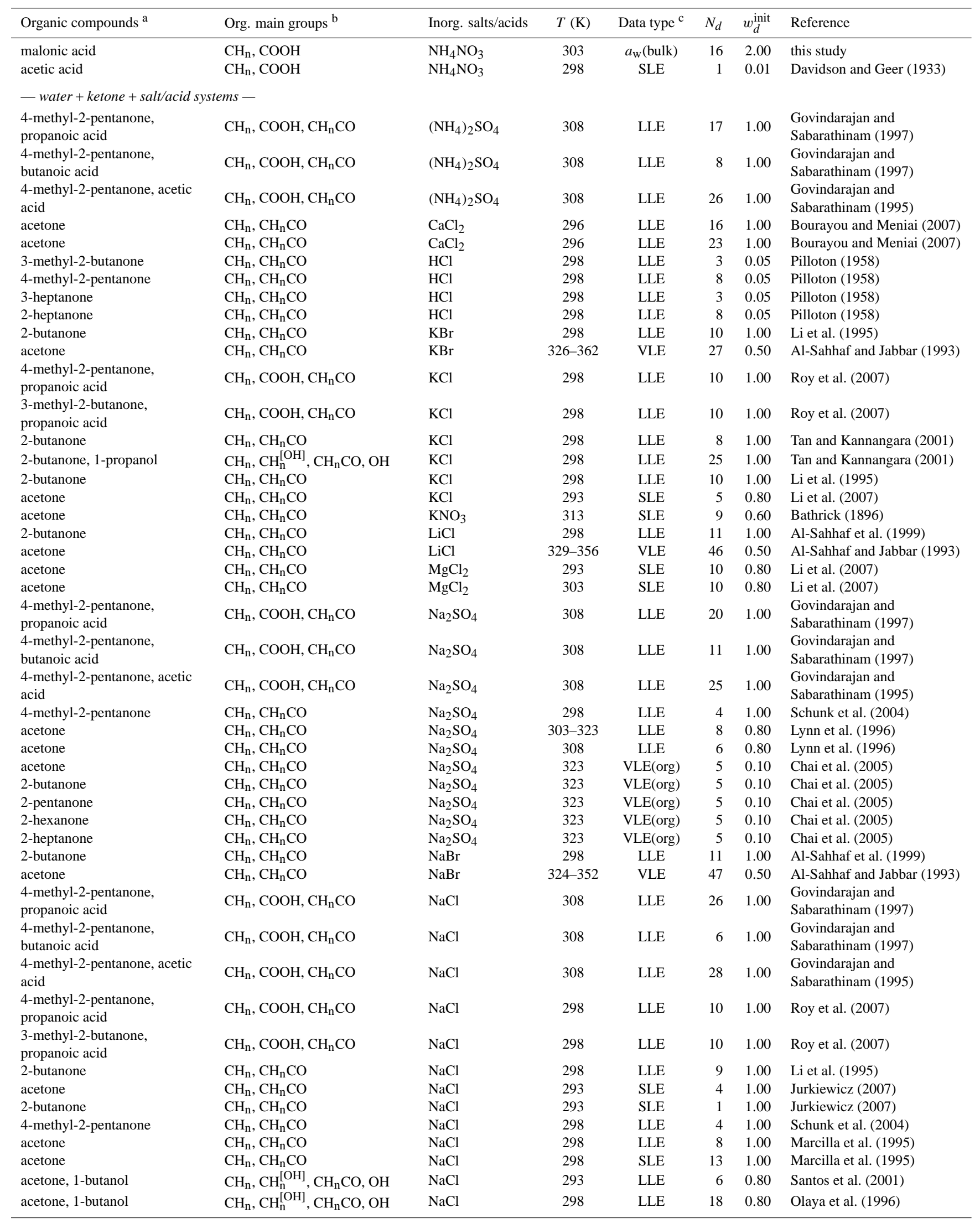


Table 2. Continued.

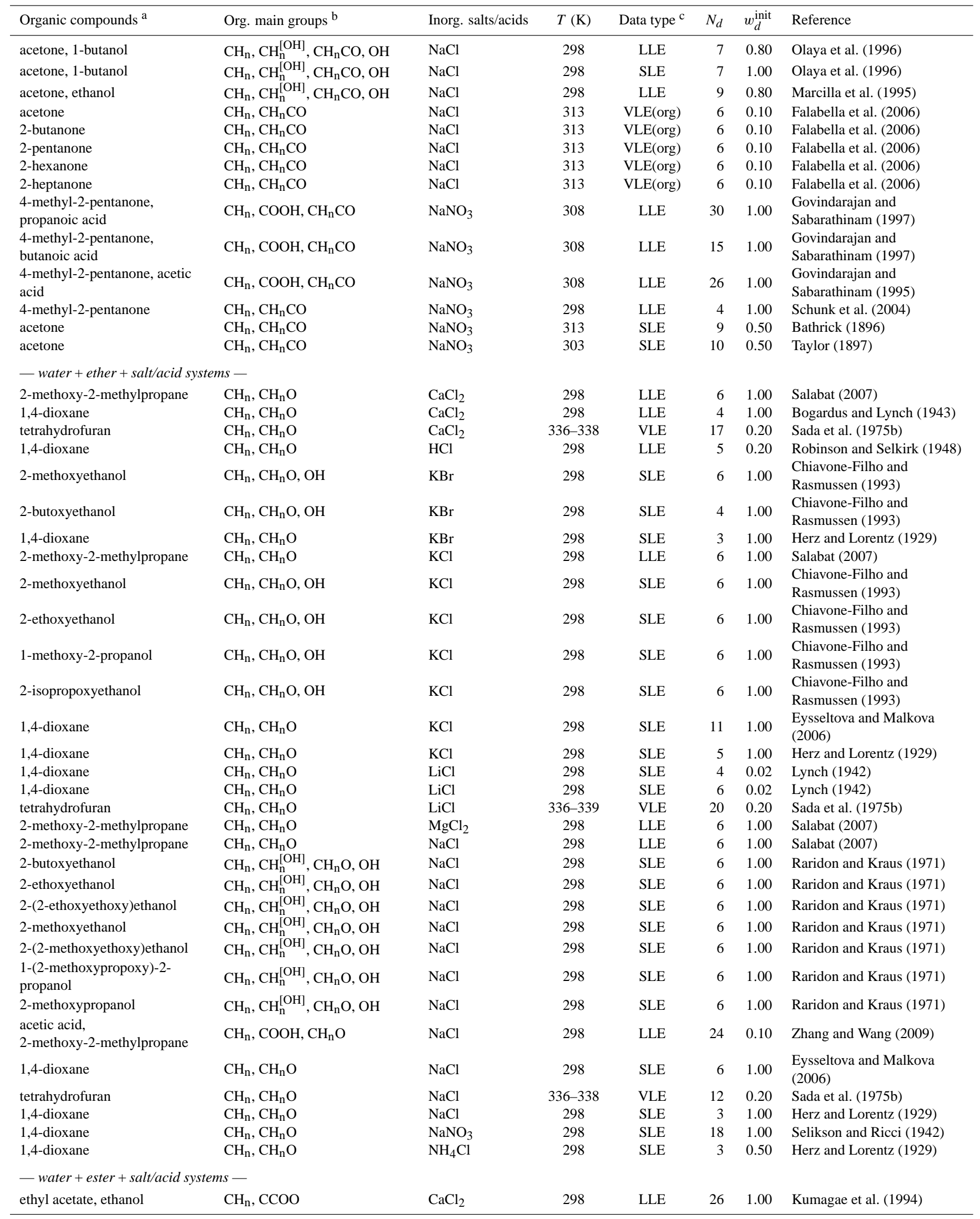


Table 2. Continued.

\begin{tabular}{|c|c|c|c|c|c|c|c|}
\hline Organic compounds ${ }^{a}$ & Org. main groups ${ }^{b}$ & Inorg. salts/acids & $T(\mathrm{~K})$ & Data type ${ }^{c}$ & $N_{d}$ & $w_{d}^{\text {init }}$ & Reference \\
\hline ethyl acetate & $\mathrm{CH}_{\mathrm{n}}, \mathrm{CCOO}$ & $\mathrm{CaCl}_{2}$ & 298 & LLE & 12 & 1.00 & Kumagae et al. (1994) \\
\hline ethyl acetate & $\mathrm{CH}_{\mathrm{n}}, \mathrm{CCOO}$ & $\mathrm{CaCl}_{2}$ & 313 & LLE & 4 & 0.80 & Lin et al. (2005) \\
\hline ethyl acetate, ethanol & $\mathrm{CH}_{\mathrm{n}}, \mathrm{CH}_{\mathrm{n}}^{[\mathrm{OH}]}, \mathrm{CCOO}, \mathrm{OH}$ & $\mathrm{CaCl}_{2}$ & 283 & LLE & 8 & 0.80 & Lin et al. (2005) \\
\hline ethyl acetate, ethanol & $\mathrm{CH}_{\mathrm{n}}, \mathrm{CH}_{\mathrm{n}}^{[\mathrm{OH}]}, \mathrm{CCOO}, \mathrm{OH}$ & $\mathrm{CaCl}_{2}$ & 313 & LLE & 8 & 0.80 & Lin et al. (2005) \\
\hline ethyl acetate & $\mathrm{CH}_{\mathrm{n}}, \mathrm{CCOO}$ & $\mathrm{CaCl}_{2}$ & $344-348$ & VLE & 14 & 0.50 & Rajendran et al. (1991) \\
\hline ethyl acetate & $\mathrm{CH}_{\mathrm{n}}, \mathrm{CCOO}$ & $\mathrm{KBr}$ & 303 & solubil. & 4 & 1.00 & $\begin{array}{l}\text { Altshuller and Everson } \\
\text { (1953) }\end{array}$ \\
\hline ethyl acetate & $\mathrm{CH}_{\mathrm{n}}, \mathrm{CCOO}$ & $\mathrm{KCl}$ & 298 & solubil. & 4 & 1.00 & $\begin{array}{l}\text { Altshuller and Everson } \\
\text { (1953) }\end{array}$ \\
\hline ethyl acetate & $\mathrm{CH}_{\mathrm{n}}, \mathrm{CCOO}$ & $\mathrm{LiBr}$ & 298 & solubil. & 4 & 1.00 & $\begin{array}{l}\text { Altshuller and Everson } \\
\text { (1953) }\end{array}$ \\
\hline ethyl acetate & $\mathrm{CH}_{\mathrm{n}}, \mathrm{CCOO}$ & $\mathrm{LiCl}$ & 298 & LLE & 11 & 1.00 & Al-Sahhaf et al. (1999) \\
\hline ethyl acetate & $\mathrm{CH}_{\mathrm{n}}, \mathrm{CCOO}$ & $\mathrm{LiCl}$ & 298 & solubil. & 4 & 1.00 & $\begin{array}{l}\text { Altshuller and Everson } \\
\text { (1953) }\end{array}$ \\
\hline $\begin{array}{l}\text { ethyl acetate, ethanol } \\
\text { (water-free) }\end{array}$ & $\mathrm{CH}_{\mathrm{n}}, \mathrm{CH}_{\mathrm{n}}^{[\mathrm{OH}]}, \mathrm{CCOO}, \mathrm{OH}$ & $\mathrm{LiNO}_{3}$ & $345-356$ & VLE & 76 & 0.50 & Topphoff et al. (2001) \\
\hline ethyl acetate & $\mathrm{CH}_{\mathrm{n}}, \mathrm{CCOO}$ & $\mathrm{Na}_{2} \mathrm{SO}_{4}$ & 303 & LLE & 4 & 1.00 & Nakamura (1969) \\
\hline ethyl acetate & $\mathrm{CH}_{\mathrm{n}}, \mathrm{CCOO}$ & $\mathrm{NaBr}$ & 298 & LLE & 10 & 1.00 & Al-Sahhaf et al. (1999) \\
\hline ethyl acetate & $\mathrm{CH}_{\mathrm{n}}, \mathrm{CCOO}$ & $\mathrm{NaBr}$ & 298 & solubil. & 4 & 1.00 & $\begin{array}{l}\text { Altshuller and Everson } \\
\text { (1953) }\end{array}$ \\
\hline ethyl acetate & $\mathrm{CH}_{\mathrm{n}}, \mathrm{CCOO}$ & $\mathrm{NaCl}$ & 303 & LLE & 5 & 1.00 & Gomis et al. (1993) \\
\hline methyl acetate & $\mathrm{CH}_{\mathrm{n}}, \mathrm{CCOO}$ & $\mathrm{NaCl}$ & 298 & solubil. & 4 & 1.00 & Segatin and Klofutar (2000) \\
\hline ethyl acetate & $\mathrm{CH}_{\mathrm{n}}, \mathrm{CCOO}$ & $\mathrm{NaCl}$ & 298 & solubil. & 4 & 1.00 & Segatin and Klofutar (2000) \\
\hline 1-propyl acetate & $\mathrm{CH}_{\mathrm{n}}, \mathrm{CCOO}$ & $\mathrm{NaCl}$ & 298 & solubil. & 4 & 1.00 & Segatin and Klofutar (2000) \\
\hline 1-butyl acetate & $\mathrm{CH}_{\mathrm{n}}, \mathrm{CCOO}$ & $\mathrm{NaCl}$ & 298 & solubil. & 4 & 1.00 & Segatin and Klofutar (2000) \\
\hline isobutyl acetate & $\mathrm{CH}_{\mathrm{n}}, \mathrm{CCOO}$ & $\mathrm{NaCl}$ & 298 & solubil. & 4 & 1.00 & Segatin and Klofutar (2000) \\
\hline 2-butyl acetate & $\mathrm{CH}_{\mathrm{n}}, \mathrm{CCOO}$ & $\mathrm{NaCl}$ & 298 & solubil. & 4 & 1.00 & Segatin and Klofutar (2000) \\
\hline tert-butyl acetate & $\mathrm{CH}_{\mathrm{n}}, \mathrm{CCOO}$ & $\mathrm{NaCl}$ & 298 & solubil. & 4 & 1.00 & Segatin and Klofutar (2000) \\
\hline 1-pentyl acetate & $\mathrm{CH}_{\mathrm{n}}, \mathrm{CCOO}$ & $\mathrm{NaCl}$ & 298 & solubil. & 4 & 1.00 & Segatin and Klofutar (2000) \\
\hline 1-hexyl acetate & $\mathrm{CH}_{\mathrm{n}}, \mathrm{CCOO}$ & $\mathrm{NaCl}$ & 298 & solubil. & 4 & 1.00 & Segatin and Klofutar (2000) \\
\hline ethyl acetate & $\mathrm{CH}_{\mathrm{n}}, \mathrm{CCOO}$ & $\mathrm{NaCl}$ & 298 & solubil. & 4 & 1.00 & $\begin{array}{l}\text { Altshuller and Everson } \\
\text { (1953) }\end{array}$ \\
\hline ethyl acetate & $\mathrm{CH}_{\mathrm{n}}, \mathrm{CCOO}$ & $\mathrm{NaCl}$ & $344-347$ & VLE & 14 & 0.50 & Rajendran et al. (1991) \\
\hline \multicolumn{8}{|c|}{ - water + multifunctional aromatic compounds + salt/acid systems -} \\
\hline benzene & $\mathrm{ACH}_{\mathrm{n}}$ & $\left(\mathrm{NH}_{4}\right)_{2} \mathrm{SO}_{4}$ & 293 & LLE & 4 & 1.00 & van Delden et al. (2004) \\
\hline benzene & $\mathrm{ACH}_{\mathrm{n}}$ & $\left(\mathrm{NH}_{4}\right)_{2} \mathrm{SO}_{4}$ & 313 & LLE & 4 & 0.80 & van Delden et al. (2004) \\
\hline 2,4-dihydroxybenzaldehyde & $\mathrm{ACH}_{\mathrm{n}}, \mathrm{ACOH}, \mathrm{CHO}$ & $\mathrm{Ca}\left(\mathrm{NO}_{3}\right)_{2}$ & 298 & SLE & 4 & 1.00 & this study \\
\hline benzene & $\mathrm{ACH}_{\mathrm{n}}$ & $\mathrm{CaCl}_{2}$ & 303 & solubil. & 5 & 0.80 & Boddu et al. (2001) \\
\hline benzene & $\mathrm{ACH}_{\mathrm{n}}$ & $\mathrm{H}_{2} \mathrm{SO}_{4}$ & 303 & solubil. & 7 & 0.20 & Hanson and Ismail (1975) \\
\hline benzene & $\mathrm{ACH}_{\mathrm{n}}$ & $\mathrm{HCl}$ & 298 & solubil. & 4 & 1.00 & McDevit and Long (1952) \\
\hline phenol & $\mathrm{ACH}_{\mathrm{n}}, \mathrm{ACOH}$ & $\mathrm{HCl}$ & 300 & solubil. & 1 & 1.00 & Jaoui et al. (2002) \\
\hline benzene & $\mathrm{ACH}_{\mathrm{n}}$ & $\mathrm{HCl}$ & 303 & LLE & 8 & 0.00 & Ishidao et al. (2001) \\
\hline phenol & $\mathrm{ACH}_{n}, \mathrm{ACOH}$ & $\mathrm{HCl}$ & 285 & LLE & 10 & 0.80 & $\begin{array}{l}\text { Schreinemakers and van den } \\
\text { Bos (1912) }\end{array}$ \\
\hline phenol & $\mathrm{ACH}_{\mathrm{n}}, \mathrm{ACOH}$ & $\mathrm{HCl}$ & 298 & $\gamma_{ \pm}$ & 27 & 2.00 & Sadek et al. (1972) \\
\hline benzene & $\mathrm{ACH}_{\mathrm{n}}$ & $\mathrm{HNO}_{3}$ & 295 & solubil. & 6 & 0.50 & Hanson and Ismail (1975) \\
\hline 2-hydroxybenzoic acid & $\mathrm{ACH}_{\mathrm{n}}, \mathrm{ACOH}, \mathrm{COOH}$ & $\mathrm{K}_{2} \mathrm{SO}_{4}$ & 298 & SLE & 1 & 1.00 & Sugunan and Thomas (1995) \\
\hline 2-hydroxybenzoic acid & $\mathrm{ACH}_{\mathrm{n}}, \mathrm{ACOH}, \mathrm{COOH}$ & $\mathrm{K}_{2} \mathrm{SO}_{4}$ & 308 & SLE & 8 & 0.50 & Sugunan and Thomas (1995) \\
\hline 4-hydroxybenzoic acid & $\mathrm{ACH}_{\mathrm{n}}, \mathrm{ACOH}, \mathrm{COOH}$ & $\mathrm{K}_{2} \mathrm{SO}_{4}$ & 298 & SLE & 1 & 1.00 & Sugunan and Thomas (1995) \\
\hline 4-hydroxybenzoic acid & $\mathrm{ACH}_{\mathrm{n}}, \mathrm{ACOH}, \mathrm{COOH}$ & $\mathrm{K}_{2} \mathrm{SO}_{4}$ & 308 & SLE & 8 & 0.20 & Sugunan and Thomas (1995) \\
\hline benzene & $\mathrm{ACH}_{\mathrm{n}}$ & $\mathrm{KBr}$ & 298 & solubil. & 2 & 1.00 & McDevit and Long (1952) \\
\hline 2-hydroxybenzoic acid & $\mathrm{ACH}_{\mathrm{n}}, \mathrm{ACOH}, \mathrm{COOH}$ & $\mathrm{KBr}$ & 298 & SLE & 3 & 1.00 & Osol and Kilpatrick (1933) \\
\hline 2-hydroxybenzoic acid & $\mathrm{ACH}_{\mathrm{n}}, \mathrm{ACOH}, \mathrm{COOH}$ & $\mathrm{KBr}$ & 298 & SLE & 1 & 1.00 & Sugunan and Thomas (1995) \\
\hline 2-hydroxybenzoic acid & $\mathrm{ACH}_{\mathrm{n}}, \mathrm{ACOH}, \mathrm{COOH}$ & $\mathrm{KBr}$ & 308 & SLE & 8 & 0.50 & Sugunan and Thomas (1995) \\
\hline 4-hydroxybenzoic acid & $\mathrm{ACH}_{\mathrm{n}}, \mathrm{ACOH}, \mathrm{COOH}$ & $\mathrm{KBr}$ & 298 & SLE & 1 & 1.00 & Sugunan and Thomas (1995) \\
\hline 4-hydroxybenzoic acid & $\mathrm{ACH}_{\mathrm{n}}, \mathrm{ACOH}, \mathrm{COOH}$ & $\mathrm{KBr}$ & 308 & SLE & 8 & 0.50 & Sugunan and Thomas (1995) \\
\hline protocatechuic acid & $\mathrm{ACH}_{\mathrm{n}}, \mathrm{ACOH}, \mathrm{COOH}$ & $\mathrm{KCl}$ & 298 & SLE & 7 & 1.00 & Noubigh et al. (2007b) \\
\hline vanillin & $\mathrm{ACH}_{\mathrm{n}}, \mathrm{ACOH}, \mathrm{CH}_{\mathrm{n}} \mathrm{O}, \mathrm{CHO}$ & $\mathrm{KCl}$ & 298 & SLE & 7 & 1.00 & Noubigh et al. (2007b) \\
\hline vanillic acid & $\mathrm{ACH}_{\mathrm{n}}, \mathrm{ACOH}, \mathrm{CH}_{\mathrm{n}} \mathrm{O}, \mathrm{COOH}$ & $\mathrm{KCl}$ & 298 & SLE & 6 & 1.00 & Noubigh et al. (2007b) \\
\hline gallic acid & $\mathrm{ACH}_{\mathrm{n}}, \mathrm{ACOH}, \mathrm{COOH}$ & $\mathrm{KCl}$ & 298 & SLE & 7 & 1.00 & Noubigh et al. (2007b) \\
\hline ferulic acid & $\begin{array}{l}\mathrm{ACH}_{\mathrm{n}}, \mathrm{ACOH}, \mathrm{CH}_{\mathrm{n}} \mathrm{O}, \mathrm{C}=\mathrm{C} \text {, } \\
\mathrm{COOH}\end{array}$ & $\mathrm{KCl}$ & 298 & SLE & 7 & 1.00 & Noubigh et al. (2007a) \\
\hline
\end{tabular}


Table 2. Continued.

\begin{tabular}{|c|c|c|c|c|c|c|c|}
\hline Organic compounds ${ }^{a}$ & Org. main groups $b$ & Inorg. salts/acids & $T(\mathrm{~K})$ & Data type $^{\mathrm{c}}$ & $N_{d}$ & $w_{d}^{\text {init }}$ & Reference \\
\hline syringic acid & $\mathrm{ACH}_{\mathrm{n}}, \mathrm{ACOH}, \mathrm{CH}_{\mathrm{n}} \mathrm{O}, \mathrm{COOH}$ & $\mathrm{KCl}$ & 298 & SLE & 7 & 1.00 & Noubigh et al. (2007a) \\
\hline benzene & $\mathrm{ACH}_{\mathrm{n}}$ & $\mathrm{KCl}$ & 298 & solubil. & 2 & 1.00 & McDevit and Long (1952) \\
\hline 2-hydroxybenzoic acid & $\mathrm{ACH}_{\mathrm{n}}, \mathrm{ACOH}, \mathrm{COOH}$ & $\mathrm{KCl}$ & 298 & SLE & 5 & 1.00 & Osol and Kilpatrick (1933) \\
\hline 3-hydroxybenzoic acid & $\mathrm{ACH}_{\mathrm{n}}, \mathrm{ACOH}, \mathrm{COOH}$ & $\mathrm{KCl}$ & 298 & SLE & 5 & 1.00 & Osol and Kilpatrick (1933) \\
\hline 4-hydroxybenzoic acid & $\mathrm{ACH}_{\mathrm{n}}, \mathrm{ACOH}, \mathrm{COOH}$ & $\mathrm{KCl}$ & 298 & SLE & 7 & 1.00 & Osol and Kilpatrick (1933) \\
\hline 2-hydroxybenzoic acid & $\mathrm{ACH}_{\mathrm{n}}, \mathrm{ACOH}, \mathrm{COOH}$ & $\mathrm{KCl}$ & 298 & SLE & 1 & 1.00 & Sugunan and Thomas (1995) \\
\hline 2-hydroxybenzoic acid & $\mathrm{ACH}_{\mathrm{n}}, \mathrm{ACOH}, \mathrm{COOH}$ & $\mathrm{KCl}$ & 308 & SLE & 8 & 0.50 & Sugunan and Thomas (1995) \\
\hline 4-hydroxybenzoic acid & $\mathrm{ACH}_{\mathrm{n}}, \mathrm{ACOH}, \mathrm{COOH}$ & $\mathrm{KCl}$ & 298 & SLE & 1 & 1.00 & Sugunan and Thomas (1995) \\
\hline 4-hydroxybenzoic acid & $\mathrm{ACH}_{\mathrm{n}}, \mathrm{ACOH}, \mathrm{COOH}$ & $\mathrm{KCl}$ & 308 & SLE & 8 & 0.50 & Sugunan and Thomas (1995) \\
\hline 2-hydroxybenzoic acid & $\mathrm{ACH}_{\mathrm{n}}, \mathrm{ACOH}, \mathrm{COOH}$ & $\mathrm{KNO}_{3}$ & 298 & SLE & 1 & 1.00 & Sugunan and Thomas (1995) \\
\hline 2-hydroxybenzoic acid & $\mathrm{ACH}_{\mathrm{n}}, \mathrm{ACOH}, \mathrm{COOH}$ & $\mathrm{KNO}_{3}$ & 308 & SLE & 8 & 0.50 & Sugunan and Thomas (1995) \\
\hline protocatechuic acid & $\mathrm{ACH}_{n}, \mathrm{ACOH}, \mathrm{COOH}$ & $\mathrm{LiCl}$ & 298 & SLE & 7 & 1.00 & Noubigh et al. (2007b) \\
\hline vanillin & $\mathrm{ACH}_{\mathrm{n}}, \mathrm{ACOH}, \mathrm{CH}_{\mathrm{n}} \mathrm{O}, \mathrm{CHO}$ & $\mathrm{LiCl}$ & 298 & SLE & 7 & 1.00 & Noubigh et al. (2007b) \\
\hline vanillic acid & $\mathrm{ACH}_{\mathrm{n}}, \mathrm{ACOH}, \mathrm{CH}_{\mathrm{n}} \mathrm{O}, \mathrm{COOH}$ & $\mathrm{LiCl}$ & 298 & SLE & 7 & 1.00 & Noubigh et al. (2007b) \\
\hline gallic acid & $\mathrm{ACH}_{\mathrm{n}}, \mathrm{ACOH}, \mathrm{COOH}$ & $\mathrm{LiCl}$ & 298 & SLE & 7 & 1.00 & Noubigh et al. (2007b) \\
\hline ferulic acid & $\begin{array}{l}\mathrm{ACH}_{\mathrm{n}}, \mathrm{ACOH}, \mathrm{CH}_{\mathrm{n}} \mathrm{O}, \mathrm{C}=\mathrm{C} \text {, } \\
\mathrm{COOH}\end{array}$ & $\mathrm{LiCl}$ & 298 & SLE & 7 & 1.00 & Noubigh et al. (2007a) \\
\hline syringic acid & $\mathrm{ACH}_{\mathrm{n}}, \mathrm{ACOH}, \mathrm{CH}_{\mathrm{n}} \mathrm{O}, \mathrm{COOH}$ & $\mathrm{LiCl}$ & 298 & SLE & 7 & 1.00 & Noubigh et al. (2007a) \\
\hline benzene & $\mathrm{ACH}_{\mathrm{n}}$ & $\mathrm{LiCl}$ & 298 & solubil. & 2 & 1.00 & McDevit and Long (1952) \\
\hline 2-hydroxybenzoic acid & $\mathrm{ACH}_{\mathrm{n}}, \mathrm{ACOH}, \mathrm{COOH}$ & $\mathrm{LiCl}$ & 298 & SLE & 4 & 1.00 & Osol and Kilpatrick (1933) \\
\hline 2,4-dihydroxybenzaldehyde & $\mathrm{ACH}_{\mathrm{n}}, \mathrm{ACOH}, \mathrm{CHO}$ & $\mathrm{Mg}\left(\mathrm{NO}_{3}\right)_{2}$ & 298 & SLE & 4 & 1.00 & this study \\
\hline 2-hydroxybenzoic acid & $\mathrm{ACH}_{\mathrm{n}}, \mathrm{ACOH}, \mathrm{COOH}$ & $\mathrm{MgSO}_{4}$ & 298 & SLE & 1 & 1.00 & Sugunan and Thomas (1995) \\
\hline 2-hydroxybenzoic acid & $\mathrm{ACH}_{\mathrm{n}}, \mathrm{ACOH}, \mathrm{COOH}$ & $\mathrm{MgSO}_{4}$ & 308 & SLE & 8 & 1.00 & Sugunan and Thomas (1995) \\
\hline 4-hydroxybenzoic acid & $\mathrm{ACH}_{\mathrm{n}}, \mathrm{ACOH}, \mathrm{COOH}$ & $\mathrm{MgSO}_{4}$ & 298 & SLE & 1 & 0.20 & Sugunan and Thomas (1995) \\
\hline 4-hydroxybenzoic acid & $\mathrm{ACH}_{\mathrm{n}}, \mathrm{ACOH}, \mathrm{COOH}$ & $\mathrm{MgSO}_{4}$ & 308 & SLE & 8 & 0.20 & Sugunan and Thomas (1995) \\
\hline benzene & $\mathrm{ACH}_{\mathrm{n}}$ & $\mathrm{Na}_{2} \mathrm{SO}_{4}$ & 298 & solubil. & 3 & 1.00 & McDevit and Long (1952) \\
\hline gallic acid & $\mathrm{ACH}_{\mathrm{n}}, \mathrm{ACOH}, \mathrm{COOH}$ & $\mathrm{Na}_{2} \mathrm{SO}_{4}$ & 298 & SLE & 3 & 1.00 & Noubigh et al. (2008) \\
\hline syringic acid & $\mathrm{ACH}_{\mathrm{n}}, \mathrm{ACOH}, \mathrm{CH}_{\mathrm{n}} \mathrm{O}, \mathrm{COOH}$ & $\mathrm{Na}_{2} \mathrm{SO}_{4}$ & 298 & SLE & 3 & 1.00 & Noubigh et al. (2008) \\
\hline protocatechuic acid & $\mathrm{ACH}_{\mathrm{n}}, \mathrm{ACOH}, \mathrm{COOH}$ & $\mathrm{Na}_{2} \mathrm{SO}_{4}$ & 298 & SLE & 3 & 1.00 & Noubigh et al. (2008) \\
\hline vanillin & $\mathrm{ACH}_{\mathrm{n}}, \mathrm{ACOH}, \mathrm{CH}_{\mathrm{n}} \mathrm{O}, \mathrm{CHO}$ & $\mathrm{Na}_{2} \mathrm{SO}_{4}$ & 298 & SLE & 3 & 1.00 & Noubigh et al. (2008) \\
\hline 2,4-dihydroxybenzaldehyde & $\mathrm{ACH}_{\mathrm{n}}, \mathrm{ACOH}, \mathrm{CHO}$ & $\mathrm{Na}_{2} \mathrm{SO}_{4}$ & 298 & SLE & 3 & 1.00 & this study \\
\hline benzene & $\mathrm{ACH}_{\mathrm{n}}$ & $\mathrm{NaBr}$ & 298 & solubil. & 3 & 1.00 & McDevit and Long (1952) \\
\hline protocatechuic acid & $\mathrm{ACH}_{\mathrm{n}}, \mathrm{ACOH}, \mathrm{COOH}$ & $\mathrm{NaCl}$ & 298 & SLE & 8 & 1.00 & Noubigh et al. (2007b) \\
\hline vanillin & $\mathrm{ACH}_{\mathrm{n}}, \mathrm{ACOH}, \mathrm{CH}_{\mathrm{n}} \mathrm{O}, \mathrm{CHO}$ & $\mathrm{NaCl}$ & 298 & SLE & 8 & 1.00 & Noubigh et al. (2007b) \\
\hline vanillic acid & $\mathrm{ACH}_{\mathrm{n}}, \mathrm{ACOH}, \mathrm{CH}_{\mathrm{n}} \mathrm{O}, \mathrm{COOH}$ & $\mathrm{NaCl}$ & 298 & SLE & 7 & 1.00 & Noubigh et al. (2007b) \\
\hline gallic acid & $\mathrm{ACH}_{\mathrm{n}}, \mathrm{ACOH}, \mathrm{COOH}$ & $\mathrm{NaCl}$ & 298 & SLE & 7 & 1.00 & Noubigh et al. (2007b) \\
\hline ferulic acid & $\begin{array}{l}\mathrm{ACH}_{\mathrm{n}}, \mathrm{ACOH}, \mathrm{CH}_{\mathrm{n}} \mathrm{O}, \mathrm{C}=\mathrm{C} \text {, } \\
\mathrm{COOH}\end{array}$ & $\mathrm{NaCl}$ & 298 & SLE & 7 & 1.00 & Noubigh et al. (2007a) \\
\hline syringic acid & $\mathrm{ACH}_{\mathrm{n}}, \mathrm{ACOH}, \mathrm{CH}_{\mathrm{n}} \mathrm{O}, \mathrm{COOH}$ & $\mathrm{NaCl}$ & 298 & SLE & 7 & 1.00 & Noubigh et al. (2007a) \\
\hline benzene & $\mathrm{ACH}_{\mathrm{n}}$ & $\mathrm{NaCl}$ & 298 & solubil. & 4 & 1.00 & McDevit and Long (1952) \\
\hline 2-hydroxybenzoic acid & $\mathrm{ACH}_{\mathrm{n}}, \mathrm{ACOH}, \mathrm{COOH}$ & $\mathrm{NaCl}$ & 298 & SLE & 4 & 1.00 & Osol and Kilpatrick (1933) \\
\hline phthalic acid & $\mathrm{ACH}_{\mathrm{n}}, \mathrm{COOH}$ & $\mathrm{NaCl}$ & 298 & SLE & 13 & 1.00 & Bretti et al. (2005) \\
\hline phenol & $\mathrm{ACH}_{\mathrm{n}}, \mathrm{ACOH}$ & $\mathrm{NaCl}$ & 300 & solubil. & 1 & 1.00 & Bretti et al. (2005) \\
\hline 2,4-dihydroxybenzaldehyde & $\mathrm{ACH}_{\mathrm{n}}, \mathrm{ACOH}, \mathrm{CHO}$ & $\mathrm{NaCl}$ & 298 & SLE & 4 & 1.00 & this study \\
\hline benzene & $\mathrm{ACH}_{\mathrm{n}}$ & $\mathrm{NaNO}_{3}$ & 298 & solubil. & 3 & 1.00 & McDevit and Long (1952) \\
\hline 2,4-dihydroxybenzaldehyde & $\mathrm{ACH}_{\mathrm{n}}, \mathrm{ACOH}, \mathrm{CHO}$ & $\mathrm{NH}_{4} \mathrm{Br}$ & 298 & SLE & 3 & 1.00 & this study \\
\hline benzene & $\mathrm{ACH}_{\mathrm{n}}$ & $\mathrm{NH}_{4} \mathrm{Cl}$ & 298 & solubil. & 3 & 1.00 & McDevit and Long (1952) \\
\hline
\end{tabular}

${ }^{\text {a }}$ Unless stated otherwise, the mixtures contain water as additional component.

b The main groups $\mathrm{CH}_{\mathrm{n}}, \mathrm{CH}_{\mathrm{n}}^{[\mathrm{alc}]}$, and $\mathrm{CH}_{\mathrm{n}}^{\text {[alc-tail] }}$ are all listed as " $\mathrm{CH}_{\mathrm{n}}$ " for simplicity, as their interaction parameters with ions are the same. The specific subgroups (with corresponding specific main groups) are listed for all organic compounds in Table 3.

c The different data types as described in Sect. 4. "VLE" indicates complete $x-y-T-p$ VLE data, "VLE(org)" are organic VLE data from Henry's constant measurements, "solubil." refers to liquid-liquid solubility limit data of organic compounds, " $a_{w}(\mathrm{~m}-\mathrm{R})$ " refers to water activity data from micro-Raman droplet experiments, and "SEDB" denotes the scanning EDB method.

parameter, Fig. 8 reveals the estimated degree of confidence associated with each of these interaction parameters (based merely on statistical considerations of data availability, i.e., without attempted judgment of data quality). This estimated degree of confidence is low for a substantial fraction of the interaction parameters and indicates where new measurements would be most beneficial for a further improvement of AIOMFAC.

The extension of AIOMFAC with the new middle-range interaction parameters in conjunction with the versatility of the group-contribution concept allows the computation of activity coefficients for thousands of mixtures. Thus, here we 
Table 3. Selected properties of organic compounds used for the middle-range parameterization of organic main group $\leftrightarrow$ ion interactions.

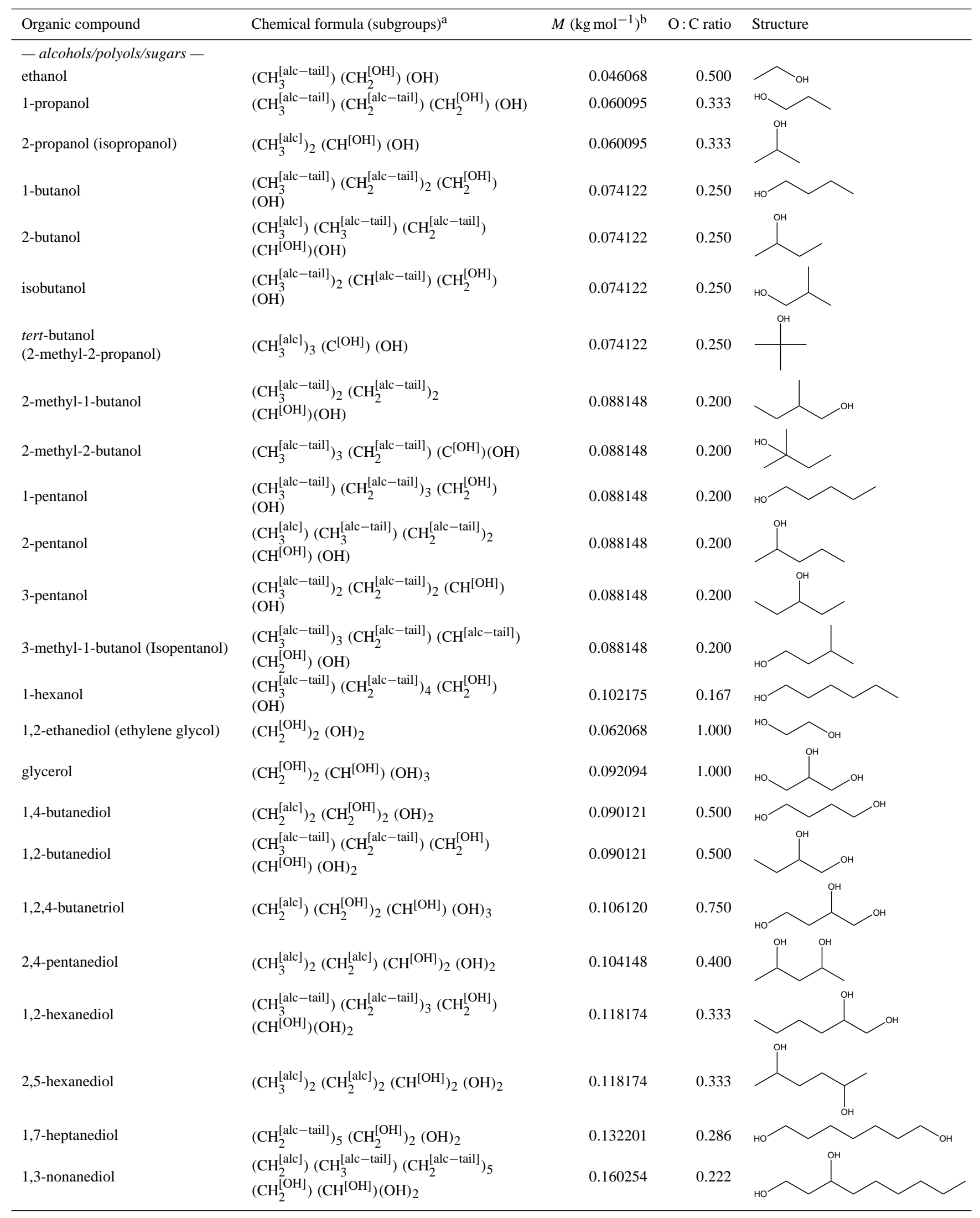


Table 3. Continued.

\begin{tabular}{|c|c|c|c|c|}
\hline Organic compound & Chemical formula (subgroups) ${ }^{\mathrm{a}}$ & $M\left(\mathrm{~kg} \mathrm{~mol}^{-1}\right)^{\mathrm{b}}$ & $\mathrm{O}: \mathrm{C}$ ratio & Structure \\
\hline $\begin{array}{l}\text { D-ribofuranose (dissolved } \\
\text { D-ribose) }\end{array}$ & $\left(\mathrm{CH}_{2}^{[\mathrm{OH}]}\right)\left(\mathrm{CH}^{[\mathrm{OH}]}\right)_{3}\left(\mathrm{CHO}[\right.$ ether] $)(\mathrm{OH})_{4}$ & 0.150130 & 1.000 & \\
\hline — carboxylic acids - & & & & \\
\hline formic acid & $(\mathrm{HCOOH})$ & 0.046025 & 2.000 & \\
\hline acetic acid & $\left(\mathrm{CH}_{3}\right)(\mathrm{COOH})$ & 0.060052 & 1.000 & \\
\hline propanoic acid (propionic acid) & $\left(\mathrm{CH}_{3}\right)\left(\mathrm{CH}_{2}\right)(\mathrm{COOH})$ & 0.074079 & 0.667 & \\
\hline butanoic acid (butyric acid) & $\left(\mathrm{CH}_{3}\right)\left(\mathrm{CH}_{2}\right)_{2}(\mathrm{COOH})$ & 0.088105 & 0.500 & \\
\hline $\begin{array}{l}\text { 2-methylpropanoic acid } \\
\text { (isobutyric acid) }\end{array}$ & $\left(\mathrm{CH}_{3}\right)_{2}(\mathrm{CH})(\mathrm{COOH})$ & 0.088105 & 0.500 & \\
\hline $\begin{array}{l}\text { methacrylic acid } \\
\text { (2-methyl-2-propenoic acid) }\end{array}$ & $\left(\mathrm{CH}_{3}\right)\left(\mathrm{CH}_{2}=\mathrm{C}\right)(\mathrm{COOH})$ & 0.086089 & 0.500 & \\
\hline oxalic acid & $(\mathrm{COOH})_{2}$ & 0.090035 & 2.000 & \\
\hline malonic acid & $\left(\mathrm{CH}_{2}\right)(\mathrm{COOH})_{2}$ & 0.104026 & 1.333 & \\
\hline succinic acid & $\left(\mathrm{CH}_{2}\right)_{2}(\mathrm{COOH})_{2}$ & 0.118052 & 1.000 & \\
\hline glutaric acid & $\left(\mathrm{CH}_{2}\right)_{3}(\mathrm{COOH})_{2}$ & 0.132078 & 0.800 & \\
\hline adipic acid & $\left(\mathrm{CH}_{2}\right)_{4}(\mathrm{COOH})_{2}$ & 0.146141 & 0.667 & \\
\hline
\end{tabular}


Table 3. Continued.

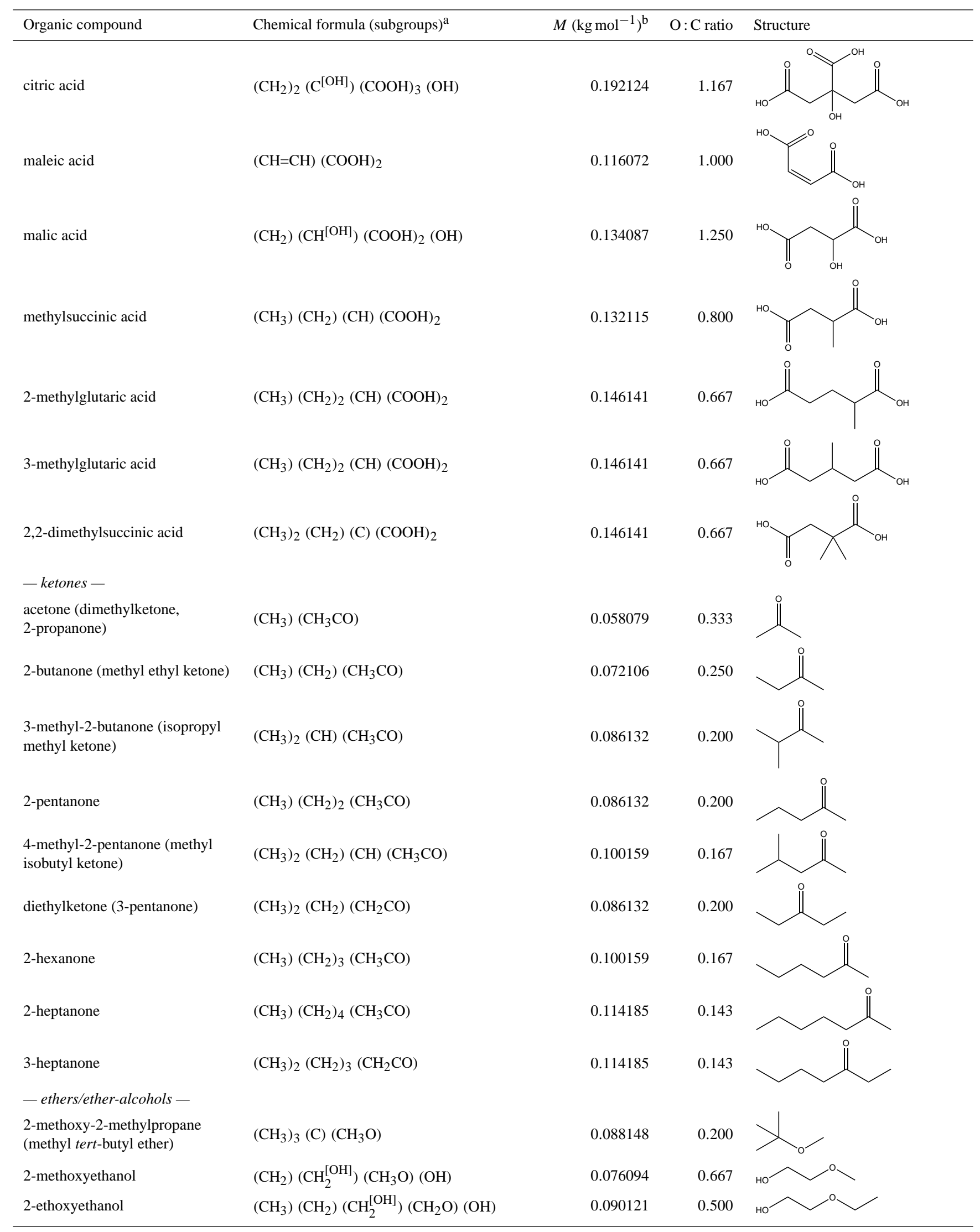


Table 3. Continued.

\begin{tabular}{|c|c|c|c|c|}
\hline Organic compound & Chemical formula (subgroups) ${ }^{\mathrm{a}}$ & $M\left(\mathrm{~kg} \mathrm{~mol}^{-1}\right)^{\mathrm{b}}$ & $\mathrm{O}: \mathrm{C}$ ratio & Structure \\
\hline 1-methoxy-2-propanol & $\left(\mathrm{CH}_{3}\right)\left(\mathrm{CH}_{2}\right)\left(\mathrm{CH}^{[\mathrm{OH}]}\right)\left(\mathrm{CH}_{3} \mathrm{O}\right)(\mathrm{OH})$ & 0.090121 & 0.500 & \\
\hline 2-isopropoxyethanol & $\left(\mathrm{CH}_{3}\right)_{2}(\mathrm{CH})\left(\mathrm{CH}_{2}^{[\mathrm{OH}]}\right)\left(\mathrm{CH}_{2} \mathrm{O}\right)(\mathrm{OH})$ & 0.104148 & 0.400 & \\
\hline 2-butoxyethanol & $\left(\mathrm{CH}_{3}\right)\left(\mathrm{CH}_{2}\right)_{3}\left(\mathrm{CH}_{2}^{[\mathrm{OH}]}\right)\left(\mathrm{CH}_{2} \mathrm{O}\right)(\mathrm{OH})$ & 0.118174 & 0.333 & \\
\hline $\begin{array}{l}\text { 2-(2-methoxyethoxy)ethanol } \\
\text { (methyl carbitol) }\end{array}$ & $\left(\mathrm{CH}_{3}\right)\left(\mathrm{CH}_{2}\right)\left(\mathrm{CH}_{2}^{[\mathrm{OH}]}\right)\left(\mathrm{CH}_{2} \mathrm{O}\right)_{2}(\mathrm{OH})$ & 0.120147 & 0.600 & \\
\hline 2-methoxypropanol & $\left(\mathrm{CH}_{3}\right)(\mathrm{CH})\left(\mathrm{CH}_{2}^{[\mathrm{OH}]}\right)\left(\mathrm{CH}_{3} \mathrm{O}\right)(\mathrm{OH})$ & 0.090121 & 0.500 & \\
\hline $\begin{array}{l}\text { 1-(2-methoxypropoxy)-2- } \\
\text { propanol }\end{array}$ & $\begin{array}{l}\left(\mathrm{CH}_{3}\right)_{2}\left(\mathrm{CH}_{2}\right)(\mathrm{CH})\left(\mathrm{CH}^{[\mathrm{OH}]}\right)\left(\mathrm{CH}_{3} \mathrm{O}\right) \\
\left(\mathrm{CH}_{2} \mathrm{O}\right)(\mathrm{OH})\end{array}$ & 0.148200 & 0.429 & \\
\hline $\begin{array}{l}\text { 1,4-dioxane (dioxoethylene } \\
\text { ether) }\end{array}$ & $\left(\mathrm{CH}_{2}\right)_{2}\left(\mathrm{CH}_{2} \mathrm{O}\right)_{2}$ & 0.088105 & 0.500 & \\
\hline \multicolumn{5}{|l|}{ - esters - } \\
\hline methyl acetate & $\left(\mathrm{CH}_{3}\right)\left(\mathrm{CH}_{3} \mathrm{COO}\right)$ & 0.074079 & 0.667 & \\
\hline ethyl acetate & $\left(\mathrm{CH}_{3}\right)\left(\mathrm{CH}_{2}\right)\left(\mathrm{CH}_{3} \mathrm{COO}\right)$ & 0.088105 & 0.500 & \\
\hline 1-propyl acetate & $\left(\mathrm{CH}_{3}\right)\left(\mathrm{CH}_{2}\right)_{2}\left(\mathrm{CH}_{3} \mathrm{COO}\right)$ & 0.102132 & 0.400 & \\
\hline tert-butyl acetate & $\left(\mathrm{CH}_{3}\right)_{3}(\mathrm{C})\left(\mathrm{CH}_{3} \mathrm{COO}\right)$ & 0.116158 & 0.333 & \\
\hline 1-pentyl acetate & $\left(\mathrm{CH}_{3}\right)\left(\mathrm{CH}_{2}\right)_{4}\left(\mathrm{CH}_{3} \mathrm{COO}\right)$ & 0.130185 & 0.286 & \\
\hline 1-hexyl acetate & $\left(\mathrm{CH}_{3}\right)\left(\mathrm{CH}_{2}\right)_{5}\left(\mathrm{CH}_{3} \mathrm{COO}\right)$ & 0.144211 & 0.250 & \\
\hline \multicolumn{5}{|c|}{ - multifunctional aromatic compounds - } \\
\hline benzene & $(\mathrm{ACH})_{6}$ & 0.078112 & 0.000 & \\
\hline phenol & $(\mathrm{ACH})_{5}(\mathrm{ACOH})$ & 0.094111 & 0.167 & \\
\hline
\end{tabular}


Table 3. Continued.

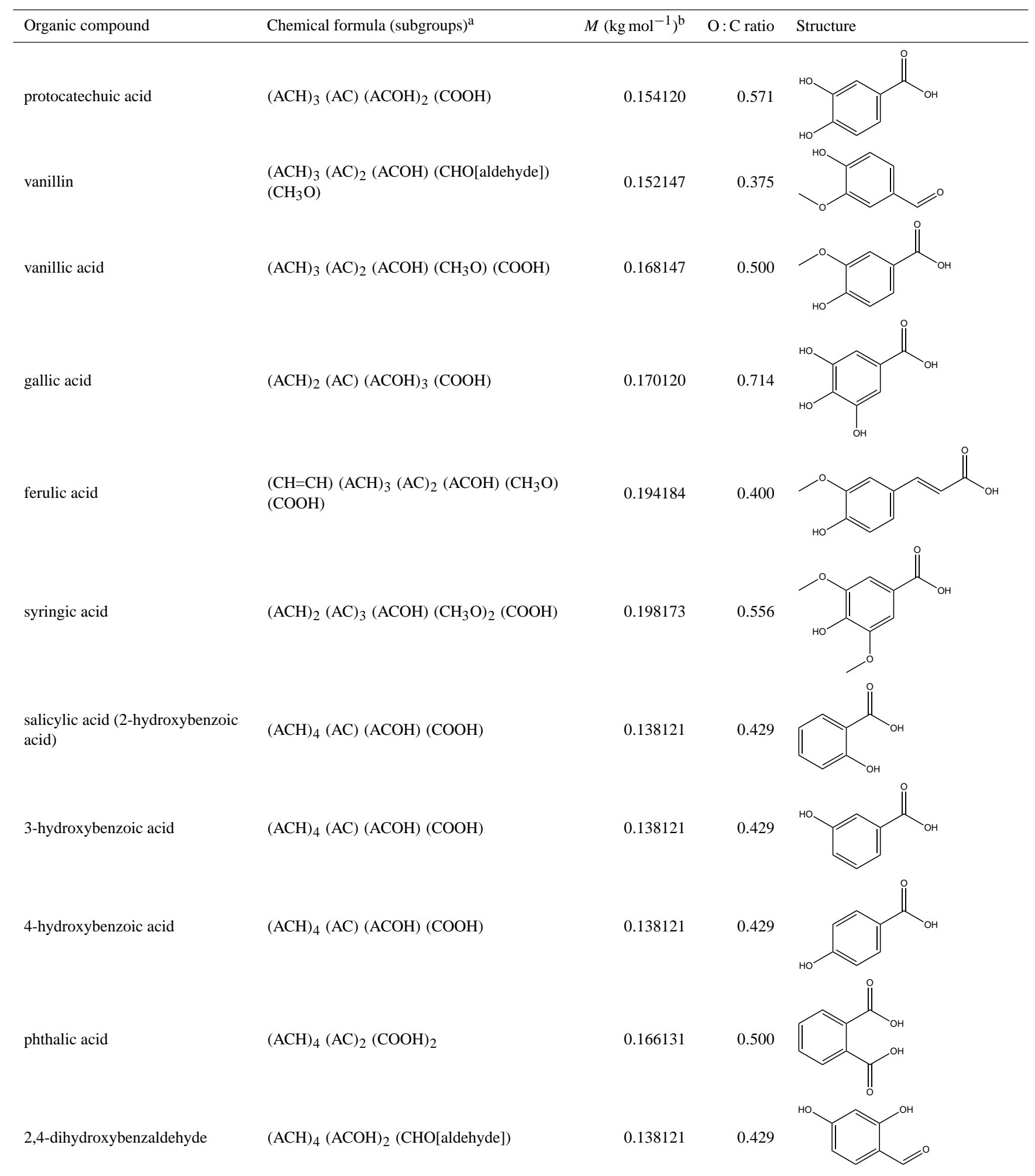

a The parentheses distinguish different functional subgroups, sectioning the molecules according to the nomenclature of UNIFAC/AIOMFAC. Note that the UNIFAC parameters and sectioning of Marcolli and Peter (2005) are used for hydroxyl groups and associated alkyl groups, i.e., the alkyl subgroups in alcohols are further distinguished into $\mathrm{CH}_{\mathrm{n}}^{\text {[alc-tail] }}$ [in hydrophobic tails of alcohols], $\mathrm{CH}_{\mathrm{n}}^{\text {[alc] }}$ [in alcohols] (but not in hydrophobic tail), and $\mathrm{CH}_{\mathrm{n}}^{[\mathrm{OH}]}$ [bonded to hydroxyl group] (where $\left.\mathrm{n}=0,1,2,3\right)$, as indicated in Fig. 1. UNIFAC parameters of Peng et al. (2001) are applied for the $\mathrm{COOH}$ group and its interactions with the functional group $\mathrm{OH}$ and with $\mathrm{H}_{2} \mathrm{O}$ (see Fig. 1 and Sect. 3.1).

${ }^{\mathrm{b}}$ Molar mass of the compound's natural isotope mixture. 
Table 4. Data types, number of data points $\left(N_{d}\right)$, initial weighting $\left(w_{d}^{\text {init }}\right)$, and sources of experimental data of binary aqueous $\mathrm{CaBr}_{2}, \mathrm{MgBr}_{2}$, $\mathrm{CaSO}_{4}$, and $\mathrm{H}_{2} \mathrm{SO}_{4}$ systems, aqueous multi-salt mixtures at $\mathrm{SLE}$ of $\mathrm{CaSO}_{4} \cdot 2 \mathrm{H}_{2} \mathrm{O}$ (gypsum), and mixtures of $\mathrm{H}_{2} \mathrm{SO}_{4}$ and $\left(\mathrm{NH}_{4}\right)_{2} \mathrm{SO}_{4}$ at various molar mixing ratios as specified in brackets.

\begin{tabular}{|c|c|c|c|c|c|c|}
\hline Solvent & Electrolytes & $T(\mathrm{~K})$ & Data type * & $N_{d}$ & $w_{d}^{\text {init }}$ & Reference \\
\hline water & $\mathrm{CaBr}_{2}$ & 298 & $\gamma_{ \pm}$ & 15 & 2.00 & Zaytsev and Aseyev (1992) \\
\hline water & $\mathrm{CaBr}_{2}$ & 298 & $\gamma_{ \pm}$ & 23 & 2.00 & Robinson and Stokes (2002) \\
\hline water & $\mathrm{CaBr}_{2}$ & 298 & $a_{\mathrm{W}}($ bulk $)$ & 23 & 2.00 & Robinson and Stokes (2002) \\
\hline water & $\mathrm{MgBr}_{2}$ & 298 & $\gamma_{ \pm}$ & 15 & 2.00 & Zaytsev and Aseyev (1992) \\
\hline water & $\mathrm{MgBr}_{2}$ & 298 & $\gamma_{ \pm}$ & 21 & 2.00 & Robinson and Stokes (2002) \\
\hline water & $\mathrm{MgBr}_{2}$ & 298 & $a_{\mathrm{W}}(\mathrm{bulk})$ & 21 & 2.00 & Robinson and Stokes (2002) \\
\hline water & $\mathrm{CaSO}_{4}$ & 298 & $\gamma_{ \pm}$ & 7 & 2.00 & Lilley and Briggs (1976) \\
\hline water & $\mathrm{CaSO}_{4}$ & 298 & $\gamma_{ \pm}$ & 20 & 2.00 & Malatesta and Zamboni (1997) \\
\hline water & $\mathrm{CaSO}_{4}, \mathrm{Na}_{2} \mathrm{SO}_{4}$ & 313 & SLE & 12 & 1.00 & Barba et al. (1984) \\
\hline water & $\mathrm{CaSO}_{4}, \mathrm{Na}_{2} \mathrm{SO}_{4}, \mathrm{MgCl}_{2}$ & 313 & SLE & 34 & 1.00 & Barba et al. (1984) \\
\hline water & $\mathrm{CaSO}_{4}, \mathrm{NaCl}$ & 308 & SLE & 13 & 1.00 & Kumar et al. (2007) \\
\hline water & $\mathrm{CaSO}_{4}, \mathrm{NaCl}, \mathrm{CaCl}_{2}$ & 308 & SLE & 32 & 1.00 & Kumar et al. (2007) \\
\hline water & $\mathrm{H}_{2} \mathrm{SO}_{4}$ & 298 & $a_{\mathrm{W}}($ bulk $)$ & 64 & 2.00 & Robinson and Stokes (2002) \\
\hline water & $\mathrm{H}_{2} \mathrm{SO}_{4}$ & 298 & $a_{\mathrm{W}}($ bulk $)$ & 81 & 2.00 & Staples (1981) \\
\hline water & $\mathrm{H}_{2} \mathrm{SO}_{4}$ & 298 & $\alpha_{\mathrm{HSO}_{4}^{-}}$ & 4 & 0.20 & Knopf et al. (2003) \\
\hline water & $\mathrm{H}_{2} \mathrm{SO}_{4}$ & 298 & $\alpha_{\mathrm{HSO}_{4}^{-}}^{-}$ & 11 & 0.20 & Myhre et al. (2003) \\
\hline water & $\left(\mathrm{NH}_{4}\right)_{2} \mathrm{SO}_{4}, \mathrm{H}_{2} \mathrm{SO}_{4}[1: 1]\left(=\mathrm{NH}_{4} \mathrm{HSO}_{4}\right)$ & 298 & $\alpha_{\mathrm{HSO}_{4}^{-}}$ & 9 & 0.20 & Young et al. (1959) \\
\hline water & $\left(\mathrm{NH}_{4}\right)_{2} \mathrm{SO}_{4}, \mathrm{H}_{2} \mathrm{SO}_{4}[1: 1]$ & 298 & $\alpha_{\mathrm{HSO}_{4}^{-}}$ & 7 & 0.20 & Dawson et al. (1986) \\
\hline water & $\left(\mathrm{NH}_{4}\right)_{2} \mathrm{SO}_{4}, \mathrm{H}_{2} \mathrm{SO}_{4}[1: 1]$ & 298 & $a_{\mathrm{W}}(\mathrm{bulk})$ & 12 & 2.00 & Tang and Munkelwitz (1977) \\
\hline water & $\left(\mathrm{NH}_{4}\right)_{2} \mathrm{SO}_{4}, \mathrm{H}_{2} \mathrm{SO}_{4}[1: 1]$ & 298 & $a_{\mathrm{w}}(\mathrm{EDB})$ & 40 & 1.00 & Spann (1984) \\
\hline water & $\left(\mathrm{NH}_{4}\right)_{2} \mathrm{SO}_{4}, \mathrm{H}_{2} \mathrm{SO}_{4}[1: 1]$ & 298 & $a_{\mathrm{w}}(\mathrm{EDB})$ & 23 & 1.00 & Kim et al. (1994) \\
\hline water & $\left(\mathrm{NH}_{4}\right)_{2} \mathrm{SO}_{4}, \mathrm{H}_{2} \mathrm{SO}_{4}[1: 2]$ & 298 & $a_{\mathrm{w}}(\mathrm{EDB})$ & 33 & 1.00 & Kim et al. (1994) \\
\hline water & $\left(\mathrm{NH}_{4}\right)_{2} \mathrm{SO}_{4}, \mathrm{H}_{2} \mathrm{SO}_{4}[2: 1]$ & 298 & $a_{\mathrm{W}}(\mathrm{bulk})$ & 12 & 2.00 & Zuend et al. (2008) \\
\hline water & $\left(\mathrm{NH}_{4}\right)_{2} \mathrm{SO}_{4}, \mathrm{H}_{2} \mathrm{SO}_{4}[2: 1]$ & 298 & $a_{\mathrm{w}}(\mathrm{EDB})$ & 33 & 0.50 & Zuend et al. (2008) \\
\hline water & $\left(\mathrm{NH}_{4}\right)_{3} \mathrm{H}\left(\mathrm{SO}_{4}\right)_{2}[3: 1]$ & 298 & $a_{\mathrm{W}}(\mathrm{bulk})$ & 9 & 2.00 & Tang and Munkelwitz (1994) \\
\hline water & $\left(\mathrm{NH}_{4}\right)_{2} \mathrm{SO}_{4}, \mathrm{H}_{2} \mathrm{SO}_{4}[0.4824: 1]$ & 298 & $a_{\mathrm{W}}($ bulk) & 36 & 2.00 & Clegg et al. (1996) \\
\hline water & $\left(\mathrm{NH}_{4}\right)_{2} \mathrm{SO}_{4}, \mathrm{H}_{2} \mathrm{SO}_{4}[1.9470: 1]$ & 298 & $a_{\mathrm{W}}($ bulk $)$ & 35 & 2.00 & Clegg et al. (1996) \\
\hline water & $\mathrm{NaHSO}_{4}$ & 298 & $a_{\mathrm{W}}(\mathrm{bulk})$ & 32 & 2.00 & Tang and Munkelwitz (1994) \\
\hline
\end{tabular}

* Data type $\alpha_{\mathrm{HSO}_{4}^{-}}$denotes measurement of the degree of dissociation of the bisulfate ion, as described in Zuend et al. (2008).

Table 5. Fitted binary cation $\leftrightarrow$ anion middle-range interaction parameters of new and revised aqueous electrolyte solutions.

\begin{tabular}{llrrrrr}
\hline$c$ & $a$ & $b_{c, a}^{(1)}\left(\mathrm{kg} \mathrm{mol}^{-1}\right)$ & $b_{c, a}^{(2)}\left(\mathrm{kg} \mathrm{mol}^{-1}\right)$ & $b_{c, a}^{(3)}\left(\mathrm{kg}^{1 / 2} \mathrm{~mol}^{-1 / 2}\right)$ & $c_{c, a}^{(1)}\left(\mathrm{kg}^{2} \mathrm{~mol}^{-2}\right)$ & $c_{c, a}^{(2)}\left(\mathrm{kg}^{1 / 2} \mathrm{~mol}^{-1 / 2}\right)$ \\
\hline $\mathrm{Ca}^{2+}$ & $\mathrm{Br}^{-}$ & $8.90929 \times 10^{-1}$ & $6.10134 \times 10^{-2}$ & $8.00000 \times 10^{-1}$ & $-2.38788 \times 10^{-1}$ & $7.62961 \times 10^{-1}$ \\
$\mathrm{Mg}^{2+}$ & $\mathrm{Br}^{-}$ & $2.60487 \times 10^{-1}$ & 1.01704 & $8.00000 \times 10^{-1}$ & $6.16264 \times 10^{-2}$ & $2.99475 \times 10^{-1}$ \\
$\mathrm{Ca}^{2+}$ & $\mathrm{SO}_{4}^{2-}$ & 1.29567 & $-6.96806 \times 10^{-1}$ & $8.00000 \times 10^{-1}$ & 1.59159 & $2.56217 \times 10^{-1}$ \\
$\mathrm{H}^{+}$ & $\mathrm{SO}_{4}^{2-}$ & $2.86343 \times 10^{-1}$ & -5.99615 & 1.36861 & $-5.35977 \times 10^{-1}$ & $9.07200 \times 10^{-1}$ \\
$\mathrm{H}^{+}$ & $\mathrm{HSO}_{4}^{-}$ & $2.15532 \times 10^{-2}$ & $5.62966 \times 10^{-1}$ & $1.42442 \times 10^{-1}$ & $7.03842 \times 10^{-2}$ & $7.14194 \times 10^{-1}$ \\
$\mathrm{Na}^{+}$ & $\mathrm{HSO}_{4}^{-}$ & $1.53214 \times 10^{-2}$ & $4.00000 \times 10^{-1}$ & $4.23635 \times 10^{-1}$ & $3.50072 \times 10^{-3}$ & $4.00000 \times 10^{-1}$ \\
$\mathrm{NH}_{4}^{+}$ & $\mathrm{HSO}_{4}^{-}$ & $7.59735 \times 10^{-3}$ & $1.43012 \times 10^{-1}$ & $2.03954 \times 10^{-1}$ & $6.31184 \times 10^{-3}$ & $8.25386 \times 10^{-1}$ \\
\hline
\end{tabular}

can demonstrate only a small fraction of the model's capabilities and applications. In general, the performance of a group-contribution model cannot be judged by comparison of calculations with only a few experimental datasets; rather, the model's overall performance should be evaluated based on a large ensemble of comparisons between measured and 

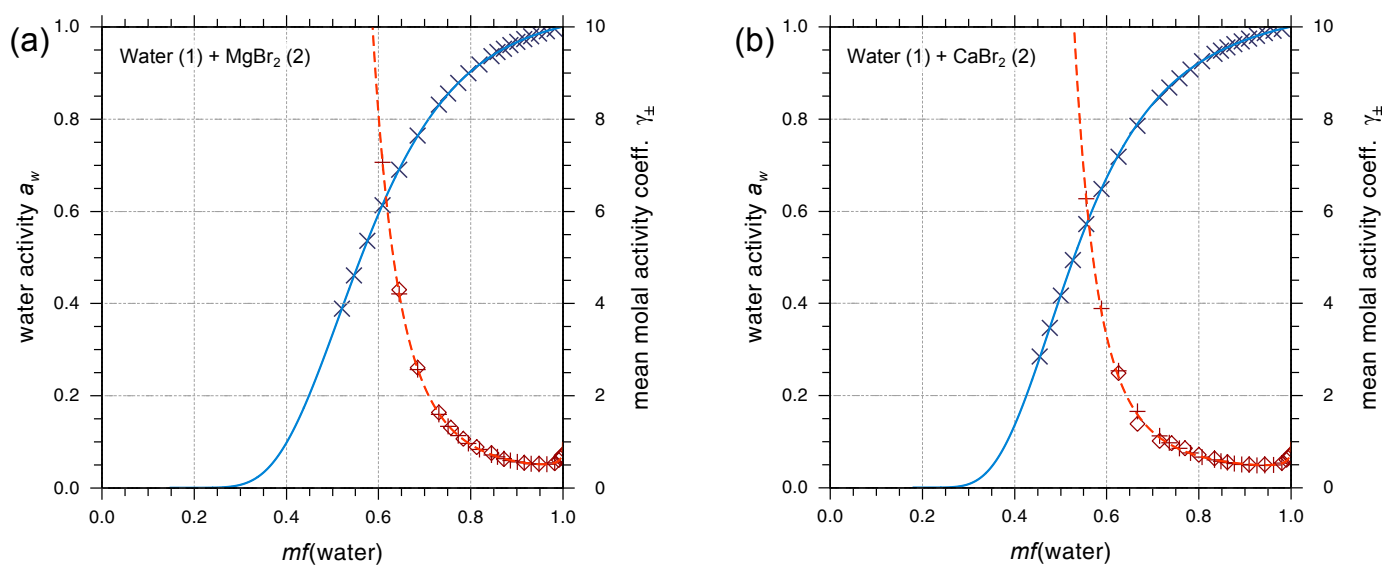

Fig. 9. Water activities and mean molal activity coefficients of the binary aqueous (a) $\mathrm{MgBr}_{2}$ and (b) $\mathrm{CaBr}_{2}$ systems at $298 \mathrm{~K}$. The curves show calculated water activities in blue and mean molal activity coefficients of the electrolytes in red (right y-axis), resulting from the AIOMFAC parameter fit to measurements (symbols), vs. mass fraction $(m f)$ of water. Experimental data in $(\mathbf{a})$ and $(\mathbf{b}): a_{\mathrm{W}}(\times)$ and $\gamma_{ \pm}(+)$ by Robinson and Stokes (2002), and $\gamma_{ \pm}(\diamond)$ by Zaytsev and Aseyev (1992).

Table 6. Fitted special middle-range parameters representing nonzero cation $\leftrightarrow$ cation and cation $\leftrightarrow$ cation $\leftrightarrow$ anion interactions. $R_{c, c^{\prime}}$ and $Q_{c, c^{\prime}, a}$ parameters of all other ion interactions are set to zero. $R_{c, c^{\prime}}$ and $Q_{c, c^{\prime}, a}$ are symmetric parameters, i.e., $R_{\mathrm{NH}_{4}^{+}, \mathrm{H}^{+}}=$ $R_{\mathrm{H}^{+}, \mathrm{NH}_{4}^{+}}$.

\begin{tabular}{lllrr}
\hline$c$ & $c^{\prime}$ & $a$ & $R_{c, c^{\prime}}\left(\mathrm{kg} \mathrm{mol}^{-1}\right)$ & $Q_{c, c^{\prime}, a}\left(\mathrm{~kg}^{2} \mathrm{~mol}^{-2}\right)$ \\
\hline $\mathrm{NH}_{4}^{+}$ & $\mathrm{H}^{+}$ & & $-1.54486 \times 10^{-1}$ & \\
$\mathrm{NH}_{4}^{+}$ & $\mathrm{H}^{+}$ & $\mathrm{HSO}_{4}^{-}$ & & $4.48354 \times 10^{-4}$ \\
\hline
\end{tabular}

computed data. This is essentially the idea and objective of the parameter optimization procedure. Figures showing the experimental data and corresponding AIOMFAC results of all datasets used for the determination of the interaction parameters are provided in the Supplement to this article. In the following, we will discuss measurements and AIOMFAC calculations for a selection of mixtures, representing examples for systems containing different organic functional groups.

\subsection{Examples of AIOMFAC calculations}

\subsubsection{Organic acids}

Dicarboxylic acids account to a considerable fraction of the identified water-soluble organic aerosol constituents. Hence, there is a need for accurate model predictions of activity coefficients and potential phase separations for mixtures of inorganic salts with dicarboxylic acids covering a wide range of relative humidities. Mixtures containing $\mathrm{C}_{2}$ to $\mathrm{C}_{6}$ dicarboxylic acids have been used in conjunction with the determination of the AIOMFAC parameters. Figure 11 shows a comparison of AIOMFAC calculations with different water activity measurements of the ternary system water + malonic acid $+\left(\mathrm{NH}_{4}\right)_{2} \mathrm{SO}_{4}$. The fixed molar ratio of malonic acid to ammonium sulfate of $1: 1$ in the experiments enables a direct comparison with corresponding model curves. Overall, the agreement between the AIOMFAC water activity curve and the experimental data is very good. Especially at high water contents above the deliquescense $\mathrm{RH}$ of $\left(\mathrm{NH}_{4}\right)_{2} \mathrm{SO}_{4}$ $\left(a_{\mathrm{w}}=0.8\right)$, the agreement is excellent. At lower water contents, AIOMFAC predictions and EDB measurements of liquid particles (on the dehydration branch of the humidogram, i.e., supersaturated solutions) are in good agreement while the data obtained from micro-Raman measurements exhibit more scatter, but within their own variability agree with the model. The calculated curves showing the activity of malonic acid and the mean molal activity coefficient of ammonium sulfate in Fig. 11 demonstrate thermodynamically reasonable and consistent AIOMFAC behavior over a wide composition range (and beyond the range of measurements). The dotted curves, representing model sensitivities for the different quantities with respect to compositional changes on the order of $x^{\text {tol }}=0.01$, show that the model sensitivity for this system is relatively low and increases only at compositions where a component is less abundant than $x^{\text {tol }}$.

Figure 12 shows a comparison of experimental data with AIOMFAC results for the systems water + malic acid + malonic acid + maleic acid + glutaric acid + methylsuccinic acid, saturated with the salts $\mathrm{NaCl}$, panels (a) and (b), and $\mathrm{NH}_{4} \mathrm{NO}_{3}$, panels (c) and (d), respectively. These systems with five different dicarboxylic acids (M5 mixture of Marcolli et al., 2004a) demonstrate the ability of AIOMFAC to compute activities and SLE of multicomponent mixtures. Calculated water activities agree well with the experimental findings. The relative deviations between model and measurements in case of the solubility data are on the order of up to $11 \%$, still in good agreement with respect to an absolute mole fraction composition scale. 


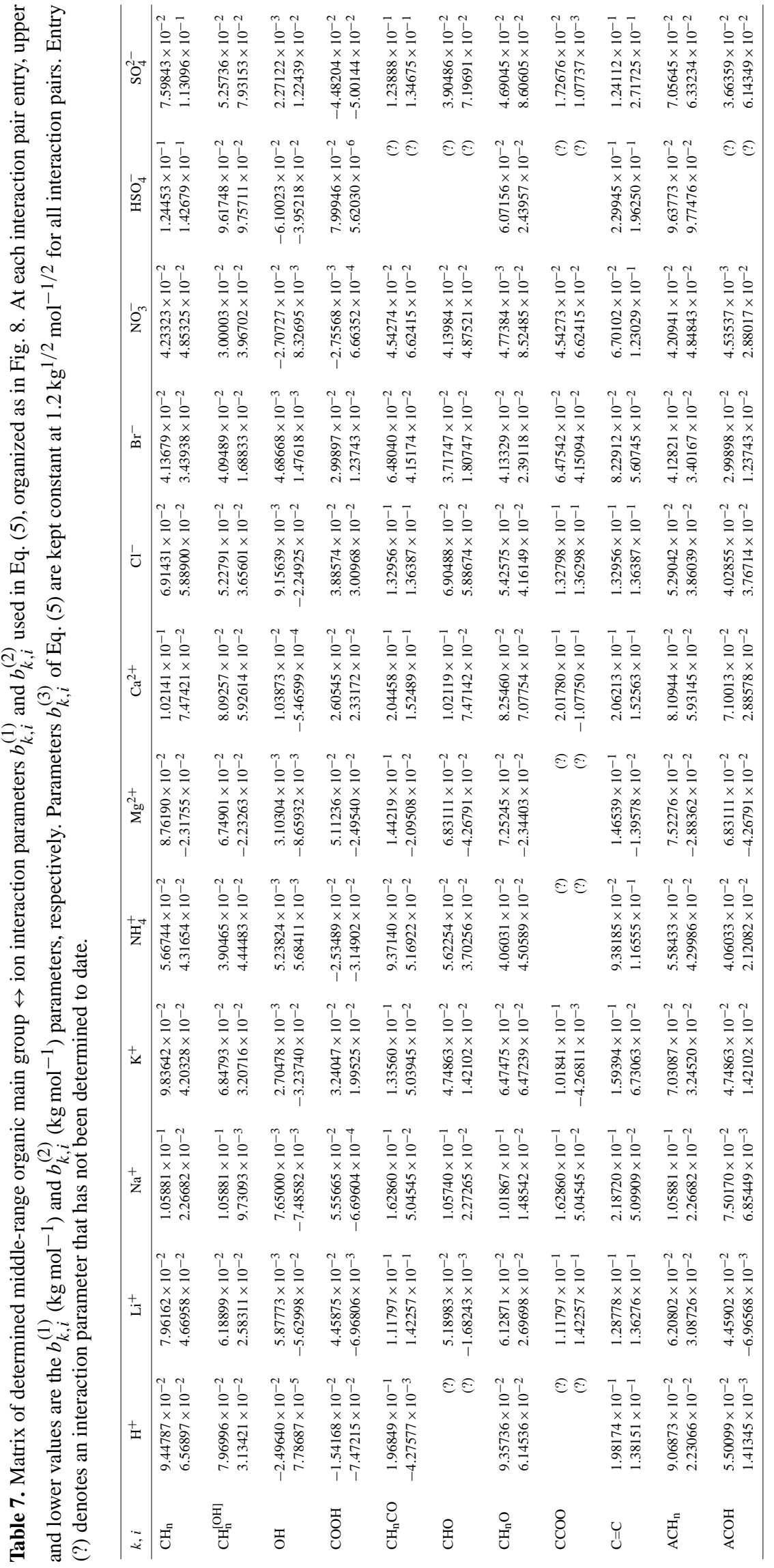



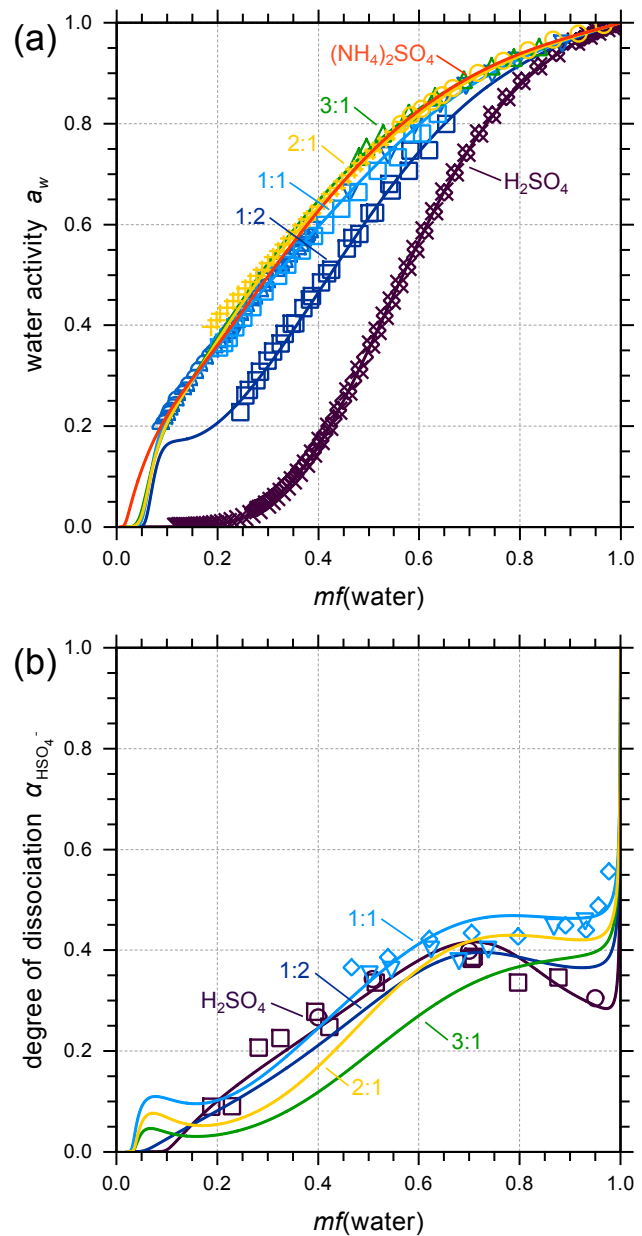

Fig. 10. Calculated and experimental water activities and degree of dissociation of the bisulfate ion in aqueous solutions of sulfuric acid and mixtures of ammonium sulfate and sulfuric acid (i.e., the degree to which the second ionization stage, $\mathrm{HSO}_{4}^{-} \rightleftharpoons \mathrm{H}^{+}+\mathrm{SO}_{4}^{2-}$, of sulfuric acid is established, see Zuend et al., 2008). The molar ratio of $\left(\mathrm{NH}_{4}\right)_{2} \mathrm{SO}_{4}: \mathrm{H}_{2} \mathrm{SO}_{4}$ is indicated for the different mixtures. (a) Calculated water activities (curves) and measured bulk and EDB water activity data (symbols) at room temperature; Robinson and

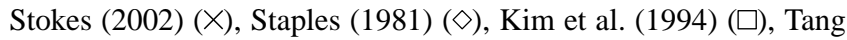
and Munkelwitz (1977) ( $\nabla)$, Spann (1984) (๑), Tang and Munkelwitz (1994) $(\triangle)$, Zuend et al. (2008) (○), Zardini et al. (2008) (+). Calculated $a_{\mathrm{W}}$ of $\left(\mathrm{NH}_{4}\right)_{2} \mathrm{SO}_{4}$ is shown for comparison. (b) Corresponding degrees of dissociation of the bisulfate ion, $\alpha \mathrm{HSO}_{4}^{-}$(Zuend et al., 2008), as a function of the mass fraction of water. Measured $\alpha_{\mathrm{HSO}_{4}^{-}}$of aqueous sulfuric acid by Knopf et al. (2003) (O) and Myhre et al. (2003) ( $\square$ ), and of the $1: 1$ mixture by Young et al. $(1959)(\diamond)$ and Dawson et al. (1986) $(\nabla)$.

For these two systems, AIOMFAC slightly underpredicts the salt solubilities at moderate organic contents, which implies that the IAP reaches the solubility limit value already at lower $x$ (salt) than found experimentally. This means that the AIOMFAC parameterization of interactions between the ions and the different organic main groups involved
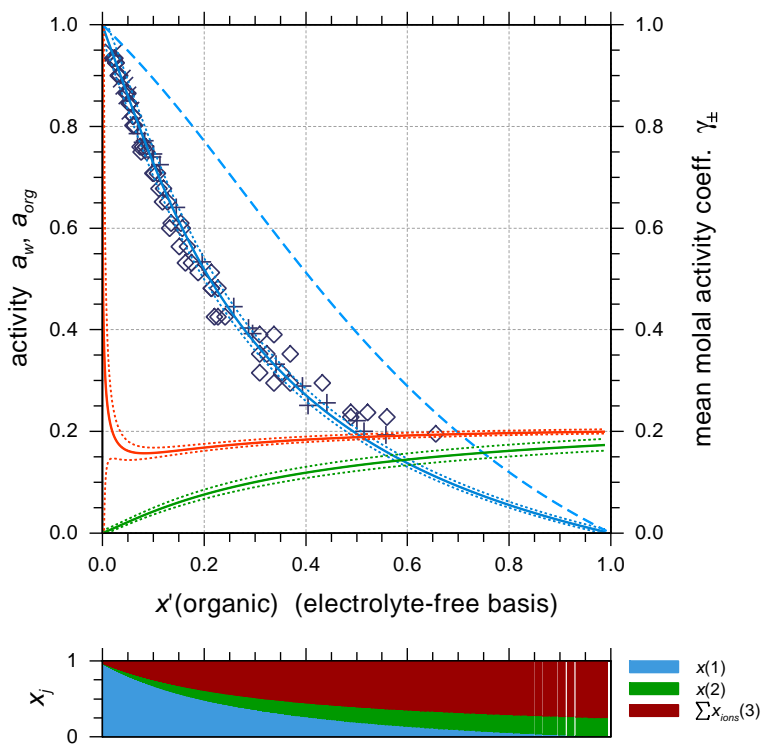

Fig. 11. Water activity measurements and AIOMFAC calculations for the system water (1) + malonic acid (2) $+\left(\mathrm{NH}_{4}\right)_{2} \mathrm{SO}_{4}$ (3). All mixtures are at a 1:1 molar ratio of malonic acid: $\left(\mathrm{NH}_{4}\right)_{2} \mathrm{SO}_{4}$. Experimental bulk data for $a_{\mathrm{w}}$ at $295 \mathrm{~K}(+)$ by Choi and Chan (2002), EDB data at $298 \mathrm{~K}(+)$ by Ling and Chan (2008), and micro-Raman data at $297 \mathrm{~K}(\diamond)$ by Yeung and Chan (2010). Calculated curves at $298 \mathrm{~K}: a_{\mathrm{W}}$ (solid blue), $a_{\mathrm{org}}$ of malonic acid (solid green), $\gamma_{ \pm}$of $\left(\mathrm{NH}_{4}\right)_{2} \mathrm{SO}_{4}$ (solid red), and $a_{\mathrm{W}}$ of salt-free mixture (dashed blue). The dotted curves bordering the solid curves in the corresponding colors represent AIOMFAC sensitivities with respect to $x^{\text {tol }}=0.01$.

$\left(\mathrm{CH}_{\mathrm{n}}, \mathrm{COOH}, \mathrm{C}=\mathrm{C}, \mathrm{OH}\right)$ slightly overpredicts here the effect on the IAP. For other mixtures at SLE containing the same functional groups, AIOMFAC sometimes overpredicts the solubility of the salt, so that this presents a trade-off, inherent to the parameter optimization with the group-contribution concept. If one assumes ideal mixing for these systems, the resulting solubility limit curve is a parallel line to the abscissa at the level of the value for $x^{\prime}$ (water) $=1.0$, i.e., $x$ (salt) $=0.1$ in case of the $\mathrm{NaCl}$ containing system. This would clearly lead to much higher deviations (up to $125 \%$ ) between calculated and measured $x$ (salt) values and demonstrates the necessity of incorporating non-ideal interaction effects.

\subsubsection{Phenolic compounds}

Figure 13 shows a comparison of experimental and calculated LLE and SLE data of ternary water + salt/acid systems containing phenolic compounds. In this figure, the number of functional groups substituting hydrogen atoms on the benzene ring increases from panel (a), phenol $\left(\mathrm{ACH}_{\mathrm{n}}, \mathrm{ACOH}\right)$, to (d), syringic acid $\left(\mathrm{ACH}_{\mathrm{n}}, \mathrm{ACOH}, \mathrm{COOH},\left(\mathrm{CH}_{\mathrm{n}} \mathrm{O}\right)_{2}\right)$, accompanied by an increase in the $\mathrm{O}: \mathrm{C}$ ratio of the phenolic compounds. The LLE system water + phenol $+\mathrm{HCl}$ at $285 \mathrm{~K}$ shown in panel (a) of Fig. 13 is an example of 
(a)
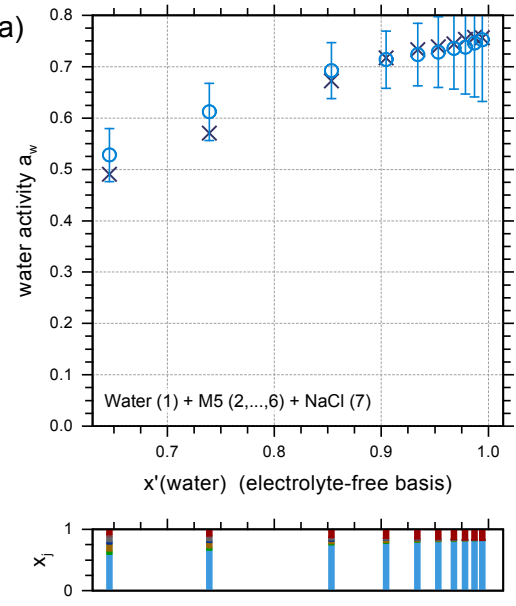

(c)

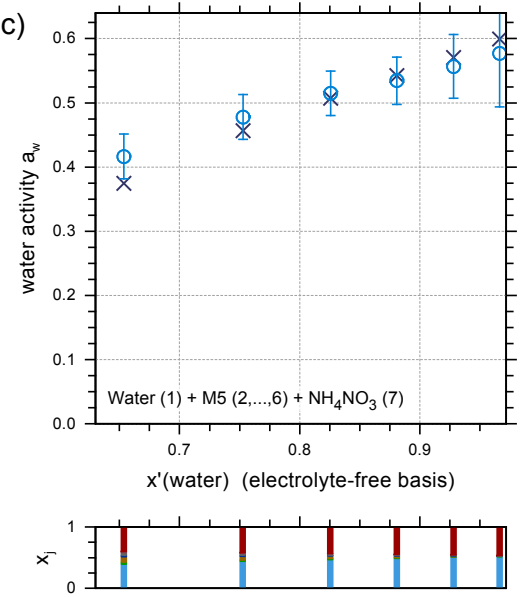

(b)

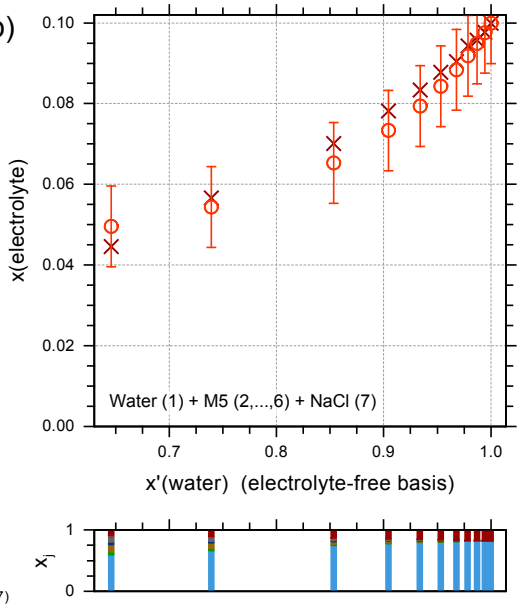

(d)

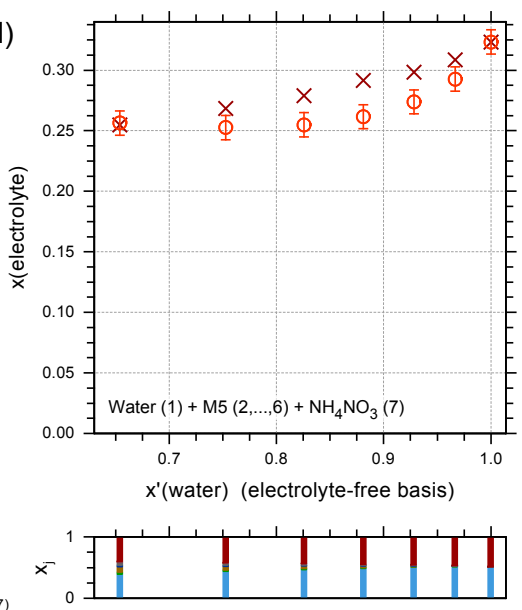

Fig. 12. Water activities and salt solubilities in saturated multicomponent solutions of water $(1)+\mathrm{M} 5(2, \ldots, 6)+\mathrm{NaCl}(7)$ and water $(1)+\mathrm{M} 5$ $(2, \ldots, 6)+\mathrm{NH}_{4} \mathrm{NO}_{3}(7)$ at $298 \mathrm{~K}$, where $\mathrm{M} 5=$ malic acid (2) + malonic acid (3) + maleic acid (4) + glutaric acid (5) + methylsuccinic acid (6) Panels (a) and (c) show measured bulk $a_{\mathrm{w}}$ data $(\times)$, calculated values $(\mathrm{O})$, and activity sensitivities (error bars) for the two systems. Panels (b) and (d) show corresponding measured $(X)$ and calculated $(O)$ salt solubility limits in terms of mole fractions of the salt on the basis of undissociated electrolyte. Experimental data by Marcolli et al. (2004a). Note the different axis scalings.

a dataset, for which the AIOMFAC based computation of the LLE phase compositions does not agree well with the measurements. A closer look reveals that the experimental data describe a liquid-liquid phase separation already for the electrolyte-free water + phenol system $\left(\right.$ at $\left.x^{\prime}(\mathrm{HCl})=0.0\right)$, while the phase equilibrium computation for this tie-line suggests a single liquid phase. This means that the UNIFAC description of the electrolyte-free system at this temperature is not very accurate - as AIOMFAC reduces to UNIFAC for electrolyte-free mixtures. Apparently there are larger uncertainties regarding the UNIFAC description of this system that are not caused by organic main group $\leftrightarrow$ ion interactions. This model inaccuracy explains, at least to some extent, the deviations between AIOMFAC and measurements. While AIOMFAC essentially calculates activity coefficients for a given mixture composition, i.e., a single mixed phase, the number of coexisting phases of a thermodynamic system have to be computed with a phase equilibrium model on the basis of an activity coefficient model (here AIOMFAC). We use the phase equilibrium model of Zuend et al. (2010) to compute the number of phases and corresponding compositions to compare AIOMFAC with experimental LLE data as described in Sect. 4.3. The current version of this phase equilibrium model limits the number of coexisting liquid phases to a maximum of two. Since for the comparisons here we a priori know the number of coexisting liquid phases from the experimental data, which is two for all considered LLE datasets, this limitation comes with no consequences. The water + phenol system of Fig. 13a shows that the phase equilibrium model still reserves the possibility of predicting only a one-phase mixture if the Gibbs energy minimization using AIOMFAC activities suggests so. Regarding complex organic-inorganic systems of many components, where potentially more than two liquid phases coexist, ideally a 
(a)

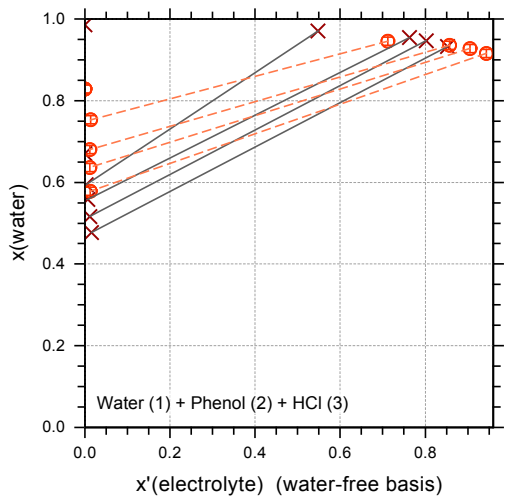

(b)
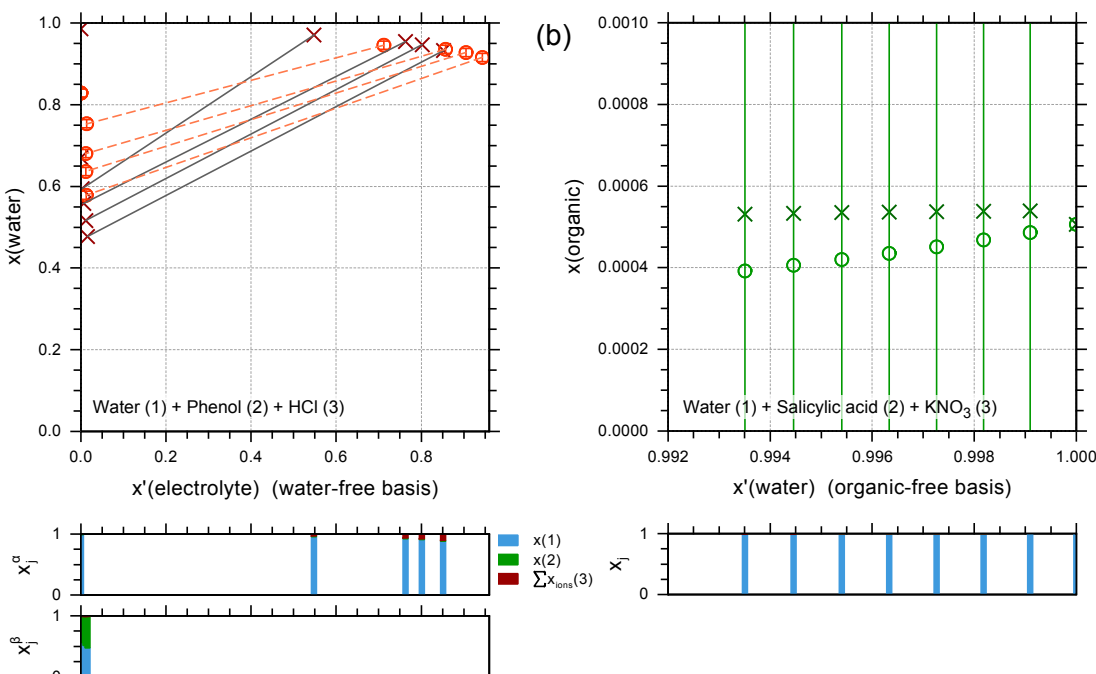

(c)

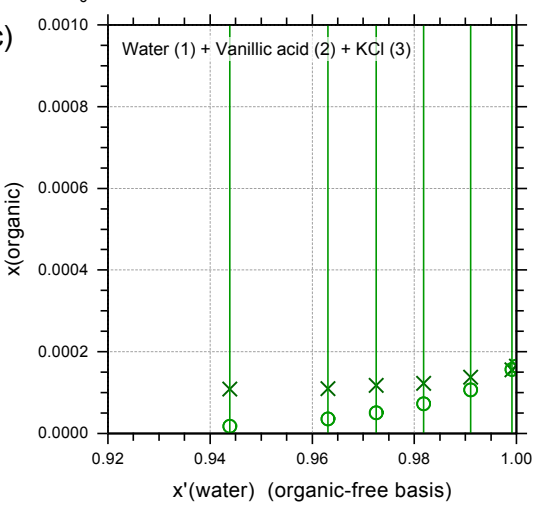

(d)
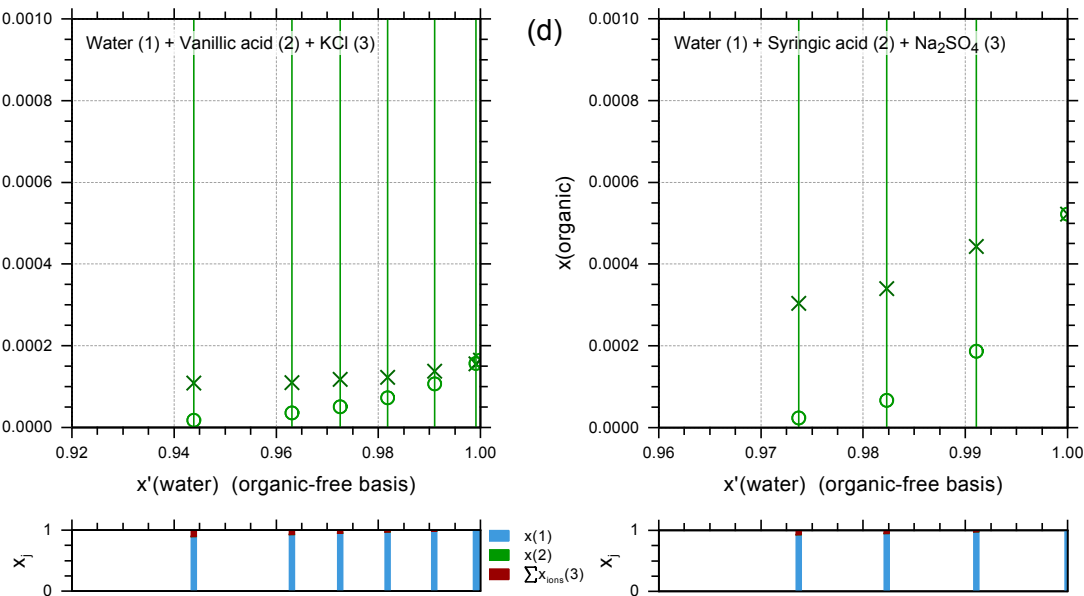

Fig. 13. Ternary systems containing multifunctional phenolic compounds. Experimental values are given by symbols $(X)$ and respective AIOMFAC calculations by (O). (a) LLE of water (1) + phenol (2) $+\mathrm{HCl}$ (3) at $285 \mathrm{~K}$. LLE composition measurements by Schreinemakers and van den Bos (1912). (b) Solubility limits of salicylic acid in aqueous $\mathrm{KNO}_{3}$ solutions at $308 \mathrm{~K}$. Measurements by Sugunan and Thomas (1995). (c) Solubility limits of vanillic acid in aqueous KCl solutions at $298 \mathrm{~K}$. Measurements by Noubigh et al. (2007b). (d) Solubility limits of syringic acid in aqueous $\mathrm{Na}_{2} \mathrm{SO}_{4}$ solutions at $298 \mathrm{~K}$. Measurements by Noubigh et al. (2008).

partitioning model should not limit the number of liquid phases to a maximum of two. The model of Zuend et al. (2010) can be extended to allow in principle a large number of coexisting phases (only limited by Gibbs' phase rule) while computing the activity coefficients of the components in each phase using AIOMFAC. Hence, while the choice and limitations of an equilibrium phase partitioning model might affect the number of predicted phases, AIOMFAC itself is not limited by any number of phases.

Calculated and measured solubility limits of the different phenolic compounds, shown in panels (b) to (d) of Fig. 13, agree relatively well (considering the scale of the y-axis). The solubility limits of such multifunctional aromatic compounds in aqueous electrolyte solutions close to room temperature are very low, as the scaling of the y-axis indicates, leading to model sensitivity (error) bars larger than the dis- played composition range. While the number of datasets to constrain the main group $\leftrightarrow$ ion interaction parameters involved in these systems is relatively low, the inequality constraints based on the functional group polarity series effectively limit the fitting capability of AIOMFAC to those datasets. Hence, slight deviations between AIOMFAC computations and the measurements in this highly dilute concentration range are accepted with the greater benefit of maintaining physically meaningful behavior to higher concentrations. The system water + salicylic acid $+\mathrm{KNO}_{3}$ shows almost constant solubility of salicylic acid with increasing salt concentration. This is caused by the salting-in effect of $\mathrm{KNO}_{3}$ on salicylic acid (and other organics), a known effect of nitrate ions and, to some extent, also potassium ions in highly dilute solutions. 

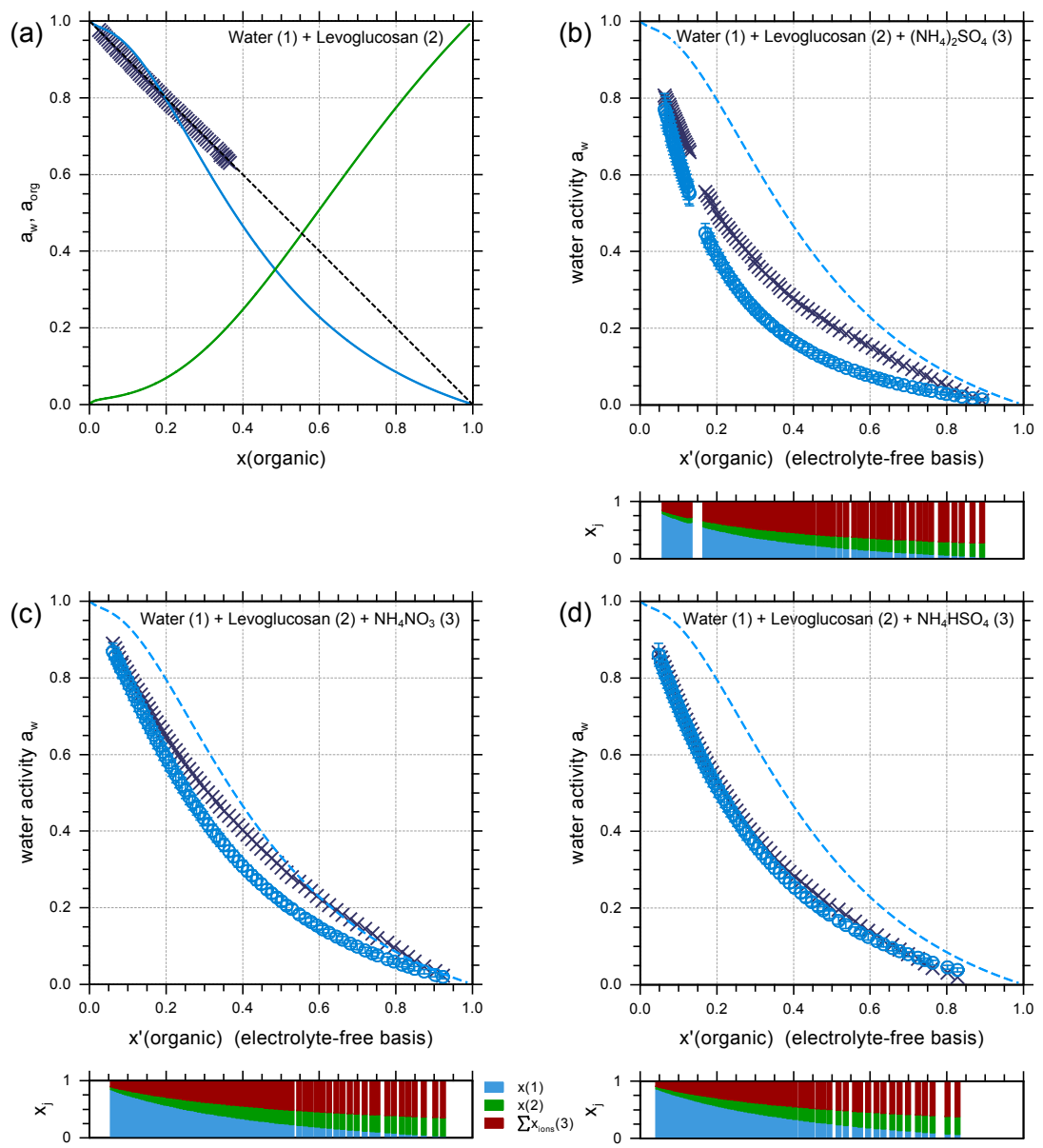

Fig. 14. Water activities of the binary and ternary water (1) + levoglucosan (2) + electrolyte (3) systems at $291 \mathrm{~K}$. (a) In case of the binary system, the EDB water activity data $(\times)$ closely matches an ideal solution (dashed line). The AIOMFAC (UNIFAC) $a_{\mathrm{W}}$-curve (blue line) shows larger deviations. The green curve shows the corresponding calculated activity of levoglucosan. (b), (c), and (d) Ternary systems containing the electrolytes ammonium sulfate, ammonium nitrate, and ammonium bisulfate, respectively, mixed at a molar ratio of $1: 1$ with levoglucosan. Symbols show the experimental water activity data $(X)$ and corresponding AIOMFAC calculations $(O)$. Error bars of the experimental data are smaller than the symbol size. The dashed, blue curve shows the electrolyte-free $a_{\mathrm{w}}$ model curve for comparison. Measurements by Lienhard et al. (2011).

\subsubsection{Levoglucosan}

Levoglucosan (1,6-anhydro- $\beta$-D-glucose) is one of the most abundant single species found in tropospheric aerosols (e.g., Schauer et al., 2001; Decesari et al., 2006), commonly associated with emissions from biomass burning. As an anhydrosugar, containing alkyl, hydroxyl, and ether functionalities, levoglucosan $(\mathrm{O}: \mathrm{C}$ ratio $=0.833)$ often serves as a proxy for water-soluble organic aerosol compounds. In Fig. 14, AIOMFAC water activities of the salt-free binary system and of three ternary water + levoglucosan + electrolyte systems are compared with EDB measurements by Lienhard et al. (2011), covering a wide range of relative humidities. The three electrolytes investigated in these mixtures are ammonium sulfate $\left(\left(\mathrm{NH}_{4}\right)_{2} \mathrm{SO}_{4}\right)$, ammonium nitrate $\left(\mathrm{NH}_{4} \mathrm{NO}_{3}\right)$, and ammonium bisulfate $\left(\mathrm{NH}_{4} \mathrm{HSO}_{4}\right)$, all important inor- ganic aerosol constituents. As found by Mochida and Kawamura (2004), the fully miscible binary water + levoglucosan system follows closely the behavior of an ideal solution (Fig. 14a). Deviations from ideal mixing are predicted by AIOMFAC (UNIFAC), especially prominent for the mole fraction range $0.3<x$ (levoglucosan $)<0.9$. This discrepancy is, for the most part, explained by the molecular structure of levoglucosan, which has several polar groups in close proximity, leading to relatively strong intramolecular interactions, not taken into account by UNIFAC (and the UNIFAC part within AIOMFAC). Due to these deviations in the binary system, discrepancies are also expected for the electrolytecontaining mixtures. Panels (b), (c), and (d) of Fig. 14 show that AIOMFAC underpredicts the water activities of the ternary solutions as compared to the measurements, especially at lower water contents. This is related to the 
deviations of UNIFAC regarding the binary system. Because the organic-free aqueous electrolyte systems are very well represented by AIOMFAC, the deviations in the ternary solutions are at least partly due to the UNIFAC part. However, in case of the ternary systems, AIOMFAC predicts water activities still more accurately than simply assuming an ideal solution. The ternary system with $\mathrm{NH}_{4} \mathrm{HSO}_{4}$, panel (d), agrees very well with the EDB data and even better than expected with regard to the deviations of the salt-free system. One reason for this result might be, that the interactions between the functional groups of levoglucosan and (especially) the ions $\mathrm{HSO}_{4}^{-}$and $\mathrm{H}^{+}$, present in this system (with explicit treatment of partial $\mathrm{HSO}_{4}^{-}$dissociation), are not well enough constrained. Consequently, the related interaction parameters were somewhat overfitted to better match this dataset and erroneously compensate to a certain extent for the deviations caused by the UNIFAC part. In this case the additional constraints based on the polarity series are less restrictive, likely because most of the organic main group $\leftrightarrow \mathrm{HSO}_{4}^{-}$interaction parameters are estimated based on very few datasets (see Fig. 8), leaving much flexibility to these parameters. Hence, more experimental data are required to improve the representation of systems containing bisulfate ions.

\subsection{Scope and limitations of a group-contribution model}

The AIOMFAC model allows thermodynamically consistent calculations of the phase behavior of mixtures of organic compounds, inorganic species, and water. These calculations are thermodynamically consistent in the way that they provide a description of a mixed organic-inorganic system that is in best simultaneous agreement with all the available thermodynamic measurements and with the laws of thermodynamics.

Of course, thermodynamic consistency is a necessary but not a sufficient requirement for "correctness". Regarding the confidence in determined interaction parameters, Fig. 8 provides a first estimate based on the number of different datasets used for the determination of a certain middle-range interaction. Table 2 offers further information concerning the data types, temperature ranges, and number of data points associated with a specific interaction parameter.

Reasons for deviations between AIOMFAC and experimental data range from uncertainties regarding measurements and lack of data, to uncertainties and limitations of the AIOMFAC expressions, their parameterization, and the underlying group-contribution concept. Hence, it is likely that a fit of AIOMFAC or of a system-specific model to a highly restricted amount of data for some systems will lead to a better description of those datasets. But such restricted approaches are feasible only for specific systems of interest and lack the generality and predictability of a group-contribution model - the main goal of AIOMFAC. A comparison and discussion on group-contribution and system-specific activity coef- ficient models is given in Zuend et al. (2008). For the various reasons discussed in Sects. 3.2 and 5.3 concerning conceptual and model uncertainties, it is clear that we cannot expect AIOMFAC calculations of organic-inorganic systems to attain the same high level of accuracy as the Pitzer-like part of AIOMFAC or other detailed thermodynamic models, such as the AIM model (Clegg et al., 1998a,b), achieve for (organicfree) aqueous electrolyte solutions. In view of this, the new parameterization of AIOMFAC is very promising and shows that computed activity coefficients and related compositions agree reasonably well with measurements for the majority of the datasets used in this study (see Supplement).

UNIFAC-based group-contribution models allow the description of thousands of organic compounds, limited only by the availability of UNIFAC parameters for different functional groups. With regard to atmospheric chemistry, limitations of UNIFAC concern the compound classes of peroxides, hydroperoxides, peroxy acids, organic nitrates, and peroxyacyl nitrates (PANs), which are all known products of the photochemical degradation of volatile organic compounds (VOCs), and the classes of organosulfates and organonitrates, suggested to be formed in the particle phase (e.g., Chan et al., 2010; Surratt et al., 2010). Although UNIFAC parameters for a subset of these functionalities became available recently (Wittig et al., 2003; Compernolle et al., 2009), the UNIFAC parameter matrix is still incomplete because not all interactions with other common functional groups (including some of those used in AIOMFAC) have been parameterized to date. In addition to these UNIFAC (SR-part) related limitations, the full extension of AIOMFAC to these functional groups would also require experimental data of organic-inorganic systems to determine the middle-range interactions with inorganic ions. When missing compound classes are required in calculations with AIOMFAC, we recommend to use an analogy approach for the currently unknown interaction parameters between ions and these main groups, as suggested by Compernolle et al. (2009).

One of the most challenging tests for a group-contribution activity coefficient model is the prediction of liquid-liquid phase equilibria compositions, since for such computations, a good representation of the activities of all system components is crucial. AIOMFAC shows this ability for many different LLE datasets considered. However, there are some LLE datasets that reveal larger deviations compared to AIOMFAC computations, often due to uncertainties in the UNIFAC SR-part or system-specific LLE behavior that is not captured by the interaction expressions and associated parameters determined with the objective of good overall model behavior.

AIOMFAC permits predictions of activity coefficients for mixtures that have not been part of the database for the parameter optimization, as long as all required functional groups and ions are part of the determined parameter matrix. This is a main advantage of the group-contribution concept. However, it is at present not possible to provide a quantitative 
estimate of how well AIOMFAC will perform for mixtures that were not part of the database used for the parameter determination. Qualitatively, one can expect the model to perform well for systems containing similar compounds as used in the parameter optimization database. Furthermore, predictions of water activities are expected to be more accurate than predicted LLE phase diagrams. The complexity of an organic compound in terms of size, number, and variety of functional groups is one of the factors influencing the accuracy of AIOMFAC and UNIFAC predictions. Since simple organic molecules composed of only a few different functional groups make up the majority of the parameterization database, the accuracy of AIOMFAC predictions can be expected to decrease with increasing structural complexity of organic compounds. Activity coefficient predictions for complex multifunctional organic compounds are less accurate, because the group-contribution concept offers only very limited means to account for intramolecular interactions between neighboring functional groups - a liquid phase is basically treated as a solution of individual functional groups (solution-of-groups concept). However, structural complexity of individual organic compounds should not be confused with number of components in a mixture. Mixtures consisting of tens to many hundreds of compounds do not need to become less accurate with increasing number of components. In fact, the solution-of-groups concept implies that AIOMFAC results are unaffected by the number of different components a set of functional groups belongs to. Therefore, AIOMFAC is well suited for computations of activity coefficients in multicomponent organic-inorganic mixtures, such as atmospheric aerosol mixtures, expected to contain up to a few thousands of different organic compounds exhibiting a wide spectrum in terms of molecular structure and polarity.

Other factors influencing the accuracy level of AIOMFAC calculations are the salt and water contents of mixtures. The accuracy of predictions is expected to decrease with an increase of the salt content in a mixture, especially if the water content is decreased at the same time. The design and parameterization of the AIOMFAC model results in a better performance for water-rich electrolyte systems than for organic-rich electrolyte systems.

\subsection{Implications for atmospheric aerosol modeling}

The AIOMFAC model allows thermodynamically rigorous calculations of the phase behavior of mixtures of organic compounds, inorganic species, and water. Many organic compounds and inorganic ions, representing important species and compound classes found in atmospheric aerosol samples, have been used to determine AIOMFAC model parameters. However, even in a laboratory chamber experiment, where mass spectrometry of both gas and particle phases is carried out, the molecular speciation of all the major oxidation products of volatile organic compounds that undergo gas-particle partitioning is usually unavailable. For an atmospheric aerosol particle, its molecular composition is even less accessible than in a laboratory system. Several approaches have evolved to represent the molecular properties of organic-inorganic aerosols, especially for regional and large-scale atmospheric models. From the viewpoint of gas-particle partitioning, an essential property of the organic aerosol is the distribution of the volatilities of its components. Measurement of the volatility distribution of an organic aerosol is experimentally accessible with the thermodenuder method (e.g., Wehner et al., 2002; An et al., 2007; Faulhaber et al., 2009). Volatility can be expressed in terms of vapor pressures, gas-phase saturation mass concentrations, or enthalpies of vaporization from a liquid mixture. However, volatility alone is not sufficient to constrain organic aerosol properties. Other properties that have been proposed to represent the organic aerosol include the $\mathrm{O}: \mathrm{C}$ atomic ratio of different compounds in the aerosol mixture and the distribution of carbon numbers and/or polarity of the components. Various two-dimensional organic aerosol representations have been proposed, involving mean carbon oxidation state vs. carbon number (Kroll et al., 2011), carbon number vs. polarity (Pankow and Barsanti, 2009) and O:C ratio vs. volatility (Jimenez et al., 2009). Use of an aerosol mass spectrometer enables indirect measurement of the elemental aerosol composition and, hence, of the $\mathrm{O}: \mathrm{C}$ ratio. A challenge is to relate the other properties to measurable quantities. A detailed thermodynamic model like AIOMFAC is valuable in generating predictions of gas-particle partitioning and phase behavior for well-defined molecular mixtures that approximate that of the actual aerosol; this includes the sensitivity of partitioning to $\mathrm{RH}$ and to addition or removal of individual classes of molecules. In this way, AIOMFAC can be used to evaluate and improve the performance of the more empirical organic aerosol models based on volatility and polarity.

AIOMFAC can also be used as a thermodynamic module to calculate phase partitioning and compound activities for the computation of reaction rates in detailed aerosol and cloud-water chemistry models (e.g., Wolke et al., 2005; Deguillaume et al., 2009). Furthermore, using AIOMFAC as a benchmark model, simplified and computationally more efficient activity coefficient parameterizations of non-ideal organic-inorganic mixing can be developed, e.g., similarly as done for inorganic mixtures by Topping et al. (2009).

\section{Conclusions}

A new and extensive room temperature parameterization of the thermodynamic group-contribution activity coefficient model AIOMFAC is presented. Thermodynamic equilibrium data of mixed organic-inorganic systems from the literature are critically assessed and used in combination with new measurements to establish a comprehensive database for the determination of AIOMFAC model parameters. Important 
issues regarding deficiencies of the database, uncertainties of experimental data, and underlying AIOMFAC model uncertainties and sensitivities are discussed and considered. The high-dimensional global minimization problem to determine optimal interaction parameters between organic functional main groups and inorganic ions is solved with a novel combination of powerful optimization algorithms. As a result, 250 new interaction parameters are obtained, describing interactions between 11 important organic functional groups and 12 inorganic ions, allowing the calculation of activity coefficients in multicomponent organic-inorganic mixtures containing thousands of different organic compounds. With this new set of interaction parameters, AIOMFAC is arguably the most versatile activity coefficient model in that it combines a group-contribution method with an accurate electrolyte solution model. The applied methodology is shown to efficiently calculate solubility limits of salts and organics and phase compositions of LLE and VLE systems.

The new parameterization of AIOMFAC achieves generally good agreement with a large number of experimental datasets. The lack of data to constrain all activity coefficients in ternary and higher-dimensional systems is likely the most important limitation of the new AIOMFAC parameterization. Hence, some of the determined interaction parameters might be subject to adjustments in future work if new and more accurate measurements suggest a revision. There are a few datasets revealing larger deviations for complex mixtures. Various causes might be responsible for these larger deviations: uncertainties in the UNIFAC short-range part of AIOMFAC, limitations in the parameter optimization database that lead to insufficiently constrained interaction parameters, and/or highly system-specific behavior that is incompatible with the currently used expressions for the description of organic-inorganic interactions with only two middle-range parameters.

The AIOMFAC framework is open to extension to further functional groups, e.g., to describe atmospherically relevant organosulfates and organonitrates, provided that required thermodynamic data on such systems become available. Furthermore, although the current selection of functional groups and ions aims at atmospheric applications of the model, the general thermodynamic treatment is also valid for applications in other scientific fields.

A website is in preparation to enable easy access to AIOMFAC and allow online calculations of activity coefficients of user-specified mixtures.

\section{Appendix A}

\section{A1 Global optimization}

The parameter optimization problem to solve here is to minimize a multidimensional ( $\sim 250$-D), multimodal, overdetermined, nonlinear, coupled, and bound-constrained objective function. Due to the high dimensionality, and nonlinear coupling of the fit parameters, this minimization problem is a genuine challenge for any global optimization method. However, in case of a parameter optimization problem it is sufficient to find a "good" local minimum, rather than the global minimum. A practical limitation exists as the many data points involved, lead to high computational costs for each objective function evaluation. In order to restrict the computation time and to limit the parameter space to a feasible domain, we ran tests with subsets of the database to find appropriate parameter bounds for the final optimization computations. Setting conservative parameter bounds also helps to confine the behavior of AIOMFAC when used for predictions beyond its tested composition range, especially in the case of interaction parameters that are constrained by a rather limited amount of experimental data points.

Efficient local minimization methods, such as LevenbergMarquardt, or methods that minimize a function with a dimension-wise approach, such as classical DownhillSimplex, depend on a good initial guess and fail in the present application. Rigorous deterministic global optimization methods based on derivatives of the objective function (Jacobian, Hessian matrices) scale exponentially with the number of dimensions and therefore are impractical here due to extremely high computational costs (hundreds of years of calculation time). Despite active developments in the field of numerical global optimization, many global optimization methods are suited only for problems of lower dimensionality. Moreover, many benchmark functions used to test and compare optimization algorithms are easy to solve compared to the problem here. After testing different global optimization algorithms with practical phase separation and parameter optimization problems, we have formulated a combination of algorithms to solve the parameter optimization problem. First, we use a modified Best-of-Random Differential Evolution (BoRDE) algorithm variant (DE/BoR/1/bin) (Lin et al., 2011) with a population size of 100 to explore the parameter space and to locate a minimum of $F_{\text {obj }}$ subject to the polarity series constraints. Second, the global trust region method BOBYQA of Powell (2009) is applied to further refine the solution. Finally, the Downhill-Simplex algorithm by Nelder and Mead (1965) is used to fully converge to the minimum.

We modified the BoRDE algorithm to achieve selfadaptive parameter setting of the Differential Evolution parameters $F$ and $C R$. To achieve this, BoRDE is combined with the competitive parameter setting strategy DEBEST by Tvrdik (2006) in the same way as described in Appendix A of Zuend et al. (2010). This Differential Evolution variant provides a good balance between exploring the parameter space (diversity) and converging to a minimum in reasonable time (computational efficiency). The reliability of finding a "good" minimum and the self-adaptive parameter setting make this BoRDE variant a robust and practical method for the minimization of high-dimensional objective functions. 
Table A1. Bulk water activity measurements of the system water (1) + oxalic acid (2) $+\left(\mathrm{NH}_{4}\right)_{2} \mathrm{SO}_{4}$ (3) at $T=293.15 \mathrm{~K}$. Aqueous solution compositions are given in mass fractions $\left(m f_{j}\right)$.

\begin{tabular}{ccc}
\hline$m f_{2}$ & $m f_{3}$ & $a_{\mathrm{w}}^{(x)}$ \\
\hline 0.042792 & 0.006276 & 0.989 \\
0.021864 & 0.006413 & 0.992 \\
0.004451 & 0.006528 & 0.997 \\
0.021317 & 0.031265 & 0.986 \\
0.004337 & 0.031807 & 0.989 \\
0.020671 & 0.060634 & 0.979 \\
0.004204 & 0.061653 & 0.982 \\
\hline
\end{tabular}

The accuracy of the water activity measurements is specified as $\pm 0.003 a_{\mathrm{W}}$.

\section{A2 Own measurements}

Water activity and solubility measurements have been conducted to provide some additional datasets for systems where literature data is scarce. Tables A1-A13 show data of bulk water activity measurements of several ternary water + dicarboxylic acid + salt systems. An AquaLab Model 3TE (830 Decagon Devices, USA) water activity meter has been used for these measurements close to room temperature. The performance of the instrument was frequently controlled and readjusted with reference samples of pure water and 8.75 M LiCl solutions to ensure accuracy. Samples were prepared using chemicals purchased from Sigma-Aldrich with purities of $\geq 99 \%$ mixed with distilled deionized water (resistivity $\geq 15 \mathrm{M} \Omega \mathrm{cm}$ ) added using a $4 \mathrm{~mL}$ volumetric flask. When present, the compositions of the aqueous solutions were corrected for water of crystallization in salt hydrates.

Solid-liquid equilibria compositions have been measured for several aqueous electrolyte solutions saturated with (anhydrous) 2,4-dihydroxybenzaldehyde, shown in Table A14. All inorganic salts used for those solubility measurements had purities of $\geq 99 \%$ except for magnesium nitrate hexahydrate which was $\geq 98 \%$. The solubility of 2,4 dihydroxybenzaldehyde in pure water was determined first, then the solubilities of the organic-inorganic mixtures. The solubilities were determined by having a fixed mass of inorganic salt dissolved in $4 \mathrm{ml}$ of distilled deionized water and by subsequently adding small amounts of the organic to the solution which was then left for equilibriation at $298 \mathrm{~K}$ over $24 \mathrm{~h}$. This procedure was repeated until the solubility limit had been reached. Based on the increments in mass added to the mixture we estimate the error to be less than $20 \%$ (by weight).
Table A2. Bulk water activity measurements of the system water (1) + malonic acid (2) $+\left(\mathrm{NH}_{4}\right)_{2} \mathrm{SO}_{4}(3)$ at $T=293.15 \mathrm{~K}$. Aqueous solution compositions are given in mass fractions $\left(m f_{j}\right)$.

\begin{tabular}{ccc}
\hline$m f_{2}$ & $m f_{3}$ & $a_{\mathrm{w}}^{(x)}$ \\
\hline 0.506526 & 0.006429 & 0.823 \\
0.339160 & 0.008609 & 0.909 \\
0.204210 & 0.010368 & 0.953 \\
0.093090 & 0.011815 & 0.973 \\
0.493827 & 0.031339 & 0.818 \\
0.327869 & 0.041614 & 0.902 \\
0.196078 & 0.049774 & 0.941 \\
0.088889 & 0.056410 & 0.965 \\
0.478821 & 0.060773 & 0.809 \\
0.314770 & 0.079903 & 0.891 \\
0.186782 & 0.094828 & 0.929 \\
0.084142 & 0.106796 & 0.948 \\
0.451389 & 0.114583 & 0.786 \\
0.291480 & 0.147982 & 0.858 \\
0.170604 & 0.173228 & 0.897 \\
0.076023 & 0.192982 & 0.915 \\
\hline
\end{tabular}

The accuracy of the water activity measurements is specified as $\pm 0.003 a_{\mathrm{W}}$.

Table A3. Bulk water activity measurements of the system water $(1)+$ glutaric acid $(2)+\left(\mathrm{NH}_{4}\right)_{2} \mathrm{SO}_{4}(3)$ at $T=293.15 \mathrm{~K}$. Aqueous solution compositions are given in mass fractions $\left(m f_{j}\right)$.

\begin{tabular}{ccc}
\hline$m f_{2}$ & $m f_{3}$ & $a_{\mathrm{w}}^{(x)}$ \\
\hline 0.394454 & 0.007889 & 0.941 \\
0.245682 & 0.009827 & 0.965 \\
0.115264 & 0.011526 & 0.980 \\
0.236390 & 0.047278 & 0.951 \\
0.110184 & 0.055092 & 0.967 \\
0.225718 & 0.090287 & 0.932 \\
0.104430 & 0.104430 & 0.967 \\
0.207026 & 0.165621 & 0.898 \\
0.094556 & 0.189112 & 0.918 \\
\hline
\end{tabular}

The accuracy of the water activity measurements is specified as $\pm 0.003 a_{\mathrm{w}}$. 
Table A4. Bulk water activity measurements of the system water (1) + succinic acid (2) $+\left(\mathrm{NH}_{4}\right)_{2} \mathrm{SO}_{4}(3)$ at $T=293.15 \mathrm{~K}$. Aqueous solution compositions are given in mass fractions $\left(m f_{j}\right)$.

\begin{tabular}{ccc}
\hline$m f_{2}$ & $m f_{3}$ & $a_{\mathrm{w}}^{(x)}$ \\
\hline 0.055368 & 0.006194 & 0.995 \\
0.028472 & 0.006370 & 0.997 \\
0.005827 & 0.006519 & 0.998 \\
0.054029 & 0.030220 & 0.988 \\
0.027765 & 0.031059 & 0.990 \\
0.005679 & 0.031764 & 0.993 \\
0.052444 & 0.058667 & 0.979 \\
0.026928 & 0.060246 & 0.983 \\
0.005504 & 0.061573 & 0.985 \\
\hline
\end{tabular}

The accuracy of the water activity measurements is specified as $\pm 0.003 a_{\mathrm{W}}$.

Table A5. Bulk water activity measurements of the system water (1) + adipic acid (2) $+\left(\mathrm{NH}_{4}\right)_{2} \mathrm{SO}_{4}$ (3) at $T=293.15 \mathrm{~K}$. Aqueous solution compositions are given in mass fractions $\left(m f_{j}\right)$.

\begin{tabular}{ccc}
\hline$m f_{2}$ & $m f_{3}$ & $a_{\mathrm{w}}^{(x)}$ \\
\hline 0.005827 & 0.006519 & 0.992 \\
0.005679 & 0.031764 & 0.985 \\
0.005504 & 0.061573 & 0.979 \\
\hline
\end{tabular}

The accuracy of the water activity measurements is specified as $\pm 0.003 a_{\mathrm{W}}$.

Table A6. Bulk water activity measurements of the system water (1) + maleic acid (2) $+\mathrm{Ca}\left(\mathrm{NO}_{3}\right)_{2}(3)$ at $T=293.15 \mathrm{~K}$. Aqueous solution compositions are given in mass fractions $\left(m f_{j}\right)$.

\begin{tabular}{ccc}
\hline$m f_{2}$ & $m f_{3}$ & $a_{\mathrm{w}}^{(x)}$ \\
\hline 0.307692 & 0.053450 & 0.903 \\
0.181818 & 0.063168 & 0.942 \\
0.100000 & 0.069485 & 0.955 \\
0.052632 & 0.073142 & 0.970 \\
0.166667 & 0.115808 & 0.916 \\
0.090909 & 0.126336 & 0.938 \\
0.047619 & 0.132352 & 0.948 \\
0.142857 & 0.198528 & 0.865 \\
0.076923 & 0.213799 & 0.891 \\
0.040000 & 0.222351 & 0.900 \\
0.111111 & 0.308821 & 0.784 \\
0.058824 & 0.326987 & 0.801 \\
0.030303 & 0.336895 & 0.813 \\
\hline
\end{tabular}

The accuracy of the water activity measurements is specified as $\pm 0.003 a_{\mathrm{W}}$.
Table A7. Bulk water activity measurements of the system water (1) + maleic acid (2) $+\mathrm{Mg}\left(\mathrm{NO}_{3}\right)_{2}$ (3) at $T=293.15 \mathrm{~K}$. Aqueous solution compositions are given in mass fractions $\left(m f_{j}\right)$.

\begin{tabular}{ccc}
\hline$m f_{2}$ & $m f_{3}$ & $a_{\mathrm{w}}^{(x)}$ \\
\hline 0.307692 & 0.044495 & 0.926 \\
0.181818 & 0.052585 & 0.943 \\
0.100000 & 0.057843 & 0.979 \\
0.052632 & 0.060888 & 0.994 \\
0.047619 & 0.110178 & 0.947 \\
0.040000 & 0.185099 & 0.886 \\
0.030303 & 0.280452 & 0.777 \\
\hline
\end{tabular}

The accuracy of the water activity measurements is specified as $\pm 0.003 a_{\mathrm{W}}$.

Table A8. Bulk water activity measurements of the system water (1) + maleic acid (2) $+\mathrm{NH}_{4} \mathrm{Br}(3)$ at $T=293.15 \mathrm{~K}$. Aqueous solution compositions are given in mass fractions $\left(m f_{j}\right)$.

\begin{tabular}{ccc}
\hline$m f_{2}$ & $m f_{3}$ & $a_{\mathrm{w}}^{(x)}$ \\
\hline 0.320000 & 0.040000 & 0.950 \\
0.190476 & 0.047619 & 0.976 \\
0.105263 & 0.052632 & 0.987 \\
0.055556 & 0.055556 & 1.000 \\
0.052632 & 0.105263 & 0.969 \\
0.047619 & 0.190476 & 0.930 \\
0.040000 & 0.320000 & 0.890 \\
\hline
\end{tabular}

The accuracy of the water activity measurements is specified as $\pm 0.003 a_{\mathrm{W}}$.

Table A9. Bulk water activity measurements of the system water (1) + malonic acid (2) $+\mathrm{NH}_{4} \mathrm{NO}_{3}$ (3) at $T=293.15$ and $303.15 \mathrm{~K}$. Aqueous solution compositions are given in mass fractions $\left(m f_{j}\right)$.

\begin{tabular}{ccrr}
\hline$m f_{2}$ & $m f_{3}$ & $a_{\mathrm{w}}^{(x)}(293.15 \mathrm{~K})$ & $a_{\mathrm{w}}^{(x)}(303.15 \mathrm{~K})$ \\
\hline 0.493827 & 0.012346 & 0.835 & 0.826 \\
0.327869 & 0.016393 & 0.920 & 0.912 \\
0.196078 & 0.019608 & 0.985 & 0.948 \\
0.108696 & 0.021739 & 0.978 & 0.964 \\
0.470588 & 0.058824 & 0.807 & 0.800 \\
0.307692 & 0.076923 & 0.890 & 0.868 \\
0.181818 & 0.090909 & 0.932 & 0.920 \\
0.100000 & 0.100000 & 0.948 & 0.938 \\
0.444444 & 0.111111 & 0.771 & 0.759 \\
0.285714 & 0.142857 & 0.859 & 0.852 \\
0.166667 & 0.166667 & 0.897 & 0.888 \\
0.090909 & 0.181818 & 0.912 & 0.907 \\
0.400000 & 0.200000 & 0.725 & 0.711 \\
0.250000 & 0.250000 & 0.801 & 0.776 \\
0.142857 & 0.285714 & 0.833 & 0.821 \\
0.076923 & 0.307692 & 0.857 & 0.826 \\
\hline
\end{tabular}

The accuracy of the water activity measurements is specified as $\pm 0.003 a_{\mathrm{W}}$. 
Table A10. Bulk water activity measurements of the system water (1) + malonic acid (2) $+\mathrm{Na}_{2} \mathrm{SO}_{4}(3)$ at $T=293.15$ and $303.15 \mathrm{~K}$. Aqueous solution compositions are given in mass fractions $\left(m f_{j}\right)$.

\begin{tabular}{ccrr}
\hline$m f_{2}$ & $m f_{3}$ & $a_{\mathrm{w}}^{(x)}(293.15 \mathrm{~K})$ & $a_{\mathrm{w}}^{(x)}(303.15 \mathrm{~K})$ \\
\hline 0.493827 & 0.012346 & 0.799 & 0.772 \\
0.327869 & 0.016393 & 0.908 & 0.857 \\
0.196078 & 0.019608 & 0.952 & 0.927 \\
0.108696 & 0.021739 & 0.989 & 0.948 \\
0.470588 & 0.058824 & 0.782 & 0.789 \\
0.307692 & 0.076923 & 0.879 & 0.890 \\
0.181818 & 0.090909 & 0.952 & 0.901 \\
0.100000 & 0.100000 & 0.973 & 0.920 \\
\hline
\end{tabular}

The accuracy of the water activity measurements is specified as $\pm 0.003 a_{\mathrm{w}}$.

Table A11. Bulk water activity measurements of the system water (1) + malonic acid (2) $+\mathrm{NaCl}(3)$ at $T=293.15$ and $303.15 \mathrm{~K}$. Aqueous solution compositions are given in mass fractions $\left(m f_{j}\right)$.

\begin{tabular}{ccrr}
\hline$m f_{2}$ & $m f_{3}$ & $a_{\mathrm{w}}^{(x)}(293.15 \mathrm{~K})$ & $a_{\mathrm{w}}^{(x)}(303.15 \mathrm{~K})$ \\
\hline 0.493827 & 0.012346 & 0.807 & 0.817 \\
0.327869 & 0.016393 & 0.905 & 0.910 \\
0.196078 & 0.019608 & 0.949 & 0.951 \\
0.108696 & 0.021739 & 0.970 & 0.966 \\
0.470588 & 0.058824 & 0.770 & 0.775 \\
0.307692 & 0.076923 & 0.841 & 0.853 \\
0.181818 & 0.090909 & 0.882 & 0.893 \\
0.100000 & 0.100000 & 0.910 & 0.913 \\
\hline
\end{tabular}

The accuracy of the water activity measurements is specified as $\pm 0.003 a_{\mathrm{W}}$.

Table A12. Bulk water activity measurements of the system water (1) + malonic acid (2) $+\mathrm{LiNO}_{3}(3)$ at $T=293.15$ and $303.15 \mathrm{~K}$. Aqueous solution compositions are given in mass fractions $\left(m f_{j}\right)$.

\begin{tabular}{ccrr}
\hline$m f_{2}$ & $m f_{3}$ & $a_{\mathrm{w}}^{(x)}(293.15 \mathrm{~K})$ & $a_{\mathrm{w}}^{(x)}(303.15 \mathrm{~K})$ \\
\hline 0.493827 & 0.012346 & 0.806 & 0.805 \\
0.327869 & 0.016393 & 0.893 & 0.911 \\
0.196078 & 0.019608 & 0.943 & 0.944 \\
0.108696 & 0.021739 & 0.964 & 0.967 \\
0.470588 & 0.058824 & 0.742 & 0.761 \\
0.307692 & 0.076923 & 0.830 & 0.843 \\
0.181818 & 0.090909 & 0.884 & 0.894 \\
0.100000 & 0.100000 & 0.907 & 0.915 \\
0.444444 & 0.111111 & 0.666 & 0.691 \\
0.285714 & 0.142857 & 0.745 & 0.759 \\
0.166667 & 0.166667 & 0.798 & 0.809 \\
0.090909 & 0.181818 & 0.811 & 0.826 \\
\hline
\end{tabular}

The accuracy of the water activity measurements is specified as $\pm 0.003 a_{\mathrm{W}}$.
Table A13. Bulk water activity measurements of the system water (1) + malonic acid (2) $+\mathrm{NH}_{4} \mathrm{Br}(3)$ at $T=293.15$ and $303.15 \mathrm{~K}$. Aqueous solution compositions are given in mass fractions $\left(m f_{j}\right)$.

\begin{tabular}{ccrr}
\hline$m f_{2}$ & \multicolumn{1}{c}{$m f_{3}$} & $a_{\mathrm{w}}^{(x)}(293.15 \mathrm{~K})$ & $a_{\mathrm{w}}^{(x)}(303.15 \mathrm{~K})$ \\
\hline 0.493827 & 0.012346 & 0.821 & 0.823 \\
0.327869 & 0.016393 & 0.913 & 0.915 \\
0.196078 & 0.019608 & 0.952 & 0.947 \\
0.108696 & 0.021739 & 0.978 & 0.972 \\
0.470588 & 0.058824 & 0.788 & 0.776 \\
0.307692 & 0.076923 & 0.880 & 0.871 \\
0.181818 & 0.090909 & 0.918 & 0.913 \\
0.100000 & 0.100000 & 0.946 & 0.937 \\
0.090909 & 0.181818 & 0.900 & 0.898 \\
\hline
\end{tabular}

The accuracy of the water activity measurements is specified as $\pm 0.003 a_{\mathrm{W}}$.

Table A14. Measured solubility limits of 2,4dihydroxybenzaldehyde in different ternary solutions of water (1) +2,4-dihydroxybenzaldehyde (2) + salt (3) at $T=298.15 \mathrm{~K}$ Aqueous solution compositions are given in mass fractions $\left(m f_{j}\right)$.

\begin{tabular}{|c|c|c|c|}
\hline$m f_{2}$ & $m f_{3}$ & $m f_{2}$ & $m f_{3}$ \\
\hline \multicolumn{4}{|c|}{ salt-free } \\
\hline 0.004975 & 0.000000 & & \\
\hline \multicolumn{2}{|c|}{$\mathrm{Ca}\left(\mathrm{NO}_{3}\right)_{2}(3)$} & \multicolumn{2}{|c|}{$\mathrm{Mg}\left(\mathrm{NO}_{3}\right)_{2}$} \\
\hline 0.008090 & 0.076581 & 0.006842 & 0.063851 \\
\hline 0.006261 & 0.138099 & 0.006126 & 0.115015 \\
\hline 0.003024 & 0.230915 & 0.004860 & 0.191936 \\
\hline 0.002991 & 0.296901 & 0.003862 & 0.247022 \\
\hline \multicolumn{2}{|c|}{$\mathrm{NH}_{4} \mathrm{Br}(3)$} & \multicolumn{2}{|c|}{$\mathrm{Na}_{2} \mathrm{SO}_{4}(3)$} \\
\hline 0.007021 & 0.058411 & 0.004879 & 0.024271 \\
\hline 0.005173 & 0.110536 & 0.004917 & 0.058534 \\
\hline 0.005003 & 0.198999 & 0.003940 & 0.110673 \\
\hline \multicolumn{4}{|c|}{$\mathrm{NaCl}(3)$} \\
\hline 0.005248 & 0.024262 & & \\
\hline 0.004567 & 0.058555 & & \\
\hline 0.004623 & 0.110597 & & \\
\hline 0.003607 & 0.199279 & & \\
\hline
\end{tabular}

The estimated error of the stated SLE compositions is $<20 \%$ (by weight). 


\section{Supplementary material related to this article is available online at: \\ http://www.atmos-chem-phys.net/11/9155/2011/ acp-11-9155-2011-supplement.pdf.}

Acknowledgements. This work was supported by Swiss National Science Foundation (SNF) under project no. PA00P2_126227, by ETH Research Grant ETH-0210-1, and by the Competence Center Environment and Sustainability of the ETH Domain (CCES) project IMBALANCE. This work was also supported by US National Science Foundation grant AGS-1057183.

\section{References}

Abrams, D. S. and Prausnitz, J. M.: Statistical Thermodynamics of Liquid Mixtures: A New Expression for the Excess Gibbs Energy of Partly or Completely Miscible Systems, AIChE J., 21, 116-128, 1975.

Al-Sahhaf, T. A. and Jabbar, N. J.: Vapor-Liquid Equilibrium of the Acetone-Water-Salt System, J. Chem. Eng. Data, 38, 522-526, 1993.

Al-Sahhaf, T. A. and Kapetanovic, E.: Salt Effects of Lithium Chloride, Sodium Bromide, or Potassium Iodide on Liquid-Liquid Equilibrium in the System Water +1-Butanol, J. Chem. Eng. Data, 42, 74-77, 1997.

Al-Sahhaf, T. A., Kapetanovic, E., and Kadhem, Q.: Salt effects on liquid-liquid equilibria in the partially miscible systems water + 2-butanone and water + ethyl acetate, Fluid Phase Equilib., 157, 271-283, 1999.

Altshuller, A. P. and Everson, H. E.: The Solubility of Ethyl Acetate in Aqueous Electrolyte Solutions, J. Am. Chem. Soc., 75, 48234827, 1953.

Amundson, N. R., Caboussat, A., He, J. W., Martynenko, A. V., Savarin, V. B., Seinfeld, J. H., and Yoo, K. Y.: A new inorganic atmospheric aerosol phase equilibrium model (UHAERO), Atmos. Chem. Phys., 6, 975-992, doi:10.5194/acp-6-975-2006, 2006.

An, W. J., Pathak, R. K., Lee, B. H., and Pandis, S. N.: Aerosol volatility measurement using an improved thermodenuder: Application to secondary organic aerosol, J. Aerosol Sci., 38, 305314, doi:10.1016/j.jaerosci.2006.12.002, 2007.

Aznar, M., Araujo, R. N., Romanato, J. F., Santos, G. R., and d'Avila, S. G.: Salt effects on liquid-liquid equilibrium in water + ethanol + alcohol + salt systems, J. Chem. Eng. Data, 45, 1055-1059, 2000.

Balaban, A. A. and Kuranov, G. L.: Solubility in WaterIsopropanol- $\mathrm{MgCl} 2$ and Water-Isopropanol-CaCl2 Systems, Russ. J. Gen. Chem., 69, 876-879, 1999.

Balaban, A. A. and Kuranov, G. L.: Liquid-Vapor Equilibrium in the Quaternary System Water-2-Propanol-Calcium ChlorideMagnesium Chloride, Russ. J. Gen. Chem., 72, 1878-1881, 2002

Banat, F., Al-Asheh, S., and Simandl, J.: Effect of dissolved inorganic salts on the isothermal vapor-liquid equilibrium of the propionic acid-water mixture, Chem. Eng. Process., 41, 793-798, 2002.

Banat, F., Al-Asheh, S., and Simandl, J.: Effect of trivalent, bivalent, and univalent cation inorganic salts on the isothermal vapor-liquid equilibria of propionic acid-water system, Chem. Eng. Process., 42, 759-766, 2003a.

Banat, F., Al-Asheh, S., and Simandl, J.: Vapor-liquid equilibria of propionic acid-water system in the presence of different types of inorganic salts: effect of temperature and salt concentration, Chem. Eng. Process., 42, 917-923, 2003b.

Barba, D., Brandani, V., and Di Giacomo, G.: Solubility of calcium sulfate dihydrate in the system sodium sulfatemagnesium chloride-water, J. Chem. Eng. Data, 29, 42-45, doi:10.1021/je00035a015, 1984.

Bathrick, H. A.: Precipitation of Salts, J. Phys. Chem., 1, 157169, doi:10.1021/j150585a003, http://pubs.acs.org/doi/abs/10. 1021/j150585a003, 1896.

Bertram, A. K., Martin, S. T., Hanna, S. J., Smith, M. L., Bodsworth, A., Chen, Q., Kuwata, M., Liu, A., You, Y., and Zorn, S. R.: Predicting the relative humidities of liquid-liquid phase separation, efflorescence, and deliquescence of mixed particles of ammonium sulfate, organic material, and water using the organic-to-sulfate mass ratio of the particle and the oxygen-tocarbon elemental ratio of the organic component, Atmos. Chem. Phys. Discuss., 11, 17759-17788, doi:10.5194/acpd-11-177592011, 2011.

Boddu, V. M., Krishnaiah, A., and Viswanath, D. S.: Liquid-Liquid Equilibria of the Benzene + Water + Acetic Acid Ternary System and Solubility of Benzene in Water: Effect of Calcium Chloride, J. Chem. Eng. Data, 46, 1172-1175, 2001.

Bogardus, H. F. and Lynch, C. C.: The ternary systems barium chloride-dioxane-water and calcium chloride-dioxane-water, J. Phys. Chem., 47, 650-654, 1943.

Bourayou, N. and Meniai, A.-H.: Effect of calcium chloride on the liquid-liquid equilibria of the water-acetone system, Desalination, 206, 198-204, doi:10.1016/j.desal.2006.04.053, 2007.

Brenner, D. K., Anderson, E. W., Lynn, S., and Prausnitz, J. M.: Liquid-liquid equilibria for saturated aqueous-solutions of sodium-sulfate + 1-propanol, 2-propanol, or 2-methylpropan2-ol, J. Chem. Eng. Data, 37, 419-422, 1992.

Bretti, C., Crea, F., Foti, C., and Sammartano, S.: Solubility and Activity Coefficients of Acidic and Basic Nonelectrolytes in Aqueous Salt Solutions. 1. Solubility and Activity Coefficients of $o$ Phthalic Acid and $L$-Cystine in $\mathrm{NaCl}(\mathrm{aq}),\left(\mathrm{CH}_{3}\right)_{4} \mathrm{NCl}(\mathrm{aq})$, and $\left(\mathrm{C}_{2} \mathrm{H}_{5}\right)_{4} \mathrm{NI}(\mathrm{aq})$ at Different Ionic Strengths and at $t=25^{\circ} \mathrm{C}$, J. Chem. Eng. Data, 50, 1761-1767, doi:10.1021/je0502039, 2005.

Brunjes, A. S. and Bogart, M. J. P.: Vapor-Liquid Equilibria for Commercially Important Systems of Organic Solvents The Binary Systems Ethanol-n-Butanol, Acetone-Water and Isopropanol-Water, Ind. Eng. Chem., 35, 255-260, 1943.

Burns, J. A. and Furter, W. F.: Thermodynamic behavior of electrolytes in mixed solvents, a symposium: 170th meeting of the American Chemical Society, Chicago, American Chemical Society, Washington, 1975.

Carslaw, K. S., Clegg, S. L., and Brimblecombe, P.: A Thermodynamic Model of the System $\mathrm{HCl}-\mathrm{HNO}_{3}-\mathrm{H}_{2} \mathrm{SO}_{4}-\mathrm{H}_{2} \mathrm{O}$, Including Solubilities of $\mathrm{HBr}$, from $<200$ to $328 \mathrm{~K}$, J. Phys. Chem., 99, 11557-11574, 1995.

Chai, X. S., Falabella, J. B., and Teja, A. S.: A relative headspace method for Henry's constants of volatile organic compounds, Fluid Phase Equilib., 231, 239-245, doi:10.1016/j.fluid.2005.02.006, 2005.

Chan, A. W. H., Chan, M. N., Surratt, J. D., Chhabra, P. S., Loza, 
C. L., Crounse, J. D., Yee, L. D., Flagan, R. C., Wennberg, P. O., and Seinfeld, J. H.: Role of aldehyde chemistry and NOx concentrations in secondary organic aerosol formation, Atmos. Chem. Phys., 10, 7169-7188, doi:10.5194/acp-10-7169-2010, 2010.

Chang, E. I. and Pankow, J. F.: Prediction of activity coefficients in liquid aerosol particles containing organic compounds, dissolved inorganic salts, and water - Part 2: Consideration of phase separation effects by an X-UNIFAC model, Atmos. Environ., 40, 6422-6436, doi:10.1016/j.atmosenv.2006.04.031, 2006.

Chiavone-Filho, O. and Rasmussen, P.: Solubilities of Salts in Mixed Solvents, J. Chem. Eng. Data, 38, 367-369, 1993.

Choi, M. Y. and Chan, C. K.: The Effects of Organic Species on the Hygroscopic Behaviors of Inorganic Aerosols, Environ. Sci. Technol., 36, 2422-2428, doi:10.1021/es0113293, 2002.

Chou, T. J., Tanioka, A., and Tseng, H. C.: Salting effect on the liquid-liquid equilibria for the partially miscible systems of npropanol-water and i-propanol-water, Ind. Eng. Chem. Res., 37, 2039-2044, 1998.

Chueh, C. F.: Predicting activity coefficients of multicomponent solutions containing formic acid, acetic acid, formaldehyde, acetaldehyde, and water, AIChE Symp. Ser., 70, 110-119, 1974.

Ciobanu, V. G., Marcolli, C., Krieger, U. K., Weers, U., and Peter, T.: Liquid-Liquid Phase Separation in Mixed Organic/Inorganic Aerosol Particles, J. Phys. Chem. A, 113, 10966-10978, doi:10.1021/jp905054d, 2009.

Clegg, S. L. and Pitzer, K. S.: Thermodynamics of multicomponent, miscible, ionic solutions: generalized equations for symmetrical electrolytes, J. Phys. Chem., 96, 3513-3520, doi:10.1021/j100187a061, 1992.

Clegg, S. L. and Seinfeld, J. H.: Improvement of the ZdanovskiiStokes-Robinson Model for Mixtures Containing Solutes of Different Charge Types, J. Phys. Chem. A, 108, 1008-1017, doi:10.1021/jp030827q, 2004.

Clegg, S. L. and Seinfeld, J. H.: Thermodynamic models of aqueous solutions containing inorganic electrolytes and dicarboxylic acids at $298.15 \mathrm{~K}$. 1. The acids as nondissociating components, J. Phys. Chem. A, 110, 5692-5717, doi:10.1021/jp056149k, 2006a.

Clegg, S. L. and Seinfeld, J. H.: Thermodynamic models of aqueous solutions containing inorganic electrolytes and dicarboxylic acids at 298.15 K. 2. Systems including dissociation equilibria, J. Phys. Chem. A, 110, 5718-5734, doi:10.1021/jp056150j, $2006 \mathrm{~b}$.

Clegg, S. L., Pitzer, K. S., and Brimblecombe, P.: Thermodynamics of multicomponent, miscible, ionic solutions. Mixtures including unsymmetrical electrolytes, J. Phys. Chem., 96, 9470-9479, doi:10.1021/j100202a074, 1992.

Clegg, S. L., Milioto, S., and Palmer, D. A.: Osmotic and Activity Coefficients of Aqueous $\left(\mathrm{NH}_{4}\right)_{2} \mathrm{SO}_{4}$ as a Function of Temperature, and Aqueous $\left(\mathrm{NH}_{4}\right)_{2} \mathrm{SO}_{4}-\mathrm{H}_{2} \mathrm{SO}_{4}$ Mixtures at $298.15 \mathrm{~K}$ and 323.15 K, J. Chem. Eng. Data, 41, 455-467, 1996.

Clegg, S. L., Brimblecombe, P., and Wexler, A. S.: Thermodynamic model of the system $\mathrm{H}^{+}-\mathrm{NH}_{4}^{+}-\mathrm{SO}_{4}^{2-}-\mathrm{NO}_{3}^{-}-\mathrm{H}_{2} \mathrm{O}$ at tropospheric temperatures, J. Phys. Chem. A, 102, 2137-2154, 1998a.

Clegg, S. L., Brimblecombe, P., and Wexler, A. S.: Thermodynamic model of the system $\mathrm{H}^{+}-\mathrm{NH}_{4}^{+}-\mathrm{Na}^{+}-\mathrm{SO}_{4}^{2-}-\mathrm{NO}_{3}^{-}-\mathrm{Cl}^{-}-\mathrm{H}_{2} \mathrm{O}$ at 298.15 K, J. Phys. Chem. A, 102, 2155-2171, 1998b.

Clegg, S. L., Seinfeld, J. H., and Brimblecombe, P.: Thermodynamic modelling of aqueous aerosols containing electrolytes and dissolved organic compounds, J. Aerosol. Sci., 32, 713-738, 2001.

Clegg, S. L., Seinfeld, J. H., and Edney, E. O.: Thermodynamic modelling of aqueous aerosols containing electrolytes and dissolved organic compounds. II. An extended ZdanovskiiStokes-Robinson approach, J. Aerosol Sci., 34, 667-690, doi:10.1016/s0021-8502(03)00019-3, 2003.

Colberg, C. A., Krieger, U. K., and Peter, T.: Morphological investigations of single levitated $\mathrm{H}_{2} \mathrm{SO}_{4} / \mathrm{NH}_{3} / \mathrm{H}_{2} \mathrm{O}$ aerosol particles during deliquescence/efflorescence experiments., J. Phys. Chem. A, 108, 2700-2709, doi:10.1021/jp037628r, 2004.

Compernolle, S., Ceulemans, K., and Müller, J.-F.: Influence of non-ideality on condensation to aerosol, Atmos. Chem. Phys., 9, 1325-1337, doi:10.5194/acp-9-1325-2009, 2009.

Davidson, A. W. and Geer, H. A.: The solubility of nitrates in anhydrous acetic acid, J. Am. Chem. Soc., 55, 642-649, 1933.

Dawson, B. S. W., Irish, D. E., and Toogood, G. E.: Vibrational spectral studies of solutions at elevated-temperatures and pressures. 8. A raman spectral study of ammonium hydrogen sulfatesolutions and the $\mathrm{HSO}_{4}^{-}-\mathrm{SO}_{4}^{2-}$ equilibrium, J. Phys. Chem., 90, 334-341, 1986.

De Santis, R., Marrelli, L., and Muscetta, P. N.: Liquid-liquid equilibria in water-aliphatic alcohol systems in the presence of sodium chloride, Chem. Eng. J., 11, 207-214, 1976.

Decesari, S., Facchini, M. C., Fuzzi, S., and Tagliavini, E.: Characterization of water-soluble organic compounds in atmospheric aerosol: A new approach, J. Geophys. Res. Atmos., 105, 14811489, doi:10.1029/1999JD900950, 2000.

Decesari, S., Fuzzi, S., Facchini, M. C., Mircea, M., Emblico, L., Cavalli, F., Maenhaut, W., Chi, X., Schkolnik, G., Falkovich, A., Rudich, Y., Claeys, M., Pashynska, V., Vas, G., Kourtchev, I., Vermeylen, R., Hoffer, A., Andreae, M. O., Tagliavini, E., Moretti, F., and Artaxo, P.: Characterization of the organic composition of aerosols from Rondônia, Brazil, during the LBASMOCC 2002 experiment and its representation through model compounds, Atmos. Chem. Phys., 6, 375-402, doi:10.5194/acp6-375-2006, 2006.

Deguillaume, L., Tilgner, A., Schroedner, R., Wolke, R., Chaumerliac, N., and Herrmann, H.: Towards an operational aqueous phase chemistry mechanism for regional chemistry-transport models: CAPRAM-RED and its application to the COSMOMUSCAT model, J. Atmos. Chem., 64, 1-35, 2009.

Deyhimi, F. and Ghalami-Choobar, B.: Activity coefficients for $\mathrm{NH}_{4} \mathrm{Cl}$ in 2-PrOH/water mixed solvent and some thermodynamic correlations for $\mathrm{NH}_{4} \mathrm{Cl}$ in $\mathrm{ROH} /$ water mixed solvents ( $\mathrm{R}=\mathrm{Me}$, Et, 1-Pr and 2-Pr), Fluid Phase Equilib., 246, 185-190, doi:10.1016/j.fluid.2006.06.004, 2006.

Deyhimi, F. and Karimzadeh, Z.: Pitzer and Pitzer-SimonsonClegg modeling approaches: Ternary $\mathrm{HCl}+$ ethanol + water electrolyte system, J. Electroanal. Chem., 635, 93-98, doi:10.1016/j.jelechem.2009.08.010, 2009.

Deyhimi, F. and Karimzadeh, Z.: Pitzer and PitzerSimonsonClegg Modeling Approaches: Ternary $\mathrm{HCl}+2$ Propanol + Water Electrolyte System, J. Solution Chem., 39, 245-257, doi:10.1007/s10953-010-9497-x, http://dx.doi.org/10.1007/s10953-010-9497-x, 2010.

Deyhimi, F., Ghalami-Choobar, B., and Salamat-Ahangari, R.: Activity coefficients for $\mathrm{NH}_{4} \mathrm{Cl}$ in ethanol-water mixed solvents by electromotive force measurements, J. Mol. Liq., 116, 93-97, 
2005.

Dykyj, J., Svoboda, J., Wilhoit, R. C., Frenkel, M., and Hall, K. R.: Organic Compounds, C1 to C57. Part 1., in: Landolt-Börnstein - Group IV Physical Chemistry Numerical Data and Functional Relationships in Science and Technology, edited by: Hall, K. R., vol. 20B: Vapor Pressure and Antoine Constants for Oxygen Containing Organic Compounds, pp. 14-110, SpringerMaterials - The Landolt-Börnstein Database, doi:10.1007/106885833, http://www.springermaterials.com,2000.

Erdakos, G. B. and Pankow, J. F.: Gas/particle partitioning of neutral and ionizing compounds to single- and multi-phase aerosol particles. 2. Phase separation in liquid particulate matter containing both polar and low-polarity organic compounds, Atmos. Environ., 38, 1005-1013, doi:10.1016/j.atmosenv.2003.10.038, 2004.

Erdakos, G. B., Chang, E. I., Pankow, J. F., and Seinfeld, J. H.: Prediction of activity coefficients in liquid aerosol particles containing organic compounds, dissolved inorganic salts, and water - Part 3: Organic compounds, water, and ionic constituents by consideration of short-, mid-, and long-range effects using X-UNIFAC.3, Atmos. Environ., 40, 6437-6452, doi:10.1016/j.atmosenv.2006.04.001, 2006.

Esteso, M. A., Gonzalez-Diaz, O. M., Hernandez-Luis, F. F., and Fernandez-Merida, L.: Activity-coefficients for $\mathrm{NaCl}$ in ethanolwater mixtures at $25^{\circ} \mathrm{C}$, J. Solution Chem., 18, 277-288, 1989.

Eysseltova, J. and Malkova, Z.: Solubility in the systems $\mathrm{MCl}(\mathrm{M}=$ $\mathrm{Na}, \mathrm{K})$-1,4-dioxane-water at $25^{\circ} \mathrm{C}$, J. Solution Chem., 35, 13291334, doi:10.1007/s10953-006-9061-x, 2006.

Falabella, J. B., Nair, A., and Teja, A. S.: Henrys Constants of 1Alkanols and 2-Ketones in Salt Solutions, J. Chem. Eng. Data, 51, 1940-1945, doi:10.1021/je0600956, 2006.

Farelo, F., Lopes, A., and Ferra, M. I. A.: Activity coefficients of potassium chloride and sodium chloride in the quaternary system KCl-NaCl-water-ethanol, J. Solution Chem., 31, 845-860, 2002.

Faulhaber, A. E., Thomas, B. M., Jimenez, J. L., Jayne, J. T., Worsnop, D. R., and Ziemann, P. J.: Characterization of a thermodenuder-particle beam mass spectrometer system for the study of organic aerosol volatility and composition, Atmos. Meas. Tech., 2, 15-31, doi:10.5194/amt-2-15-2009, 2009.

Fountoukis, C. and Nenes, A.: ISORROPIA II: a computationally efficient thermodynamic equilibrium model for $\mathrm{K}^{+}-$ $\mathrm{Ca}^{2+}-\mathrm{Mg}^{2+}-\mathrm{NH}_{4}{ }^{+}-\mathrm{Na}^{+}-\mathrm{SO}_{4}{ }^{2-}-\mathrm{NO}_{3}{ }^{-}-\mathrm{Cl}^{-}-\mathrm{H}_{2} \mathrm{O}$ aerosols, Atmos. Chem. Phys., 7, 4639-4659, doi:10.5194/acp-7-46392007, 2007.

Fox, J. J. and Gauge, A. J. H.: The solubility of potassium sulphate in concentrated aqueous solutions of non-electrolytes, J. Chem. Soc., 97, 377-385, 1910.

Fredenslund, A., Jones, R. L., and Prausnitz, J. M.: GroupContribution Estimation of Activity Coefficients in Nonideal Liquid Mixtures, AIChE J., 21, 1086-1099, 1975.

Fu, J. Q.: Salt effect on vaporliquid equilibria for binary systems of propanol $/ \mathrm{CaCl}_{2}$ and butanol/ $\mathrm{CaCl}_{2}$, Fluid Phase Equilib., 237, 219-223, doi:10.1016/j.fluid.2005.07.023, 2005.

Gilardoni, S., Liu, S., Takahama, S., Russell, L. M., Allan, J. D., Steinbrecher, R., Jimenez, J. L., De Carlo, P. F., Dunlea, E. J., and Baumgardner, D.: Characterization of organic ambient aerosol during MIRAGE 2006 on three platforms, Atmos. Chem. Phys., 9, 5417-5432, doi:10.5194/acp-9-5417-2009, 2009.

Gironi, F. and Lamberti, L.: Vapour-liquid equilibrium data for the water-2-propanol system in the presence of dissolved salts, Fluid Phase Equilib., 105, 273-286, 1995.

Gmehling, J., Onken, U., and Arlt, W.: Vapor-Liquid Equilibrium Data Collection, Aqueous-Organic Systems (Supplement 1). DECHEMA Chemistry Data Ser. I, DECHEMA Chemistry Data Ser. I, 1, 1-715, 1981.

Gomis, V., Ruiz, F., Marcilla, A., and Pascual, M. D.: Equilibrium for the Ternary System Water + Sodium Chloride + Ethyl Acetate at $30^{\circ} \mathrm{C}$, J. Chem. Eng. Data, 38, 589-590, 1993.

Gomis, V., Ruiz, F., Devera, G., Lopez, E., and Saquete, M. D.: Liquid-liquid-solid equilibria for the ternary-systems water sodium-chloride or potassium-chloride 1-propanol or 2propanol, Fluid Phase Equilib., 98, 141-147, 1994.

Gomis, V., Ruiz, F., Asensi, J. C., and Saquete, M. D.: Liquid-liquid-solid equilibria for the ternary systems butanols + water + sodium chloride or + potassium chloride, J. Chem. Eng. Data, 41, 188-191, 1996.

Gomis, V., Ruiz, F., Boluda, N., and Saquete, M. D.: Liquidliquid-solid equilibria for ternary systems water + lithium chloride + pentanols, Fluid Phase Equilib., 215, 79-83, doi:10.1016/S0378-3812(03)00361-3, 2004.

Gomis, V., Ruiz, F., Boluda, N., and Saquete, A. D.: Unusual S-Shaped Binodal Curves of the System Water + Lithium Chloride + 2-Methyl-2-propanol, J. Chem. Eng. Data, 53, 2851-2853, doi:10.1021/je800588p, 2008.

Govindarajan, M. and Sabarathinam, P.: Effect of Some Inorganic Salts on the Ternary Liquid-Liquid Equilibria of the Water + 4Methyl-2-pentanone + Propanoic or Butanoic Acid at $35^{\circ} \mathrm{C}, \mathrm{J}$. Chem. Eng. Data, 42, 402-408, 1997.

Govindarajan, M. and Sabarathinam, P. L.: Salt effect on liquidliquid equilibrium of the methyl isobutyl ketone-acetic acidwater system at $35^{\circ} \mathrm{C}$, Fluid Phase Equilib., 108, 269-292, 1995.

Greve, A. and Kula, M. R.: Phase diagrams of new aqueous phase systems composed of aliphatic alcohols, salts and water, Fluid Phase Equilib., 62, 53-63, doi:10.1016/0378-3812(91)87005-T, 1991.

Griffin, R. J., Dabdub, D., and Seinfeld, J. H.: Secondary organic aerosol - 1. Atmospheric chemical mechanism for production of molecular constituents, J. Geophys. Res. Atmos., 107(D17), 4332, doi:10.1029/2001JD000541, 2002.

Hallquist, M., Wenger, J. C., Baltensperger, U., Rudich, Y., Simpson, D., Claeys, M., Dommen, J., Donahue, N. M., George, C., Goldstein, A. H., Hamilton, J. F., Herrmann, H., Hoffmann, T., Iinuma, Y., Jang, M., Jenkin, M. E., Jimenez, J. L., Kiendler-Scharr, A., Maenhaut, W., McFiggans, G., Mentel, Th. F., Monod, A., Prvt, A. S. H., Seinfeld, J. H., Surratt, J. D., Szmigielski, R., and Wildt, J.: The formation, properties and impact of secondary organic aerosol: current and emerging issues, Atmos. Chem. Phys., 9, 5155-5236, doi:10.5194/acp-95155-2009, 2009.

Hansen, H. K., Rasmussen, P., Fredenslund, A., Schiller, M., and Gmehling, J.: Vapor-liquid-equilibria by UNIFAC group contribution. 5. Revision and extension, Ind. Eng. Chem. Res., 30, 2352-2355, 1991.

Hanson, C. and Ismail, H. A. M.: Solubility and Distribution Data for Benzene and Toluene Between Aqueous and Organic Phases, J. appl. Chem. Biotechnol., 25, 319-325, 1975.

Hernandez-Luis, F., Grandoso, D., and Lemus, M.: Activity Coefficients of $\mathrm{NaCl}$ in Fructose + Water at 298.15 K, J. Chem. Eng. 
Data, 49, 668-674, doi:10.1021/je034240g, http://dx.doi.org/10. 1021/je034240g, 2004.

Hernandez-Luis, F., Galleguillos, H. R., Graber, T. A., and Taboada, M. E.: Activity Coefficients of $\mathrm{LiCl}$ in EthanolWater Mixtures at 298.15 K, Ind. Eng. Chem. Res., 47, 2056-2062, doi:10.1021/ie070704i, http://dx.doi.org/10.1021/ ie070704i, 2008.

Herz, W. and Lorentz, E.: Physikalisch-chemische Untersuchungen an Dioxan, Z. Phys. Chem. A, 140, 406-422, 1929.

Hu, M., Tang, J., Li, S., Xia, S., and Jiang, Y.: Activity Coefficients of Lithium Chloride in $\mathrm{ROH} /$ Water Mixed Solvent $(\mathrm{R}=\mathrm{Me}, \mathrm{Et})$ Using the Electromotive Force Method at 298.15 K, J. Chem. Eng. Data, 53, 508-512, doi:10.1021/je700614h, 2008.

Ishidao, T., Iwai, Y., Arai, Y., Ochi, K., Yamamura, T., and Ishikawa, T.: Bubble points of hydrogen chloride-waterisopropanol and hydrogen chloride-water-isopropanol-benzene systems and liquid-liquid equilibria of hydrogen chloride-waterbenzene and hydrogen chloride-water-isopropanol-benzene systems, Fluid Phase Equilib., 178, 239-257, 2001.

Jaoui, M., Achard, C., and Rogalski, M.: Solubility as a Function of Temperature of Selected Chlorophenols and Nitrophenols in Aqueous Solutions Containing Electrolytes or Surfactants, J. Chem. Eng. Data, 47, 297-303, doi:10.1021/je0102309, 2002.

Jimenez, J. L., Canagaratna, M. R., Donahue, N. M., Prevot, A. S. H., Zhang, Q., Kroll, J. H., DeCarlo, P. F., Allan, J. D., Coe, H., Ng, N. L., Aiken, A. C., Docherty, K. S., Ulbrich, I. M., Grieshop, A. P., Robinson, A. L., Duplissy, J., Smith, J. D., Wilson, K. R., Lanz, V. A., Hueglin, C., Sun, Y. L., Tian, J., Laaksonen, A., Raatikainen, T., Rautiainen, J., Vaattovaara, P., Ehn, M., Kulmala, M., Tomlinson, J. M., Collins, D. R., Cubison, M. J., Dunlea, E. J., Huffman, J. A., Onasch, T. B., Alfarra, M. R., Williams, P. I., Bower, K., Kondo, Y., Schneider, J., Drewnick, F., Borrmann, S., Weimer, S., Demerjian, K., Salcedo, D., Cottrell, L., Griffin, R., Takami, A., Miyoshi, T., Hatakeyama, S., Shimono, A., Sun, J. Y., Zhang, Y. M., Dzepina, K., Kimmel, J. R., Sueper, D., Jayne, J. T., Herndon, S. C., Trimborn, A. M., Williams, L. R., Wood, E. C., Middlebrook, A. M., Kolb, C. E., Baltensperger, U., and Worsnop, D. R.: Evolution of Organic Aerosols in the Atmosphere, Science, 326, 1525-1529, doi:10.1126/science.1180353, 2009.

Johnson, A. I. and Furter, W. F.: Salt effect in vapor-liquid equilibrium. Part I., Can. J. Technol., 34, 413-424, 1957.

Johnson, A. I. and Furter, W. F.: Vapor-liquid equilibrium in systems containing dissolved salts, Can. J. Chem. Eng., 43, 356, 1965.

Jurkiewicz, K.: Phase equilibrium in the system of water, alcohol or ketone, and sodium chloride, Fluid Phase Equilib., 251, 24-28, doi:10.1016/j.fluid.2006.10.019, 2007.

Kanakidou, M., Seinfeld, J. H., Pandis, S. N., Barnes, I., Dentener, F. J., Facchini, M. C., Van Dingenen, R., Ervens, B., Nenes, A., Nielsen, C. J., Swietlicki, E., Putaud, J. P., Balkanski, Y., Fuzzi, S., Horth, J., Moortgat, G. K., Winterhalter, R., Myhre, C. E. L., Tsigaridis, K., Vignati, E., Stephanou, E. G., and Wilson, J.: Organic aerosol and global climate modelling: a review, Atmos. Chem. Phys., 5, 1053-1123, doi:10.5194/acp-5-1053-2005, 2005.

Kato, M., Sato, T., and Hirata, M.: Measurement of Salt Effect on Vapor-saLiquid Equilibria by Bubble and Condensation Point Method, J. Chem. Eng. Jpn., 4, 308-311, 1971.
Kiepe, J., Noll, O., and Gmehling, J.: Modified LIQUAC and modified LIFAC - A further development of electrolyte models for the reliable prediction of phase equilibria with strong electrolytes, Ind. Eng. Chem. Res., 45, 2361-2373, doi:10.1021/ie0510122, 2006.

Kim, Y. P., Pun, B. K. L., Chan, C. K., Flagan, R. C., and Seinfeld, J. H.: Determination of water activity in ammonium-sulfate and sulfuric-acid mixtures using levitated single particles, Aerosol Sci. Technol., 20, 275-284, 1994.

Kirschbaum, E. and Gerstner, H.: Gleichgewichtskurven, Siedeund Taulinien von Äthylalkohol-Wasser-Gemischen bei Unterdrücken, VDI Zeitschrift, Beiheft Verfahrenstechnik, 34, 10$15,1939$.

Kiss, E. and Borbas, R.: Protein adsorption at liquid/liquid interface with low interfacial tension, Colloids Surf., B, 31, 169-176, doi:10.1016/S0927-7765(03)00136-X, 2003.

Knight, S. B., Crockford, H. D., and James, F. W.: Electromotive Force Studies in Aqueous Solutions of Hydro-chloric Acid and Glycerol from 0 to $40^{\circ}$, J. Phys. Chem., 57, 463466, doi:10.1021/j150505a017, http://pubs.acs.org/doi/abs/10. 1021/j150505a017, 1953.

Knopf, D. A., Luo, B. P., Krieger, U. K., and Koop, T.: Thermodynamic dissociation constant of the bisulfate ion from Raman and ion interaction modeling studies of aqueous sulfuric acid at low temperatures, J. Phys. Chem. A, 107, 4322-4332, doi:10.1021/jp027775+, 2003.

Kroll, J. H., Donahue, N. M., Jimenez, J. L., Kessler, S. H., Canagaratna, M. R., Wilson, K. R., Altieri, K. E., Mazzoleni, L. R., Wozniak, A. S., Bluhm, H., Mysak, E. R., Smith, J. D., Kolb, C. E., and Worsnop, D. R.: Carbon oxidation state as a metric for describing the chemistry of atmospheric organic aerosol, Nat. Chem., 3, 133-139, doi:10.1038/nchem.948, http://dx.doi. org/10.1038/nchem.948, 2011.

Kumagae, Y., Suzuta, T., Abe, T., Iwai, Y., and Arai, Y.: LiquidLiquid Equilibria of Heptane-Methanol-Toluene-Calcium Chloride and Ethyl Acetate-Water-Ethanol-Calcium Chloride Quaternary Systems, Can. J. Chem. Eng., 72, 695-700, 1994.

Kumar, A., Sanghavi, R., and Mohandas, V. P.: Solubility Pattern of $\mathrm{CaSO}_{4} \cdot 2 \mathrm{H}_{2} \mathrm{O}$ in the System $\mathrm{NaCl}+\mathrm{CaCl}_{2}+\mathrm{H}_{2} \mathrm{O}$ and Solution Densities at $35^{\circ} \mathrm{C}$ : Non-ideality and Ion Pairing, J. Chem. Eng. Data, 52, 902-905, doi:10.1021/je0604941, http://dx.doi.org/10. 1021/je0604941, 2007.

Kurihara, K., Nakamichi, M., and Kojima, K.: Isobaric VaporLiquid-Equilibria for Methanol + Ethanol,+ Water and the 3 Constituent Binary-Systems, J. Chem. Eng. Data, 38, 446-449, 1993.

Kwamena, N.-O. A., Buajarern, J., and Reid, J. P.: Equilibrium Morphology of Mixed Organic/Inorganic/Aqueous Aerosol Droplets: Investigating the Effect of Relative Humidity and Surfactants, J. Phys. Chem. A, 114, 5787-5795, doi:10.1021/jp1003648, 2010.

Lee, S. H., Murphy, D. M., Thomson, D. S., and Middlebrook, A. M.: Chemical components of single particles measured with Particle Analysis by Laser Mass Spectrometry (PALMS) during the Atlanta SuperSite Project: Focus on organic/sulfate, lead, soot, and mineral particles, J. Geophys. Res. Atmos., 107, 4003, doi:10.1029/2000JD000011, 2002.

Li, J. D., Polka, H. M., and Gmehling, J.: A g(e) model for single and mixed-solvent electrolyte systems. 1. Model and results for strong electrolytes, Fluid Phase Equilib., 94, 89-114, 1994. 
Li, Z. C., Tang, Y. P., Liu, Y., and Li, Y. G.: Salting effect in partially miscible systems of n-butanol water and butanone water .1 . Determination and correlation of liquid-liquid equilibrium data, Fluid Phase Equilib., 103, 143-153, 1995.

Li, J. T., Wang, J. K., and Wang, Y. L.: Solubility of $\mathrm{KCl}$ and $\mathrm{MgCl} 2$ in Binary Solvents Formed by Acetone and Water in the Temperature Range between (293.15 and 323.15 K), J. Chem. Eng. Data, 52, 1069-1071, doi:10.1021/je700017b, http://pubs. acs.org/doi/abs/10.1021/je700017b, 2007.

Lienhard, D. M., Krieger, U. K., Marcolli, C., Zuend, A., Bones, D. L., and Reid, J. P.: Hygroscopicity behavior of single particles containing levoglucosan and ammonium salts, in preparation, 2011.

Lilley, T. H. and Briggs, C. C.: Activity Coefficients of Calcium Sulphate in Water at $25^{\circ} \mathrm{C}$, Proc. R. Soc. London, Ser. A, 349, 355-368, http://www.jstor.org/stable/79086, 1976.

Lin, C., Qing, A., and Feng, Q.: A new differential mutation base generator for differential evolution, J. Glob. Optim., 49, 6990, doi:10.1007/s10898-010-9535-7, http://dx.doi.org/10.1007/ s10898-010-9535-7, 2011.

Lin, C. L., Lee, L. S., and Tseng, H. C.: Phase Equilibria for Propan-1-ol + Water + Sodium Chloride and + Potassium Chloride and Propan-2-ol + Water + Lithium Chloride and + Lithium Bromide, J. Chem. Eng. Data, 38, 306-309, 1993.

Lin, H. M., Yeh, C. E., Hong, G. B., and Lee, M. J.: Enhancement of liquid phase splitting of water + ethanol + ethyl acetate mixtures in the presence of a hydrophilic agent or an electrolyte substance, Fluid Phase Equilib., 237, 21-30, doi:10.1016/j.fluid.2005.08.009, 2005.

Ling, T. Y. and Chan, C. K.: Partial crystallization and deliquescence of particles containing ammonium sulfate and dicarboxylic acids, J. Geophys. Res. Atmos., 113, D14205, doi:10.1029/2008JD009779, 2008.

Lintomen, L., Pinto, R. T. P., Batista, E., Meirelles, A. J. A., and Maciel, M. R. W.: Liquid-Liquid Equilibrium of the Water + Citric Acid + 2-Butanol + Sodium Chloride System at 298.15 K, J. Chem. Eng. Data, 45, 1211-1214, 2000.

Liu, S., Takahama, S., Russell, L. M., Gilardoni, S., and Baumgardner, D.: Oxygenated organic functional groups and their sources in single and submicron organic particles in MILAGRO 2006 campaign, Atmos. Chem. Phys., 9, 6849-6863, doi:10.5194/acp9-6849-2009, 2009.

Lopes, A., Farelo, F., and Ferra, M. I. A.: Activity coefficients of potassium chloride in water-ethanol mixtures, J. Solution Chem., 28, 117-131, 1999.

Lopes, A., Farelo, F., and Ferra, M. I. A.: Activity coefficients of sodium chloride in water-ethanol mixtures: A comparative study of Pitzer and Pitzer-Simonson models, J. Solution Chem., 30, 757-770, 2001.

Lynch, C. C.: The ternary system lithium chloride-dioxane-water, J. Phys. Chem., 46, 366-370, 1942.

Lynn, S., Schiozer, A. L., Jaecksch, W. L., Cos, R., and Prausnitz, J. M.: Recovery of Anhydrous $\mathrm{Na}_{2} \mathrm{SO}_{4}$ from $\mathrm{SO}_{2}$-Scrubbing Liquor by Extractive Crystallization: Liquid-Liquid Equilibria for Aqueous Solutions of Sodium Carbonate, Sulfate, and/or Sulfite Plus Acetone, 2-Propanol, or tert-Butyl Alcohol, Ind. Eng. Chem. Res., 35, 4236-4245, 1996.

Ma, Y., Li, S., Zhai, Q., Jiang, Y., and Hu, M.: Activity Coefficients of Potassium Chloride in Ethylene Glycol-Water Mixtures
Using Electromotive Force Measurements at $(278.15,288.15$, 298.15, and 308.15 K), J. Chem. Eng. Data, 55, 1573-1579, doi:10.1021/je900690d, 2010.

Malatesta, F. and Zamboni, R.: Activity and osmotic coefficients from the EMF of liquid membrane cells. VI-ZnSO $4, \mathrm{MgSO}_{4}$, $\mathrm{CaSO}_{4}$, and $\mathrm{SrSO}_{4}$ in water at $25^{\circ} \mathrm{C}$, J. Solution Chem., 26, 791-815, doi:10.1007/BF02767784, http://dx.doi.org/10.1007/ BF02767784, 1997.

Marcilla, A., Ruiz, F., and Garcia, A.: Liquid-liquid-solid equilibria of the quaternary system water-ethanol-acetone-sodium chloride at $25^{\circ} \mathrm{C}$, Fluid Phase Equilib., 112, 273-289, 1995.

Marcolli, C. and Krieger, U. K.: Phase changes during hygroscopic cycles of mixed organic/inorganic model systems of tropospheric aerosols, J. Phys. Chem. A, 110, 1881-1893, doi:10.1021/jp0556759, 2006.

Marcolli, C. and Peter, Th.: Water activity in polyol/water systems: new UNIFAC parameterization, Atmos. Chem. Phys., 5, 15451555, doi:10.5194/acp-5-1545-2005, 2005.

Marcolli, C., Luo, B. P., and Peter, T.: Mixing of the Organic Aerosol Fractions: Liquids as the Thermodynamically Stable Phases, J. Phys. Chem. A, 108, 2216-2224, doi:10.1021/jp0360801, 2004a.

Marcolli, C., Luo, B. P., Peter, Th., and Wienhold, F. G.: Internal mixing of the organic aerosol by gas phase diffusion of semivolatile organic compounds, Atmos. Chem. Phys., 4, 25932599, doi:10.5194/acp-4-2593-2004, 2004b.

Maria, S. F., Russell, L. M., Turpin, B. J., Porcja, R. J., Campos, T. L., Weber, R. J., and Huebert, B. J.: Source signatures of carbon monoxide and organic functional groups in Asian Pacific Regional Aerosol Characterization Experiment (ACE-Asia) submicron aerosol types, J. Geophys. Res. Atmos., 108(D23), 8637, doi:10.1029/2003JD003703, 2003.

Maria, S. F., Russell, L. M., Gilles, M. K., and Myneni, S. C. B.: Organic aerosol growth mechanisms and their climate-forcing implications, Science, 306, 1921-1924, doi:10.1126/science.1103491, 2004.

McDevit, W. F. and Long, F. A.: The Activity Coefficient of Benzene in Aqueous Salt Solutions, J. Am. Chem. Soc., 74, 17731777, 1952.

McGlashan, M. L.: Deviations from Raoult's law, J. Chem. Educ., 40, 516-518, doi:10.1021/ed040p516, http://pubs.acs.org/doi/ abs/10.1021/ed040p516, 1963.

Meyer, T., Polka, H. M., and Gmehling, J.: Low-pressure isobaric vapor-liquid-equilibria of ethanol water mixtures containing electrolytes, J. Chem. Eng. Data, 36, 340-342, 1991.

Middlebrook, A. M., Murphy, D. M., and Thomson, D. S.: Observations of organic material in individual marine particles at Cape Grim during the First Aerosol Characterization Experiment (ACE 1), J. Geophys. Res. Atmos., 103, 16475-16483, 1998.

Mikhailov, E., Vlasenko, S., Martin, S. T., Koop, T., and Pöschl, U.: Amorphous and crystalline aerosol particles interacting with water vapor: conceptual framework and experimental evidence for restructuring, phase transitions and kinetic limitations, Atmos. Chem. Phys., 9, 9491-9522, doi:10.5194/acp-9-9491-2009, 2009.

Ming, Y. and Russell, L. M.: Thermodynamic equilibrium of organic-electrolyte mixtures in aerosol particles., AIChE J., 48, 1331-1348, 2002.

Miro, A. R. and Gonzalez, J. R. A.: Efecto Salino en los Diagra- 
mas de Equilibrio Liquido-Vapor. III. Sistemas n-propanol-agua e isopropanol-agua con nitrato calcio, Anales de la Real Sociedad Espanola de Fisica y Quimica, Serie B., 54, 797-802, 1958.

Mochida, M. and Kawamura, K.: Hygroscopic properties of levoglucosan and related organic compounds characteristic to biomass burning aerosol particles, J. Geophys. Res., 109, D21202, doi:10.1029/2004JD004962, http://dx.doi.org/10.1029/ 2004JD004962, 2004.

Moré, J. J., Garbow, B. S., and Hillstrom, K. E.: User Guide for MINPACK-1, Argonne National Laboratory Report ANL-80-74, Argonne, Ill., USA, http://www.netlib.org/minpack/, 1980.

Moré, J. J., Sorensen, D. C., Hillstrom, K. E., and Garbow, B. S.: The MINPACK Project, in: Sources and Development of Mathematical Software, Prentice-Hall, Inc., Upper Saddle River, NJ, USA, 1984.

Morrison, J. F., Baker, J. C., Meredith, H. C., Newman, K. E., Walter, T. D., Massie, J. D., Perry, R. L., and Cummings, P. T.: Experimental Measurement of Vapor-Liquid Equilibrium in Alcohol/Water/Salt Systems, J. Chem. Eng. Data, 35, 395-404, 1990.

Murphy, D. M. and Thomson, D. S.: Chemical composition of single aerosol particles at Idaho Hill: Negative ion measurements, J. Geophys. Res. Atmos., 102, 6353-6368, 1997.

Murphy, D. M., Cziczo, D. J., Froyd, K. D., Hudson, P. K., Matthew, B. M., Middlebrook, A. M., Peltier, R. E., Sullivan, A., Thomson, D. S., and Weber, R. J.: Single-particle mass spectrometry of tropospheric aerosol particles, J. Geophys. Res. Atmos., 111, D23S32, doi:10.1029/2006JD007340, 2006.

Murray, B. J.: Inhibition of ice crystallisation in highly viscous aqueous organic acid droplets, Atmos. Chem. Phys., 8, 54235433, doi:10.5194/acp-8-5423-2008, 2008.

Mydlarz, J., Jones, A. G., and Millan, A.: Solubility and density isotherms for potassium sulfate-water-2-propanol, J. Chem. Eng. Data, 34, 124-126, 1989.

Myhre, C. E. L., Christensen, D. H., Nicolaisen, F. M., and Nielsen, C. J.: Spectroscopic study of aqueous $\mathrm{H}_{2} \mathrm{SO}_{4}$ at different temperatures and compositions: Variations in dissociation and optical properties, J. Phys. Chem. A, 107, 1979-1991, doi:10.1021/jp026576n, 2003.

Nakamura, A.: Effect of Salts on Liquid-Liquid Equilibria, Int. Chem. Eng., 9, 521-525, 1969.

Narayana, A. S., Naik, S. C., and Rath, P.: Salt Effect in Isobaric Vapor-Liquid Equilibria of Acetic Acid-Water System, J. Chem. Eng. Data, 30, 483-485, 1985.

Nelder, J. A. and Mead, R.: A simplex-method for function minimization, Comput. J., 7, 308-313, 1965.

Nenes, A., Pandis, S. N., and Pilinis, C.: ISORROPIA: A new thermodynamic equilibrium model for multiphase multicomponent inorganic aerosols, Aquat. Geochem., 4, 123-152, 1998.

Noubigh, A., Abderrabba, M., and Provost, E.: Temperature and salt addition effects on the solubility behaviour of some phenolic compounds in water, J. Chem. Thermodyn., 39, 297-303, doi:10.1016/j.jct.2006.06.014, 2007a.

Noubigh, A., Mgaidi, A., Abderrabba, M., Provost, E., and Furst, W.: Effect of salts on the solubility of phenolic compounds: experimental measurements and modelling, J. Sci. Food Agric., 87, 783-788, doi:10.1002/jsfa.2762, 2007b.

Noubigh, A., Cherif, M., Provost, E., and Abderrabba, M.: Solubility of Gallic Acid, Vanillin, Syringic Acid, and Protocatechuic Acid in Aqueous Sulfate Solutions from (293.15 to 318.15 K),
J. Chem. Eng. Data, 53, 1675-1678, doi:10.1021/je800205e, http://pubs.acs.org/doi/abs/10.1021/je800205e, 2008.

Obmelyukhina, T. N., Danov, S. M., Sivenkov, E. A., and Chubarov, G. A.: Mutual solubility and liquid-liquid equilibrium in the system methacrylic acid-water ammonium bisulfate, Journal of Applied Chemistry of the USSR, 52, 878-879, 1979.

Olaya, M. M., Garcia, A. N., and Marcilla, A.: Liquid-LiquidSolid Equilibria for the Quaternary System Wate + Acetone + 1Butanol + Sodium Chloride at $25^{\circ} \mathrm{C}$, J. Chem. Eng. Data, 41, 910-917, 1996.

Osol, A. and Kilpatrick, M.: The "Salting-out" and "Saltingin" of Weak Acids. II. The Activity Coefficients of the Molecules of Ortho, Meta and Para-Hydroxybenzoic Acids in Aqueous Salt Solutions, J. Am. Chem. Soc., 55, 4440 4444, doi:10.1021/ja01338a017, http://pubs.acs.org/doi/abs/10. 1021/ja01338a017, 1933.

Pankow, J. F.: An absorption model of gas/particle partitioning of organic compounds in the atmosphere, Atmos. Environ., 28, 185-188, 1994.

Pankow, J. F.: Gas/particle partitioning of neutral and ionizing compounds to single and multi-phase aerosol particles. 1. Unified modeling framework, Atmos. Environ., 37, 3323-3333, doi:10.1016/S1352-2310(03)00346-7, 2003.

Pankow, J. F. and Barsanti, C. K.: The carbon numberpolarity grid: A means to manage the complexity of the mix of organic compounds when modeling atmospheric organic particulate matter, Atmos. Environ., 43, 2829-2835, doi:10.1016/j.atmosenv.2008.12.050, 2009.

Pena, M. P., Vercher, E., and Martinez-Andreu, A.: Isobaric Vapor-Liquid Equilibrium for Ethanol + Water + Sodium Nitrate, J. Chem. Eng. Data, 41, 1097-1100, 1996.

Peng, C., Chan, M. N., and Chan, C. K.: The hygroscopic properties of dicarboxylic and multifunctional acids: Measurements and UNIFAC predictions, Environ. Sci. Technol., 35, 4495-4501, doi:10.1021/es0107531, 2001.

Pereira, M. A. P. and Aznar, M.: Salt effect on (liquid+liquid) equilibrium of (water + tertbutanol + 1-butanol) system: Experimental data and correlation, J. Chem. Thermodyn., 38, 84-89, doi:10.1016/j.jct.2005.03.025, 2006.

Pilloton, R. L.: Convergence of Tie Lines in Ternary Liquid Systems and its Application to Liquid Extraction, in: Symposium on Solvent Extraction, in: The Analysis of Metals, pp. 5-12, American Society for Testing Materials, Philadelphia, PA, USA, doi:10.1520/STP39521S, 1958.

Pinho, S. P. and Macedo, E. A.: Representation of salt solubility in mixed solvents: A comparison of thermodynamic models, Fluid Phase Equilib., 116, 209-216, 1996.

Polka, H. M. and Gmehling, J.: Effect of Calcium Nitrate on the Vapor-Liquid Equilibria of Ethanol+Water and 2Propanol + Water, J. Chem. Eng. Data, 39, 621-624, 1994.

Pope, F. D., Dennis-Smither, B. J., Griffiths, P. T., Clegg, S. L., and Cox, R. A.: Studies of Single Aerosol Particles Containing Malonic Acid, Glutaric Acid, and Their Mixtures with Sodium Chloride. I. Hygroscopic Growth, J. Phys. Chem. A, 114, 53355341, doi:10.1021/jp100059k, 2010.

Powell, M. J. D.: The BOBYQA algorithm for bound constrained optimization without derivatives, Technical Report NA2009/06, Department of Applied Mathematics and Theoretical Physics, University of Cambridge, http://www.damtp.cam.ac.uk/user/na/ 
NA_papers/NA2009_06.pdf, 2009.

Putnin', A. Y., Shvarts, E. M., Ievin'sh, A. F., Kotlyarevski, I. L., and Mazur, V. G.: Solubility of 1,3-nonanediol in systems 1,3nonanediol-water-salting out agent, Latv. PSR Zinat. Akad. Vestis Khim. Ser., 2, 133-136, 1974.

Raatikainen, T. and Laaksonen, A.: Application of several activity coefficient models to water-organic-electrolyte aerosols of atmospheric interest, Atmos. Chem. Phys., 5, 2475-2495, 2005, http://www.atmos-chem-phys.net/5/2475/2005/.

Rajendran, M., Renganarayanan, S., and Srinivasan, D.: Salt effect in phase-equilibria and heat of mixing - effect of dissolved inorganic salts on the liquid-liquid equilibria of ethyl-acetate 2propanol water-system and the vapor-liquid-equilibria and heat of mixing of its constituent binaries, Fluid Phase Equilib., 70, 65-106, 1991.

Raridon, R. J. and Kraus, K. A.: Activity Coefficients of Sodium Chloride at Saturation in Aqueous Solutions of Some Oxy-Oxa Compounds at $25^{\circ} \mathrm{C}$, J. Chem. Eng. Data, 16, 241-243, 1971.

Rieder, R. M. and Thompson, A. R.: Salt effect in vapor-liquid equilibria - ethanol-water saturated with potassium nitrate, Ind. Eng. Chem., 42, 379-382, 1950.

Robinson, R. A. and Selkirk, R. C.: The System Hydrogen Chloride Dioxan Water At $25^{\circ} \mathrm{C}$, J. Chem. Soc., 1460, doi:10.1039/JR9480001456, 1948.

Robinson, R. A. and Stokes, R. H.: Electrolyte Solutions, Dover Publications Inc., New York, USA, 2nd, revised edn., 2002.

Rogge, W. F., Mazurek, M. A., Hildemann, L. M., Cass, G. R., and Simoneit, B. R. T.: Quantification of Urban Organic Aerosols at a Molecular Level Identification, Abundance and Seasonal Variation, Atmos. Environ., 27, 1309-1330, 1993.

Roy, B. C., Awual, M. R., and Goto, M.: Effect of Inorganic Salts on Ternary Equilibrium Data of Propionic Acid-Water-Solvents Systems, J. Appl. Sci., 7, 1053-1060, 2007.

Roy, R. N., Vernon, W., and Bothwell, A. L. M.: Standard potentials of the silver + silver chloride electrode from 5 to $45^{\circ} \mathrm{C}$ and the thermodynamic properties of hydrochloric acid in 95 mass per cent isopropanol, J. Chem. Thermodynamics, 3, 769-777, doi:10.1016/S0021-9614(71)80005-8, 1971a.

Roy, R. N., Vernon, W., and Bothwell, A. L. M.: Thermodynamics of Hydrochloric Acid in Glycerol-Water Mixtures from EMF Measurements between 5 and $45^{\circ} \mathrm{C}$, J. Electrochem. Soc., 118, 1302-1306, doi:10.1149/1.2408310, 1971b.

Roy, R. N., Vernon, W., and Bothwell, A. L. M.: Standard Potentials of Silver-Silver Chloride Electrode in t-Butyl Alcohol-Water Mixtures and Thermodynamics of Solutions of Hydrochloric Acid at Different Temperatures, J. Chem. Soc. A, 1242-1246, doi:10.1039/J19710001242, 1971c.

Roy, R. N., Vernon, W., Gibbons, J. J., and Bothwell, A. L. M.: Thermodynamics of hydrochloric acid in 1-propanol from e.m.f. measurements at 5 to $45^{\circ} \mathrm{C}$, J. Chem. Thermodynamics, 3, 883889, doi:10.1016/S0021-9614(71)80018-6, 1971d.

Roy, R. N., Vernon, W., and Bothwell, A. L. M.: The ActivityCoefficient and Related Thermodynamic Quantities of $\mathrm{HCl}$ in 5 wt \% 1-Butanol, Electrochim. Acta, 17, 1057-1063, 1972a.

Roy, R. N., Vernon, W., and Bothwell, A. L. M.: Thermodynamic Studies of Hydrochloric Acid in Propan-2-ol from Electromotive Force Measurements between 5 and $45^{\circ} \mathrm{C}$, J. Chem. Soc., Faraday Trans., 1, 68, 2047-2052, 1972b.

Rudakoff, G., Hahn, R., and Decker, U.: Calculation of activity- coefficients in ternary-systems with nonvolatile components from measurements of total vapor-pressure, Z. Chem., 12, 467470, 1972.

Russell, L. M., Takahama, S., Liu, S., Hawkins, L. N., Covert, D. S., Quinn, P. K., and Bates, T. S.: Oxygenated fraction and mass of organic aerosol from direct emission and atmospheric processing measured on the $R / V$ Ronald Brown during TEXAQS/GoMACCS 2006, J. Geophys. Res. Atmos., 114, doi:10.1029/2008JD011275, 2009.

Sada, E., Morisue, T., and Miyahara, K.: Salt effects on vaporliquid equilibrium of isopropanol-water system, J. Chem. Eng. Jpn., 8, 196-201, 1975a.

Sada, E., Morisue, T., and Miyahara, K.: Salt Effects On VaporLiquid-Equilibrium Of Tetrahydrofuran-Water System, J. Chem. Eng. Data, 20, 283-287, 1975b.

Sadek, H., El-Harakany, A. A., and El-Nadory, N. A.: Thermodynamics of $\mathrm{HCl}$ in water-phenol mixtures. Standard potentials of the silver/silver-chloride electrode and medium effects, Electrochim. Acta, 17, 1745-1754, doi:10.1016/00134686(72)85064-3, 1972.

Salabat, A.: Liquid-liquid equilibria for the MTBE + water + salts systems at $298.15 \mathrm{~K}$, Fluid Phase Equilib., 257, 1-5, doi:10.1016/j.fluid.2007.04.026, 2007.

Salcedo, D.: Equilibrium phase diagrams of aqueous mixtures of malonic acid and sulfate/ammonium salts, J. Phys. Chem. A, 110, 12158-12165, doi:10.1021/jp063850v, 2006.

Santos, F. S., d'Avila, S. G., and Aznar, M.: Salt effect on liquidliquid equilibrium of water + 1-butanol + acetone system: experimental determination and thermodynamic modeling, Fluid Phase Equilib., 187, 265-274, 2001.

Saxena, P. and Hildemann, L.: Water-soluble organics in atmospheric particles: A critical review of the literature and application of thermodynamics to identify candidate compounds, J. Atmos. Chem., 24, 57-109, 1996.

Schauer, J. J., Kleeman, M. J., Cass, G. R., and Simoneit, B. R. T.: Measurement of Emissions from Air Pollution Sources. 3. C1C29 Organic Compounds from Fireplace Combustion of Wood, Environ. Sci. Technol., 35, 1716-1728, doi:10.1021/es001331e, http://dx.doi.org/10.1021/es001331e, 2001.

Schreinemakers, F. A. H. and van den Bos, J. L. M. V.: The System Water-Phenol-Hydrochloric Acid at $12{ }^{\circ} \mathrm{C}$, Zeitschrift fuer Physikalische Chemie - Stoechiometrie und Verwandtschaftslehre, 79, 551-553, 1912.

Schunk, A. and Maurer, G.: Activity of Water in Aqueous Solutions of Sodium Citrate and in Aqueous Solutions of (An Inorganic Salt and Citric Acid) at 298.15 K, J. Chem. Eng. Data, 49, 944 949, doi:10.1021/je034258r, 2004.

Schunk, A., Menert, A., and Maurer, G.: On the influence of some inorganic salts on the partitioning of citric acid between water and organic solutions of tri-n-octylamine Part I: Methyl isobutyl ketone as organic solvent, Fluid Phase Equilib., 224, 55-72, doi:10.1016/j.fluid.2004.04.010, 2004.

Segatin, N. and Klofutar, C.: Salting-out of some alkyl acetates in aqueous sodium chloride solutions, Monatsh. Chem., 131, 131144, 2000.

Selikson, B. and Ricci, J. E.: The System Sodium Nitrate-DioxaneWater at $25^{\circ}$ C, J. Am. Chem. Soc., 64, 2474-2476, 1942.

Sergeeva, V. F. and Matyushinskaya, L. B.: Effect of Salts on Liquid-Liquid Equilibrium. 1. System Isobutyric Acid-Water, 
Zh. Obshch. Khim., 39, 15-19, 1969.

Smith, M. L., Kuwata, M., and Martin, S. T.: Secondary Organic Material Produced by the Dark Ozonolysis of $\alpha$ Pinene Minimally Affects the Deliquescence and Efflorescence of Ammonium Sulfate, Aerosol Sci. Technol., 45, 244-261, doi:10.1080/02786826.2010.532178, http://dx.doi.org/10.1080/ 02786826.2010.532178, 2011.

Solimo, H. N., Bonatti, C. M., Zurita, J. L., and de Doz, M. B. G.: Liquid-liquid equilibria for the system water + propionic acid + 1-butanol at 303.2 K. Effect of addition of sodium chloride, Fluid Phase Equilib., 137, 163-172, 1997.

Soonsin, V., Zardini, A. A., Marcolli, C., Zuend, A., and Krieger, U. K.: The vapor pressures and activities of dicarboxylic acids reconsidered: the impact of the physical state of the aerosol, Atmos. Chem. Phys., 10, 11753-11767, doi:10.5194/acp-1011753-2010, 2010.

Spann, J. F.: A laboratory study of single sulfate aerosols using electrodynamic suspension, Ph.D. thesis, University of Arkansas, Fayetteville, 1984.

Staples, B. R.: Activity and Osmotic Coefficients of Aqueous Sulfuric Acid at 298.15 K, J. Phys. Chem. Ref. Data, 10, 779-798, doi:10.1063/1.555648, 1981.

Sugunan, S. and Thomas, B.: Salting coefficient of hydroxybenzoic acids, Indian J. Chem., Sect A, 34, 134-136, 1995.

Sun, L.-H., Jiang, B., and Xiu, Z.-L.: Aqueous two-phase extraction of 2,3-butanediol from fermentation broths by isopropanol/ammonium sulfate system, Biotechnol. Lett., 31, 371376, doi:10.1007/s10529-008-9874-3, http://dx.doi.org/10.1007/ s10529-008-9874-3, 2009.

Surratt, J. D., Chan, A. W. H., Eddingsaas, N. C., Chan, M. N., Loza, C. L., Kwan, A. J., Hersey, S. P., Flagan, R. C., Wennberg, P. O., and Seinfeld, J. H.: Reactive intermediates revealed in secondary organic aerosol formation from isoprene, PNAS, 107, 6640-6645, doi:10.1073/pnas.0911114107, http:// www.pnas.org/content/107/15/6640, 2010.

Taboada, M. E.: Liquid-liquid and solid-liquid equilibrium of the 1-propanol + lithium sulfate + water system at 25, 35 and $45^{\circ} \mathrm{C}$, Fluid Phase Equilib., 204, 155-165, doi:10.1016/S03783812(02)00258-3, 2003.

Taboada, M. E., Veliz, D. M., Galleguillos, H. R., and Graber, T. A.: Solubilities, densities, viscosities, electrical conductivities, and refractive indices of saturated solutions of potassium sulfate in water + 1-propanol at 298.15, 308.15, and $318.15 \mathrm{~K}$, J. Chem. Eng. Data, 47, 1193-1196, 2002.

Takahama, S., Schwartz, R. E., Russell, L. M., Macdonald, A. M., Sharma, S., and Leaitch, W. R.: Organic functional groups in aerosol particles from burning and non-burning forest emissions at a high-elevation mountain site, Atmos. Chem. Phys., 11, 6367-6386, doi:10.5194/acp-11-6367-2011, 2011.

Tan, T. C. and Aravinth, S.: Liquid-liquid equilibria of water/acetic acid/1-butanol system - effects of sodium (potassium) chloride and correlations, Fluid Phase Equilib., 163, 243-257, 1999.

Tan, T. C. and Kannangara, K. K. D. D. S.: Liquid-liquid equilibria of water/1-propanol/methyl ethyl ketone/potassium chloride, Fluid Phase Equilib., 190, 179-189, 2001.

Tang, I. N. and Munkelwitz, H. R.: Aerosol Growth Studies - III. Ammonium bisulfate aerosols in a moist atmosphere, J. Aerosol Sci., 8, 321-330, 1977.

Tang, I. N. and Munkelwitz, H. R.: Water activities, densities, and refractive-indexes of aqueous sulfates and sodium-nitrate droplets of atmospheric importance, J. Geophys. Res. Atmos., 99, 18801-18808, 1994.

Taylor, A. E.: Precipitation of Salts, J. Phys. Chem., 1, 718733, doi:10.1021/j150593a003, http://pubs.acs.org/doi/abs/10. 1021/j150593a003, 1897.

Tong, C., Clegg, S. L., and Seinfeld, J. H.: Comparison of activity coefficient models for atmospheric aerosols containing mixtures of electrolytes, organics, and water, Atmos. Environ., 42, 54595482, doi:10.1016/j.atmosenv.2008.02.040, 2008.

Topphoff, M., Kiepe, J., and Gmehling, J.: Effects of Lithium Nitrate on the Vapor-Liquid Equilibria of Methyl Acetate + Methanol and Ethyl Acetate + Ethanol, J. Chem. Eng. Data, 46, 1333-1337, 2001.

Topping, D. O., McFiggans, G. B., and Coe, H.: A curved multicomponent aerosol hygroscopicity model framework: Part 1 - Inorganic compounds, Atmos. Chem. Phys., 5, 1205-1222, doi:10.5194/acp-5-1205-2005, 2005a.

Topping, D. O., McFiggans, G. B., and Coe, H.: A curved multicomponent aerosol hygroscopicity model framework: Part 2 Including organic compounds, Atmos. Chem. Phys., 5, 1223-1242, doi:10.5194/acp-5-1223-2005, 2005 b.

Topping, D. O., Lowe, D., and McFiggans, G.: Partial Derivative Fitted Taylor Expansion: An efficient method for calculating gas-liquid equilibria in atmospheric aerosol particles: 1. Inorganic compounds, J. Geophys. Res. Atmos., 114, D04304, doi:10.1029/2008JD010099, 2009.

Tsonopoulos, C. and Prausnitz, J. M.: Fugacity Coefficients in Vapor-Phase Mixtures of Water and Carboxylic Acids, Chem. Eng. J., 1, 273-278, doi:10.1016/0300-9467(70)85014-6, 1970.

Tvrdik, J.: Differential Evolution: Competitive Setting of Control Parameters., Proceedings of the International Multiconference on Computer Science and Information Technology, 1, 207-213, 2006.

van Delden, M. L., Kuipers, N. J. M., and de Haan, A. B.: Liquid-Liquid Equilibria and Physical Properties of the Quaternary Systems Water + Caprolactam + Ammonium Sulfate + Benzene and Toluene, J. Chem. Eng. Data, 49, 1760-1770, doi:10.1021/je049797q, 2004.

Vener, R. E. and Thompson, A. R.: Solubility and density isotherms for sodium sulfate ethylene glycol water, Ind. Eng. Chem., 41, 2242-2247, 1949.

Vercher, E., Pena, M. P., and Martinez-Andreu, A.: Isobaric VaporLiquid Equilibrium for Ethanol + Water + Potassium Nitrate, J. Chem. Eng. Data, 41, 66-69, 1996.

Vercher, E., Rojo, F. J., and Martinez-Andreu, A.: Isobaric VaporLiquid Equilibria for 1-Propanol + Water + Calcium Nitrate, J. Chem. Eng. Data, 44, 1216-1221, 1999.

Vercher, E., Vazquez, M. I., and Martinez-Andreu, A.: Isobaric vaporliquid equilibria for 1-propanol + water + lithium nitrate at $100 \mathrm{kPa}$, Fluid Phase Equilib., 202, 121-132, 2002.

Verevkin, S., Safarov, J., Bich, E., Hassel, E., and Heintz, A.: Study of vapour pressure of lithium nitrate solutions in ethanol, J. Chem. Thermodyn., 38, 611-616, doi:10.1016/j.jct.2005.07.015, http://www. sciencedirect.com/science/article/B6WHM-4H3937J-1/2/ 55f709f1d79b99f6c6d58c1882057b72, 2006.

Virtanen, A., Joutsensaari, J., Koop, T., Kannosto, J., Yli-Pirilä, P., Leskinen, J., Mäkelä, J. M., Holopainen, J. K., Pöschl, U., Kul- 
mala, M., Worsnop, D. R., and Laaksonen, A.: An amorphous solid state of biogenic secondary organic aerosol particles, Nature, 467, 824-827, doi:10.1038/nature09455, 2010.

Wang, Y., Yan, Y., Hu, S., Han, J., and Xu, X.: Phase Diagrams of Ammonium Sulfate + Ethanol/1-Propanol/2-Propanol + Water Aqueous Two-Phase Systems at $298.15 \mathrm{~K}$ and Correlation, J. Chem. Eng. Data, 55, 876-881, doi:10.1021/je900504e, 2010.

Wehner, B., Philippin, S., and Wiedensohler, A.: Design and calibration of a thermodenuder with an improved heating unit to measure the size-dependent volatile fraction of aerosol particles, J. Aerosol Sci., 33, 1087-1093, doi:10.1016/S00218502(02)00056-3, 2002.

Wise, M. E., Surratt, J. D., Curtis, D. B., Shilling, J. E., and Tolbert, M. A.: Hygroscopic growth of ammonium sulfate/dicarboxylic acids, J. Geophys. Res. Atmos., 108, doi:10.1029/2003JD003775, 2003.

Wittig, R., Lohmann, J., and Gmehling, J.: Vapor-Liquid Equilibria by UNIFAC Group Contribution. 6. Revision and Extension, Ind. Eng. Chem. Res., 42, 183-188, doi:10.1021/ie0205061, http:// pubs.acs.org/doi/abs/10.1021/ie0205061, 2003.

Wolke, R., Sehili, A. M., Simmel, M., Knoth, O., Tilgner, A., and Herrmann, H.: SPACCIM: A parcel model with detailed microphysics and complex multiphase chemistry, Atmos. Environ., 39, 4375-4388, 2005.

Yan, W. D., Topphoff, M., Rose, C., and Gmehling, J.: Prediction of vapor-liquid equilibria in mixed-solvent electrolyte systems using the group contribution concept, Fluid Phase Equilib., 162, 97-113, 1999.

Yang, L., Zhuo, K., Zhao, Y., and Wang, J.: Thermodynamics of the Interaction between Electrolyte $\left(\mathrm{CaCl}_{2}, \mathrm{NaCl}, \mathrm{NaBr}, \mathrm{NaI}\right)$ and Monosaccharide (D-mannose, D-ribose) in Water at 298.15 K, Z. Phys. Chem., 218, 349-362, doi:10.1524/zpch.218.3.349.26494, http://dx.doi.org/10.1524/zpch.218.3.349.26494, 2004.

Yeung, M. C. and Chan, C. K.: Water Content and Phase Transitions in Particles of Inorganic and Organic Species and their Mixtures Using Micro-Raman Spectroscopy, Aerosol Sci. Technol., 44, 269-280, doi:10.1080/02786820903583786, 2010.

Young, T. F., Maranville, L. F., and Smith, H. M.: The Structure of Electrolytic Solutions, Wiley, New York, USA, 1959.

Yun, S. H., Kim, C., Lee, E. S., and Kim, Y. C.: Effect of magnesium chloride on the isobaric vapor-liquid equilibria of formic acid-water system, Fluid Phase Equilib., 149, 209-221, 1998.

Zafarani-Moattar, M. T. and Salabat, A.: Phase Diagrams of Aliphatic Alcohols + Magnesium Sulfate + Water, J. Chem. Eng. Data, 42, 1241-1243, 1997.

Zardini, A. A., Sjogren, S., Marcolli, C., Krieger, U. K., Gysel, M., Weingartner, E., Baltensperger, U., and Peter, T.: A combined particle trap/HTDMA hygroscopicity study of mixed inorganic/organic aerosol particles, Atmos. Chem. Phys., 8, 55895601, doi:10.5194/acp-8-5589-2008, 2008.

Zaveri, R. A., Easter, R. C., and Peters, L. K.: A computationally efficient Multicomponent Equilibrium Solver for Aerosols (MESA), J. Geophys. Res., 110, D24203, doi:10.1029/2004JD005618, 2005.
Zaytsev, I. D. and Aseyev, G. G. (Eds).: Properties of Aqueous Solutions of Electrolytes, CRC Press, Boca Raton, FL, USA, 16th edn., 1992.

Zdanovskii, A. B.: Zakonomernosti v izmeneniyakh svoistv smeshannykh rastvorov: Trudy solyanoi laboratorii (Fundamental Aspects of Variation of Properties of Mixed Solutions: Works of Salt Laboratory), Tr. Solyanoi Lab. Akad. Nauk SSSR, 5-70, 1936.

Zdanovskii, A. B.: Novyi metod rascheta rastvorimostei elektrolitov v mnogokomponentny sistema. 1. (New methods of calculating solubilities of electrolytes in multicomponent systems, 1.), Zh. Fiz. Khim., 22, 1478-1485, 1948.

Zhang, H. and Wang, T.: Measurement and Correlation of LiquidLiquid Equilibrium Data for Water + Acetic Acid+Methyl tert-Butyl Ether $+\mathrm{NaCl}$, J. Chem. Eng. Data, 54, 945-949, doi:10.1021/je800724g, 2009.

Zhang, Q., Jimenez, J. L., Canagaratna, M. R., Allan, J. D., Coe, H., Ulbrich, I., Alfarra, M. R., Takami, A., Middlebrook, A. M., Sun, Y. L., Dzepina, K., Dunlea, E., Docherty, K., DeCarlo, P. F., Salcedo, D., Onasch, T., Jayne, J. T., Miyoshi, T., Shimono, A., Hatakeyama, S., Takegawa, N., Kondo, Y., Schneider, J., Drewnick, F., Borrmann, S., Weimer, S., Demerjian, K., Williams, P., Bower, K., Bahreini, R., Cottrell, L., Griffin, R. J., Rautiainen, J., Sun, J. Y., Zhang, Y. M., and Worsnop, D. R.: Ubiquity and dominance of oxygenated species in organic aerosols in anthropogenically-influenced Northern Hemisphere midlatitudes, Geophys. Res. Lett., 34, L13801, doi:10.1029/2007GL029979, 2007.

Zobrist, B., Marcolli, C., Pedernera, D. A., and Koop, T.: Do atmospheric aerosols form glasses?, Atmos. Chem. Phys., 8, 52215244, doi:10.5194/acp-8-5221-2008, 2008.

Zobrist, B., Soonsin, V., Luo, B.-P., Krieger, U. K., Marcolli, C., Peter, T., and Koop, T.: Ultra-slow water diffusion in aqueous sucrose glasses, Phys. Chem. Chem. Phys., 13, 3514-3526, doi:10.1039/C0CP01273D, http://dx.doi.org/10. 1039/C0CP01273D, 2011.

Zuend, A., Marcolli, C., Luo, B. P., and Peter, T.: A thermodynamic model of mixed organic-inorganic aerosols to predict activity coefficients, Atmos. Chem. Phys., 8, 4559-4593, doi:10.5194/acp8-4559-2008, http://www.atmos-chem-phys.net/8/4559/2008/, 2008.

Zuend, A., Marcolli, C., Peter, T., and Seinfeld, J. H.: Computation of liquid-liquid equilibria and phase stabilities: implications for RH-dependent gas/particle partitioning of organic-inorganic aerosols, Atmos. Chem. Phys., 10, 7795-7820, doi:10.5194/acp10-7795-2010, 2010.

Zurita, J. L., de Doz, M. B. G., Bonatti, C. M., and Solimo, H. N.: Effect of Addition of Calcium Chloride on the Liquid-Liquid Equilibria of the Water + Propionic Acid + 1-Butanol System at 303.15 K, J. Chem. Eng. Data, 43, 1039-1042, 1998. 